University of Louisville

ThinkIR: The University of Louisville's Institutional Repository

$5-2008$

\title{
I. Studies of cyclic peptides containing the arginine-glycine- aspartic acid pharmacophore; II. Targeting drugs to bone.
}

Natali Brooke Richter

University of Louisville

Follow this and additional works at: https://ir.library.louisville.edu/etd

\section{Recommended Citation}

Richter, Natali Brooke, "I. Studies of cyclic peptides containing the arginine-glycine-aspartic acid pharmacophore; II. Targeting drugs to bone." (2008). Electronic Theses and Dissertations. Paper 1203. https://doi.org/10.18297/etd/1203

This Doctoral Dissertation is brought to you for free and open access by ThinkIR: The University of Louisville's Institutional Repository. It has been accepted for inclusion in Electronic Theses and Dissertations by an authorized administrator of ThinkIR: The University of Louisville's Institutional Repository. This title appears here courtesy of the author, who has retained all other copyrights. For more information, please contact thinkir@louisville.edu. 


\title{
I. STUDIES OF CYCLIC PEPTIDES CONTAINING THE ARGININE-GLYCINE-ASPAR'IIC ACID PHARMACOPHORE
}

II. TARGETING DRUGS TO BONE

\author{
By \\ Natali Brooke Richter

\begin{abstract}
A Dissertation
Submitted to the Faculty of the

Graduate School at the University of Louisville

in Partial Fulfillment of the Requirements

for the Degree of
\end{abstract}

Doctor of Philosophy

Department of Chemistry

University of Louisville

Louisville, Kentucky

May, 2008 


\section{STUDIES OF CYCLIC PEPTIDES CONTAINING THE ARGININE-GLYCINE-ASPARTIC ACID PHARMACOPHORE}

II. TARGETING DRUGS TO BONE

By Natali Brooke Richter

A Dissertation Approved on

April 30, 2008

By the Following Reading Committee:

Dissertation Director 


\section{TABLE OF CONTENTS}

ACKNOWLEDGEMENTS .......................................................

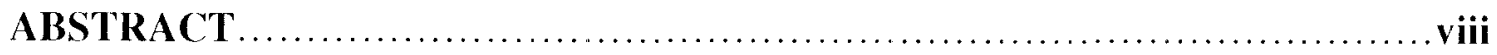

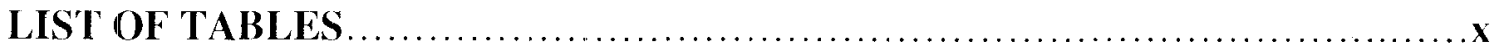

LIST OF SCHEMES ...............................................................

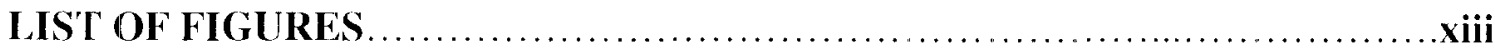

\section{CHAPTER 1:}

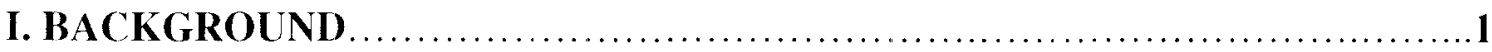

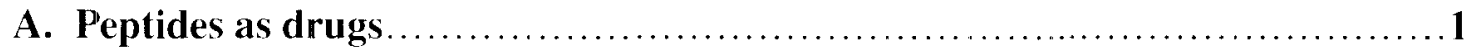

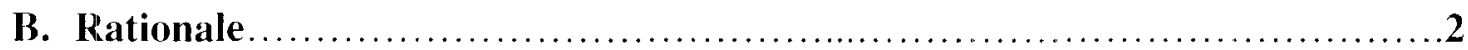

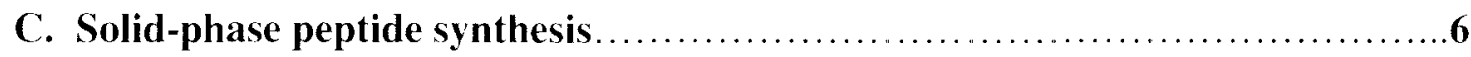

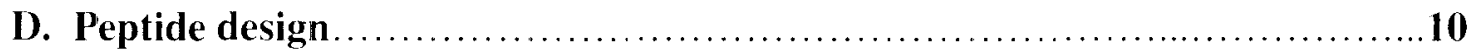

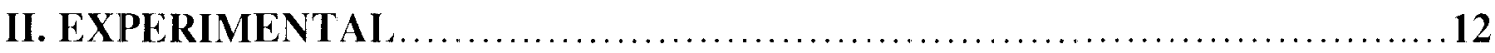

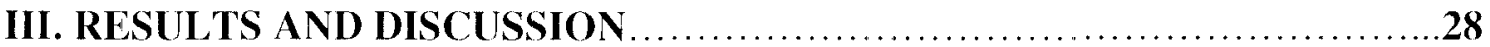

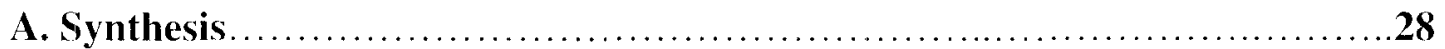

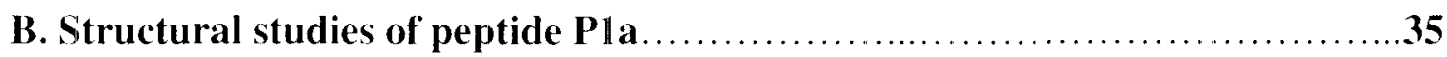

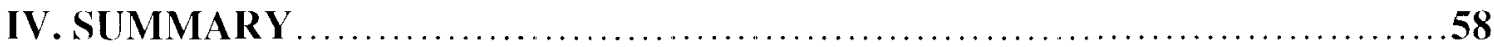




\section{CHAPTER 2:}

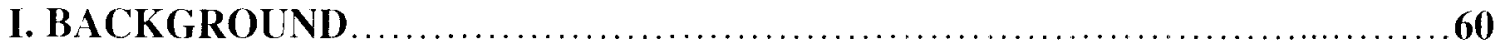

A. Pathophysiology and Pharmacological Treatment of Bone Disorders...........60

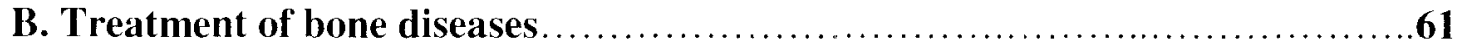

C. Designing “smarter" molecules..........................................62

D. Chemicals that bind to hydroxyapatite ..................................63

E. Tetracycline as a "bone-seeking"' molecule ..................................63

F. Bone-targeted drug conjugates .......................................64

G. Development of a novel bone-targeting agent ..........................65

H. Synthesis and evaluation of a series of bone-targeted estrogens..............66

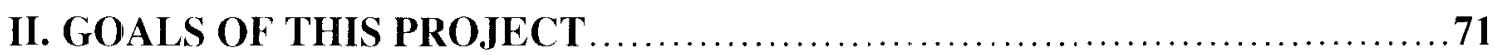

A. Develop a "shelf-stable" bone-targeting entity ............................71

B. Further investigate the effect of the spacer ("s") on oral activity ............72

C. Design and synthesize new bone-targeted conjugates.....................73

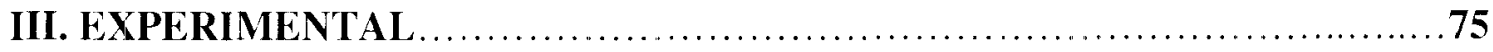

IV. RESULTS AND DISCUSSION ......................................143

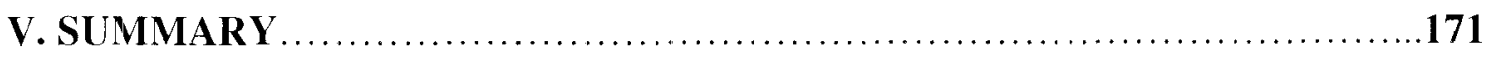

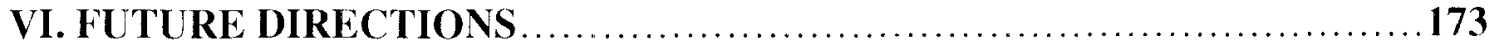

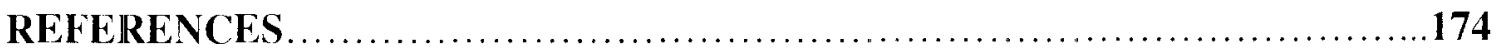




\section{APPENDICES:}

1. Biological Testing of Bone-Targeted Compounds..........................180

2. Glossary of abbreviations..................................................... 195

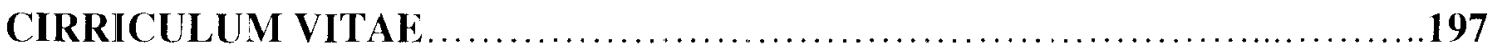




\section{ACKNOWLEDGEMENTS}

I have been very fortunate to work with a number of interesting, diverse, and accommodating people over the years. I am indebted to them all, as they have each contributed to my growth as both a scientist and a human being.

I am very grateful to Dr. K. Grant Taylor, as he has been a constant source of wisdom and guidance for the past four years of my graduate studies. Dr. Taylor was kind enough to take me as his last graduate student and patient enough to allow me to finish. He also did not give me the option of stopping with just my M.S., as I was so tempted to do several times over the years.

I also would like to thank Dr. William Pierce. I feel privileged to have contributed to his expansive research on bone disease and treatments. Working on this project gave me confidence as a synthetic chemist and laid the groundwork for my future career.

I will forever be thankful to Dr. Peteris Romanovskis who acted as my mentor on a daily basis in the laboratory for more than four years. Peter was a most helpful colleague and also a good friend. His advice to "keep it simple" has been ingrained into my thought process when approaching a problem in the lab.

I would like to acknowledge Dr. Christine Rich for her support and advice. Dr. Shipra Dubey for her contributions to the synthesis of the cyclic peptides, Dr. Neal Stolowich for his tremendous patience and assistance with NMR techniques, and Drs. Muriel Maurer and Cecilia Yappert for their help and suggestions with the peptide NMR studies. There are many other friends and coworkers to whom I owe a great deal of gratitude: Dr. Yonis 
Ahmed, Dr. Florence Brunel, Dr. Piotr Mroz, Dr. Giulia Isetti, Dr. Jose Andino, Elizabeth Romaine-Schmidt.

Of course, I could not have completed a single week of my studies if it were not for the continued support of my husband, Joshua, my beautiful daughters, Haylee and Sophia, my parents, Dennis and Terri Sparks, my brother and sister-in-law, Adam and Christina Sparks, and my brother, Alex Sparks.

Finally, I would like to thank Dr. Arno Spatola, in whose memory this dissertation is dedicated. 


\begin{abstract}
I. STUDIES OF CYCLIC PEPTIDES CONTAINING THE

ARGININE-GLYCINE-ASPARTIC ACID PHARMACOPHORE

II. TARGETING DRUGS TO BONE

Natali Brooke Richter
\end{abstract}

May 10, 2008

\title{
CHAPTER I:
}

Seven novel head-to-tail cyclic pentapeptides and pseudopentapeptides containing the arginine-glycine-aspartic acid (RGD) tripeptide motif were synthesized. All of the peptides were constructed using solid phase peptide synthesis. Functionalities of varying degrees of flexibility were incorporated into the cyclic peptide to pose as "linkers." Chosen as linkers for this study were the following: 3-aminomethylbenzoic acid ("3AMB"), 4-aminomethylbenzoic acid, aminocaproic acid, 8-amino-3,6-dioxaoctanoic acid, glycine-phenylalanine, glycine-glycine, and two pseudopeptides, $\mathrm{Gly}_{4}\left[\mathrm{CH}_{2} \mathrm{~S}\right] \mathrm{Gly}$ and Gly $\Psi\left[\mathrm{CH}_{2} \mathrm{~S}\right] \mathrm{Phe}$.

The cyclic peptide $c(1)-F-3 A M B-R G D)$ was chosen for structural evaluation using nuclear magnetic resonance (NMR) spectroscopy. Studies performed in 100\% DMSO-d 6 and DMSO- $\mathrm{d}_{6}: \mathrm{H}_{2} \mathrm{O}(2: 1)$ allowed two structural constraints to be placed on the peptide in both systems to generate two working models. A comparison of the structures in the two solvent systems based on the NH-C $\mathrm{C}_{a k} \mathrm{H}$ dihedral angles of Arg and Phe, revealed that a rather dramatic conformational change took place when water was added to the system. 
Broadening of the Asp proton signals in 100\% DMSO was indicative of restricted conformational exchange, possibly due to the formation of an internal Asp-Arg salt bridge. The signal broadening is relieved upon the addition of $30 \%$ water, indicating a disruption of the salt bridge. All of the backbone amide protons except for that of aspartic acid were found to display a temperature-dependent change in chemical shift, indicating that the Asp NH is involved in an intramolecular hydrogen bond in the presence of water, most likely with the carboxylate of its own side-chain.

\section{CHAPTER II:}

Ten new bone-targeted molecules were designed, synthesized, purified, and characterized, including two "universal" bone-targeting agents based on a model of the A-ring of tetracycline: 2-(2-(2-(3-carbamoyl-2-hydroxy-4-methox yphenylamino)-2oxoethoxy)ethoxy)ethanaminium chloride and 5-(2-(2-(2-(3-carbamoyl-2-hydroxy-4methox yphenylamino)-2-oxoethoxy)ethoxy)ethylamino)-5-oxopentanoic acid. To demonstrate the potential of the "universal" bone-targeting agents, as well as produce potentially highly specific bone therapeutic or diagnostic agents, bone-targeted conjugates of estradiol, doxorubicin, fluorescein, and genistein were synthesized. The resulting compounds preserved the putative pharmacophore while incorporating the bone-targeting elements. Each of these conjugates displayed significantly different solubility properties and, consequently, demanded different methods of isolation and purification. 


\section{LIST OF TABLES}

\section{Chapter 1:}

1. Data from Synthesis of Cyclic Peptides......................................30

2. Summary of ${ }^{1} \mathrm{H}$ Chemical Shifts of P1a DMSO-d $\mathrm{d}_{6}$ at $37^{\circ} \mathrm{C}(8 \mathrm{mM}) \ldots \ldots \ldots . . .35$

3. Proton chemical shifts of P1a in DMSO-d $\mathrm{d}_{6}$ at $37^{\circ} \mathrm{C}(8 \mathrm{mM}) \ldots \ldots \ldots \ldots \ldots . \ldots . \ldots . \ldots 6$

4. Proton chemical shifts of $\mathbf{P l a}$ in DMSO- $\mathrm{d}_{6}: \mathrm{H}_{2} \mathrm{O}(2: 1 ; 5 \mathrm{mM})$ at $15^{\circ} \mathrm{C} \ldots \ldots .47$

5. Proton chemical shifts of dimeric peptide $\mathbf{P 1 b} \ldots \ldots \ldots \ldots \ldots \ldots \ldots \ldots \ldots \ldots$

\section{Chapter 2:}

1. Novel hone-targeted compounds synthesized for this project. $145-146$

2. Summary of synthetic results from bone-targeted mini-PEGS and estradiol conjugates.

3. Bone-targeted estradiol conjugates. 


\section{LIST OF SCHEMES}

\section{Chapter 1:}

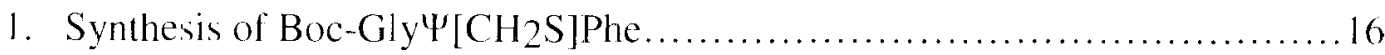

2. Synthesis of Boc-Glycine $\Psi\left[\mathrm{CH}_{2} \mathrm{~S}\right]$ Glycine.......................... 18

3. Solid-phase peptide synthesis c(D-Phe-3-AMB-Arg-Gly-Asp)...........23-27

\section{Chapter 2:}

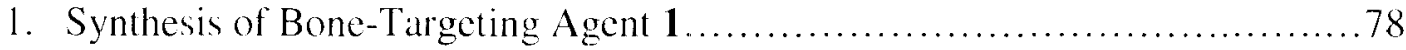

2. Coupling of Fmoc-mini-PEG to bone-targeting agent 2-hydroxy-6-methoxy-3-

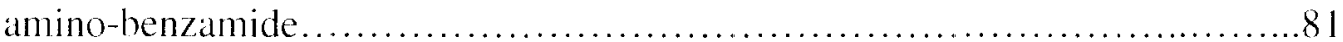

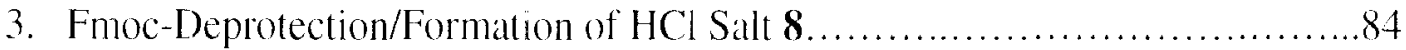

4. a. Coupling of bone-targeting agent (2-hydroxy-6-methoxy-3-amino-benzamide) to Fmoc-11-amino-3,6,9-trioxaundecanoic acid. b. Fmoc-Deprotection/Formation of $\mathrm{HCl}$ salt 9

5. Coupling of Fmoc-mini-PEG to Bone-Targeting Agent 2-hydroxy-6-benzyloxy-3amino-benzamide hydrochloride.

6. Deprotection of $\mathbf{1 0 / F o r m a t i o n ~ o f ~ H C I ~ S a l t ~} 11$ .96

7. Coupling of $\beta$-estro-O-propanoic acid to $\mathbf{8}$.

8. Coupling of $\beta$-estro-O-propanoic acid to $\mathbf{1 1}$

9. Coupling of Glutaric Anhydride to 8

10. Coupling of $\mathbf{1 5}$ to Doxorubicin $\bullet \mathrm{HCl}$ .120

11. Coupling of fluorescein isothiocyanate to 8 
12. Regioselective carboxyalkylation of genistein.

13. Acidolysis of $\mathbf{1 8}$ yields an acidic genistein derivative

14. Formation of bone-targeted genistein.

15. Proposed synthetic strategy for making bone-targeted fluorophore

16. Strategy 2. Esterify fluorescein, alkylate at phenolic position, then finally conjugate through acidic functionality

17. Proposed synthetic scheme for selectively alkylating genistein with t-butyl bromoacetate. 166 


\section{LIST OF FIGURES}

\section{Chapter 1:}

1. Examples of cyclic peptides currently on the pharmaceutical market...............3

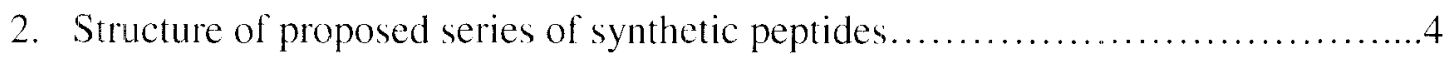

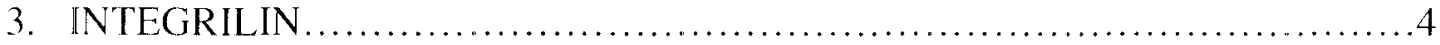

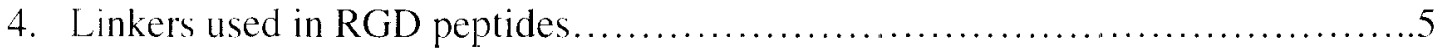

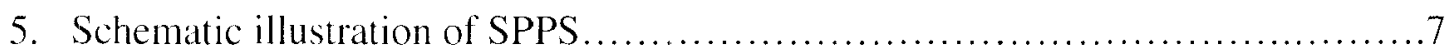

6. Schematic Illustration of Peptide Cyclization Options........................

7. BOP and HOBt coupling agents........................................

8. Mechanism of BOP/HOBt Peptide Coupling ............................. 10

9. Schematic representations of cyclic peptides.............................28

10. Three-dimensional view of how side-chain steric interactions in a peptide containing L-phenyalanine can be relieved when D-phenylalanine is used

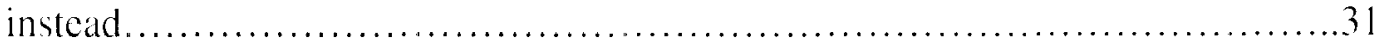

11. Formation of internal succinimide by aspartic acid side-chain.................. 31

12. Formation of a cyclic peptide "dimes" via intermolecular cyclization..............33

13. HPLC Chromatograms of P1a ..........................................

14. The monomeric cyclic peptide Pla ..................................... 35

15. 1-dimensional ${ }^{1} \mathrm{H}$ NMR spectrum of P1a in $100 \%$ DMSO- $_{6}(8 \mathrm{mM})$; amide

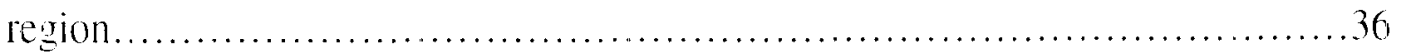

16. Fingerprint region of TOCSY spectrum of P1a in $100 \%$ DMSO- $\mathrm{d}_{6}(8 \mathrm{mM}) \ldots . \ldots .37$ 
17. TOCSY vs COSY experiment ............................................

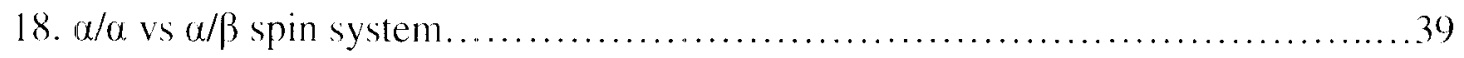

19. An HMBC spectrum of peptide Pla in $100 \%$ DMSO-d $_{6}(8 \mathrm{mM}) \ldots \ldots \ldots \ldots \ldots . . . . .40$

20. Weak through-bond couplings were observed between a proton at $\delta 7.8$ ppm......41

21. All five amide protons were clearly visible in the DMSO: $\mathrm{H}_{2} \mathrm{O}(2: 1 ; 5 \mathrm{mM})$ system

22. The 3-aminomethyl benzoic acid proton highlighted in blue makes an upfield shift when water is added to the solvent system.

23. TOCSY fingerprint of Pla, DMSO-d $\mathrm{d}_{6}: \mathrm{H}_{2} \mathrm{O}(2: 1 ; 5 \mathrm{mM}), 16^{\circ} \mathrm{C} \ldots \ldots \ldots \ldots \ldots . \ldots 4$

24. TOCSY fingerprint region of Pla, DMSO- $\mathrm{d}_{6}: \mathrm{H}_{2} \mathrm{O}(2: 1 ; 5 \mathrm{mM}), 16^{\circ} \mathrm{C} \ldots \ldots \ldots .45$

25. Fingerprint region of P1a, DMSO- $\mathrm{d}_{6}: \mathrm{H}_{2} \mathrm{O}(2: 1 ; 5 \mathrm{mM}), 16^{\circ} \mathrm{C} \ldots \ldots \ldots \ldots \ldots . \ldots 46$

26. Fingerprint region of Pla, DMSO-d $\mathrm{d}_{6}: \mathrm{H}_{2} \mathrm{O}(2: 1 ; 5 \mathrm{mM}), 16^{\circ} \mathrm{C} \ldots \ldots \ldots \ldots \ldots . .47$

27. Proposed structure of Pla in $100 \%$ DMSO................................. 48

28. The generated structure corresponds well with observed ROESY interactions....49

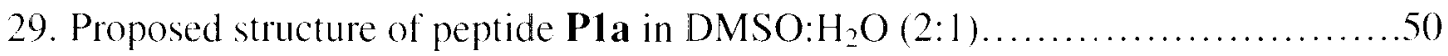

30. 'H NMR spectrum of the peptide in DMSO-water at 15,25 , and $37^{\circ} \mathrm{C} \ldots \ldots \ldots . .52$

31. Plot of NH shifts as a function of temperature .............................

32. 'H NMR spectrum of Plb............................................. 57

\section{Chapter 2:}

1. Tetracycline.... .64

2. Three series of molecules based on the A ring of tetracycline..................67

3. Structure-activity relationship variables of bone-targeted estrogens..............68

4. Comparative hydroxyapatite binding of bone-targeted estrogens................ 70 
5. Postulated intramolecular cyclization of previous bone-targeting agents with linker arms

6. Bone-talgeting agents "D2" (1: $\left.\mathbf{R}=\mathbf{C H}_{3}\right)$ and "D3" (2: $\mathbf{R}=\mathbf{B} \mathbf{z}$ ) were found to result in the most potent and selective estradiol conjugates

7. Genistin is hydrolyzed by a $\beta$-glucosidase during digestion to yield genistein.....73

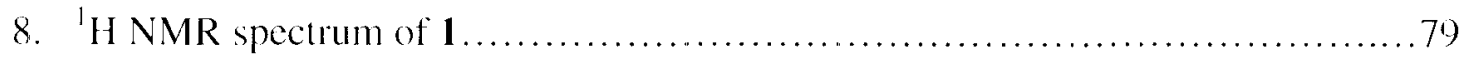

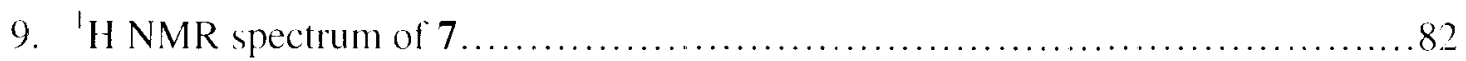

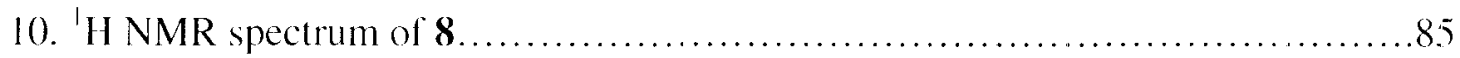

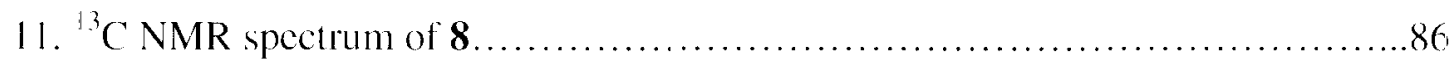

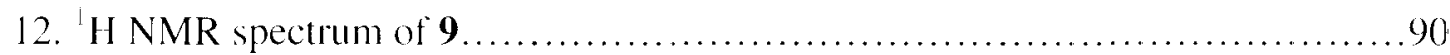

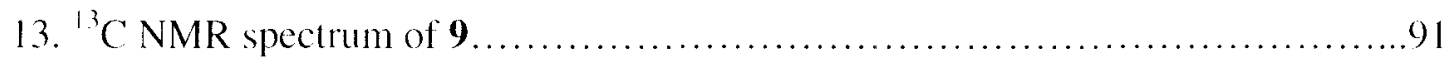

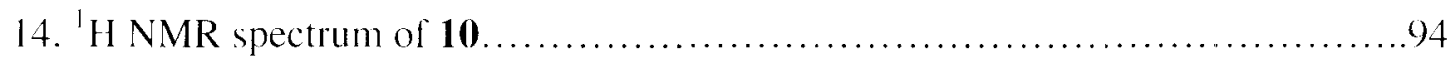

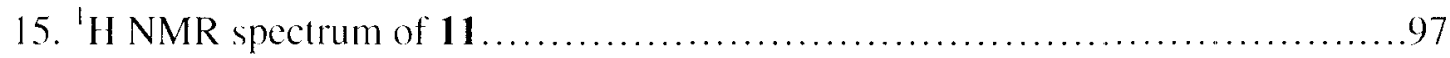

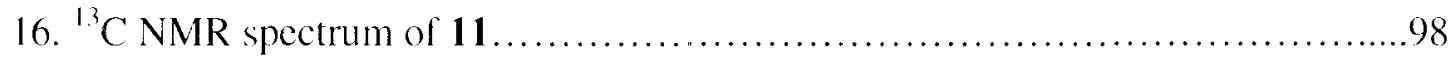

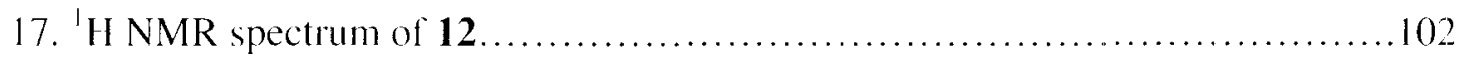

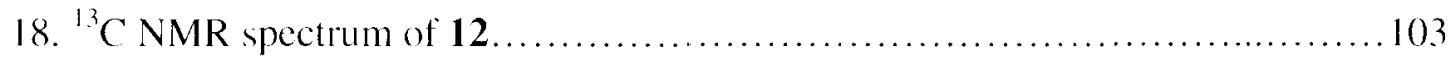

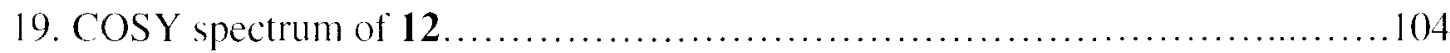

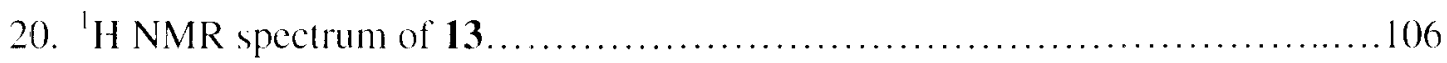

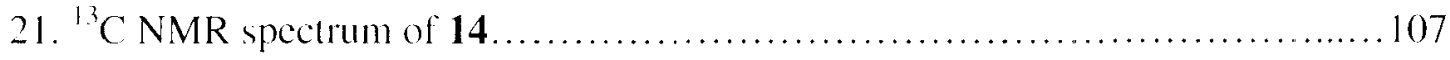

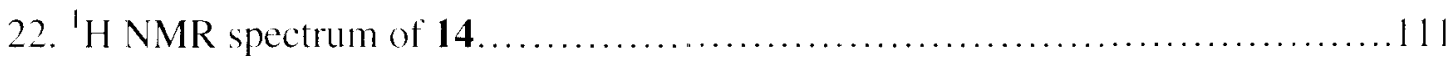

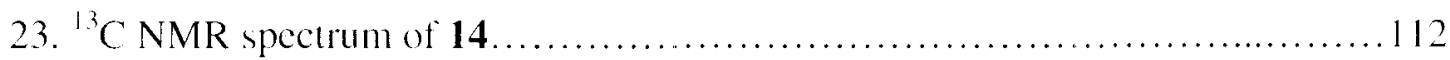

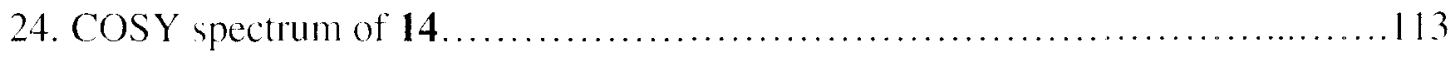

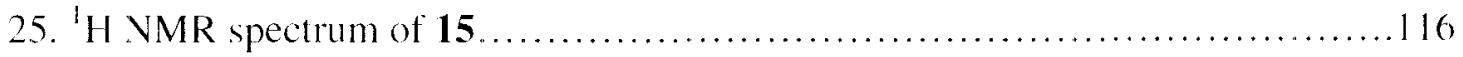




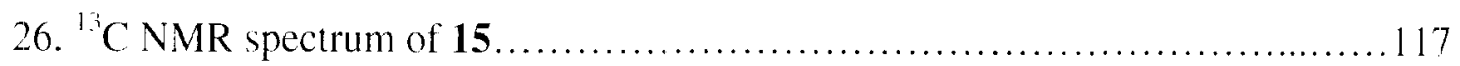

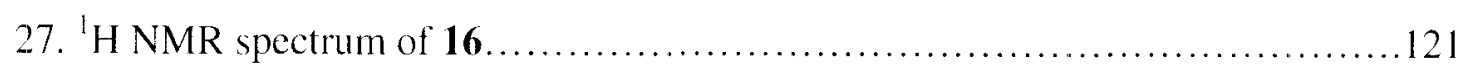

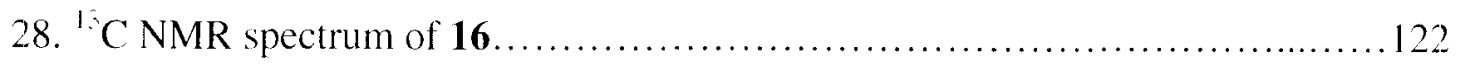

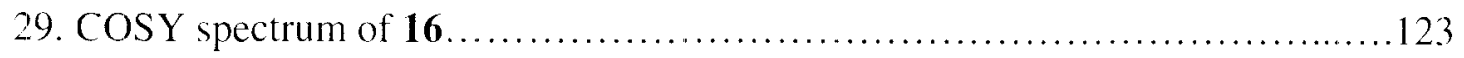

30. ${ }^{1} \mathrm{H}$ NMR spectrum of $\mathbf{1 7 \ldots \ldots \ldots \ldots \ldots \ldots \ldots \ldots \ldots \ldots \ldots \ldots \ldots \ldots \ldots \ldots \ldots \ldots \ldots \ldots \ldots \ldots \ldots \ldots \ldots \ldots \ldots \ldots \ldots \ldots \ldots}$

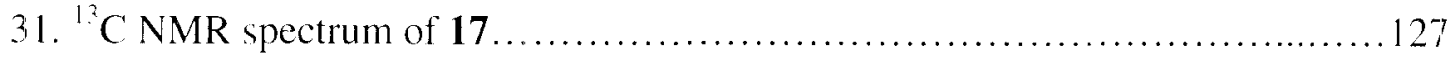

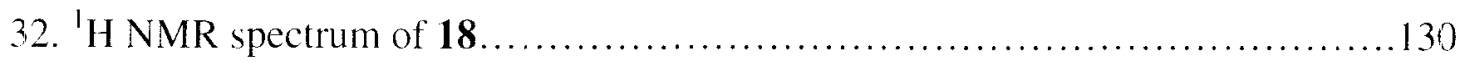

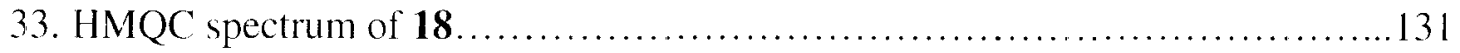

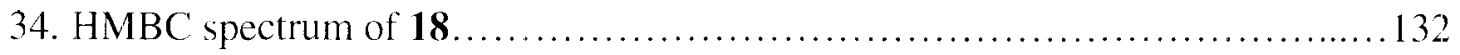

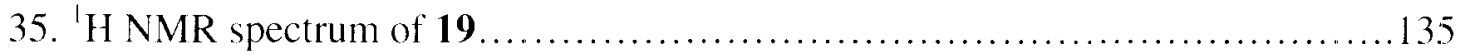

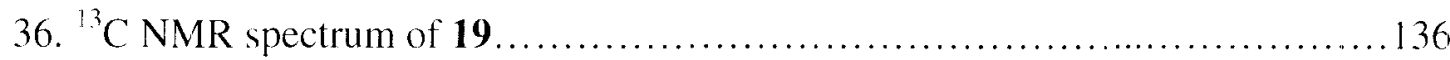

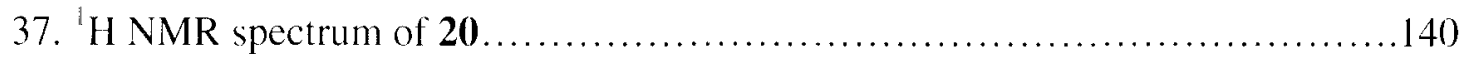

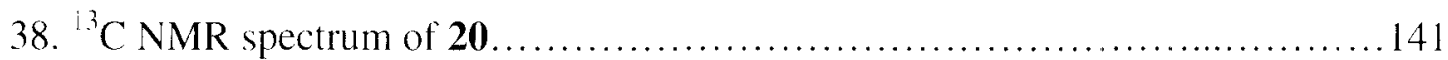

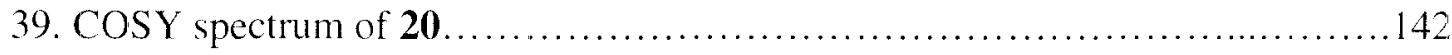

40. Bone-targeted estrogen conjugates BTE2-D2 and BTE2-D3 ..................143

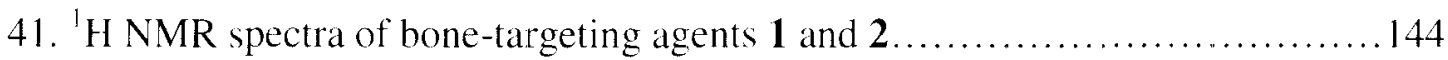

42. Bone-targeting agents $\mathbf{1}$ and $\mathbf{2}$ were linked to mini-PEG molecules..............148

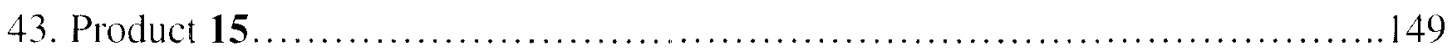

44. 1-dimensional 'H NMR spectra of BT-MPs 8, 9, and $11 \ldots \ldots \ldots \ldots \ldots \ldots \ldots 152$

45. COSY interactions of bone-targeted conjugate ............................. 154

46. Upon coupling, a downfield shift could be noted in the terminal methylene

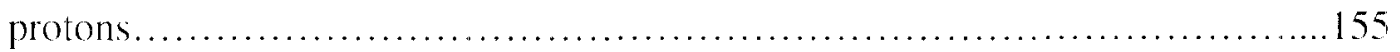

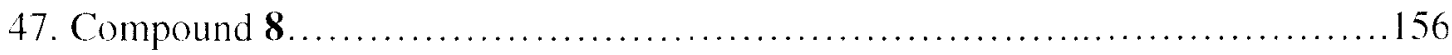


49. 5-aminofluorescein

50. 5-aminofluorescein exists as in equilibrium between a lactone and an open-chain acid.

51. Fluorescence excitation and emission spectra of product $\mathbf{1 7}$ .163

52. Genistein. 164

53. Options for the regioselective alkylation of genistein 165

54. Alkylated genistein product $\mathbf{1 8}$ 168

55. 'H NMR of alkylated genistein product $\mathbf{1 8}$ .168

56. HMBC spectrum of alkylated genistein product 170

57. Micro-computed CT scans show the effect of OVX on bone density.... 186

58. Effects of available treatments for osteoporosis after 6 weeks of administration. 186

59. Effects of estradiol conjugate 13 (BTE2-pg3-D2) after 6 weeks of administration .186

60. Archimedes density test results. 187

61. Indentation test results. 188

62. Serum osteocalcin

63. Body weight effect of conjugate $\mathbf{1 3}$.

64. Uterine mass effect of conjugate $\mathbf{1 3}$ .190

65. Colony formation assay results

66. Cell proliferation data. 


\section{CHAPTER 1}

\section{STUDIES OF CYCLIC PEPTIDES CONTAINING THE ARGININE-GL YCINE- ASPARTIC ACID PHARMACOPHORE}

\section{BACKGROUND}

\section{A. Peptides as Drugs}

Since Merrifield's development of Solid-Phase Peptide Synthesis (SPPS) in the 1960s, the pharmaceutical industry has had a vested interest in peptides as drug candidates. By exploiting the biological diversity of peptide molecules, therapeutic agents such as HIV protease inhibitors, acetylcholine esterase (ACE) inhibitors, calcitonins, and vasopressin and somatostatin analogues have been cultivated. As a class, peptides exhibit high biological activity, high specificity, and short half-lives, all of which make them valuable for drug design. However, there is one major drawback to employing peptides as pharmaceuticals: Iow bioavailability (i.e. absence of oral activity and limited stability). This problem is due largely to the fact that linear peptides in aqueous solution lack a fixed threc-dimensional conformation. Therefore, peptides and peptidomimetics that have a more rigid structure are currently being investigated for drug development. (Jackson, et al, 1994).

Through cyclization, peptides adopt a more restricted conformation, which may mimic that of pharmacologically active natural products (Rizo \& Gierasch, 1992). At the 
moment there are several cyclic peptide drugs available on the market (see Figure 1). By incorporating functionalities of varying degrees of flexibility into a cyclic peptide, one can systematically study the effect on the cyclic conformation and, consequently, its biological activity. Cyclization also makes the peptides more resistant to proteolysis than their linear counterparts due to the lack of exopeptidase cleavage sites (Spatola, 1983).

\section{B. Rationale}

In the present study we have introduced a range of non-functionalized units, which we call "linkers," within a head-to-tail cyclic pentapeptide frame to act as dipeptide replacements. Such linkers allow not only for conformational adjustments, but also lipophilic modifications. Moreover, an appropriate linker can reduce the number of amide bonds in the peptide, further improving proteolytic resistance.

The current project focuses on the synthesis of a series of novel head-to-tail cyclic pentapeptides and pseudopentapeptides containing the arginine-glycine-aspartic acid (RGD) tripeptide motif all having the basic structure shown in Figure 2. RGD is known to be the recognition sequence of many integrin receptors. Integrins are receptors for extracellular matrix proteins such as fibrinogen, fibronectin, thrombospondin, and von Willebrand factor. Such proteins are necessary for platelet adhesion and aggregation and, therefore, integrin receptors have been linked to angiogenic disease, osteoporosis, and restenosis. Many of the integrins recognize the tripeptide Arg-Gly-Asp (RGD), which is present in their respective ligands (Ruoslahti \& Pierschbacher, 1987; Haubner, et al, 1997). Hence, RGD peptides and related peptides are useful for targeting therapeutic proteins, such as integrins. INTEGRILIN ${ }^{(1)}$, marketed by Millenium Pharmaceuticals, is 


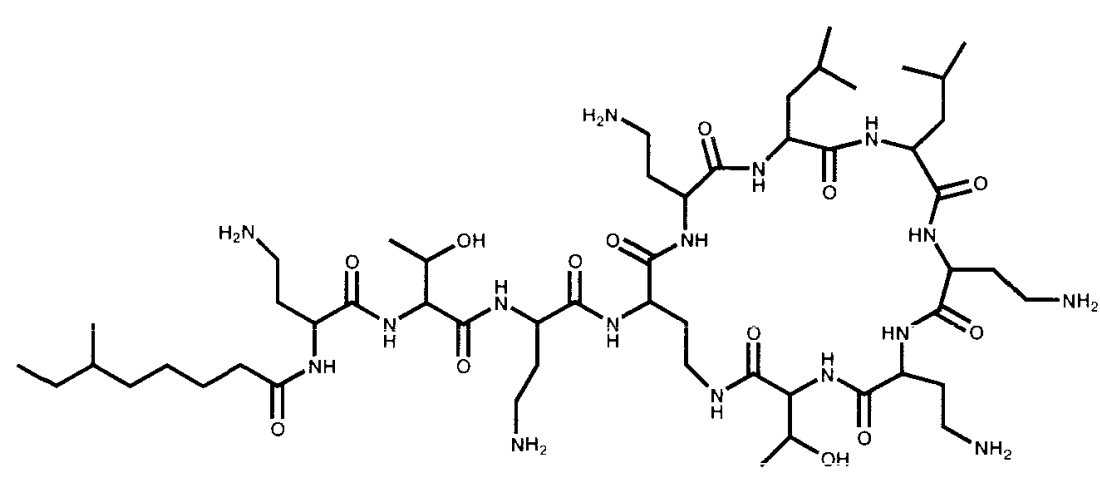

Colistin

(topical antibiotic)

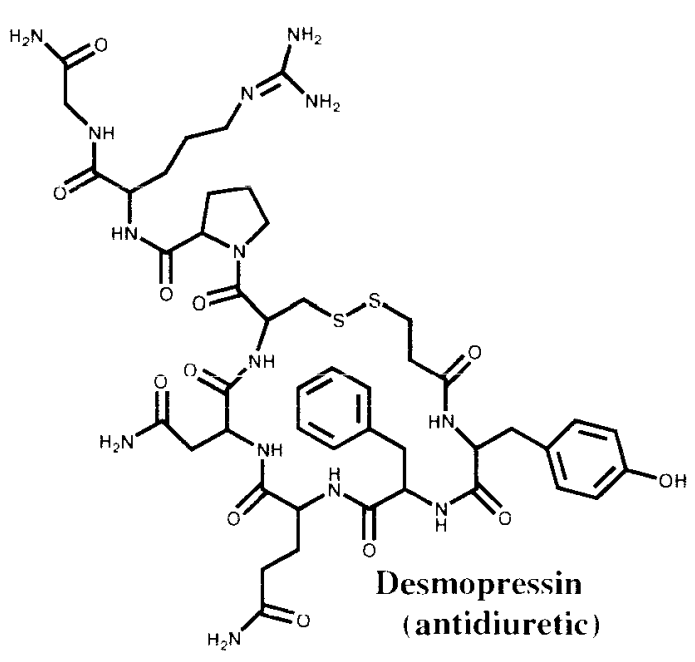

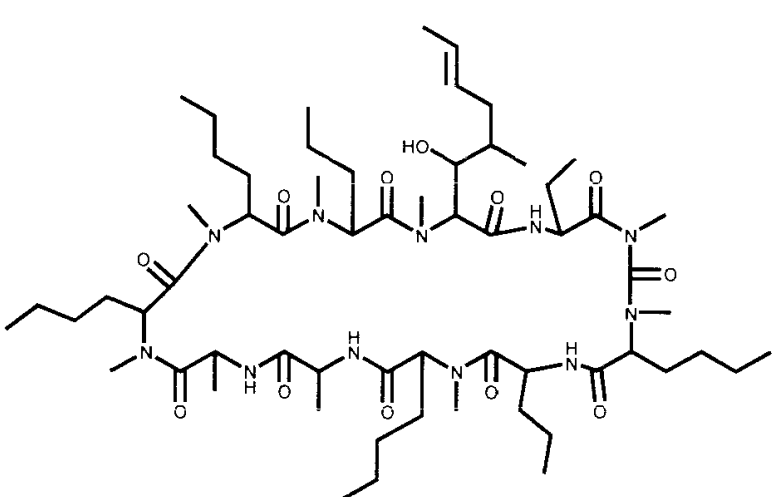

Cyciosporin

(immunosuppressant)

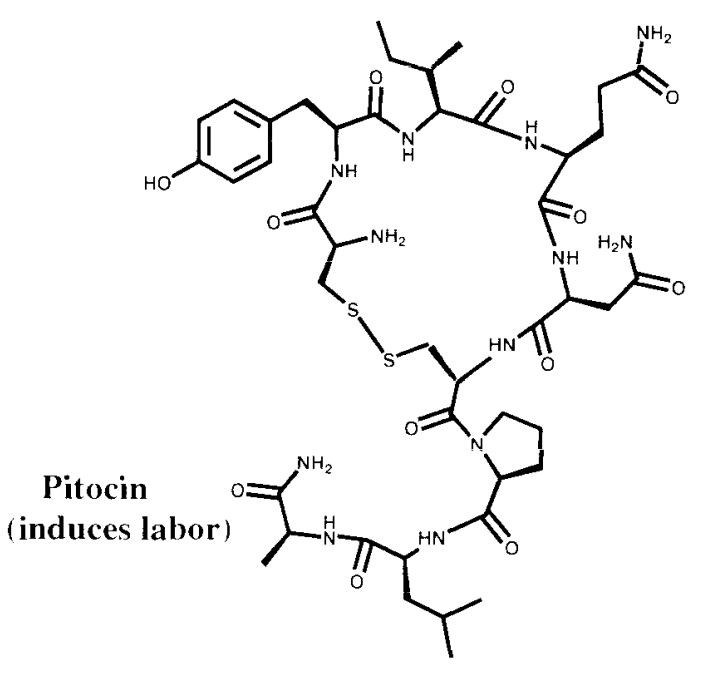

Figure 1: Examples of eyclic peptides currently on the pharmaceutical market. 
one of the best examples of an RGD-containing cyclic peptide that is commercially available today (Figure 3).

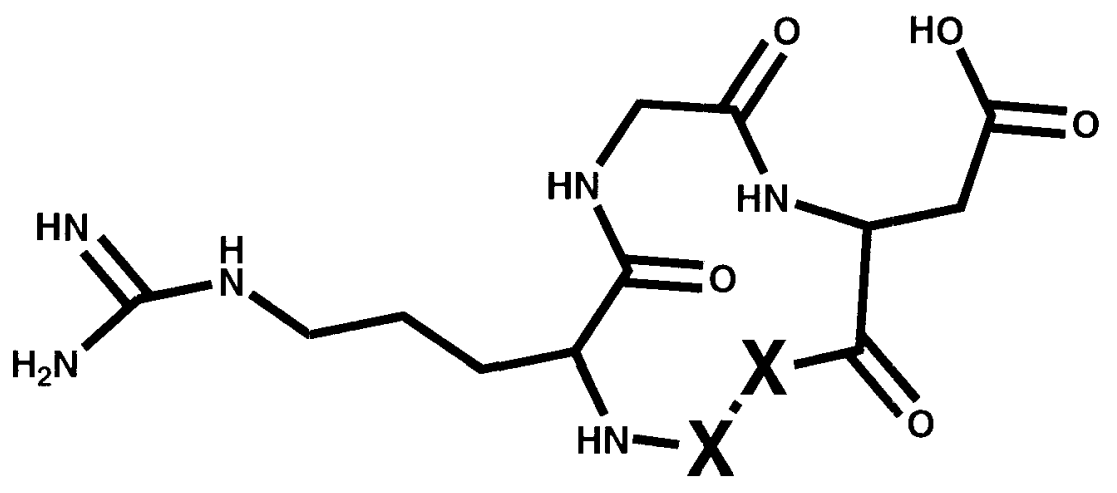

Figure 2: Structure of proposed series of synthetic peptides.

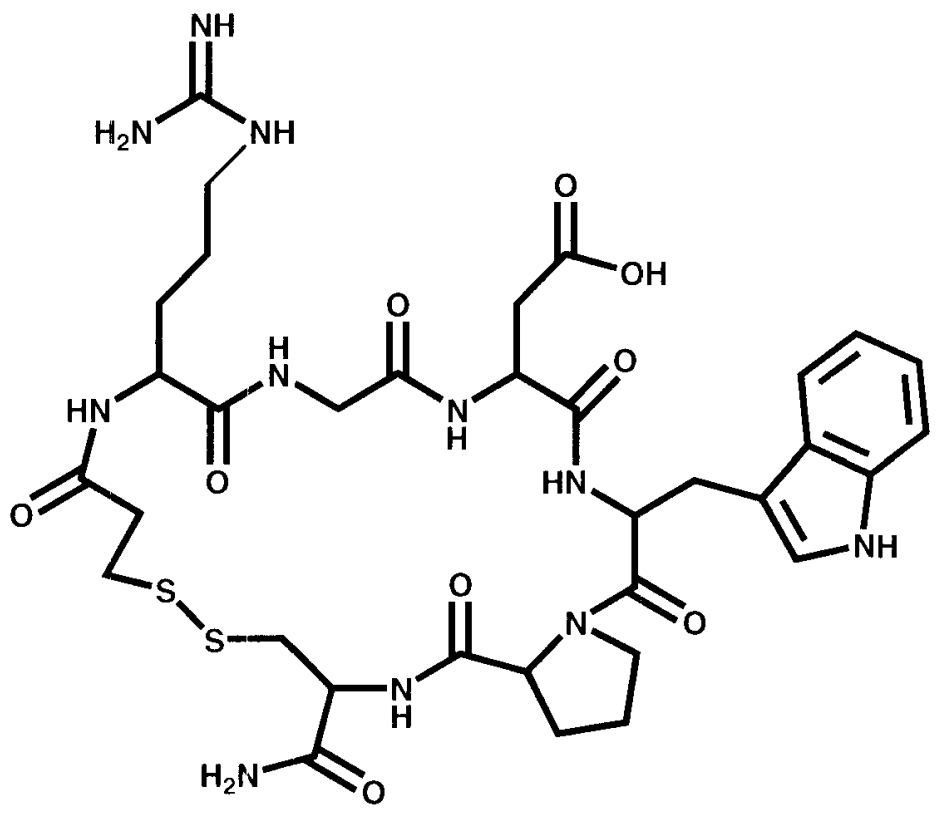

Figure 3: INTECiRILIN". marketed by Millenium Pharmaceuticals, is an example of a cyclic RGD peptide that is currently being used clinically. INTIGGRIL.IN" is an anticoagulant. 
It appears that different conformations of the RGD sequence play a significant role in integrin recognition and selectivity (Kostidis, et al, 2004). Therefore, introduced within each of the cyclic peptides, to pose as "linkers," were a variety of nonfunctionalized structures (see Figure 4). Considering that these linkers may provide the bioactive conformation to the RGD pharmacophore, some of the compounds may be evaluated for competitive inhibition of fibrinogen binding to $\mathrm{GpII}_{h} \mathrm{III}_{\mathrm{a}}$ integrin receptor.
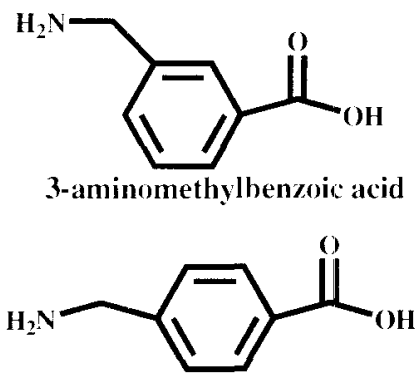

4-aminomethylbenzoic acid

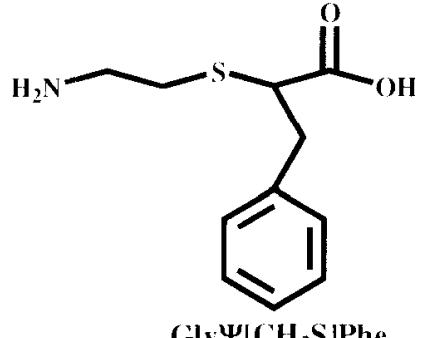

(ily $\Psi\left|\mathrm{CH}_{2} \mathrm{~S}\right| \mathrm{Phe}$<smiles>NCCSCC(=O)O</smiles>

Gly $\Psi\left[\mathrm{CH}_{2} \mathrm{~S}\right] \mathrm{CHI}$<smiles>NCC(=O)NCC(=O)O</smiles>

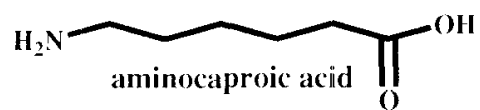

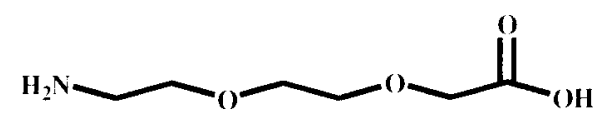

8-amino-3,6-dioxaoctanoic acid ("mini-PE(;")<smiles>NCC(=O)NC(Cc1ccccc1)C(=O)O</smiles>

Figure 4: linkers used in RGD peptides (the symbol " $\Psi$ " indicates that the amide bond has been replaced with the bracketed moiety that follows! 


\section{Solid-Phase Peptide Synthesis}

All of the peptides were constructed using solid phase peptide synthesis (SPPS) (Merrifield, 1964; see Figure 5). Synthesis on the solid phase begins with the attachment of the C-terminal amino acid residue to an inert polystyrene-based resin. After the linkage of the first residue, the amine group is deprotected and the next amino acid is coupled. These steps of deprotection and coupling, with several wash steps in between, are repeated until the desired amino acid sequence has been assembled. Finally, the peptide is cleaved from the resin and the free peptide is released. In order to make a "head-to-tail" cyclic peptide, the $\mathrm{N}$ - and C-termini of the peptide are joined via an amide bond. This cyclization can take place before, during, or after the peptide cleavage from the resin (see Figure 6).

For our studies we chose to use synthetic pathway $\mathbf{B}$, as shown in figure $\mathbf{6}$. The anchoring of peptides to the solid-phase via an aspartic acid side-chain was a method introduced by Rovero, Quartara, and Fabbri (1991) and utilized by Spatola, et al to synthesize cyclic peptides libraries (Darlak, 1994; Spatola, 1996; Spatola \& Crozet, 1996; Spatola, 1998). Since all of our desired peptides contained an aspartic acid residue, it was decided to proceed with the side-chain attachment and on-resin cyclization protocol. 


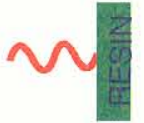

$\mathrm{AA}_{1}$
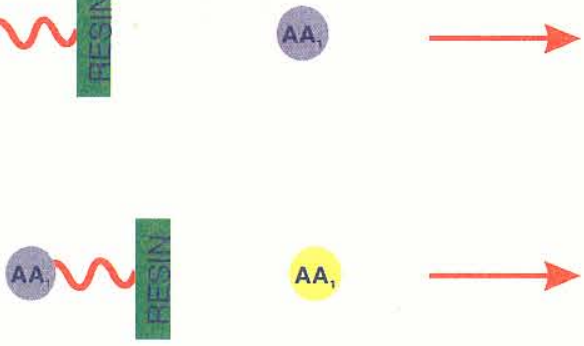

$\mathrm{AA}_{1}$

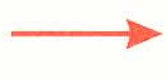

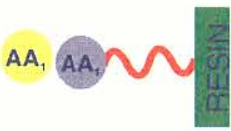

AA
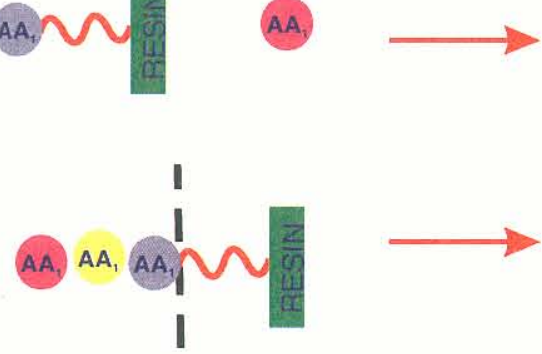

$A A, \cap \frac{3}{9}$

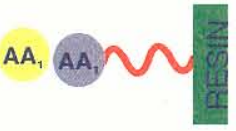

AA, $A A, A A \cap \cap$ 贯

AA. $A A_{1}\left(A A_{1}\right.$

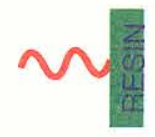

Figure 5: Schematic illustration of SPPS
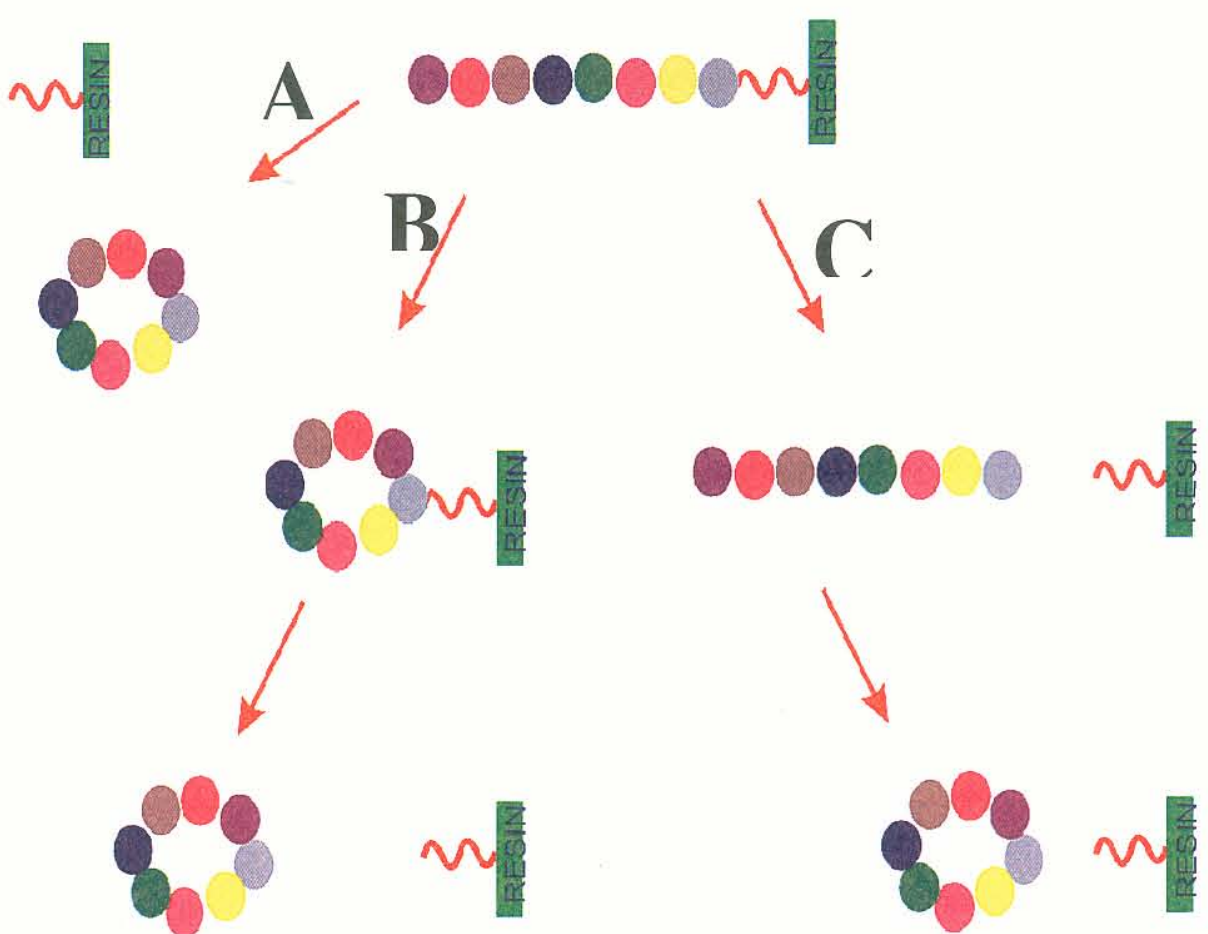

Figure 6: Schematic Illustration of Peptide Cyclization Options: Path A: cleavage from the solid phase with simultaneous cyclization, Path $\mathbf{B}$ : on-resin cyclization followed by cleavage from the solid phase, Path $\mathbf{C}$ : cleavage from the solid phase followed by solution-phase cyclization 
The number and variety of condensing reagents available for amino acid coupling to form amide bonds has increased dramatically over the past several decades. Although carbodiimides have been the classical reagents of choice for peptide bond formation, many novel reagents have been developed to decrease racemization, increase yield, and lessen the chances for the allergic response caused by carbodiimide exposure. Today, the peptide chemist has available an array of activating agents that act via ester, anhydride, azide, or acyl halide formation, among others. The coupling agents used throughout the solid-phase synthesis of our peptides were benzotriazol-1-yloxytris(dimethylamino)phosphonium hexafluorophosphate (BOP) and hydroxybenzotriazole (HOBt) (see Figure 7). The coupling takes place as shown in Figure 8.

In order to make a "head-to-tail" cyclic peptide, or one in which the C-terminus of the peptide is covalently bound to the $\mathrm{N}$-terminus, we used the strategy of attaching the $\mathrm{C}$ terminal residue to the solid support via its side-chain. This way, the $\mathrm{C}$-terminal carboxylic acid functionality is left open for later cyclization. Since all of the peptides synthesized for this study contained the arginine-glycine-aspartic acid motif, the side chain of the aspartic acid residue lent itself well for resin attachment. A hydroxymethylfunctionalized resin was chosen for all of the cyclic peptide syntheses. 

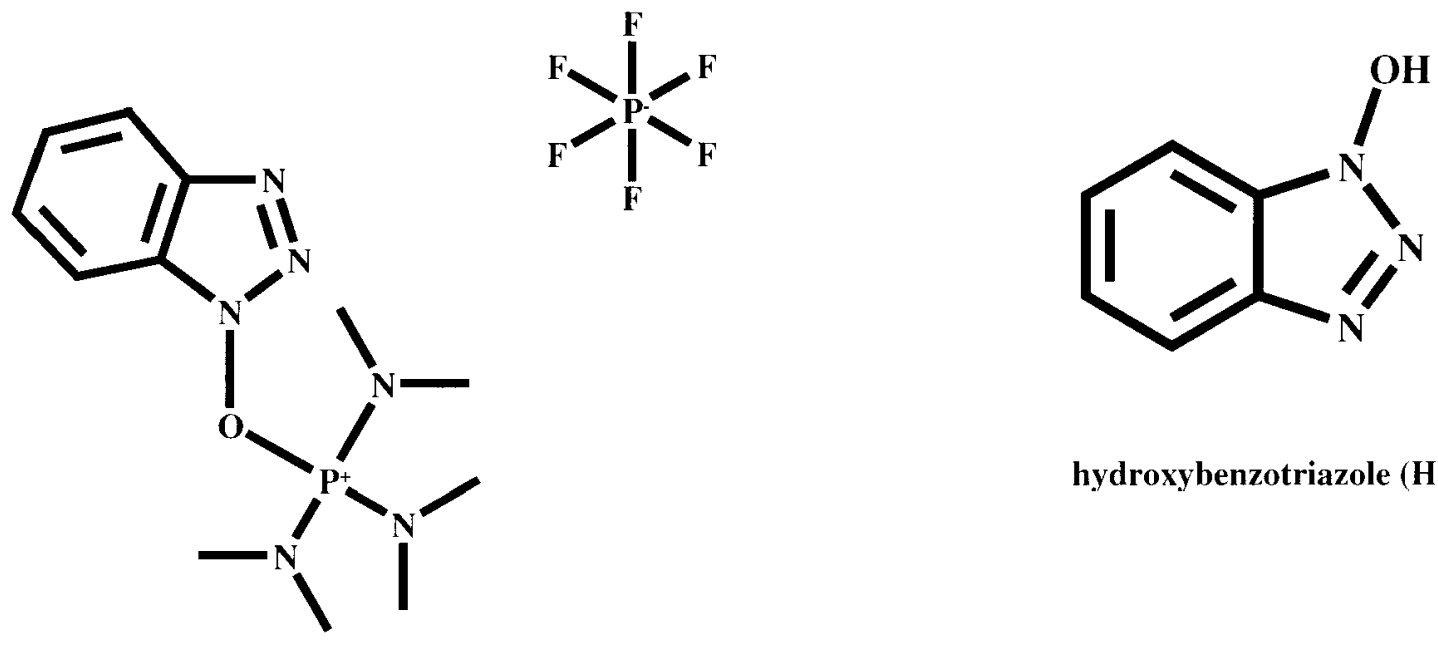

hydroxybenzotriazole (HOBt)

benzotriazol-1-yloxytris(dimethylamino)-phosphonium hexafluorophosphate (BOP)

Figure 7: $\mathrm{BOP}$ and $\mathrm{HOBt}$ coupling agents 

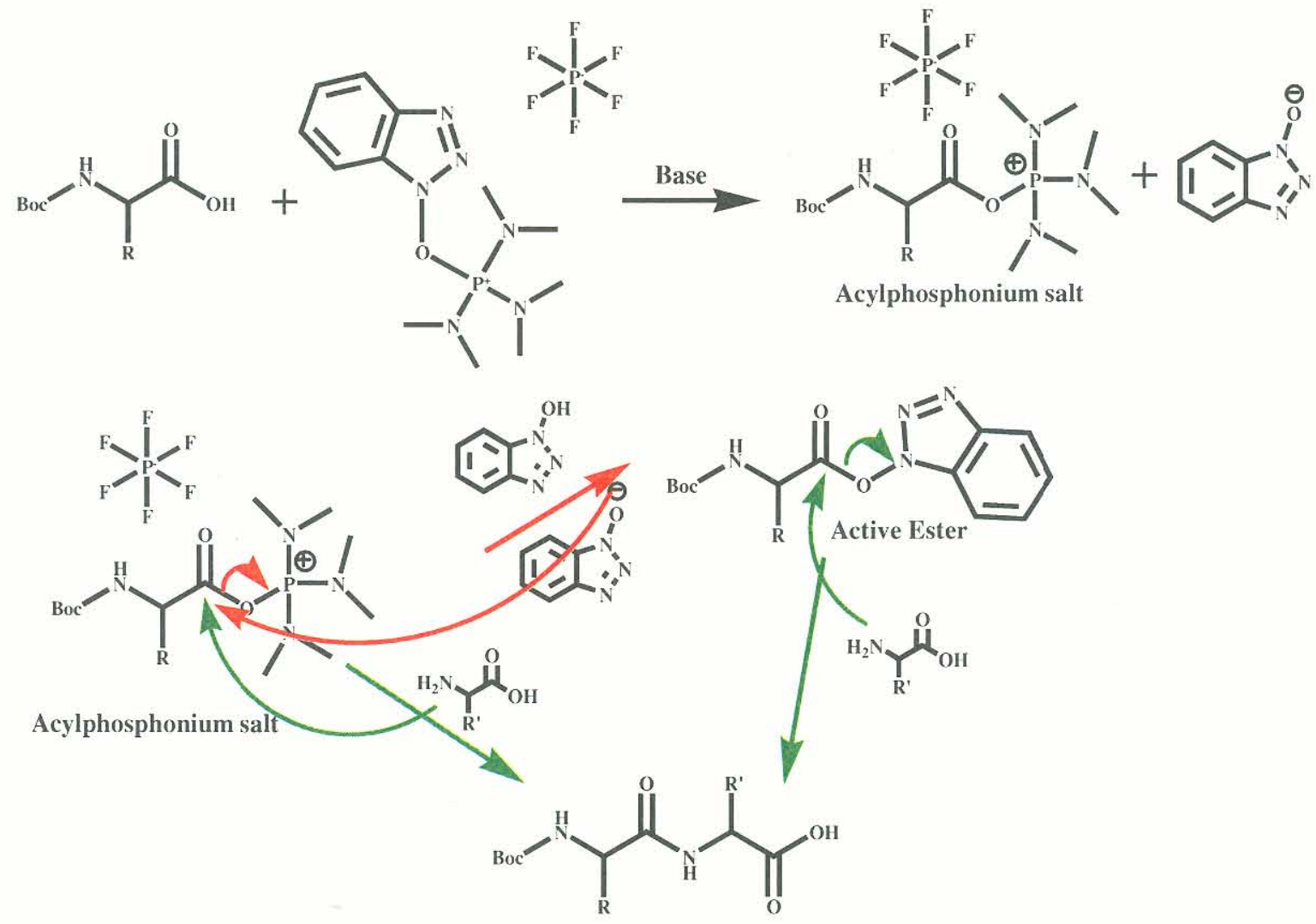

Figure 8: Mechanism of BOP/HOBt Peptide Coupling. In the presence of base, BOP reacts with the carboxylic acid to form an acylphosphonium salt. This highly reactive species can then either be attacked directly by a free amino group (as shown with the green arrows) or can go on to form an active ester by reacting with $\mathrm{HOBt}$ (red arrows). The active ester will be converted to the amide by attack of a free amine.

\section{Peptide design}

An assortment of linkers was selected for incorporation into the cyclic peptide series (see Figure 4). The linkers vary in structure, from the rigid aminomethylbenzoic acid moieties to the flexible aminocaproic and 8-amino-3, 6-dioxaoctanoic acids. Varying degrees of rigidity should lead to varying conformational consequences. Also, insertion 
of these different linkers into the cyclic RGD peptides should induce changes in lipophilicity. Further, we incorporated the pseudopeptides Gly ${ }^{\prime}\left[\mathrm{CH}_{2} \mathrm{~S}\right] \mathrm{Gly}$ and Gly'Y $\left[\mathrm{CH}_{2} \mathrm{~S}\right]$ Phe (where " $\Psi$ " indicates an amide bond replacement with the group contained in brackets) as linking units because of their moderate flexibility and stability towards enzymatic degradation. We also synthesized the peptide analogs containing Gly-Gly-and-Gly-Phe- linkers for biological activity comparison.

Degrado and coworkers synthesized and studied a series of cyclic RGD peptides (Jackson, et al, 1994; Bach, et al, 1994). The two most potent of these compounds were found to be c(D-Abu-N-MeArg-Gly-Asp-3AMB) and c(o-Val-N-MeArg-Gly-Asp$3 \mathrm{AMB})$. It was found that the features that most restricted peptide conformation, and hence were important for tight binding to the $\mathrm{II}_{b} / \mathrm{III}_{\mathrm{a}}$ integrin receptor, were the $\mathrm{D}$ chirality at position 1, N-methylation of the arginine residue, and the incorporation of the 3-aminomethylbenzoic acid (3AME) motif. With these ideas in mind, we chose to study our $3 \mathrm{AMB}$-containing peptide more closely for structural evaluation. 


\section{EXPERIMENTAI.}

General Methods. All chemicals and solvents (reagent grade) were purchased from Peptides International, Advanced Chemtech, Fisher Scientific, or Sigma-Aldrich unless otherwise indicated and were used without further purification. Boc-3aminomethylbenzoic acid was purchased from Bachem. Solvents were purchased from Fisher Scientific or Sigma-Aldrich and distilled as needed.

The crude peptides were all purified via preparative reverse-phase HPLC on cither a Varian 5000 liquid chromatograph with a column from Vydac or Waters instrument with a NovaPak column. All peptides were subjected to mass spectroscopy using an Applied Biosystems Voyager DE-Pro MALDI-TOF instrument in reflector-positive mode with delayed extraction and a $\alpha$-cyano-4-hydroxycinnamic acid matrix on a stainless steel plate. Nuclear magnetic spectroscopy studies were performed on a Varian INOVA 500 MHz spectrometer. Substitution level of Boc-aspartic acid to the hydroxymethyl resin was determined by the methods described by Green and Bradley (1993).

\section{Synthesis of Boc-Glycine $\Psi\left[\mathrm{CH}_{2} \mathrm{~S}\right] \mathrm{Phenylalanine} \mathrm{(Scheme} \mathrm{1).}$}

a. tert-butyl 2-hydroxyethylcarbamate (1). Ethanolamine $(5 \mathrm{~mL}, 82.8 \mathrm{mmol})$ was dissolved in DCM $(150 \mathrm{~mL})$ and was treated at room temperature with triethylamine (11.6 mL, $82.8 \mathrm{mmol})$ and di-tert-butyl dicarbonate $(18.05 \mathrm{~g}, 82.8 \mathrm{mmol})$ for 18 hours at room temperature. After this time, more di-tert-butyl dicarbonate $(4.50 \mathrm{~g}, 20.7 \mathrm{mmol})$ was aldded to the solution, as thin-layer chromatography indicated that the reaction had not gone to completion. After four additional hours of stirring, the reaction was complete. The reaction mixture was with saturated sodium chloride $3 \mathrm{X}$ and $1 \mathrm{~N} \mathrm{HCl} 3 \mathrm{X}$. The organic layer was then dried over sodium sulfate, filtered, and concentrated via 
rotary evaporation to yield $\mathbf{1}$ ( $11.2 \mathrm{~g}$, transparent oil, $84.2 \% ;{ }^{1} \mathrm{H}$ NMR $\left(500 \mathrm{MHz}, \mathrm{CDCl}_{3}\right.$ ) $\delta 1.39\left(\mathrm{~s}, 9 \mathrm{H}, \mathrm{t}\right.$-butyl), $\left.3.42\left(\mathrm{~d}, 2 \mathrm{H}, \mathrm{CH}_{2}\right), 4.10\left(\mathrm{t}, 2 \mathrm{H}, \mathrm{CH}_{2}\right), 4.89(\mathrm{br} s, 1 \mathrm{H}, \mathrm{NH})\right)$.

\section{b. 2-(tert-butoxycarbonylamino)ethyl 4-methylbenzenesulfonate (2). Boc-}

ethanolamine (4.14 g, $25.4 \mathrm{mmol})$ and triethylamine $(7.9 \mathrm{~mL}, 56.8 \mathrm{mmol})$ were dissolved in DCM $(50 \mathrm{~mL})$ and cooled in an ice bath. p-toluenesulfonyl chloride $(5.37 \mathrm{~g}, 28.2$ mmol) dissolved in DCM $(50 \mathrm{~mL})$ was added. The reaction mixture was stirred in an ice bath for 1 hour and at ambient temperature for 48 hours. The reaction mixture was then filtered and washed with DCM. The filltrate was washed with $0.25 \mathrm{~N}$ sulfuric acid $3 \mathrm{X}$, saturated $\mathrm{NaCl} 3 \mathrm{X}$, and dried over $\mathrm{Na}_{2} \mathrm{SO}_{4}$ and filtered. The solution was concentrated under vacuum to yield an oil. The oil was triturated in hexane/ethyl acetate and a white solid precipitated. The mixture was kept at $4^{\circ} \mathrm{C}$ overnight then the solid product 2 was collected via vacuum filtration. $\left(3.35 \mathrm{~g}\right.$, white solid, $41.9 \%$, mp: $63{ }^{\circ} \mathrm{C} ;{ }^{\prime} \mathrm{H}$ NMR (500) $\left.\mathrm{MH}_{z}, \mathrm{CDCl}_{3}\right) \delta 1.42\left(\mathrm{~s}, 9 \mathrm{H}, \mathrm{t}-\right.$ butyl) $, 2.47\left(\mathrm{~s}, 3 \mathrm{H}, \mathrm{OCH}_{3}\right), 3.25\left(\mathrm{t}, 2 \mathrm{H}, \mathrm{CH}_{2}\right), 4.08(\mathrm{~d}, 2 \mathrm{H}$, $\mathrm{CH}_{2}, 4.85($ br s, $1 \mathrm{H}, \mathrm{NH}), 7.38(\mathrm{~d}, 4 \mathrm{H}$, aromatic), 7.81 (d, $4 \mathrm{H}$, aromatic)).

c. (R)-2-bromo-3-phenylpropanoic acid (3). D-phenylalanine $(6.6 \mathrm{~g}, 41 \mathrm{mmol})$ and potassium bromide (28.39 g. $239 \mathrm{mmol}$ ) were dissolved in $2.5 \mathrm{~N} \mathrm{H}_{2} \mathrm{SO}_{4}(75 \mathrm{~mL})$. The solution was cooled in an ice-salt bath and sodium nitrite (4.25 g, $62 \mathrm{mmol})$ in water (25 $\mathrm{mL}$ ) was added dropwise. The solution was stirred continuously overnight at ambient temperature. The reaction solution was extracted with ether $3 X$. The organic layers were combined and washed with $2.5 \mathrm{~N} \mathrm{H}_{2} \mathrm{SO}_{4} 4 \mathrm{x}$ and water $3 \mathrm{X}$, then dried over $\mathrm{Na}_{2} \mathrm{SO}_{4}$ and filtered. The ether layer was then concentrated to give 3(8.31 g, yellow oil. $88.6 \%$; ${ }^{1} \mathrm{HH}$ NMR ( $\left.500 \mathrm{MHz}, \mathrm{CDCl}_{3}\right) \delta 3.30(\mathrm{~d}$ of d, I H, benzylic), 3.5 (d of $\mathrm{d}, 1 \mathrm{H}$. benzylic), $4.40(\mathrm{t}$, $1 \mathrm{H},(\alpha-\mathrm{CH}), 7.25(\mathrm{~m}, 5 \mathrm{H}$, aromatic), $9.00(\mathrm{brs}, 1 \mathrm{H}, \mathrm{COOH}))$. 
d. (S)-2-mercapto-3-phenylpropanoic acid (5). To a solution of $\mathbf{3}(7.34 \mathrm{~g}, 33.4 \mathrm{mmol})$

in dry acetone $(15 \mathrm{~mL})$ was added via dropwise addition a solution of thiourea $(2.53 \mathrm{~g}$. $33.4 \mathrm{mmol})$ in dry acetone $(45 \mathrm{~mL})$ at room temperature. After stirring overnight, the solution was subjected to rotary evaporation to afford the isothiouronium sall 4 . The salt was then dissolved in water (brought to $\mathrm{pH} 10$ by the addition of $10 \%$ sodium hydroxide) and the solution was set to reflux for 7-8 hours. After cooling to room temperature, the solution was extracted with EIOAc $3 \mathrm{X}$ and the aqueous layer was then acidified to $\mathrm{pH} 1.5$ and extracted with EtOAc 3X. The organic layer was dried over $\mathrm{Na}_{2} \mathrm{SO}_{4}$, filtered, and evaporated to afford 5 (3.68 g, dark yellow oil, 60.7\%; 'H NMR (500 $\left.\mathrm{MHz}, \mathrm{CDCl}_{3}\right) \delta$ $2.10(\mathrm{~d}, 1 \mathrm{H}, \mathrm{SH}), 2.94$ (d of d, 2H, benzylic), 3.15 (d of d, 1H, benzylic), 3.54 (q, 1H, $\alpha-$ CH), $7.25(\mathrm{~m}, 5 \mathrm{H}$, alromatic), 8.34 (br s, $1 \mathrm{H}, \mathrm{COOH}))$.

\section{e. 2-(2-(tert-butoxycarbonylamino)ethylthio)-3-phenylpropanoic acid ("Boc-}

Gly $\Psi\left|\mathrm{CH}_{2} \mathrm{~S}\right| \mathrm{Phe}$, 6). Sodium ethoxide was prepared by dissolving sodium metal $(536$ $\mathrm{mg}$ ) in absolute ethanol ( $12 \mathrm{~mL})$. Compound 5 ( $1.5 \mathrm{~g}, 8.2 \mathrm{mmol})$ was dissolved in absolute ethanol $(15 \mathrm{~mL})$ and added to the sodium ethoxide solution. The solution was then warmed to $60^{\circ} \mathrm{C}$ under argon. Compound $2(2.59 \mathrm{~g}, 8.2 \mathrm{mmol})$ dissolved in absolute ethanol $(20 \mathrm{~mL})$ and dry THF $(20 \mathrm{~mL})$ was added dropwise over a 2 -hour period. After: stirring for 3.5 hours at $60^{\circ} \mathrm{C}$, the solvent was stripped under vacuum and the resulting residue was taken up in water $(15 \mathrm{~mL})$. The aqueous solution was washed with ether $3 X$, and then acidified with $2 \mathrm{~N} \mathrm{H}_{2} \mathrm{SO}_{4}$. The product was then extracted with EtOAc $3 \mathrm{X}$, the organic layers combined and dried over $\mathrm{Na}_{2} \mathrm{SO}_{4}$, and the mixture filtered. The filtrate was concentrated under vacuum to give an oily residue. The residue was triturated in ether with a few drops of dicyclohexylammonia until a precipitate was formed. The 
mixture sat overnight at $20^{\circ} \mathrm{C}$. The precipitate was collected and recrystallized from EtOAc. The resulting solid was dissolved in a minimal amount of $0.2 \mathrm{~N} \mathrm{H}_{2} \mathrm{SO}_{4}$ and wats extracted with ether $3 \mathrm{X}$. The ether layer was dried and evaporated to give $6(1.71 \mathrm{~g}$, brown oil, 63.8\%; MALDI peak $(\mathrm{n}+\mathrm{l}+\mathrm{Na})$ : 348.3514, $(\mathrm{n}+\mathrm{l}+\mathrm{K})$ : 364.3209); 'H NMR $\left(500 \mathrm{MHz}, \mathrm{CDCl}_{3}\right) \delta 1.46\left(\mathrm{~s}, 9 \mathrm{H}, \mathrm{t}\right.$-butyl), 2.7 and 2.82, (m, 4H, $\left.\mathrm{CH}_{2}\right), 2.94$ and $3.22(\mathrm{~d}$ of d. $2 \mathrm{H}$, bencylic), $3.53(\mathrm{t}, 1 \mathrm{H}, \alpha-\mathrm{CH}), 4.85(\mathrm{~s}, 1 \mathrm{H}, \mathrm{NH}), 7.28(\mathrm{~m}, \mathrm{H}$, aromatic)). 


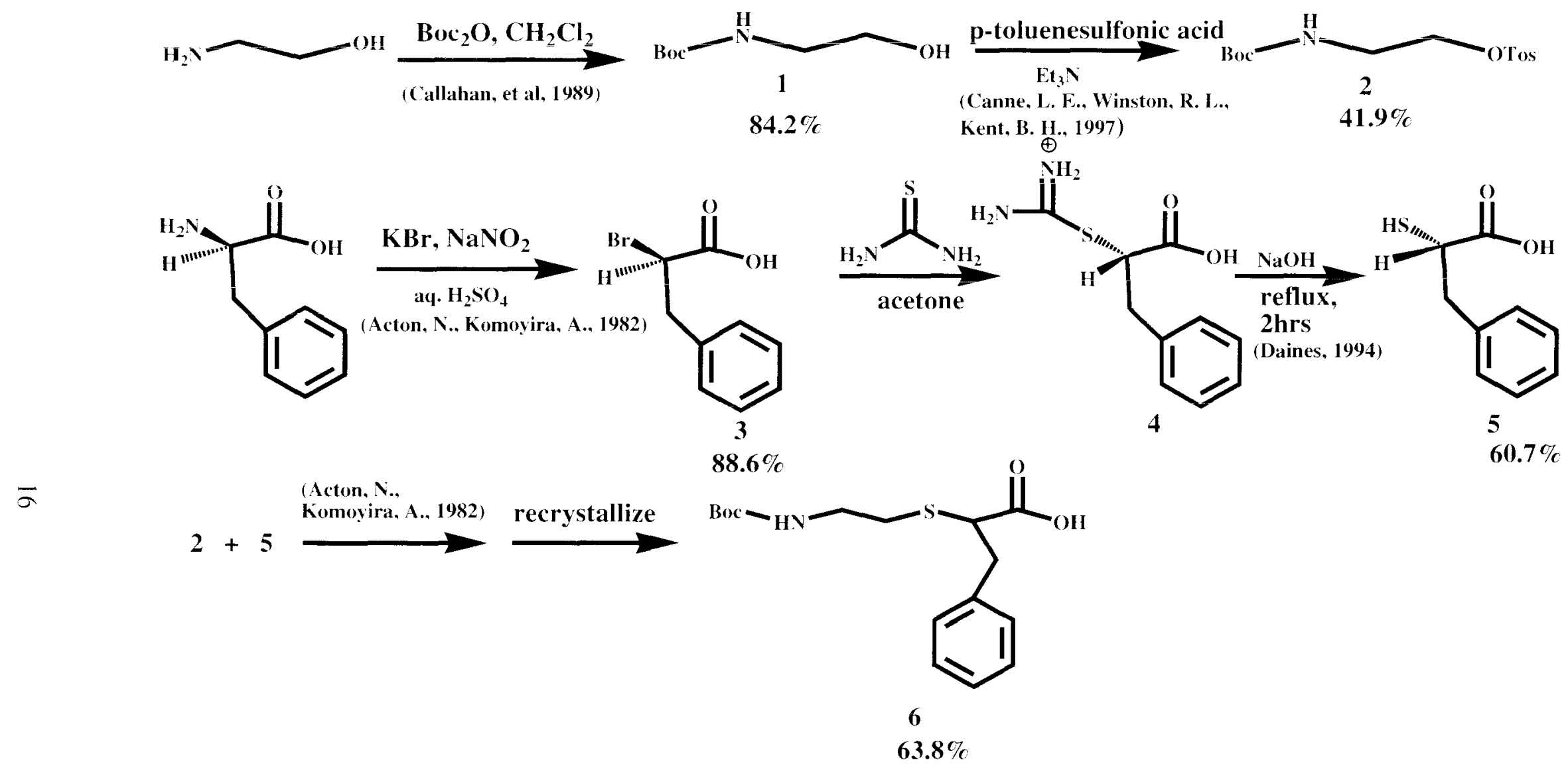




\section{Synthesis of Boc-Glycine $\Psi\left[\mathrm{CH}_{2} \mathrm{~S}\right]$ Glycine (2-(2-(tert-}

butoxycarbonylamino)ethylthio)acetic acid; 7, Scheme 2). Freshly shaved sodium metal ( $245 \mathrm{mg}$ ) was dissolved in absolute ethanol $(5 \mathrm{~mL})$. To this solution was added thioacetic acid ( $351 \mathrm{mg}, 3.8 \mathrm{mmol})$ in absolute ethanol $(5 \mathrm{~mL})$. The solution was warmed to 6$)^{\circ} \mathrm{C}$ and compound 2 (scheme $1 ; 1.2 \mathrm{~g}, 3.8 \mathrm{mmol}$ ), dissolved in anhydrous ether (20) $\mathrm{mL})$ and dry THF (20 mL), was added dropwise over a 1-hour period. The mixture was stirred at room temperature under nitrogen for 4 hours. The solution was then evaporated and taken up in water $(15 \mathrm{~mL})$. The aqueous solution was extracted with ether $3 \mathrm{X}$, then acidified with $2 \mathrm{~N} \mathrm{H}_{2} \mathrm{SO}_{4}$. The product was extracted with EtOAc 3X, the organic layers combined and dried over $\mathrm{Ni}_{2} \mathrm{SO}_{4}$, and the mixture filtered. The filtrate was concentrated under vacuum to give an oily residue. The residue was triturated in ether with a few drops of dicyclohexylammonia until a precipitate was formed. The mixture sat overnight at $20^{\circ} \mathrm{C}$. The precipitate was collected and recrystallized from EtOAc. The resulting solid was dissolved in a minimal amount of $0.2 \mathrm{~N} \mathrm{H}_{2} \mathrm{SO}_{4}$ and was extracted with ether 3X. The ether layer was dricd and evaporated to give 7 (540mg, 60.3\%). 


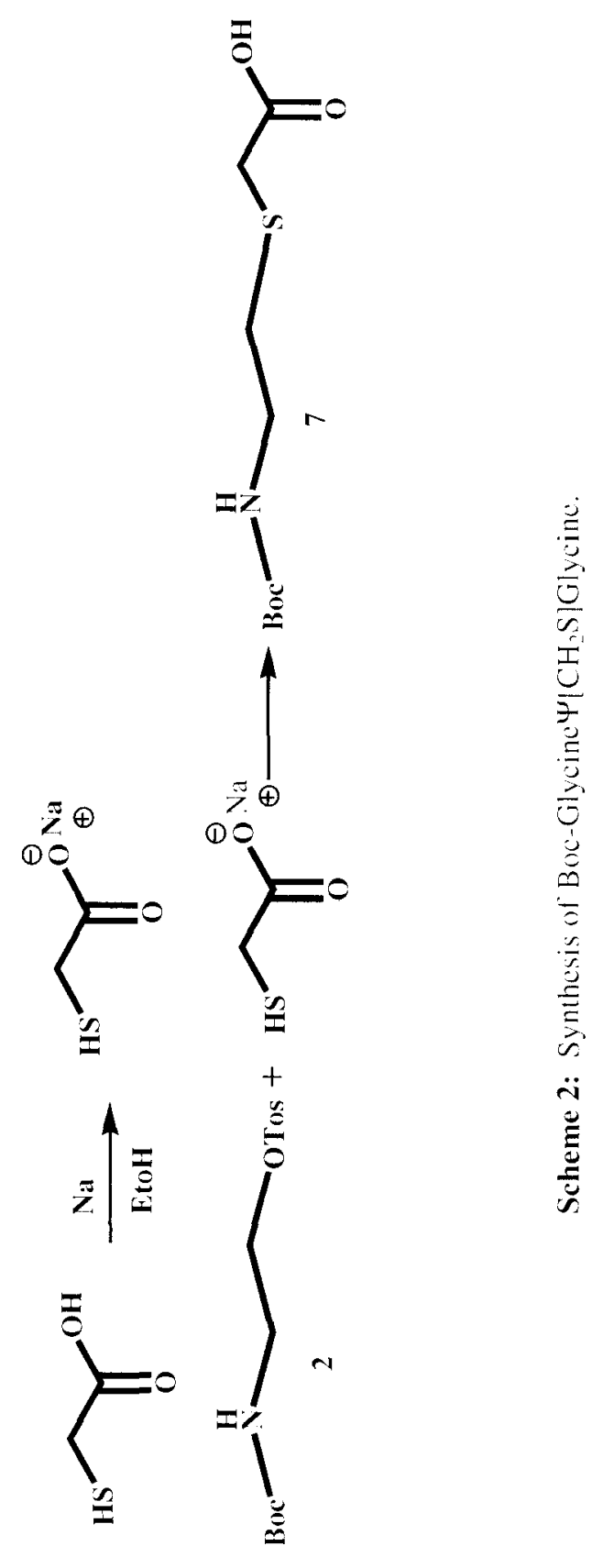


3. Solid-Phase Peptide Synthesis of Cyclic RGD Peptides. All peptides were synthesized manually using $10 \mathrm{~mL}$ fritted syringes as the reaction vessels. To monitor peptide deprotection/couplings, a Kaiser test kit was purchased from Sigma-Aldrich. Kaiser tests were performed after each deprotection and coupling step as follows:

1. A few beads were collected from the resin sample and placed in a test tube.

2. 3 drops of each of the following reagents was added to the test tube: Ninhydrin Solution, $6 \%$ in Ethanol; Phenol Solution, $\sim 80 \%$ in Ethanol; Potassium cyanide Solution, in Pyridine.

3. The test tube was heated in a boiling water bath for 5 minutes.

4. A positive Kaiser test yields blue beads; a negative test yields colorless or yellow beads.

Neutralization of the resin following removal of the Boc-group was performed in situ by using a 2:1 ratio of base:carboxylic acid during the coupling steps.

The following describes the synthesis of the peptide c(1)-Phe-3-AMB-Arg-Gly-Asp) (see Scheme 3). All other peptides were synthesized analogously.

a. i. Boc-Aspartic Acid Internal Anhydride. Boc-aspartic acid (5.00 g, $21.5 \mathrm{mmol})$ was dissolved in $25 \mathrm{~mL}$ of ethyl acetate. In a separate flask, dicyclohexylcarbodiimide (DCC) $(4.42 \mathrm{~g}, 21.5 \mathrm{mmol})$ was dissolved in $3 \mathrm{~mL}$ of ethyl acetate. The DCC solution was then added dropwise to the Boc-asp solution while chilled in an ice bath. The reaction proceeded for 1 hour at $0^{\circ} \mathrm{C}$ and then at ambient temperature for 1 hour. The mixture was filtered, the filtrate evaporated, and a white solid was obtained. The solid product 8 was used immediately in the next step. 
ii. Boc-Asp-OFm. Product 8 was dissolved in $25 \mathrm{~mL}$ of tetrahydrofuran (THF). To this solution was added $4.22 \mathrm{~g}(21.5 \mathrm{mmol})$ of fluorenylmethanol and diisopropylethylamine (DIE:A; $3.75 \mathrm{~mL}, 21.5 \mathrm{mmol}$ ) while the solution stirred. The reaction was allowed to stir overnight at room temperature. The solvent was then evaporated to yield an oily product. The oil was taken up in EtOAc and acidified to $\mathrm{pH}=2$ with $1 \mathrm{~N} \mathrm{HCl}$. The organic layer was washed $3 \mathrm{X}$ with $1 \mathrm{~N} \mathrm{HCl}, 3 \mathrm{x}$ with brine, and then dried over sodium sulfate. After gravity filtration, the filtrate was concentrated under vacuum and a white powder was obtained. The solid was recrystallized with hexane and EtOAc to give product 9 . Yield: $4.69 \mathrm{~g}(53 \%)$. mp $167.5-169.5^{\circ} \mathrm{C}$.

b. Attachment of Boc-Asp-OFm to Hydroxymethyl Resin. $3.00 \mathrm{~g}$ of hydroxymethyl resin ( $1 \mathrm{mmol} / \mathrm{g}$ loading capacity) was swollen in $25 \mathrm{~mL}$ of dichloromethane (DCM) for 1 hour. In the meantime, $9(2.47 \mathrm{~g}, 6.00 \mathrm{mmol})$ and di-tert-butyl dicarbonate $(1.31 \mathrm{~g}$, $6.00 \mathrm{mmol}$ ) were dissolved in $10 \mathrm{~mL}$ of DCM and added to the swollen resin. Pyridine $(0.49 \mathrm{~mL}, 6.00 \mathrm{mmol})$ was then added to the reaction mixture and it was allowed to stir overnight at room temperature. The resin was filtered and washed $3 \mathrm{X}$ with DCM, $2 \mathrm{X}$ with methanol, $3 X$ with DCM, $2 X$ with ether, and $2 X$ with hexane. The substitution level of product $\mathbf{1 0}$ was determined to be $0.69 \mathrm{mmol}$ per gram. Yield: $4.05 \mathrm{~g}$.

c. Capping of Hydroxymethyl resin. Product 10 (4.05 g, 0.31 mmol of uncapped resin) was swollen in $25 \mathrm{~mL}$ of DCM for 1 hour. To the resin was added acetic anhydride $(0.213 \mathrm{~mL}, 3.72 \mathrm{mmol})$ and pyridine $(0.301 \mathrm{~mL}, 3.72 \mathrm{mmol})$. The reaction mixture was stirred for 30 minutes, and then the resin was washed with DCM and methanol. The capping reaction and washing steps were repeated twice more. A final DCM wash (3X) prepared the resin, 11, for use immediately in the next step. 
e. i. Boc-deprotection of Aspartic Acid. Product 11 was stirred in $25 \mathrm{~mL}$ of trifluoroacetic acid: DCM: anisole (45:50:5) for 45 minutes. The resin was washed with DCM 3x, methanol 2X, and DCM 3X. After performing a Kaiser test and achieving a positive result, the resin-bound product 12 was washed with DMF $3 X$ in preparation for the next coupling step.

ii. Coupling of Boc-Glycine to Aspartic Acid. Boc-glycine ( $1.09 \mathrm{~g}, 6.21 \mathrm{mmol}), \mathrm{HOBt}$ $(0.839 \mathrm{~g}, 6.21 \mathrm{mmol}), \operatorname{BOP}(2.75 \mathrm{~g}, 6.21 \mathrm{mmol})$, and DIEA $(2.16 \mathrm{~mL}, 12.42 \mathrm{mmol})$ were stirred in $10 \mathrm{~mL}$ of DMF for 90 seconds. The solution was then added to swollen product 12 and allowed to stir at room temperature for 2 hours. The resin was washed with DMF 3X, methanol 2X, and DCM 3X. A Kaiser test was performed and was negative, indicating that product $\mathbf{1 3}$ was formed.

iii. Peptide Chain-Elongation. Boc-deprotection and subsequent coupling were repeated until the desired Boc-protected linear peptide sequence (structure 14) was achieved. In the case of the peptide containing the mini-PEG linker, Fmoc-mini-PEG was used and, therefore, $\mathrm{N}$-terminal deprotection was performed with $20 \%$ piperidine in DMF. Since the C-terminus was also Fmoc-protected, the mini-PEG residue was at the $\mathrm{N}$-terminal position of the peptide before cyclization. This differs from the other peptides in this series which all have phenylalanine $\mathrm{N}$-terminal residues.

f. On-Resin Head-to-Tail Cyclization of the Peptide. In order to cyclize the linear peptide, the C-terminal Fmoc-group was first removed with $20 \%$ piperidine in DMF followed by Boc-deprotection of the terminus with a $45 \%$ TFA solution. The coupling agents BOP and HOBt ( 3 molar equivalents of each) were then added to the resin mixture, along with 6 molar equivalents of DIEA, and the reaction was allowed to stir 
overnight at room temperature. After the resin was washed with DMF 3x, methanol $2 \mathrm{X}$, and DCM 3X, a Kaiser test was performed. Most cyclizations had to be repeated 3 to 4 times before a negative Kaiser test was achieved. Structure $\mathbf{1 5}$ shows the head-to-tail cyclic resin-bound peptide.

g. HF cleavage of Cyclic Peptide from Resin. To remove the cyclic peptide form the solid support, the resin was dried overnight and then placed in an HF reaction vessel, along with a stir bar and $\sim 0.5 \mathrm{~mL}$ of anisole. The vessel was cooled in a dry ice-acetone bath for 20 minutes. The vessel was then evacuated for 5 minutes and anhydrous hydrofluoric acid was introduced $(\sim 10 \mathrm{~mL}$ per gram of resin). After completion of the HF gas transfer, the reaction vessel was brought to room temperature and allowed to stir for 3 hours. The vessel was then evacuated for 1.5 hours. The resin was removed from the reaction vessel and washed with diethyl ether over a fritted funnel. Finally, the peptide was extracted by rinsing the resin on the frit with $25 \%$ acetic acid $5 \mathrm{X}$. The aqueous extract was frozen in a dry ice/acetone bath and lyophilized to give a white solid product 16.

h. Purification of Cyclic Peptides. All peptides were purified via preparative reversephase HPLC using a C 18 column. The peptides were eluted with a 10-50\% acetonitrile gradient, with the exception of the peptide containing the 8-amino-3, 6-dioxactanoic acid linker which required a $2-50 \%$ acetonitrile gradient. The gradients ran over a 30 minute period and the peptide elution was monitored via UV absorbance at $\lambda=220 \mathrm{~nm}$. The appropriate fractions were pooled and lyophilized to give the products discussed in the next section. 
Scheme 3: Solid-phase peptide synthesis c(D-Phe-3-AMB-Arg-Gly-Asp)

a. Synthesis of Boc-Asp-OFm
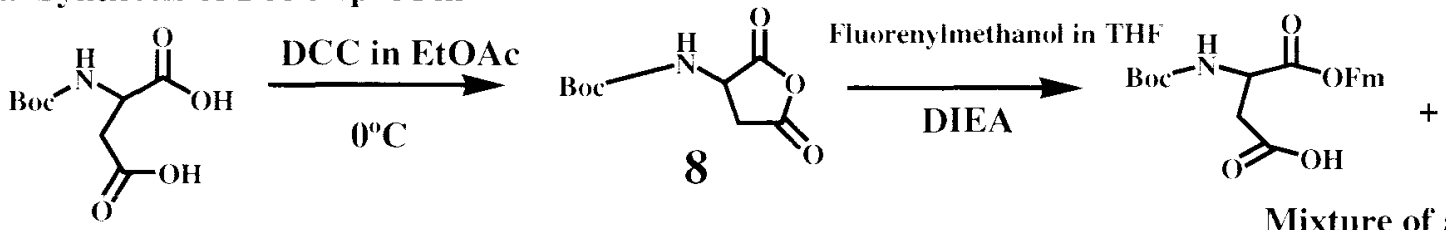

$+$

Mixture of alpha + beta

isomers of Boc-L-Asp-OFm

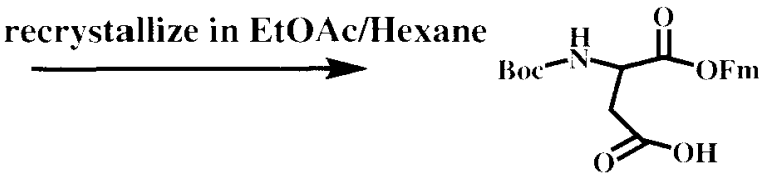

9

b. Side-chain attachment of Boc-Asp-OFm to resin
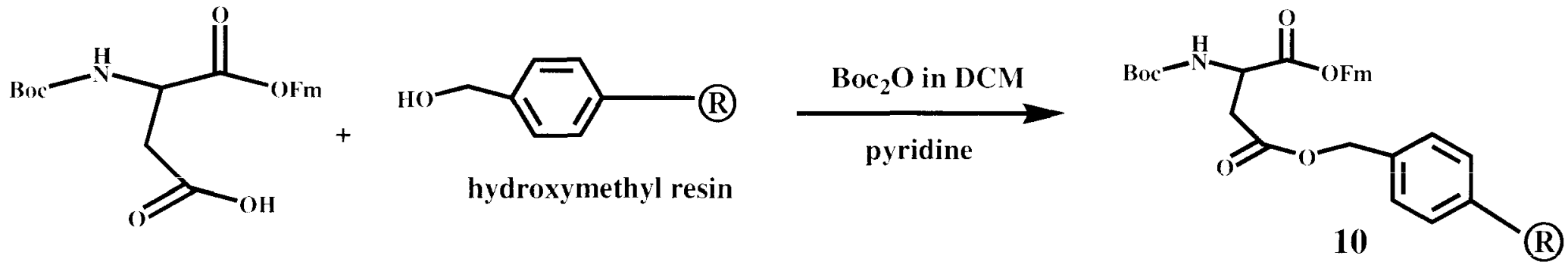
c. Capping of Hydroxymethyl Resin

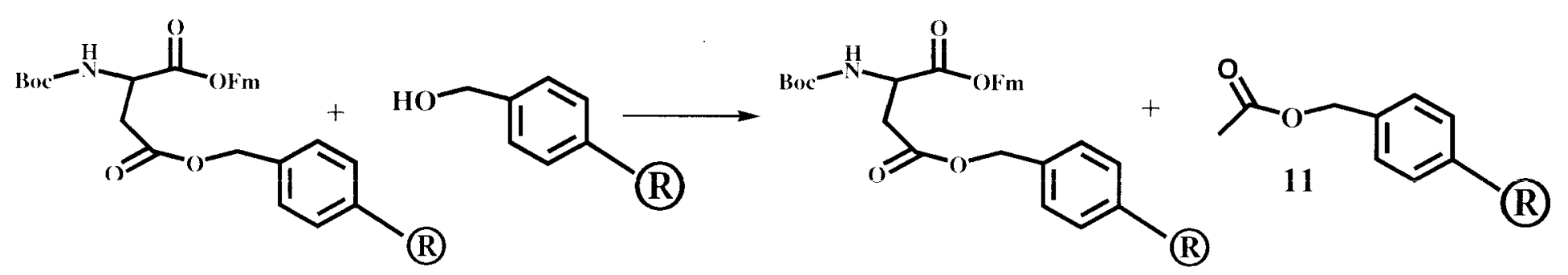

d. Linear peptide chain elongation<smiles>CCC(CC(=O)OCc1ccc(Br)cc1)C(=O)O</smiles>

$\stackrel{\oplus}{9}$

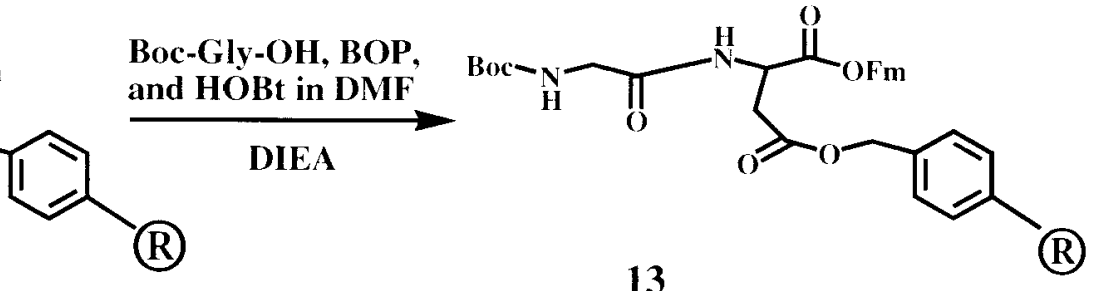

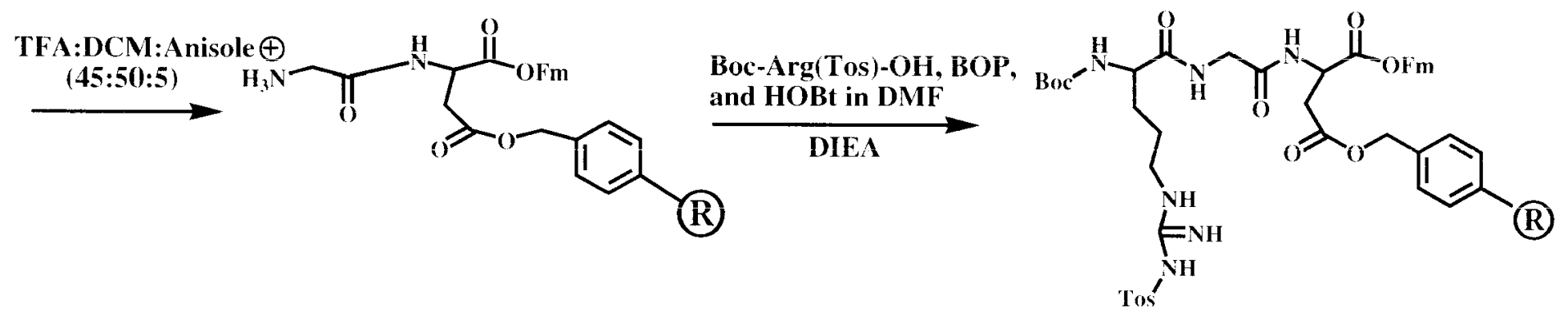




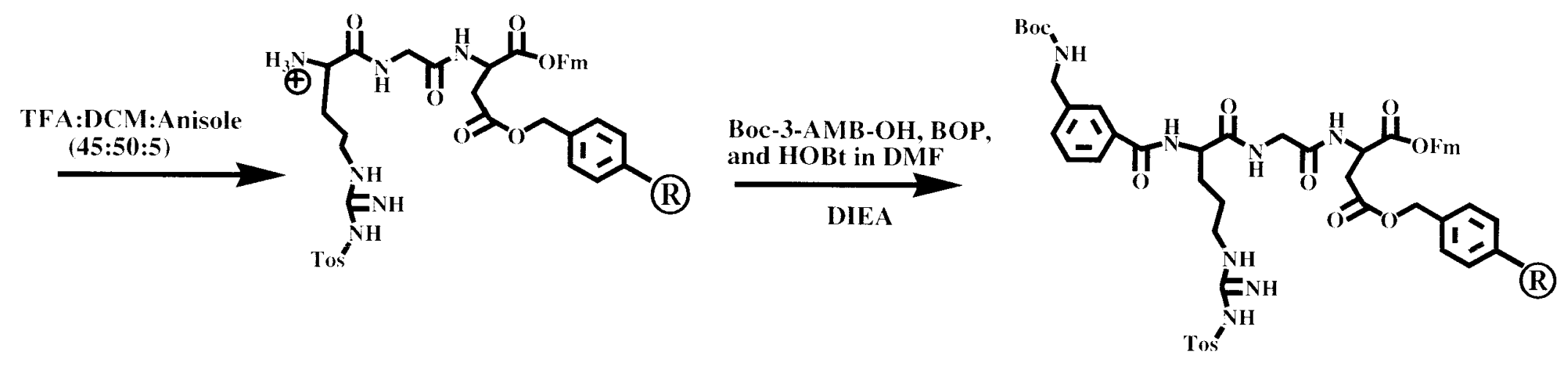

U
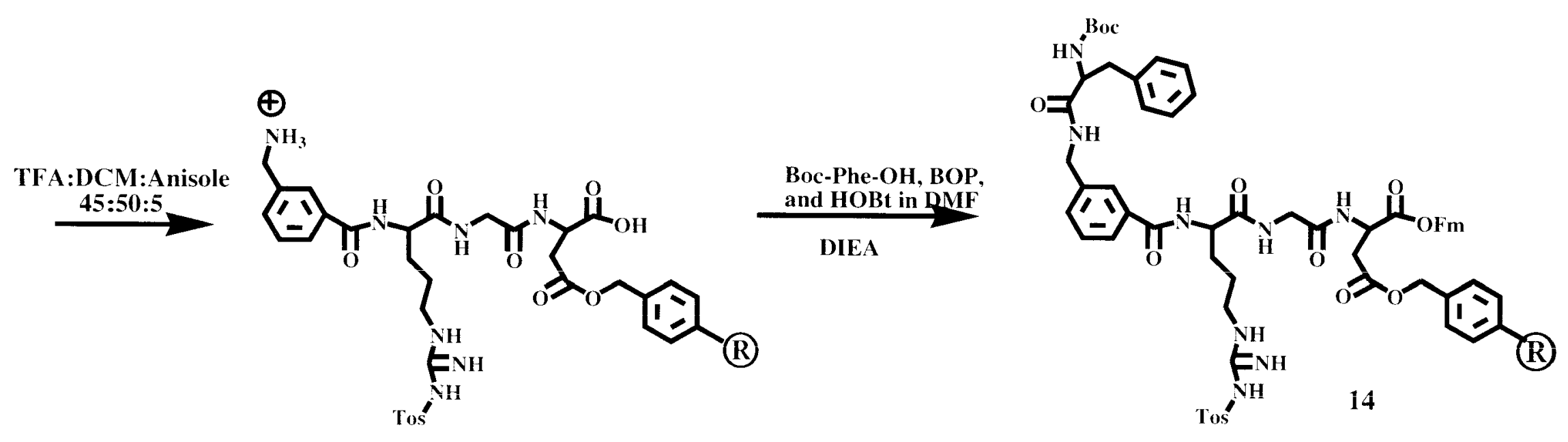
e. Intramolecular cyclization
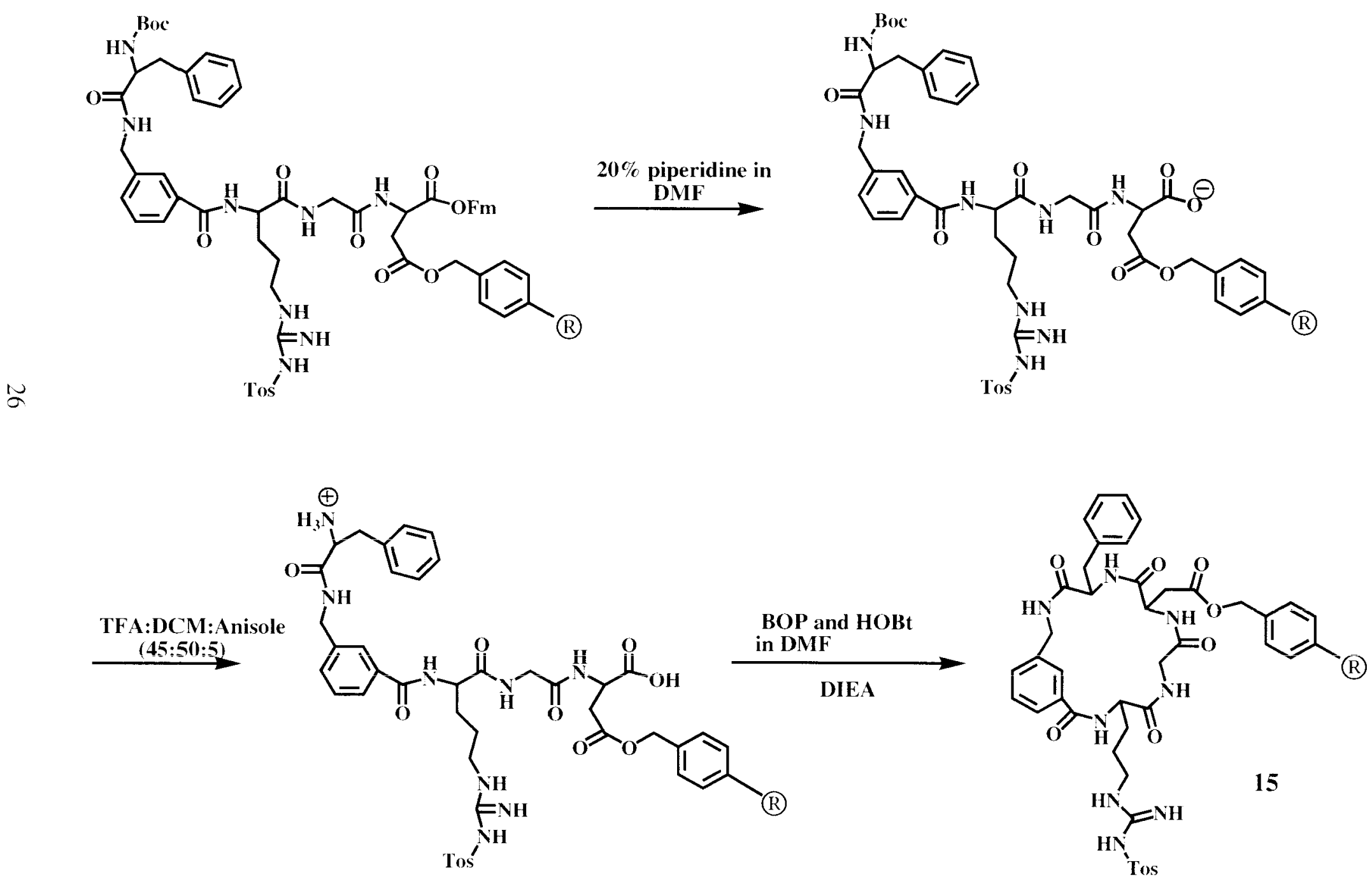


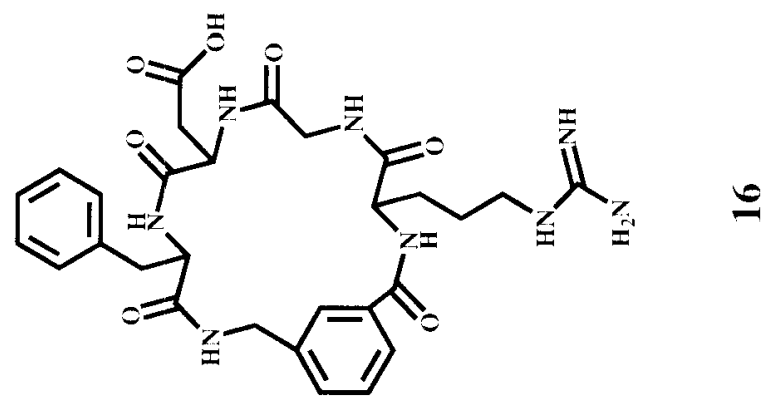



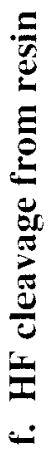

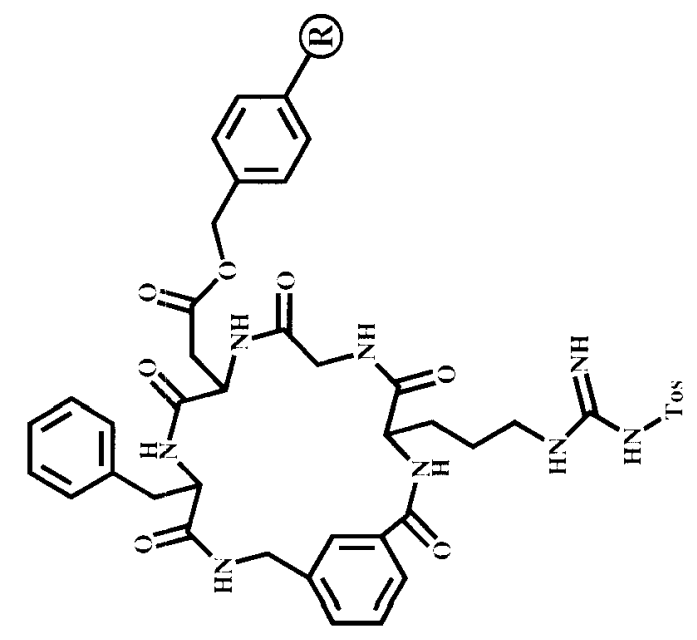




\section{RESULTS AND DISCUSSION}

\section{A. Synthesis}

All of the cyclic peptides products are summarized in Table 1. Figure 9 shows schematic representations of the peptides. Note that peptides $\mathbf{P 1 - P 7}$ have the structure cyclo(F-X-X-RGD) while peptide $\mathbf{P 8}$ has structure cyclo(X-X-A-RGD), where "X-X" represents the linker moiety. The differences in the two sequences arose from the incompatibility of protecting groups during the solid phase synthesis using the 8-amino-3, 6-dioxaoctanoic acid linker.

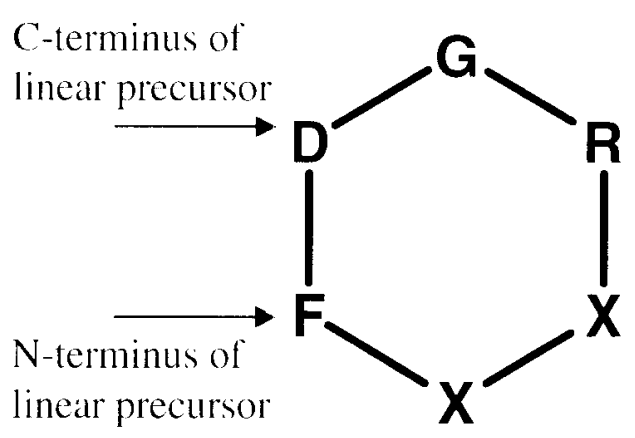

A

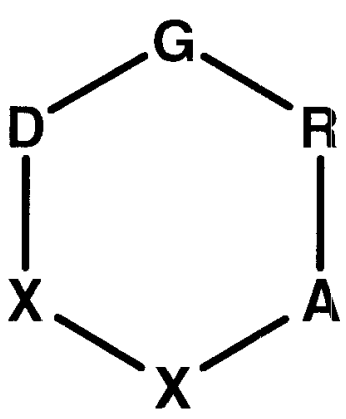

B

Figure 9: Schematic representations of cyclic peptides. Peptides P1-P7 (Table 1) are represented as A. while peptide P8 is represented by $B$. " $X-X "$ " = linker.

The peptide containing 4-aminomethylbenzoic acid (peptide $\mathbf{P 2}$, Table 1) was unattainable as a cyclic molecule. The rigid, linear 4-AMB residue did not lend itself well to ring closure. After seven consecutive reiterations of reagent addition, stirring, filtering, and wash steps over a period of one week, a positive Kaiser test was still observed. However, inclusion of the bent 3-AMB molecule did allow for cyclization, as seen in peptide P1 (Table $\mathbf{1}$ ). 
Notice that the peptides are not composed of only four residues (as originally proposed), but rather five residues. It was discovered that the ring-closing step with only four residues was unsuccessful, most likely due to torsional strain. Such strain was relieved with the addition of another residue. In all but one of the peptides this fifth residue was chosen to be phenylalanine.

It was also found that a "D" configuration at the fifth position rather than an "L" seemed to be preferred for ring closing. Therefore, peptide P1, containing the 3-AMB linker, was synthesized with D-Phe at the N-terminal position. Although the 3-AMB peptide was still obtained in low yield, the change in configuration at this position resulted in an improvement from less than $1 \%$ to nearly $5 \%$ purified yield. The preference of the D-amino acid at position 5 is most likely due to steric interactions that are lessened during ring closure. Figure $\mathbf{1 0}$ shows a pictorial depiction of the differences in steric interactions when a D-residue is used in place of an $\mathrm{L}$.

Though all of the peptides were obtained in seemingly low yields, it is not uncommon in the literature to find a wide range of yields for cyclic peptides. For example, Jackson, et al (1994) report yields of similar cyclic peptides spanning from $3.8 \%$ up to $72.2 \%$. It appears the yields of these small cyclic peptides are very sequence dependent, most likely due to the steric and torsional requirements necessary for successful ring closure. 


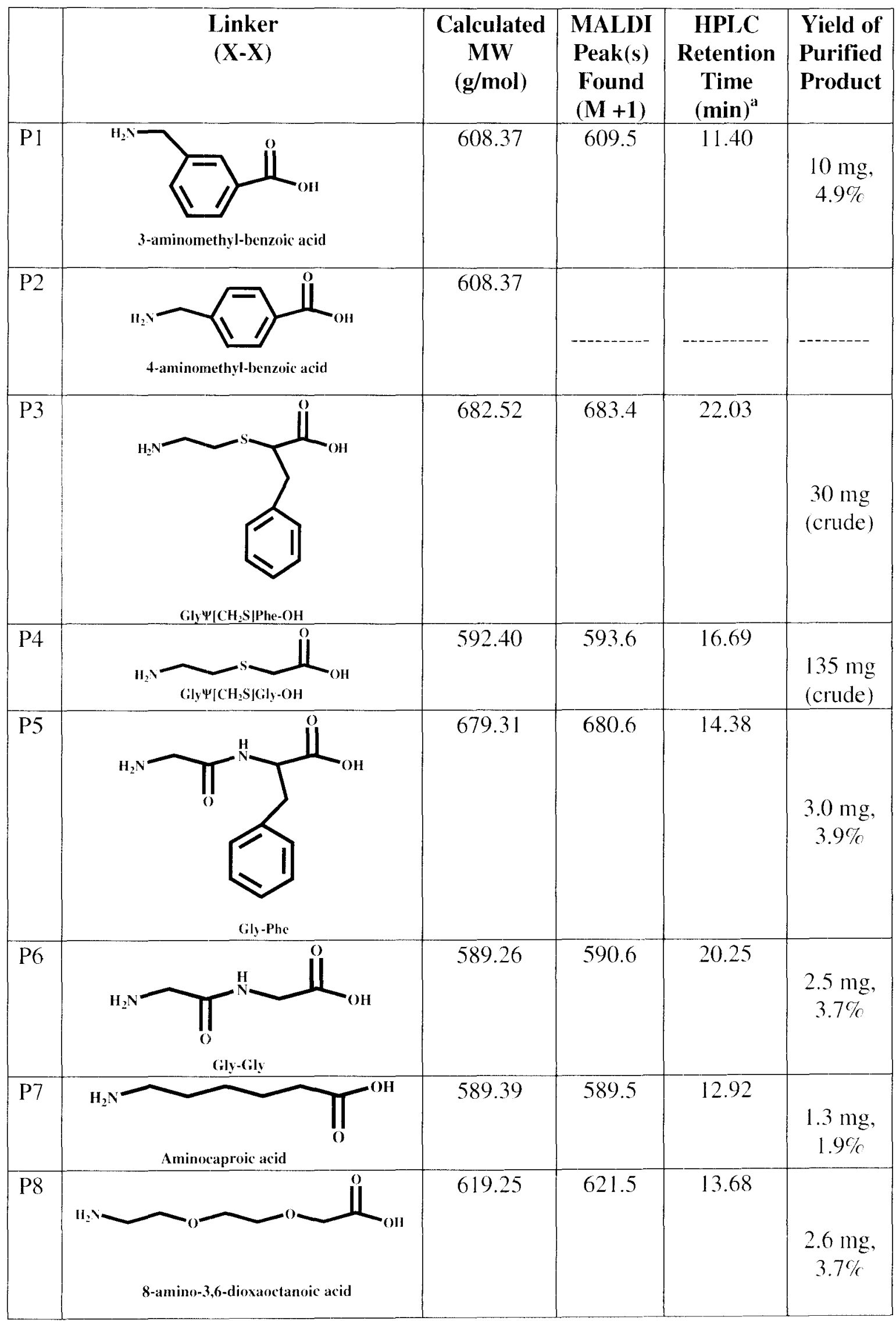

Table 1: Data from Synthesis of Cyclic Peptides. Mass spectral data was obtained after one-point calibration of the matrix peak. 

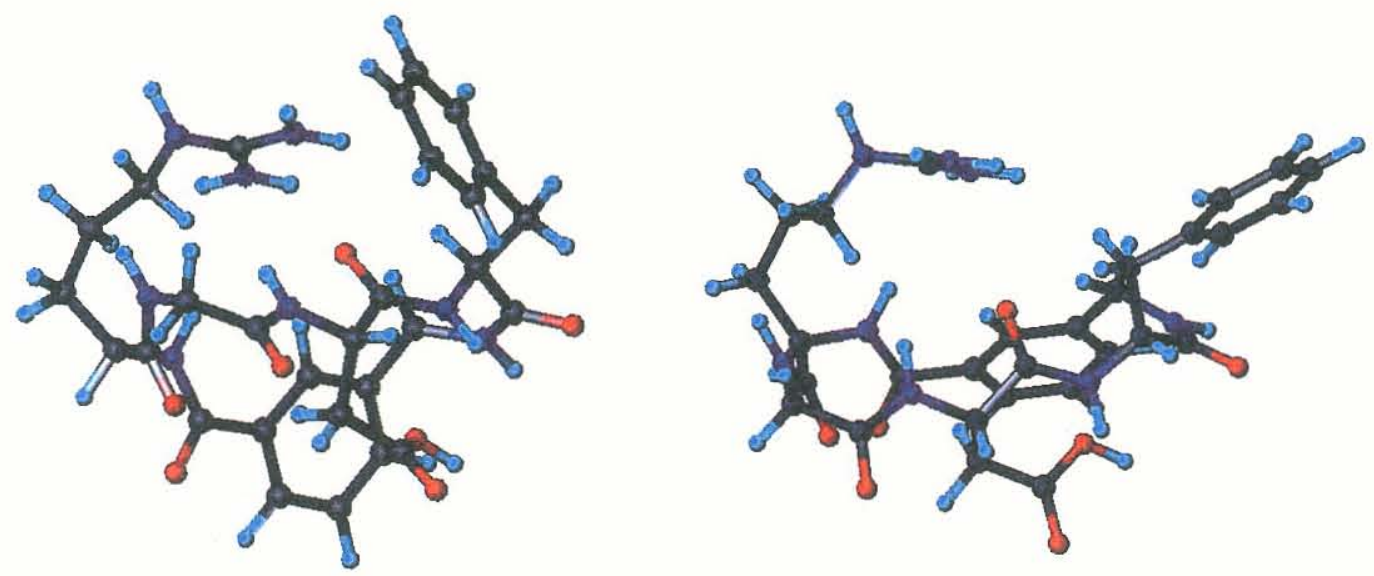

Figure 10: Three-dimensional view of how side-chain steric interactions in a peptide containing Lphenyalanine (left) can be relieved when D-phenylalanine is used instead (right).

Matrix-assisted laser desorption/ionization time of flight (MALDI-TOF) mass spectrometry analysis of each crude cyclic peptide product revealed various side-products that also contributed to low purified yields. The most common of these side-products were internal succinimides and dimeric species. As depicted in Figure 11, it is possible for an aspartic acid residue to form an intramolecular succinimide with a neighboring backbone amide group. Such a product is characterized by a MALDI-TOF peak of mass minus 18 (water) and is frequently observed in peptide synthesis.

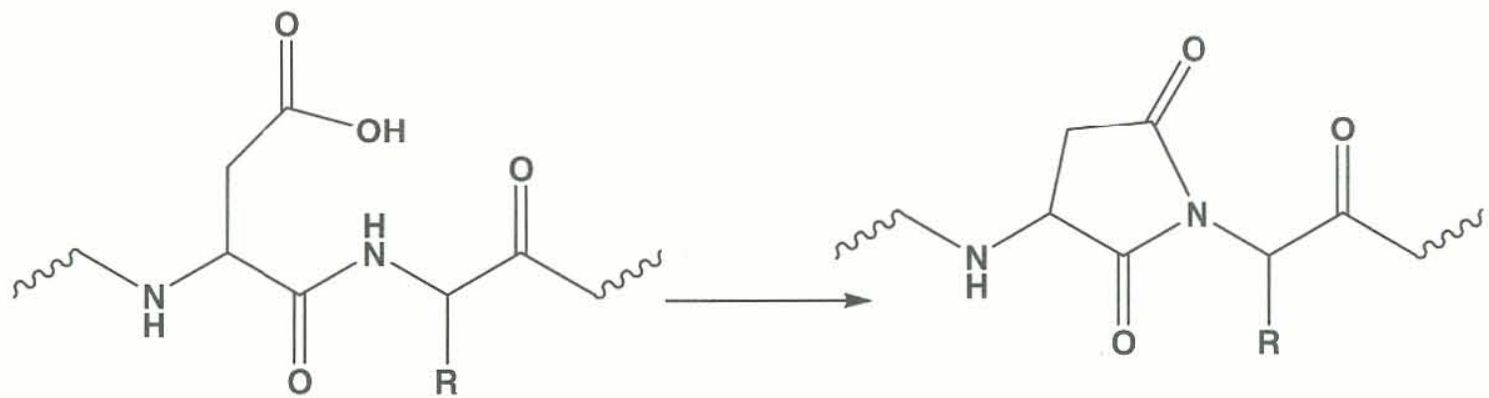

Figure 11: Formation of internal succinimide by aspartic acid side-chain. 
When synthesizing a head-to-tail cyclic peptide via solid-phase methods, a possible side-product is a so-called cyclic peptide "dimer." Figure $\mathbf{1 2}$ shows how this dimer can form. The construction of higher order oligomers is also possible in an analogous fashion. To prevent such side-products from forming, peptide chemists often employ high-dilution techniques when using solution-phase chemistry, to reduce the probability that two linear peptide molecules would come into close contact and form oligomeric species. To accomplish this task on the solid phase (as was done for this project) the resin is not loaded to full capacity. Still, dimeric side-products were observed in nearly all of the cyclic peptides, as identified by a MALDI-TOF peak of two times the desired molecular weight. These dimers can be isolated, in addition to the desired monomeric species, by means of chromatographic separation. The RP-HPLC chromatogram of the crude 3-AMB-containing peptide (P1) is shown in Figure 13. In the interest of biological activity as well as structural comparison, we decided to isolate the monomeric 3-AMB peptide, P1a, and its dimer P1b. 


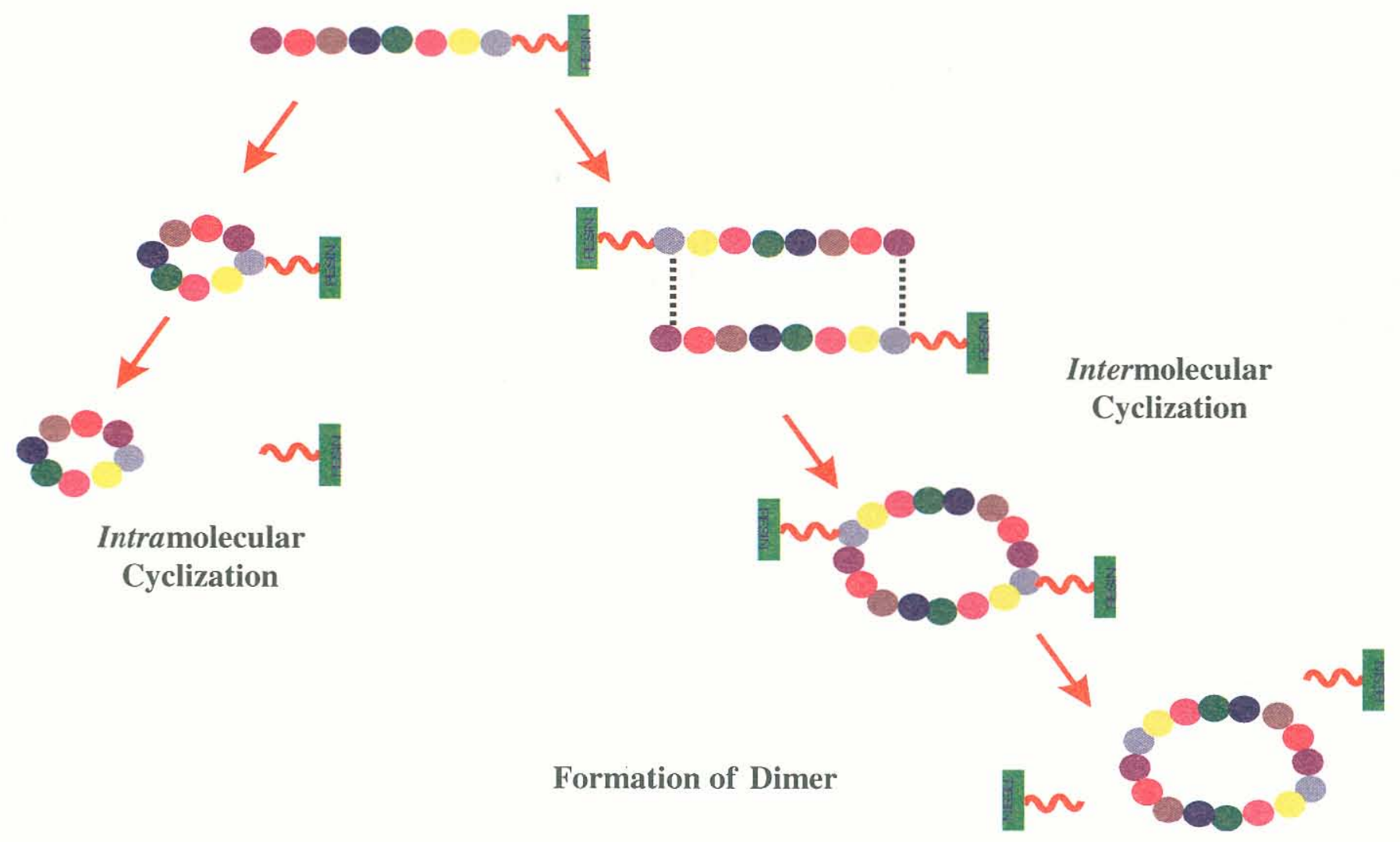

Figure 12: Formation of a cyclic peptide "dimer" via intermolecular cyclization. 
Crude Cyclic 3AMB Peptide

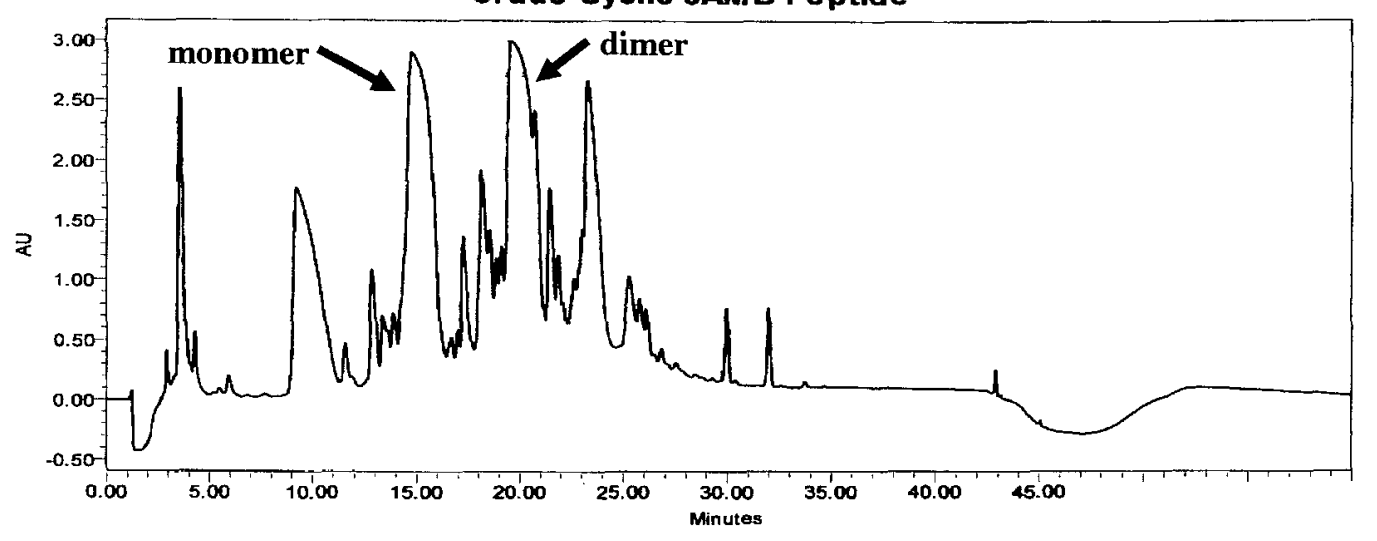

Purified Monomer Product

Figure 13: Above: RP-HPLC chromatogram of crude peptide P1.

Right and below: The monomeric and dimeric species are separable.
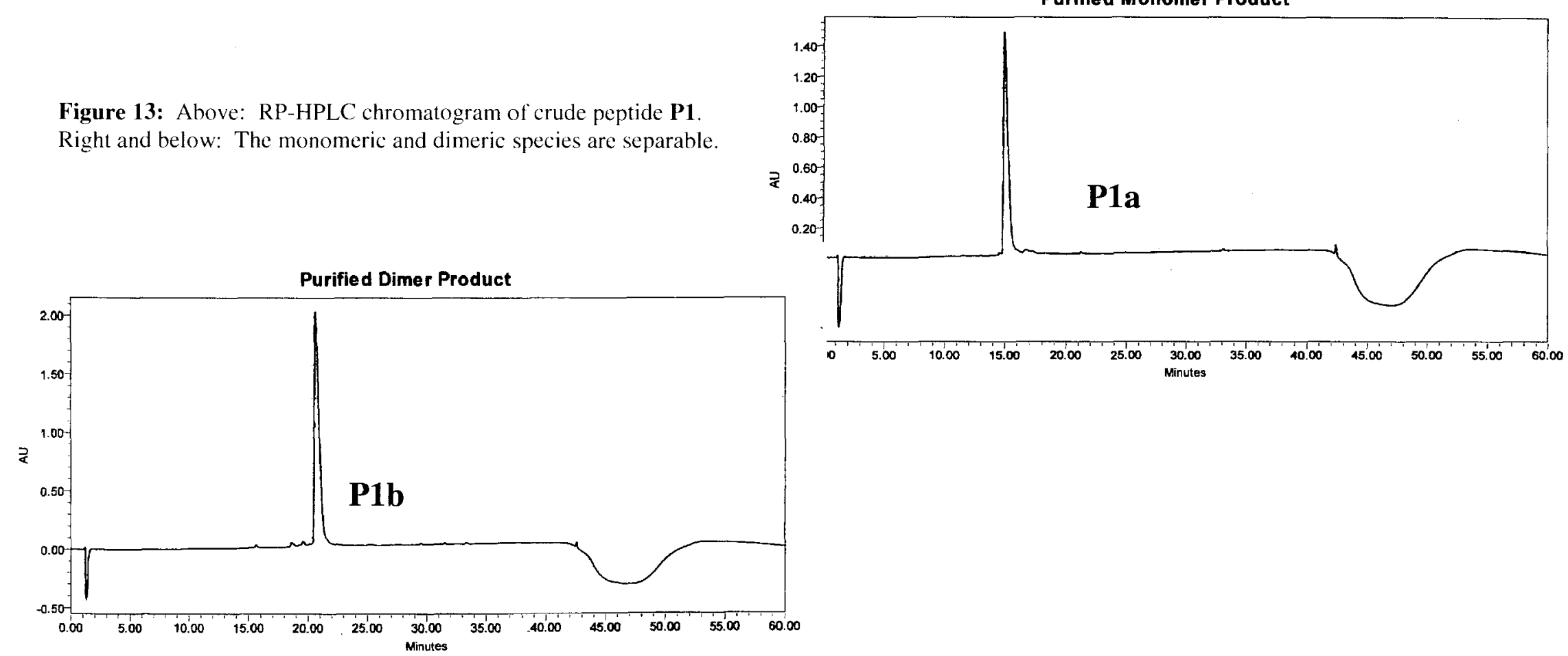


\section{B. Structural Studies of Peptide P1a}

\section{Studies in $100 \%$ DMSO}

The monomeric cyclic peptide P1a (Figure 14) was chosen for structural evaluation using nuclear magnetic resonance (NMR) spectroscopy. Because the peptide was insoluble in water, it was first dissolved in DMSO- $\mathrm{d}_{6}$. The first spectra obtained are shown in Figures $\mathbf{1 5}$ and $\mathbf{1 6}$. The protons were assigned from COSY, HMBC/HMQC, and TOCSY NMR data. The assignments are summarized in Tables $\mathbf{2}$ and $\mathbf{3}$.

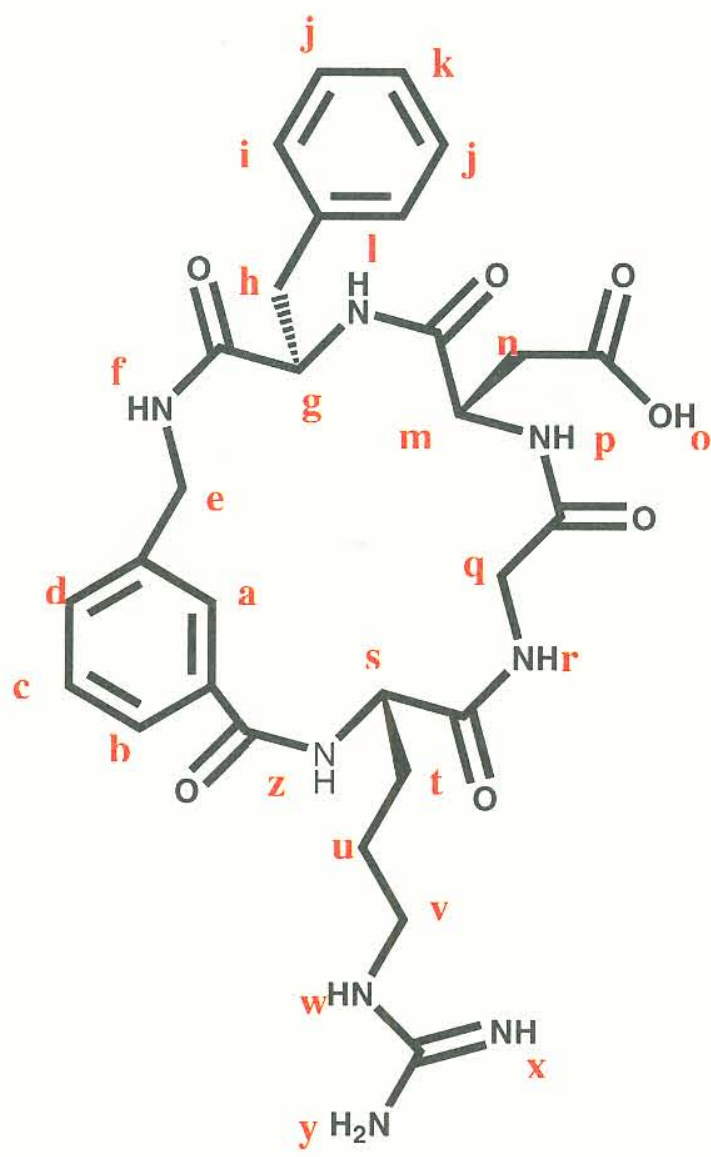

Figure 14: The monomeric cyclic peptide P1a.

Table 2: Summary of ${ }^{1} \mathrm{H}$ Chemical Shifts DMSO- $\mathrm{d}_{6}$ at $37^{\circ} \mathrm{C}(8 \mathrm{mM})$

\begin{tabular}{|c|c|}
\hline $\begin{array}{c}\text { Proton } \\
\text { (see figure 14) }\end{array}$ & Shift (ppm) \\
\hline a & 8.32 \\
\hline b & \multirow{3}{*}{$7.43,7.73$} \\
\hline c & \\
\hline d & \\
\hline e & $4.04,4.68$ \\
\hline f & 8.36 \\
\hline $\mathrm{g}$ & 4.61 \\
\hline h & $2.59,3.27$ \\
\hline i & \multirow{3}{*}{$7.17,7.21,7.41$} \\
\hline $\mathbf{j}$ & \\
\hline $\mathbf{k}$ & \\
\hline 1 & 8.09 \\
\hline $\mathbf{m}$ & 4.64 \\
\hline $\mathbf{n}$ & $2.76,3.00$ \\
\hline o & -..-- \\
\hline p & 7.80 \\
\hline$q$ & $3.45,4.23$ \\
\hline $\mathbf{r}$ & 8.20 \\
\hline s & 4.56 \\
\hline$t$ & 2.11 \\
\hline $\mathbf{u}$ & $1.52,1.77$ \\
\hline $\mathbf{v}$ & 3.11 \\
\hline$w$ & 7.75 \\
\hline $\mathbf{x}$ & -.---- \\
\hline $\mathbf{y}$ & - -.--. \\
\hline $\mathrm{z}$ & 9.19 \\
\hline
\end{tabular}




\begin{tabular}{|c|c|c|c|c|c|c|}
\hline residue & $\mathrm{HN}^{\text {"H }}$ & $\mathbf{H}_{\alpha}{ }^{\prime \prime}$ & $\mathrm{H}_{\beta}{ }^{*}$ & $\mathbf{H}_{\gamma}^{*}$ & Other" & 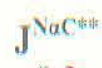 \\
\hline Arg & 9.19 & 4.56 & 2.11 & $1.52 / 1.77$ & 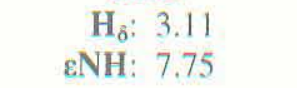 & 9.3 \\
\hline Gly & 8.20 & $3.45 / 4.23$ & & & & \\
\hline Asp & 7.80 & 4.64 & $2.76 / 3.00$ & & & \\
\hline 1)-Phe & 8.09 & 4.61 & $2.59 / 3,27$ & & $\begin{aligned} & \text { aromatic: } 7.17 \\
& 7.21 \\
& 7.41\end{aligned}$ & 9.2 \\
\hline 3-AMB & 8.36 & $4.04 / 4.68$ & & & $\begin{array}{cc}\text { proton a: } & 8.32 \\
\text { protons b,c,d: } & 7.43 \\
& 7.73\end{array}$ & \\
\hline
\end{tabular}

Table 3: Proton chemical shifts of P1a in DMSO $-\mathrm{d}_{6}$ at $37^{\circ} \mathrm{C}(8 \mathrm{mM})$.

(*ppm, **Hz)

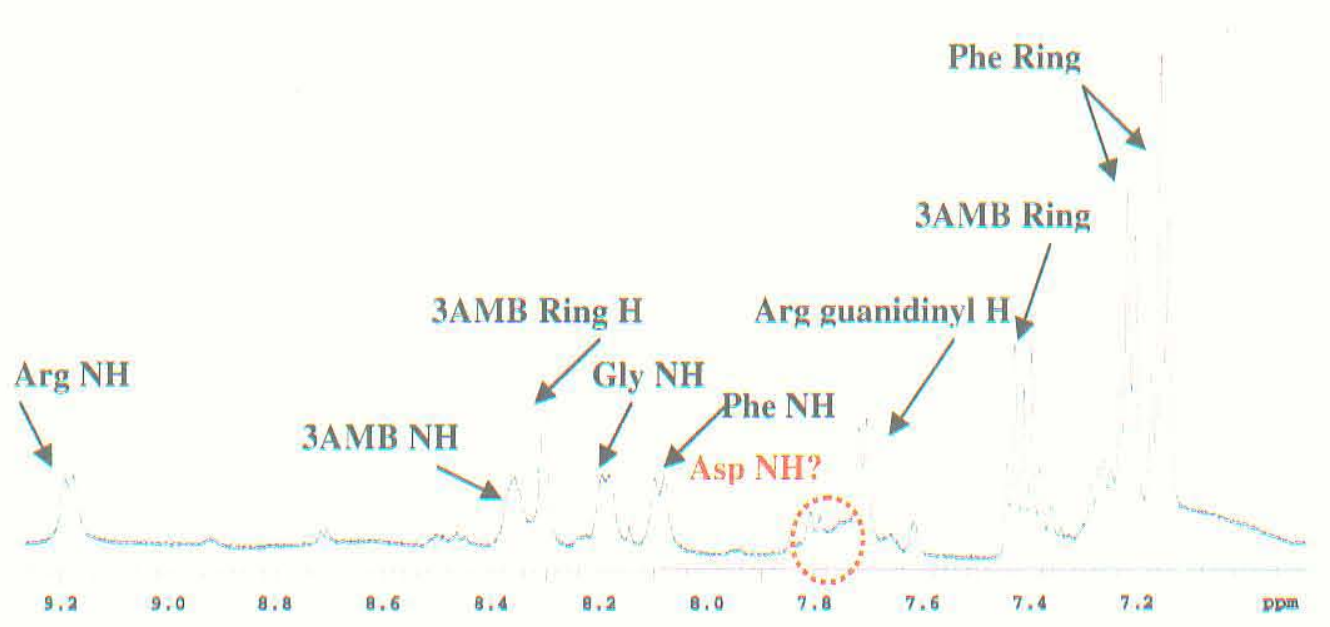

Figure 15: 1-dimensional ' $\mathrm{H}$ NMR spectrum of P1a in $100 \%$ DMSO- $\mathrm{d}_{6}(8 \mathrm{mM})$; amide region. 


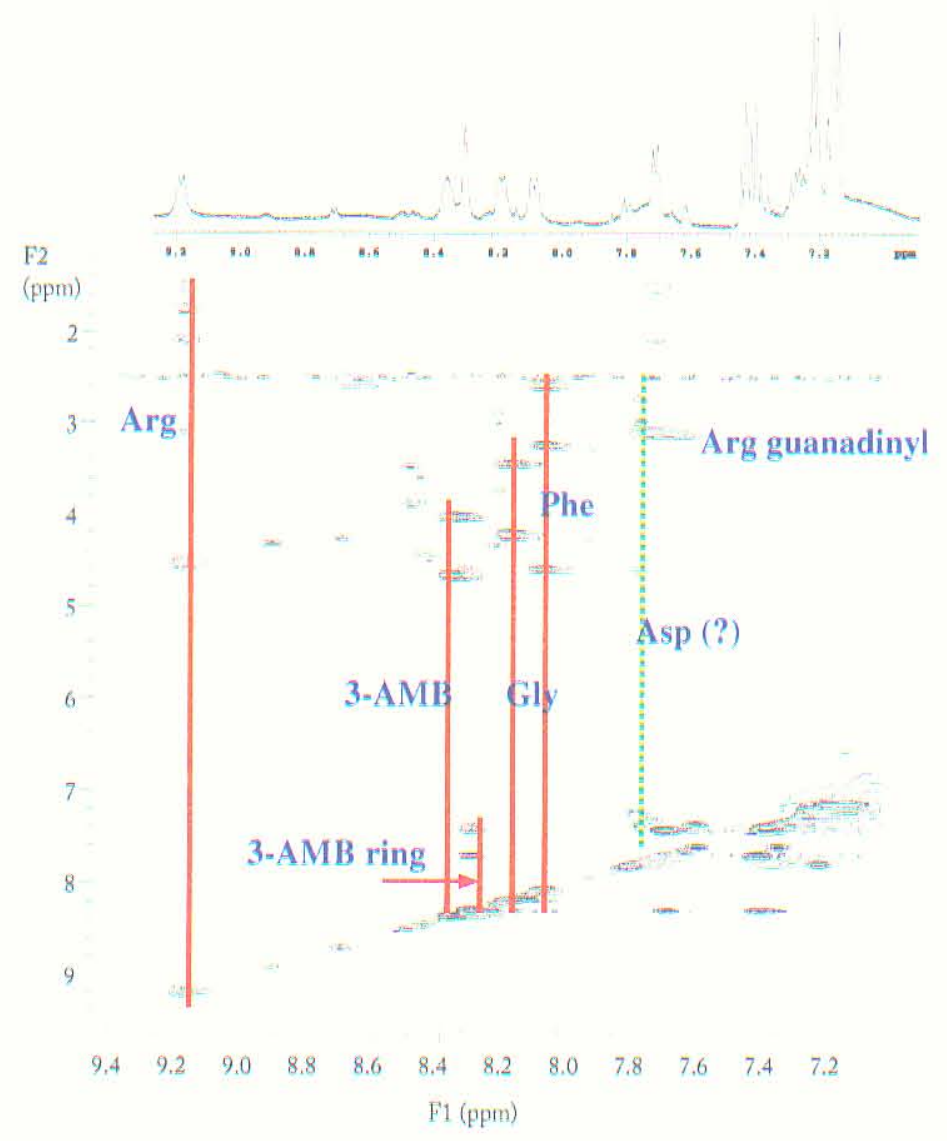

Figure 16: Fingerprint region of TOCSY spectrum of P1a in $100 \%$ DMSO- $_{6}(8 \mathrm{mM})$

The so-called "fingerprint" region of a TOCSY (TOtal Correlation SpectroscopY) spectrum is used to quickly assign the chemical shifts of amide and aliphatic protons of peptide or protein residues. The correlations observed in this region arise from throughbond coupling of backbone amide protons with the neighboring protons attached to carbon- $\alpha$, carbon- $\beta$, and so on, normally extending out to the $\gamma$ - or $\delta$ - position (see Figure 17). The fingerprint region of a $\operatorname{COSY}($ COrrelation SpectroscopY) spectrum on the 
other hand shows only interactions between the amide proton and its immediate neighbor, the $\alpha$-proton.
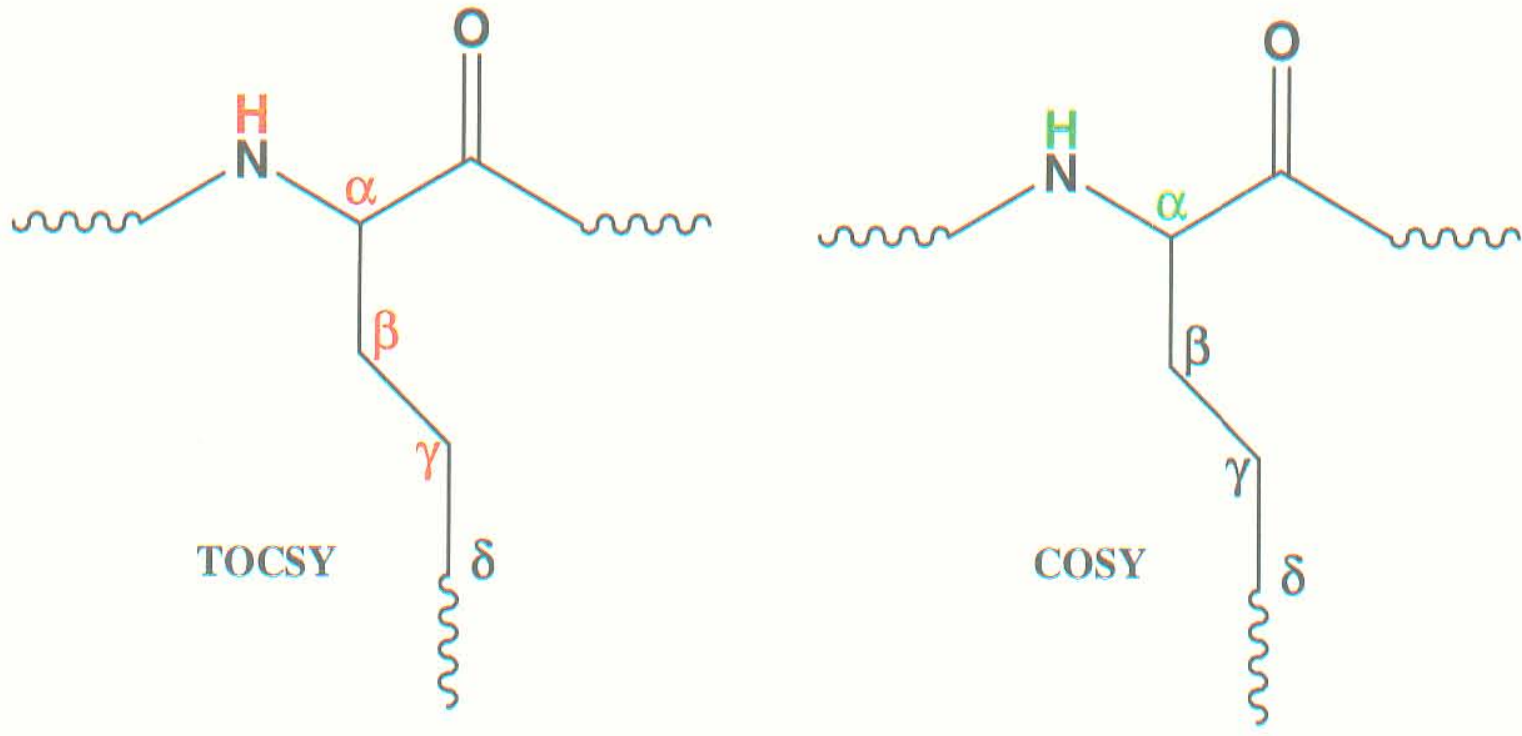

Figure 17: Through-bond coupling interactions in a TOCSY experiment can be observed between the amide backbone proton and the protons on neighboring carbons atoms. Normally the coupling can be observed out to the $\gamma$ - or $\delta$ - position. The COSY experiment shows only couplings between the amide $\mathrm{NH}$ and its immediate neighbor, the $\alpha$-proton.

To differentiate between a spin system like aspartic acid, which has both $\alpha$ and $\beta$ protons, and one like glycine or 3-AMB, which has two $\alpha$ protons, sometimes only a TOCSY experiment is necessary. However, in small, constrained peptides, the two $\alpha$ protons, being diastereotopic, are likely to have distinct chemical shifts, as they are held in different magnetic environments. For a similar peptide, Bach et al (1994) reported alpha-proton resonances for Gly at 3.53 and $3.99 \mathrm{ppm}$ and for 3-AMB at 4.06 and 4.52 ppm. Consequently, an $\alpha / \alpha$ system will be indistinguishable from an $\alpha / \beta$ system in the TOCSY spectrum. In these cases, the COSY experiment may be used to distinguish the $\alpha / \alpha$ and $\alpha / \beta$ spin systems (Figure 18). 


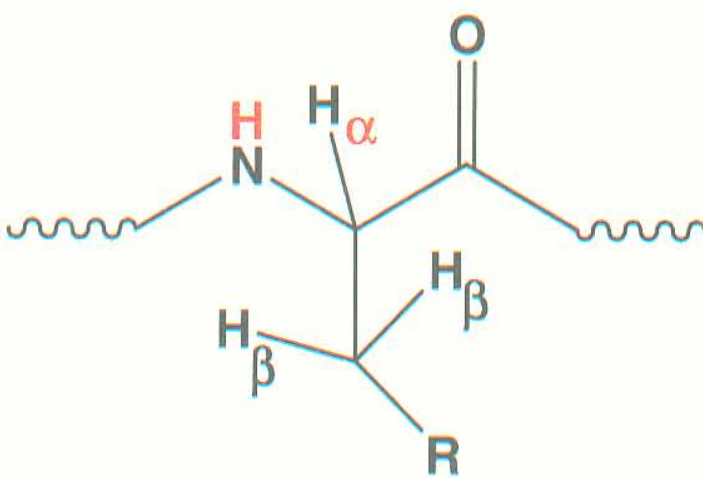

“ $\alpha / \beta$ " spin system

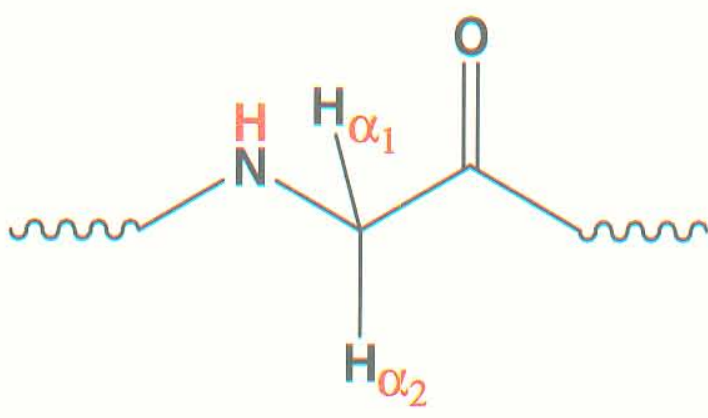

nonequivalent " $\alpha / \alpha$ " spin system

Figure 18: A TOCSY experiment alone cannot be used to differentiate these two systems. However, the two spin systems will have distinct appearances in a COSY spectrum, as correlations will only be observed between neighboring protons (red),

If all five residues of P1a were apparent in the TOCSY and COSY spectra, one would expect to observe two $\alpha / \alpha$ systems, corresponding to glycine and 3-AMB, and three $\alpha / \beta$ systems, corresponding to arginine, phenylalanine, and aspartic acid. When assigning these spectra, however, it was noted that all of the residues except for aspartic acid could be clearly discerned. Arginine was easily distinguished from the other residues in the TOCSY spectrum, as couplings were observed between its amide proton and $\mathrm{H}_{\alpha}, \mathrm{H}_{\beta}, \mathrm{H}_{\gamma}$, and even $\mathrm{H}_{\delta}$ (see Figure 16). The assignments of phenylalanine and 3aminomethylbenzoic acid were confirmed by observed correlations between aromatic carbons and aliphatic alpha protons in the HMQC/HMBC spectra. It was apparent that some of these aliphatic protons corresponded to an $\alpha / \alpha$ system (3-AMB) and some to an $\alpha / \beta$ system (Phe). Figure 19 shows the HMBC correlations. The remaining spin system was found to be $\alpha / \alpha$ and, therefore, corresponded to glycine. 


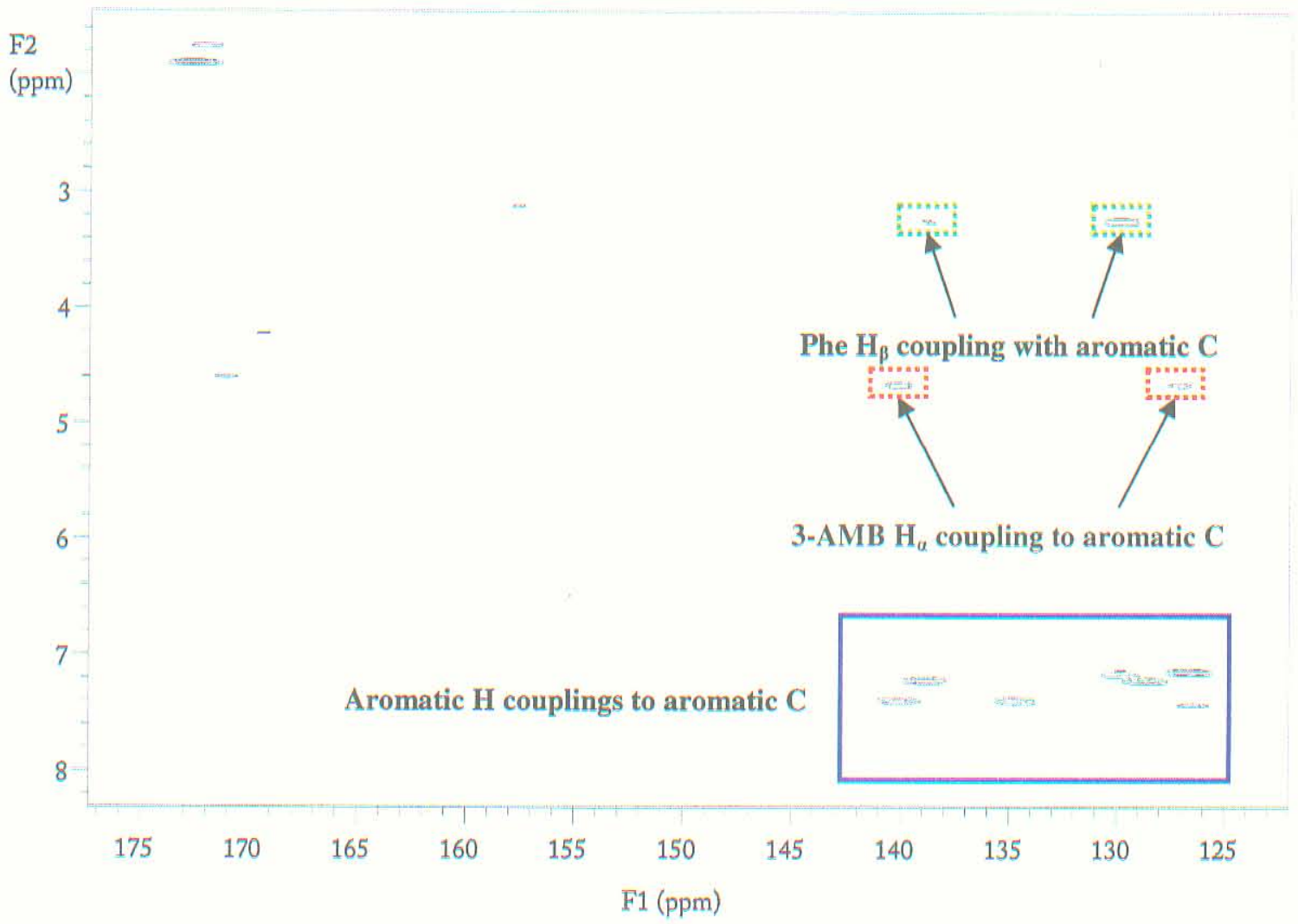

Figure 19: An HMBC spectrum of peptide P1a in 100\% DMSO- $\mathrm{d}_{6}(8 \mathrm{mM})$. Couplings were observed between phenylalanine $\mathrm{H}_{\beta}$ and aromatic carbons. Similar couplings were observed with 3-

aminomethylbenzoic acid $\mathrm{H}_{\alpha}$ and aromatic carbons. These correlations confirmed the assignment of the Phe and 3-AMB NH protons.

It was speculated that the amide proton of aspartic acid was the peak around $\delta 7.8 \mathrm{ppm}$, but the TOCSY signal intensity for the through bond couplings of that proton were found to be quite weak. The intensity of the $\mathrm{NH}$ to $\mathrm{H}_{\alpha}$ correlation appeared to be more pronounced in the COSY spectrum. Figure $\mathbf{2 0}$ highlights the couplings observed between backbone amide protons and aliphatic protons in the TOCSY and COSY spectra. 
TOCSY fingerprint

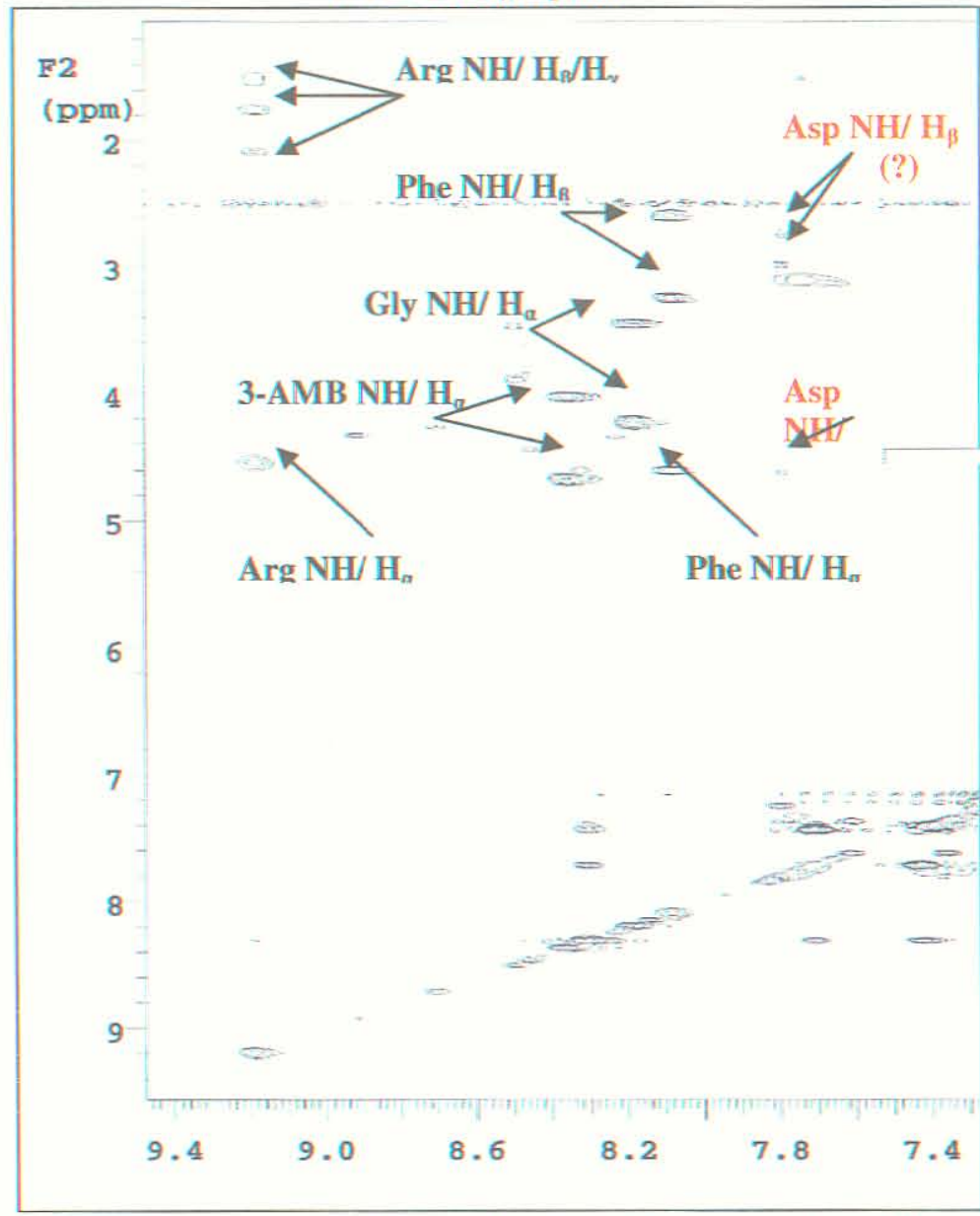

Figure 20: Weak through-bond couplings were observed between a proton at $\delta 7.8 \mathrm{ppm}$ and aliphatic protons in both the TOCSY and DQCOSY spectra of P1a in $100 \%$ DMSO- $\mathrm{d}_{6}$ $(8 \mathrm{mM})$. The proton was speculated to be the backbone amide proton of aspartic acid.

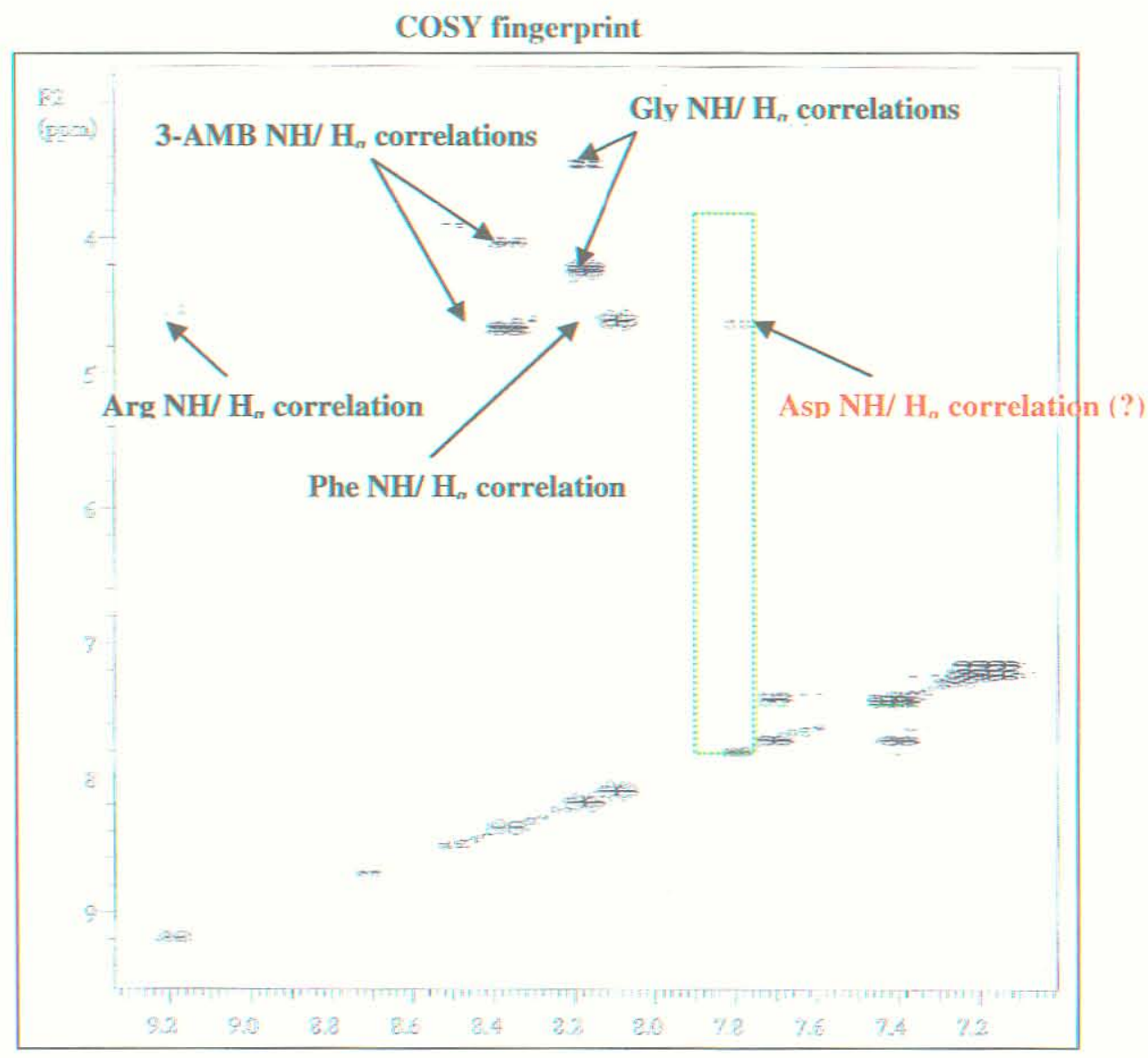




\section{Studies in a Mixed Solvent System}

When the solvent system was changed from $100 \%$ DMSO- $\mathrm{d}_{6}$ to DMSO- $\mathrm{d}_{6}: \mathrm{H}_{2} \mathrm{O} 2: 1$, some notable changes were observed. The most remarkable of these changes was that all five amide protons were clearly visible in the DMSO: $\mathrm{H}_{2} \mathrm{O}$ system, as observed in the TOCSY spectrum (Figure 21).

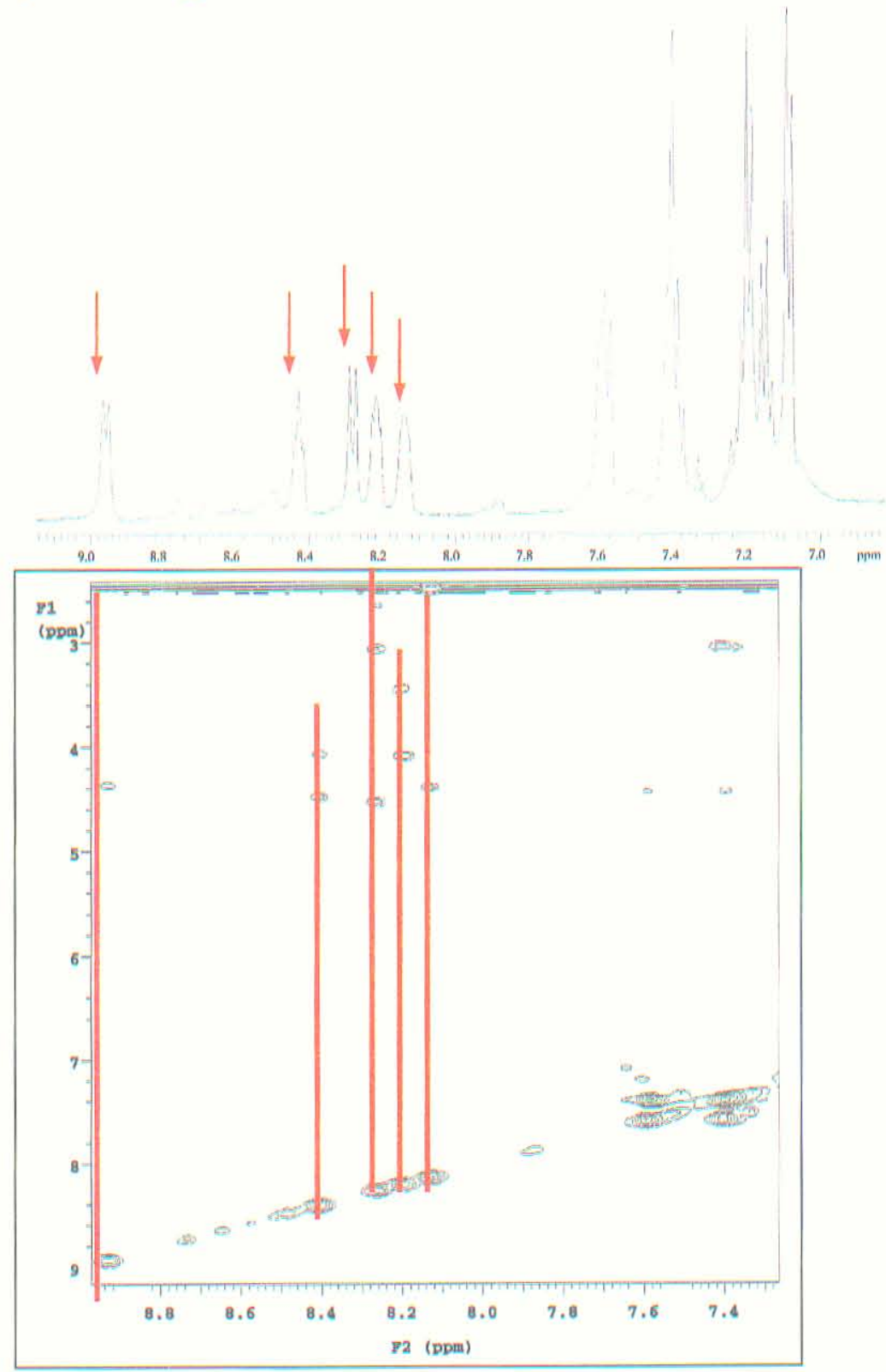

Figure 21: All five amide protons were clearly visible in the DMSO: $\mathrm{H}_{2} \mathrm{O}(2: 1 ; 5 \mathrm{mM})$ system, as observed in the TOCSY spectrum. 
Another notable difference was the upfield shift of a 3-AMB aromatic proton from about $\delta 8.3$ to approximately $\delta 7.4$, as shown in Figure 22.

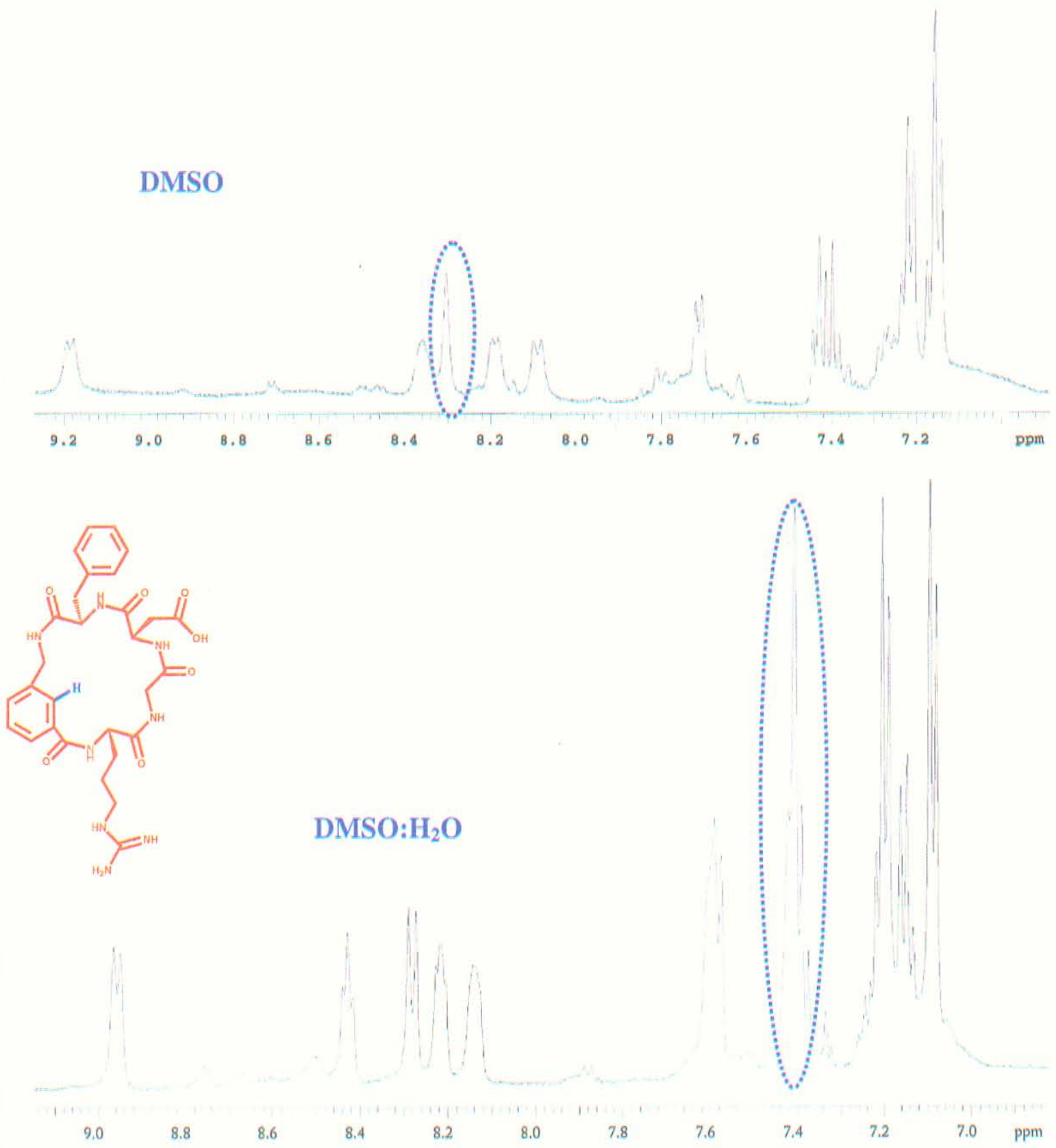

Figure 22: The 3-aminomethyl benzoic acid proton highlighted in blue makes an upfield shift when water is added to the solvent system. 
Little data could be gathered on the monomeric peptide species in the mixed solvent system, as suppression of the water signal under these conditions was difficult to optimize and many of the peaks in the two-dimensional spectra were not assignable. However, by comparing the TOCSY spectrum taken at $100 \%$ DMSO- $\mathrm{d}_{6}$ to that at $30 \%$ water, some tentative assignments could be made. The backbone amide proton of arginine was clearly still the most downfield at about $\delta 8.96$, so assignments could be made for some of the side-chain protons (Figure 23).

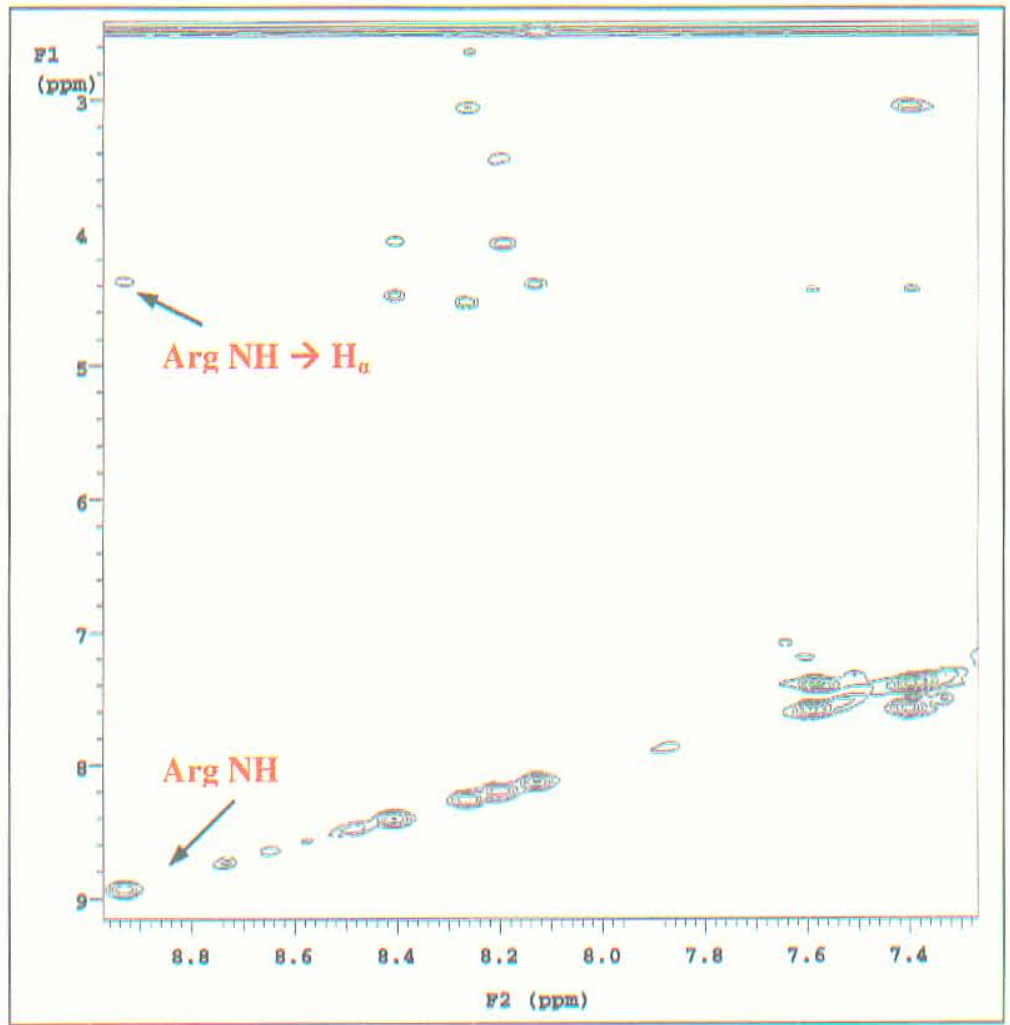

Figure 23: TOCSY fingerprint of P1a, DMSO- $\mathrm{d}_{6}: \mathrm{H}_{2} \mathrm{O}(2: 1 ; 5 \mathrm{mM}), 16^{\circ} \mathrm{C}$. The arginine backbone amide proton was still the furthest downfield, making it easy to identify Arg through-bond couplings. 
Taking into account the splitting patterns of the amide protons and the fact that the protons in the $\alpha$-position of an amino acid are typically more deshielded than those in the $\beta$-position, it was surmised that the two amide protons at $\sim \delta 8.4$ and $\sim \delta 8.2$ belonged to $\alpha / \alpha$ spin systems, namely glycine and 3-AMB. The remaining two protons in the amide region were then assumed to belong to the two $\alpha / \beta$ systems, phenylalanine and aspartic acid.

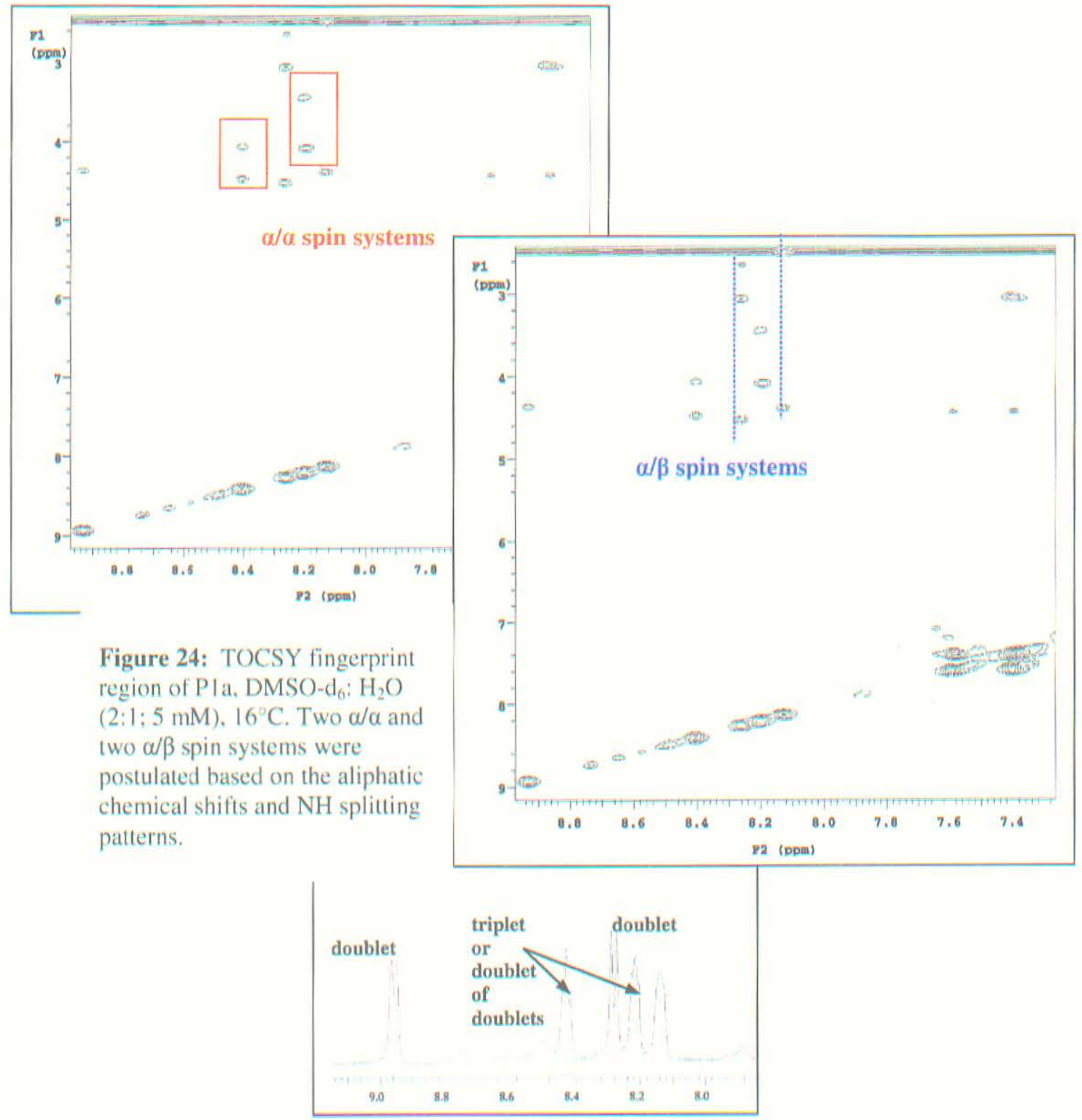


In trying to deduce which $\alpha / \alpha$ system was Gly and which was 3-AMB, it was reasoned that the chemical shift of the 3-AMB amide proton should remain further downfield than the Gly amide proton. Therefore, the respective assignments of the 3AMB and Gly amide protons were speculated to be $\delta 8.4$ and $\delta 8.2$.
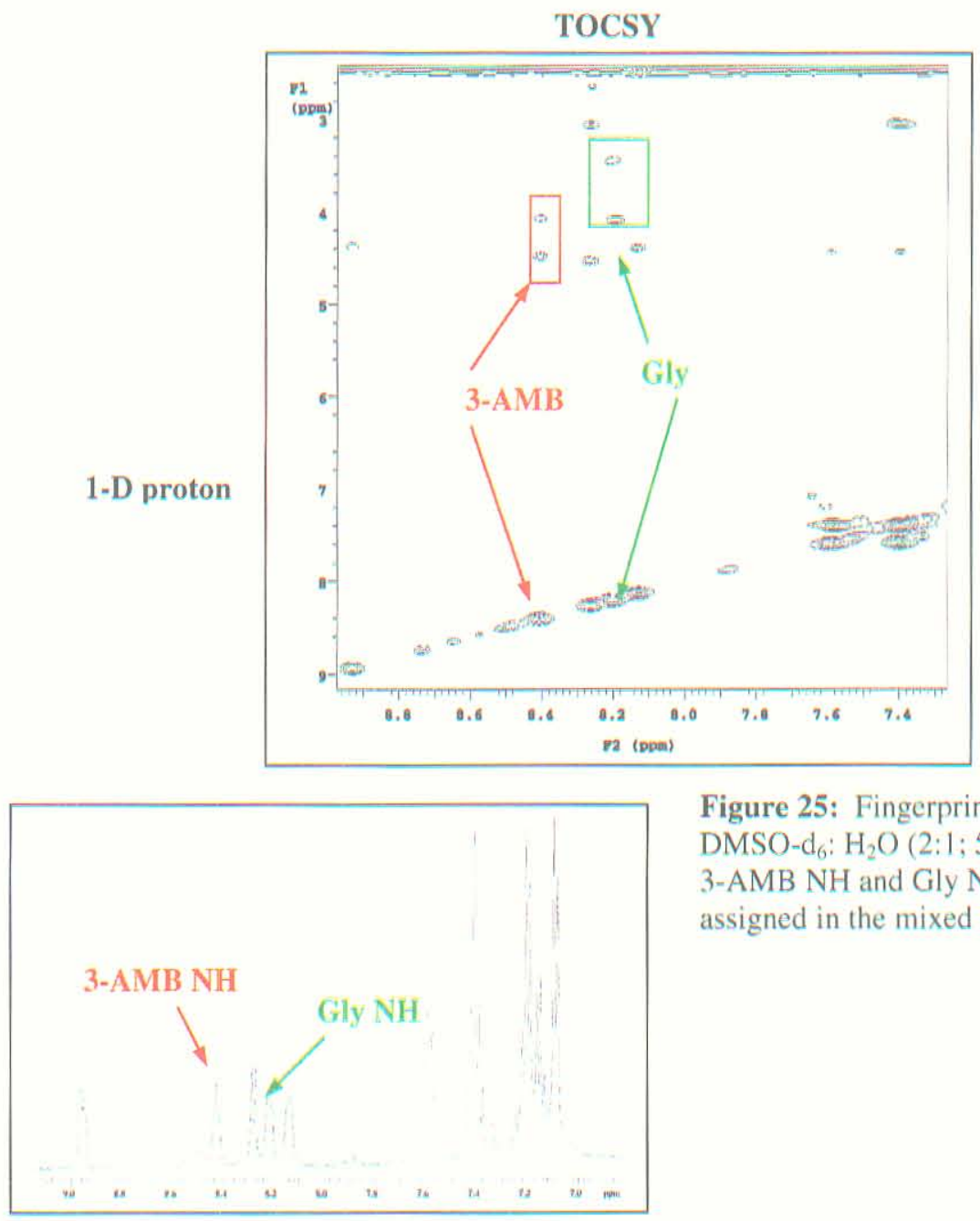

Figure 25: Fingerprint region of $\mathrm{Pla}$, DMSO-d $6: \mathrm{H}_{2} \mathrm{O}(2: 1 ; 5 \mathrm{mM}), 16^{\circ} \mathrm{C}$. The 3 -AMB NH and Gly NH were tentatively assigned in the mixed solvent system.

The assignment of the Phe and Asp amide protons were a little more straightforward, as only one set of $\mathrm{H}_{\beta}$ protons appear to have distinct chemical shifts. Since the $\mathrm{Phe}_{\beta}$ protons are adjacent to an aromatic ring, it would make sense that these two $\beta$-protons 
could be held in magnetically different environments. Hence, the amide protons of Phe and Asp were assigned as $\delta 8.28$ and $\delta 8.14$, respectively.

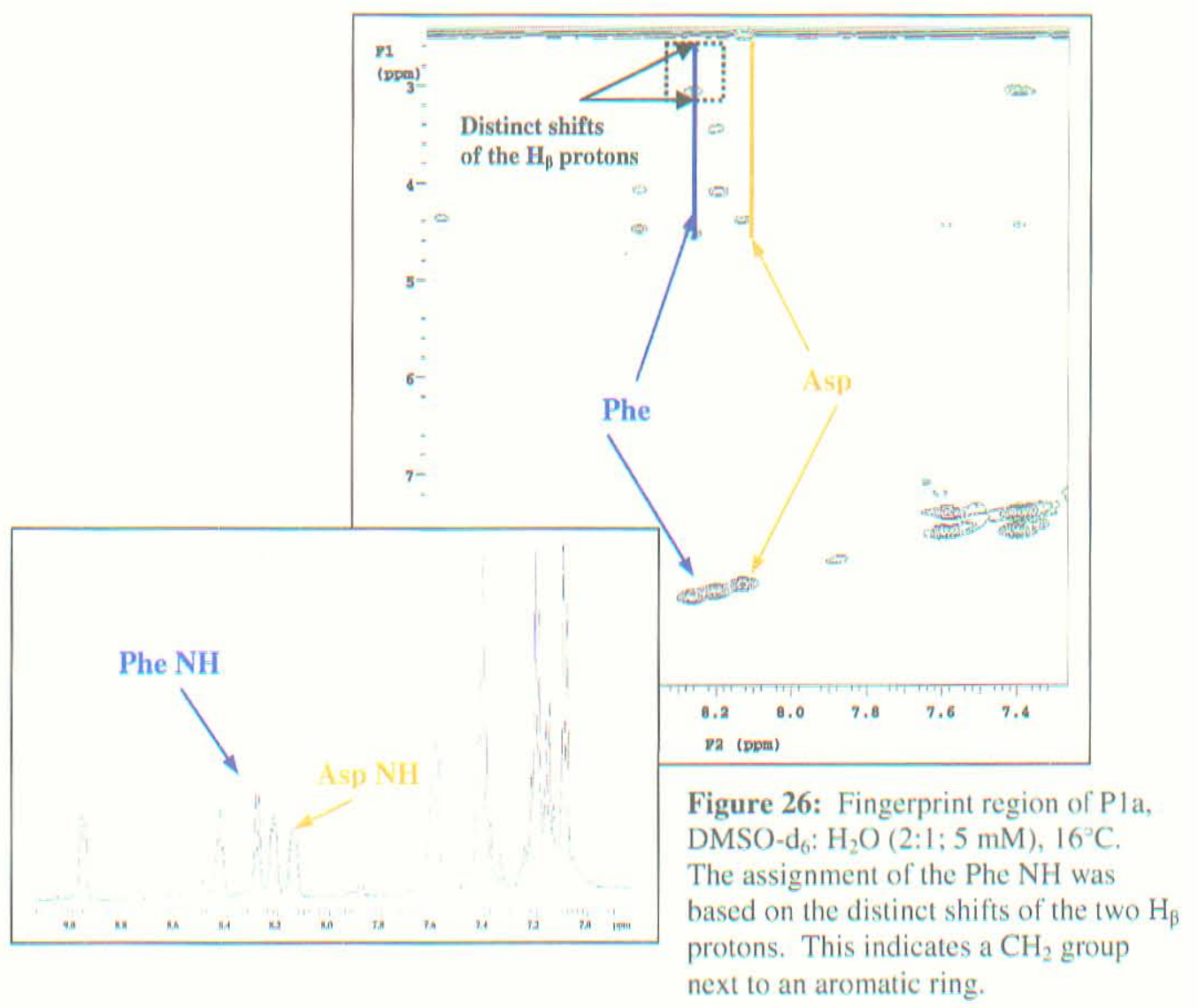

The tentative assignments of the protons of the peptide in the mixed solvent system at $16^{\circ} \mathrm{C}$ are tabulated below (Table 4).

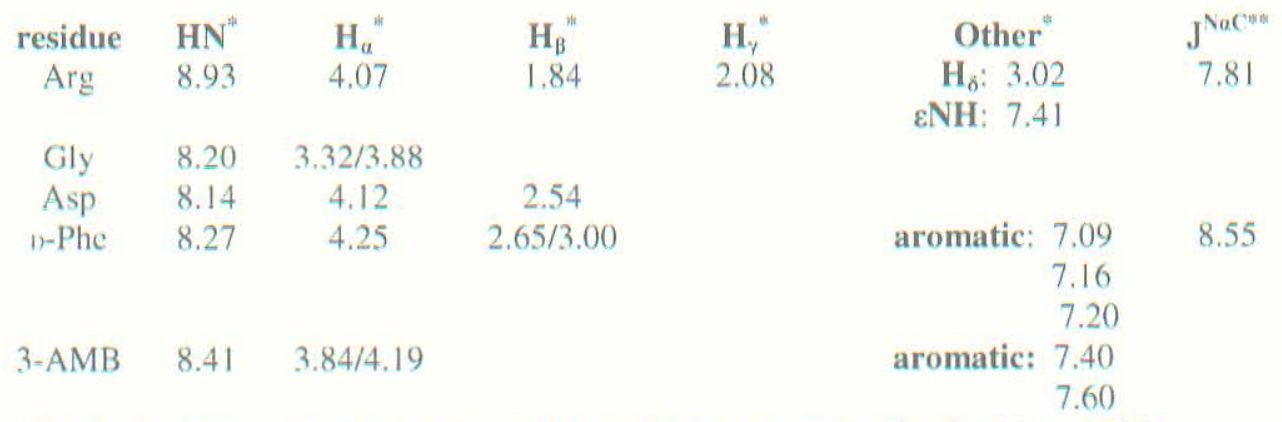

Table 4: Proton chemical shifts of P1a in DMSO $=\mathrm{d}_{6}: \mathrm{H}_{2} \mathrm{O}(2: 1 ; 5 \mathrm{mM})$ at $15^{\circ} \mathrm{C}$.

("ppm, "** $\mathrm{Hz}$ ) 


\section{Structural evaluation of P1a}

\section{A. $100 \%$ DMSO}

By calculating the dihedral angles of the $\mathrm{NH}-\mathrm{C}_{\alpha} \mathbf{H}$ from the $\mathrm{J}$-coupling constants, two structural constraints could be placed on the molecule. The Karplus equation, shown below with coefficients from Bystrov (1973), calculated the dihedral angle for both Phe and $\mathrm{Arg} \mathbf{N H}-\mathrm{C}_{\alpha} \mathbf{H}$ was found to be $\sim 156^{\circ}$. ChemOffice Chem3D Ultra software with MM2 energy minimization generated the structure in Figure 27.

$$
3 \mathrm{~J}=\mathrm{Acos}^{2}(\varphi)+\mathrm{B} \cos (\varphi)+\mathrm{C}
$$

\section{Karplus Equation}

$$
(\mathrm{A}=9.4, \mathrm{~B}=-\mathbf{1 . 1} \text {, and } \mathrm{C}=0.4)
$$

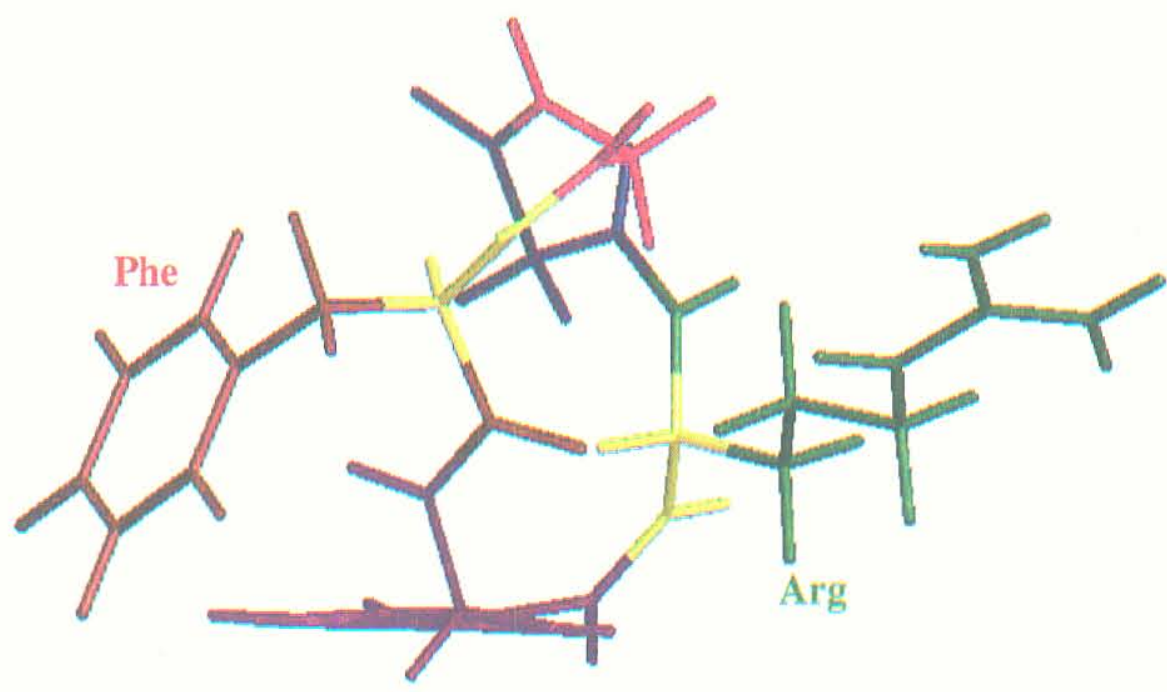

Figure 27: Proposed structure of P1a in 100\% DMSO generated from MM2 minimization. Highlighted in are the backbone $\mathrm{NH}$ and the $\mathrm{C}_{\alpha}$ and $\mathrm{H}_{\alpha}$ atoms of Arg and Phe. By calculating the dihedral angles of Phe and Arg from the J-coupling constants, two constraints were placed on the conformation. 
Observed ROESY interactions support the proposed structure. A fairly strong NOE was observed between the 3AMB ring proton a (Figure 1) and the Arg NH. Another NOE (of weaker intensity) was observed between the proton a and the alpha proton of Phe. Figure 28 depicts these interactions.
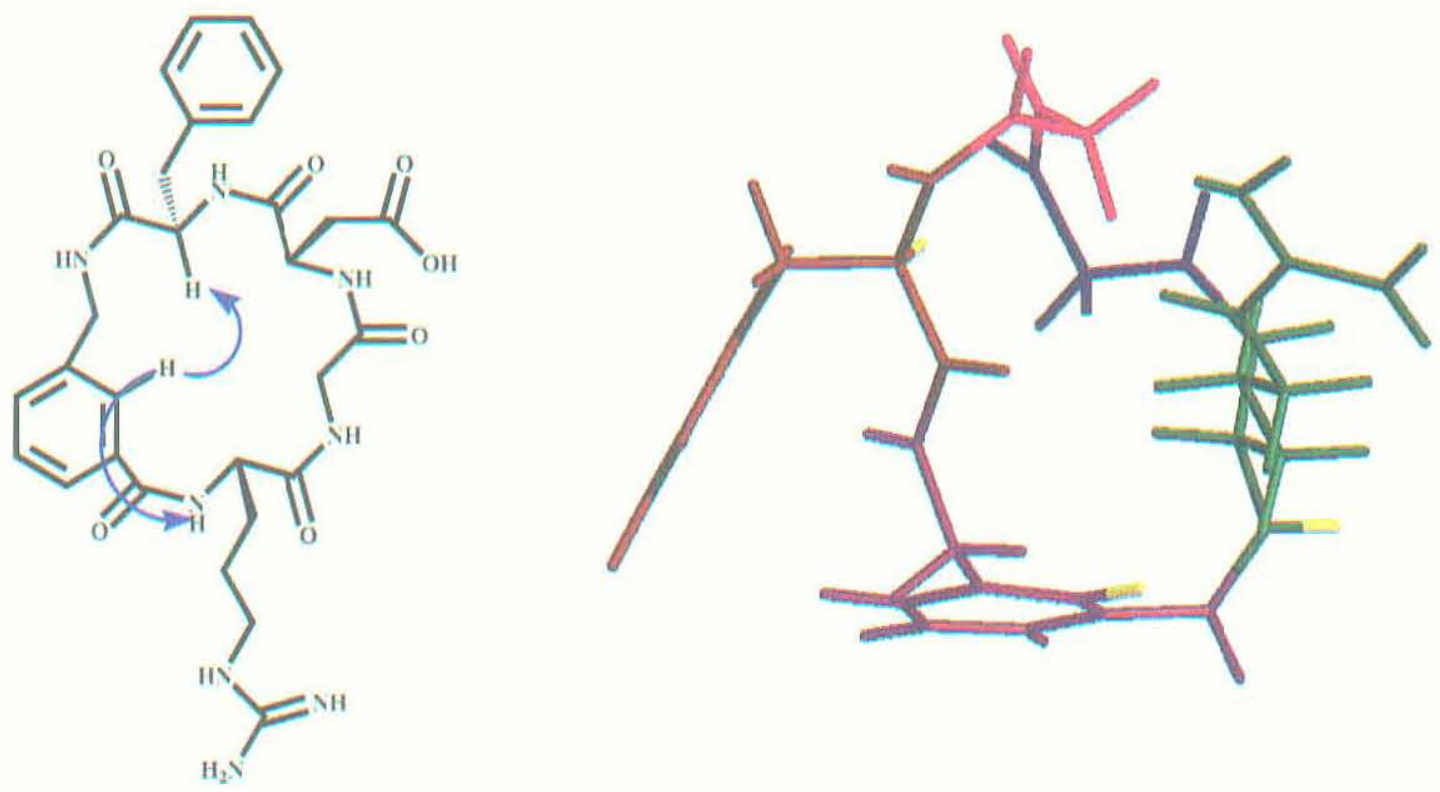

Figure 28: The generated structure corresponds well with observed ROESY interactions (blue arrows) between the $3-\mathrm{AMB}$ ring proton and $\mathrm{H}_{\alpha}$ of Phe and the $\mathrm{NH}$ proton of Arg highlighted in

Unfortunately, no conformational data could be gathered about the Asp residue, as the corresponding signals were weak. 


\section{B. DMSO: $\mathrm{H}_{2} \mathrm{O}(2: 1)$}

Using the Phe and $\operatorname{Arg~NH}-\mathrm{C}_{a} \mathrm{H}$ J-coupling data in the mixed solvent system, a second structure could be generated. The $\mathrm{J}_{\mathrm{NH}-\mathrm{CaH}}$ values of $8.55 \mathrm{~Hz}$ and $7.81 \mathrm{~Hz}$ corresponded to dihedral angles of $151^{\circ}$ and $148^{\circ}$ for Phe and Arg, respectively. As in 100\% DMSO, no other J-coupling constants could be measured because the splitting patterns were unclear. The Figure 29 shows the structure using the two constraints.

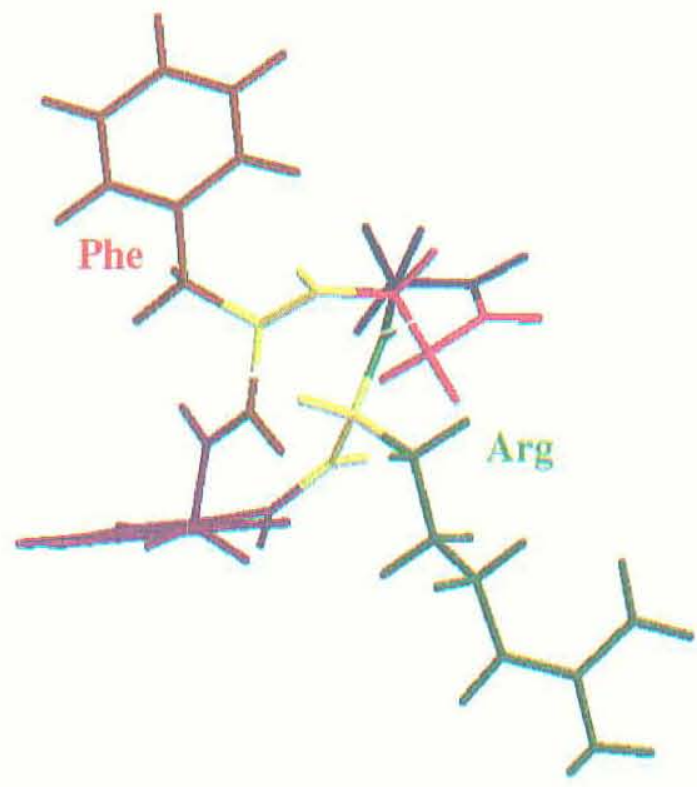

Figure 29: Proposed structure of peptide P1a in DMSO: $\mathrm{H}_{2} \mathrm{O}(2: 1)$. Highlighted in are the backbone $\mathrm{NH}$ and the $\mathrm{C}_{\alpha}$ and $\mathrm{H}_{t a}$ atoms of $\mathrm{Arg}$ and Phe. By calculating the dihedral angles of Phe and Arg from the J-coupling constants, two constraints were placed on the conformation.

The amide proton chemical shifts in the mixed solvent system were found to display temperature-dependence. Figure $\mathbf{3 0}$ shows the ${ }^{1} \mathrm{H}$ NMR spectrum of the peptide at 15 , 25 , and $37^{\circ} \mathrm{C}$. The shifts of each amide proton were plotted at various temperatures to determine the temperature coefficient of each (Figure 31).

Temperature coefficients (i. e. $\Delta \delta / \Delta$ T) can be informative tools for determining hydrogen-bonding interactions (Kessler, 1982). A temperature coefficient of greater 
absolute value than $4 \times 10^{-3} \mathrm{ppm}$ indicates an intermolecular hydrogen bond (e.g. with solvent), as these interactions are disrupted with increased heat. The proton becomes more shielded as temperature increases and moves upfield. If the absolute value of the coefficient is found to be less than $2 \times 10^{-3} \mathrm{ppm}$, intramolecular H-bonding is suggested, as these bonds are affected much less by the temperature. 


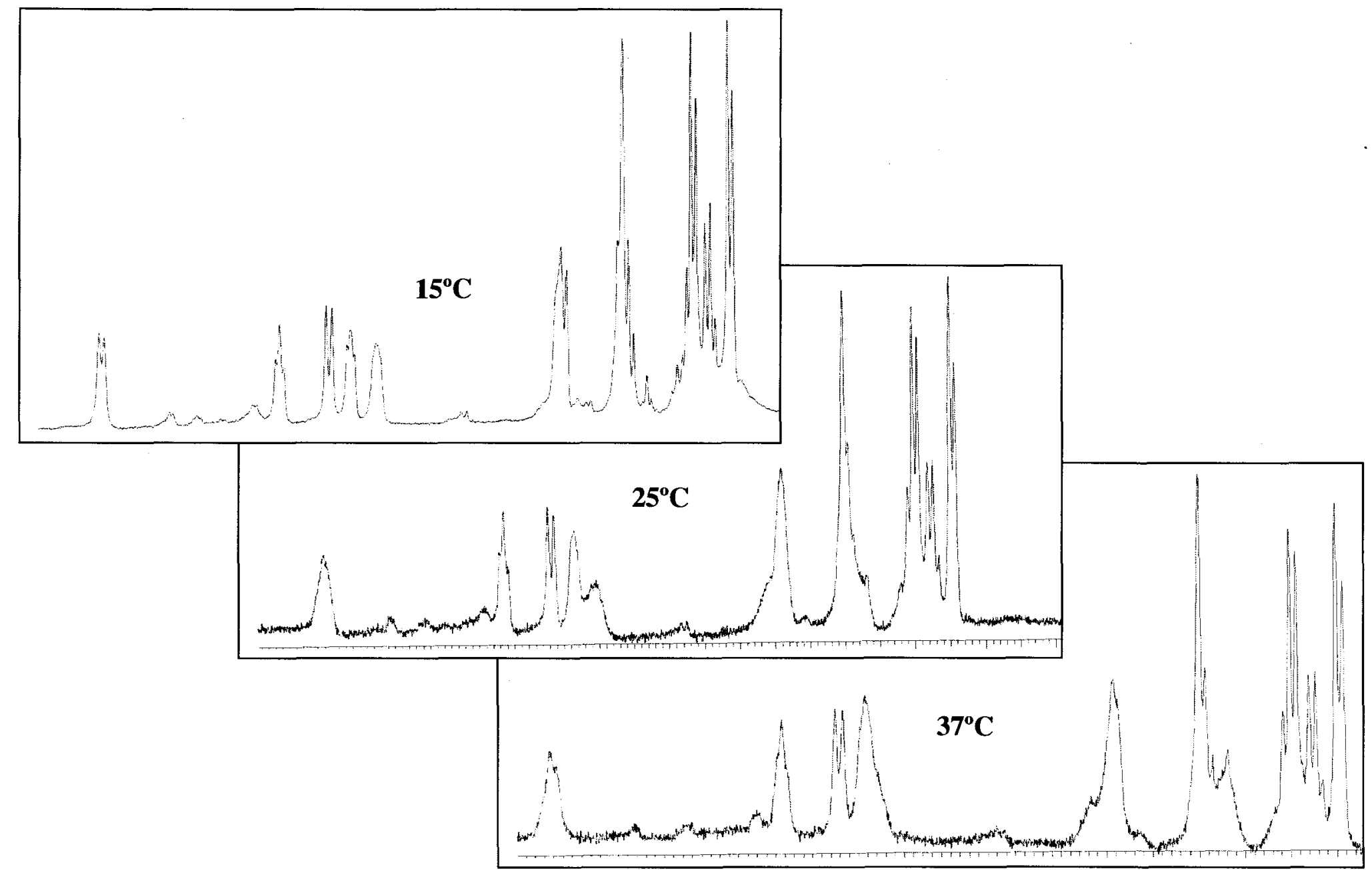

Figure 30: ${ }^{1} \mathrm{H}$ NMR spectrum of the peptide in DMSO-water at 15,25 , and $37^{\circ} \mathrm{C}$. A temperature-dependence of the Asp NH signal intensity was noted. 


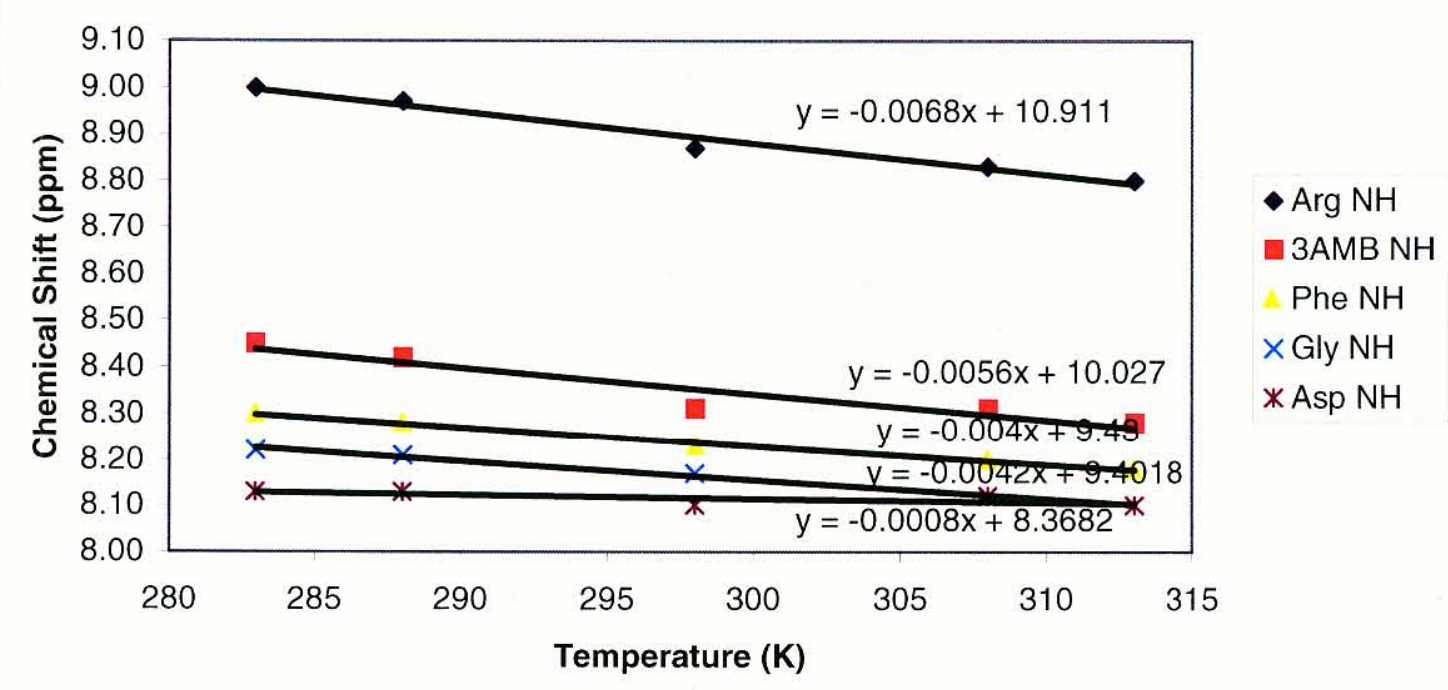

Figure 31: Plot of NH shifts as a function of temperature. Temperature coefficients were taken as the slope of the linear trendline for each $\mathrm{NH}$.

From the large negative temperature coefficient measured for the $\operatorname{Arg~NH}\left(-6.8 \times 10^{-3}\right.$ $\mathrm{ppm})$, it is apparent that this proton interacts with the solvent. The proton is very deshielded in both DMSO and in the mixed solvent system, indicating that the DMSO is acting as a hydrogen-bond acceptor to the solvent-exposed proton. As the temperature is increased in the mixed solvent system, the H-bonding interaction is interrupted, the proton becomes more shielded, and therefore, resonates at a higher field.

The opposite case can be made for the Asp NH. This proton has associated with it a very small negative temperature coefficient $\left(-0.8 \times 10^{-3} \mathrm{ppm}\right.$, as measured in the mixed solvent system), signifying intramolecular H-bonding. Although no change in the chemical shift is noted with the Asp NH as the temperature increases, the corresponding peak does seem to broaden quite dramatically compared to the other amide protons, as seen in Figure 30. A possible explanation for the observed temperature-dependent broadening is that the $\mathrm{NH}$ proton begins exchanging more rapidly with its H-bond 
acceptor as heat is added to the system. It is unclear whether the H-bond acceptor is a transannular carbonyl or perhaps the carbonyl of its own side chain.

Based on their corresponding temperature coefficients, the remaining three amide protons, Phe, Gly, and 3-AMB, seem to interact with the solvent. The 3-

aminomethylbenzoic acid aromatic proton a (Figure 1) signal also displays a significant upfield shift upon the addition of water, showing that the residue is highly responsive to solvent, probably due to H-bonding. The Phe and Gly residues seemed to be equally affected by temperature with coefficients of $-4.2 \times 10^{-3}$ and $-4.0 \times 10^{-3}$, respectively.

\section{Further Discussion of Aspartic Acid}

The most puzzling observation from the two studies of the monomeric peptide species was the very weak signals of the Asp residue in 100\% DMSO. It can be postulated that perhaps the Asp residue was interconverting between two conformers in the DMSO solvent at such a rate that the signals were broadened. A salt bridge between the arginine and aspartate residues could possibly affect the rate of interconversion. If the Asp NH is indeed the signal observed at $7.8 \mathrm{ppm}$ in $100 \%$ DMSO, it is fairly shielded, indicating that it is not interacting with solvent.

The other potential explanation for such signal broadening would be rapid exchange with an H-bond acceptor (other than DMSO). Although it would seem possible for the Asp NH to undergo such exchange, the aliphatic protons most likely would not. The aliphatic regions of the TOCSY and COSY show the same diminished signal intensity as seen in the amide region.

When water was added, the Asp amide and aliphatic signals became very apparent. The addition of water would most likely disrupt any salt bridge and allow the Asp residue 
to become involved in an intramolecular H-bond. Most likely this H-bond would be between the aspartate $\mathrm{NH}$ and its carboxylate side chain. The Asp NH signal clearly moved downfield compared to the $100 \%$ DMSO system, signifying a more deshielded environment, perhaps from a strong H-bonding interaction.

A comparison of the structures generated in the two solvent systems, both based on the NH- $\mathrm{C}_{a} \mathrm{H}$ dihedral angles of $\mathrm{Arg}$ and Phe, reveals that a rather dramatic conformational change takes place when water is added to the system.
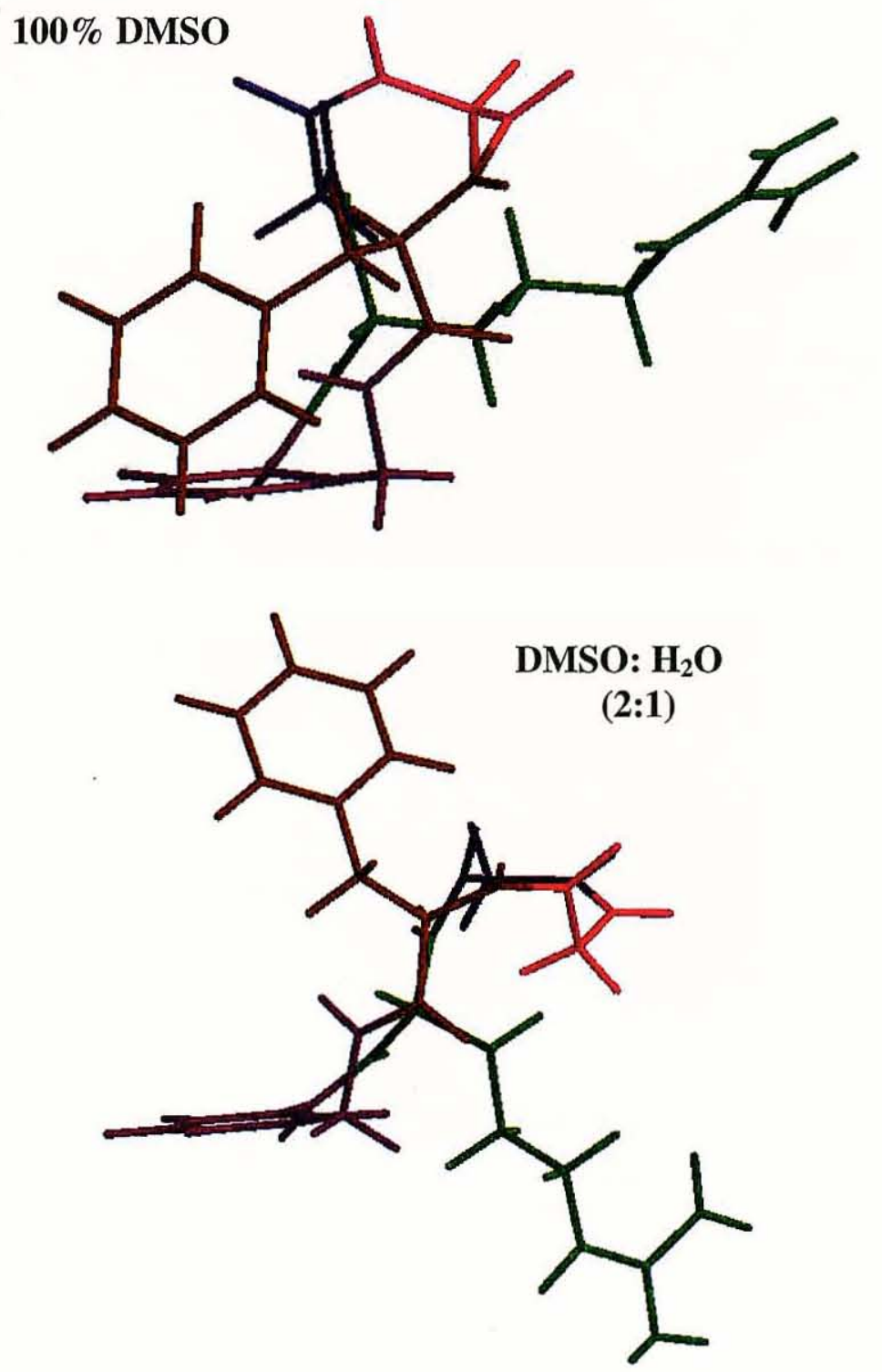
The Phe and Arg residues undergo rotation about the NH- $\mathrm{C}_{\alpha}$ bond in the presence of water, placing their respective side chains in significantly different orientations in space. Perhaps the change in proximity of the Phe aromatic ring to the $3 \mathrm{AMB}$ ring has an effect on the chemical shift of the aromatic proton a. The difference in the position of the Arg side chain in the two solvent systems may account for the observed shift of the Asp NH proton, possibly allowing an intramolecular $\mathrm{H}$-bonding interaction to take place in the presence of water. In both structures, it appears that the backbone amide proton of Arg would be solvent accessible and, therefore, it would be possible for hydrogen bonding interactions to take place between that proton and the solvent.

\section{Structural Assessment of Peptide P1b: a cyclic peptide dimer}

Unlike the monomeric peptide species P1a, head-to-tail cyclic peptide dimer P1b gives five strong backbone amide signals in 100\% DMSO (Figure 32). From this observation, several conclusions can be drawn about the structure of P1b in solution. Most obvious of these conclusions is that the dimeric conformation is symmetrical in nature. If the dimer were asymmetric, all ten backbone amide protons would have distinct chemical shifts. Since the Asp residue appears to be involved in an intramolecular interaction, as the Asp NH protons resonates downfield at $8.53 \mathrm{ppm}$ and is intense, it is reasonable to assume that no salt bridges are formed in the larger molecule. Also worth noting, is that the $3-\mathrm{AMB}$ aromatic proton a (Figure 1) is upfield at $\delta 7.65$, as observed in the monomer in DMSO/water. The chemical shifts of P1b are summarized in Table 5. 


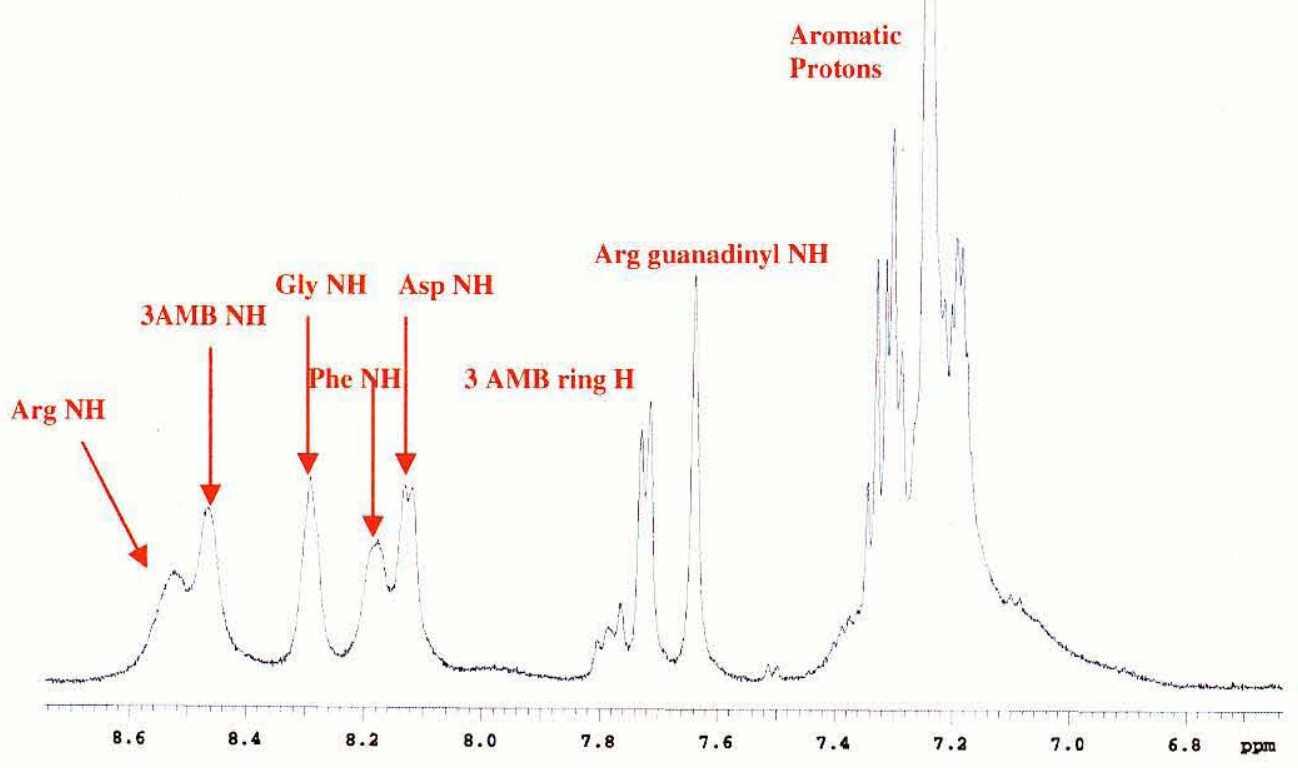

Figure 32: ${ }^{1} \mathrm{H}$ NMR spectrum of P1b. All five residues appear clearly in $100 \%$ DMSO- $\mathrm{d}_{6}$.

$\begin{array}{cccccc}\text { residue } & \mathbf{H N}^{*} & \mathbf{H}_{\alpha}{ }^{*} & \mathbf{H}_{\beta}{ }^{*} & \mathbf{H}_{\gamma}{ }^{*} & \begin{array}{c}\text { Other }^{*} \\ \text { Arg }\end{array} \\ 8.53 & 4.31 & 1.50 & 1.78 & \begin{array}{c}\mathbf{H}_{\delta}: 3.04 \\ \mathbf{N H}: 7.66\end{array} \\ \text { Gly } & 8.28 & 3.72 / 4.23 & & & \\ \text { Asp } & 8.10 & 4.46 & 2.39 & & \text { aromatic: } 7.20 \\ \text { D-Phe } & 8.18 & 4.40 & 2.89 / 3.14 & & 7.31 \\ & & & & & \text { aromatic: } 7.28 \\ \text { 3-AMB } & 8.46 & 3.65 / 4.49 & & & 7.62 \\ & & & & & 7.68\end{array}$

Table 5: Proton chemical shifts of dimeric peptide P1b. 


\section{SUMMARY}

Seven novel head-to-tail cyclic peptides, all containing the Arg-Gly-Asp pharmacophore, were synthesized, purified and characterized. Linkers of varying composition and flexibility were incorporated into the peptides. The peptide containing 4-aminomethylbenzoic acid was unattainable as a cyclic molecule as the rigid, linear 4AMB residue did not lend itself well to ring closure. However, inclusion of the bent 3AMB molecule did allow for cyclization. It was discovered that the ring-closing step with only four residues was unsuccessful, most likely due to torsional strain. Such strain was relieved with the addition of another residue. In all but one of the peptides, this fifth residue was chosen to be phenylalanine. It was also found that a " $D$ " configuration at the fifth position rather than a "L" seemed to be preferred for ring closing, most likely due to steric interactions that are lessened during ring closure with a D-amino acid.

The monomeric cyclic peptide P1a was chosen for structural evaluation using nuclear magnetic resonance (NMR) spectroscopy in both $100 \%$ DMSO- $\mathrm{d}_{6}$ and a mixed solvent system composed of DMSO- $\mathrm{d}_{6}: \mathrm{H}_{2} \mathrm{O}(2: 1)$. The most puzzling observation from the two studies of the monomeric peptide species was the very weak signals of the Asp residue in $100 \%$ DMSO. When water was added, the Asp amide and aliphatic signals became very apparent.

The amide proton chemical shifts in the mixed solvent system were found to display temperature-dependence. From the large negative temperature coefficient measured for the $\operatorname{Arg} \mathrm{NH}$, it is apparent that this proton interacts with the solvent. The Asp amide proton, on the other hand, has associated with it a very small negative temperature coefficient, signifying intramolecular H-bonding. The Asp NH peak seemed to broaden 
quite dramatically compared to the other amide protons as heat was added to the system, possibly because the $\mathrm{NH}$ proton begins exchanging more rapidly with its $\mathrm{H}$-bond acceptor.

By calculating the dihedral angles of the $\mathrm{NH}-\mathrm{C}_{\alpha} \mathbf{H}$ from the J-coupling constants, two structural constraints could be placed on the molecule and a model structure generated for the peptide in both solvent systems. A comparison of the structures generated in the two solvent systems reveals that a rather dramatic conformational change takes place when water is added to the system. The difference in the position of the Arg side chain in the two solvent systems may account for the observed shift of the Asp NH proton, possibly allowing an intramolecular $\mathrm{H}$-bonding interaction to take place in the presence of water. 


\section{CHAPTER 2}

\section{TARGETING DRUGS TO BONE}

\section{BACKGROUND}

\section{A. Pathophysiology and Pharmacological Treatment of Bone Disorders}

Healthy bone is a dynamic tissue, constantly being remodeled via catabolic and anabolic processes. Normally bone remodeling is balanced and maintains bone strength. Highly specialized cells control the remodeling process: osteoblasts deposit new bone tissue, while osteoclasts resorb the tissue. Osteoblasts secrete an extracellular proteinaceous matrix, mainly composed of collagen. The matrix becomes mineralized by hydroxyapatite $\left(\mathrm{Ca}_{10}\left(\mathrm{PO}_{4}\right)_{6}(\mathrm{OH})_{2}\right)$. Two-thirds of the mineral mass in the human body is in the bone tissue (Siconolfi, et al., 1998).

Diseases of the bone can disrupt the balance of bone formation and resorption. Osteoporosis is a disease in which bone resorption outpaces bone formation, causing nearly 1.3 million bone fractures each year (Hirabayashi and Fujisaki, 2003). One factor contributing to the development of osteoporosis in post-menopausal women is a marked decrease in estrogen levels. Low estrogen levels have been linked to an increase in osteoclast formation, leading to higher rates of bone resorption, and hence, lower bone density (Lindsay, et al, 1976).

Bone cancer is a disease that affects the tissue by a different mechanism. Malignant tumors of the bone result from aggressive, invasive cell growth and destroy normal bone tissue. These cells can originate from the bone itself (primary tumor) or from metastasis 
of cells from soft tissues (secondary tumor). Primary bone tumors are far less common than secondary tumors, accounting for only about $0.2 \%$ of all cancers (American Cancer Society, 2008).

\section{B. Treatment of Bone Diseases}

Most current medications for treating bone diseases are delivered systemically and, therefore, can have adverse effects (Hirabayashi \& Fujisaki, 2003). One of the most widely publicized examples of a treatment that has the potential for undesired side effects is hormone-replacement therapy (HRT). Hormone-replacement therapy raises estrogen levels and prevents further bone loss. The major drawback of HRT is that higher concentrations of estrogen are associated with an increased risk of cancer of the female reproductive tissues (Colditz, et al, 1995; Schairer, et al, 2000; Persson, et al, 1999; Smith, Prentice, Thompson, \& Hermann, 1975; Ziel \& Finkle, 1975; Rodriguez, et al, 2001).

Other therapies for osteoporosis are available and have drawbacks associated with them as well. The bisphosphonates (alendronate, risedronate, ibandronate), can cause erosion of the esophageal lining (Sia, Iser, Heng \& Chen, 2004). Parathyroid hormone, ("PTH"; teriparatide) although an anabolic, rather than simply anticatabolic, treatment, requires daily injections and cannot be used for more than two years.

Chemotherapy agents are notorious for the effects they have on rapidly dividing cells, such as the hair follicles and the lining of the gastrointestinal tract. The anthracyclines (doxorubicin, daunorubicin, epirubicin, and idarubicin), although highly potent and useful against cancer cells, can also affect the musculature of the heart. The cardiotoxicity of the anthracyclines can be partially attributed to the formation of free 
radicals and subsequent free radical lipid peroxidation (Sallan \& Clavell, 1984; Floyd, et al, 2005).

\section{Designing "Smarter" Molecules}

A challenge facing the pharmaceutical industry is making a drug that is not only highly effective, but also highly specific in its biological action. When a molecule is selected as a potential drug candidate, it must be highly effective at the target tissue or organ, while having minimal effects on other tissues. The continuing evolution of pharmacology and medicinal chemistry has allowed for considerable progress in the development of precise and effective drug action. As the inner workings of biological systems are elucidated, opportunities to utilize biomolecules as drug targets become more abundant and more specific. Sometimes the biomolecules themselves can be developed into therapeutic entities.

A commonly used strategy for designing molecules with specific pharmacological properties involves exploiting the natural biological activity of a known ligand, antigen, or substrate to achieve selective binding. For instance, the well-known chemotherapeutic agent tamoxifen, used for the treatment of breast cancer, competes with estrogen for binding to the estrogen receptor in the breast tissue and tumors. By "blocking" the receptor from binding with estrogen, tamoxifen inhibits the growth of estrogen-dependent tumor cells and eventually leads to cell death (Jordan, 1993).

Besides the teeth, bone is the only tissue in the human body that is mineralized by hydroxyapatite. Unlike teeth, bone is also highly vascularized, so it can interact with socalled "bone-seeking" substances (Stepensky, Kleinberg, \& Hoffman, 2003). Hence, 
molecules that have an affinity for hydroxyapatite can be utilized to act as "drug carriers" that can deliver medicinal agents in a tissue-specific manner.

\section{Chemicals that Bind to Hydroxyapatite}

Some compounds and elements have a natural affinity for bone due to its high composition of hydroxyapatite. Stepensky, Kleinberg, and Hoffman (2003) have written about the binding properties of some of the substances that bind to bone, including fluoride, lead, bisphosphonates, tetracycline, and radioactive agents. Although the pharmacokinetics and pharmacodynamics of so-called "bone-seeking" agents may vary, a consistent property of these materials is that they are very slowly released from the bone tissue once bound.

Of the drugs currently on the market for the treatment of osteoporosis, bisphosphonates are the only compounds that specifically target bone. Bisphosphonates are analogues of pyrophosphates that contain a carbon atom instead of an oxygen atom linking two phosphonic acids. The deprotonated bisphosphonic acid form of the molecules acts as the bone-targeting entity (Zhang, Gangal, and Uludag, 2007). The main drawbacks of bisphosphonates and their conjugates as drugs are their long biological half-lives (several months to years) and poor oral availability (less than 1\%) (Stepensky, Kleinberg, \& Hoffman, 2003). The design and development of novel hydroxyapatite-binding molecules to use for targeting drugs to bone is, therefore, a worthwhile venture in pharmaceutical research.

\section{E. Tetracycline as a "Bone-Seeking" Molecule}

Tetracycline, first prepared by catalytic hydrogenolysis of aureomycin in 1953 (Boothe), is noted to be a potent antimicrobial agent. The fact that it also binds to bone 
has been well established (Skinner, 1975; Myers, 1968). During bone formation, tetracycline binds tightly to calcium and it has a terminal half-life on the order of weeks , although most of a dose is mostly eliminated from the body within one week, with 3-6\% remaining in the skeleton (Stepensky, Kleinberg, \& Hoffman, 2003).

Infrared spectroscopic studies of tetracycline adsorbed to hydroxyapatite indicate that the "A" ring of the molecule (see Figure 1) is involved in complexation (Myers, TochonDanguy, and Baud, 1983). Significant shifts in the frequencies of the $\mathrm{C} 2$ amide bond vibrations $\left(\mathrm{C}=\mathrm{O}\right.$ and $\left.\mathrm{NH}_{2}\right)$ were observed in adsorbed versus free tetracycline. The data also suggested that the two oxygen atoms adjacent to the $\mathrm{C} 2$ amide (those at carbons 1 and 3) are equivalent, with only one frequency observed for both carbonyls at $1615 \mathrm{~cm}^{-1}$. This finding is consistent with the crystal data. The amide bond at $\mathrm{C} 2$ and the flanking carbonyl groups at $\mathrm{C} 1$ and $\mathrm{C} 3$ are essential for calcium binding (Albert, 1979).

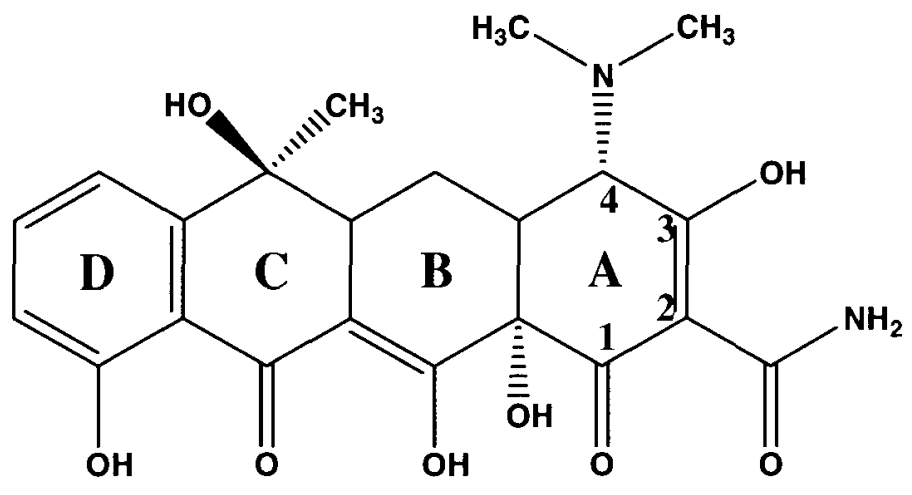

Figure 1: Tetracycline

\section{F. Bone-Targeted Drug Conjugates}

Although no bone-specific drug conjugates are presently available for patient use, a good deal of research has been performed on developing such entities over the past 
several decades. One of the most widely studied classes of molecules for making bonetargeted pharmaceuticals has been the bisphosphonates. While bisphosphonates themselves act as bone resorption inhibitors, they can also be exploited as bone-targeted carriers for other drugs. Some of the bisphosphonate conjugates in preclinical trials (as of 2003) are three agents for the treatment of osteoporosis, three bone cancer drugs, a bone-targeted antibiotic, and an osteoarthritis therapy (see review article Hirabiyashi and Fujisaki, 2003). An oligopeptide composed of six aspartic acid residues was conjugated to estradiol and found to preferentially bind to bone (Kasugai, et al, 2000). Tetracycline has been used as a bone-specific carrier for a carbonic anhydrase inhibitor (Pierce and Waite, 1987) and for estradiol (Orme and Labroo, 1994).

\section{G. Development of a Novel Bone-Targeting Agent}

The A ring of tetracycline is known to be one of the calcium binding domains of the molecule. Prior work in this laboratory was focused on developing a novel bonetargeting agent (BTA) modeled on the structure of this A ring. The motivation for constructing a new BTA instead of using the entire tetracycline molecule is three-fold. One, because bones are surrounded by a highly selective cell lining, large molecules cannot easily access the surface of the bone (Hirabiyashi and Fujisaki, 2003). Secondly, tetracycline is in fact an antibiotic drug and could act as such, even when conjugated, leading to unwanted side effects. Lastly, from a synthetic standpoint, the A ring of tetracycline is a much more practical choice as a chemical synthesis precursor than is the entire tetracycline molecule. Because of the number of functional groups, making drug conjugates of tetracycline is much more likely to result in unwanted synthetic products and would require selective protection/deprotection schemes. 
The work described on pages 67 to 71 is presented in the dissertation of Dr. Jason Neale (2002). Structure-activity relationship (SAR) studies were first carried out on three series of bone-targeting molecules (see Figure 2). All three of the bone-targeting entities used in the study contained the crucial tricarbonyl moiety mentioned in section $\mathbf{E}$. To rapidly check for calcium binding properties, the three potential BTAs were subjected to a hydroxyapatite-binding assay. The results from these experiments indicated that the Series III compounds had the highest affinity for hydroxyapatite, binding nearly $50 \%$ as well as tetracycline. The compounds from this series also exhibited no apparent adverse effects in vivo. Thus, Series III was chosen for further investigation.

\section{H. Synthesis and Evaluation of a Series of Bone-Targeted Estrogens}

In order to further assess the bone-targeting properties of the Series III BTAs, a new line of BTA-estrogen conjugates were synthesized (see Figure 3). The conjugates were composed of four regions: a bone-targeting domain, an estrogenic domain, a spacer ("S") between the two domains, and the linkage ("L") connecting the estrogenic domain to the spacer. Among these regions, only the estrogenic domain was held constant and was derived from 17- $\beta$-estradiol. The linkage at $\mathrm{C} 17$ of estradiol, the length of the spacer between the BTA and the estrogenic domain, and the C6 substituent of the BTA were varied. The conjugates were all linked via an amide bond at the bone-targeted end of the molecule.

Changing the $\mathrm{C} 17$ linkage from an ester to an ether to a ureido bond altered the susceptibility of the bond to hydrolysis. The spacer in between the BTA and estradiol 


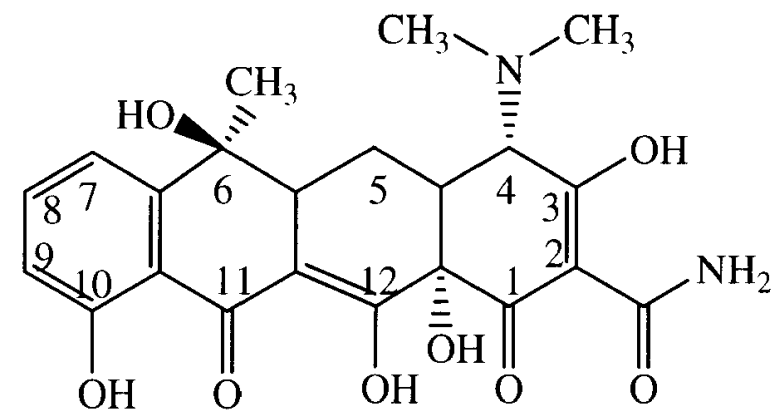

$\mathrm{D}$ ring $\mathrm{C}$ ring $\mathrm{B}$ ring $\mathrm{A}$ ring

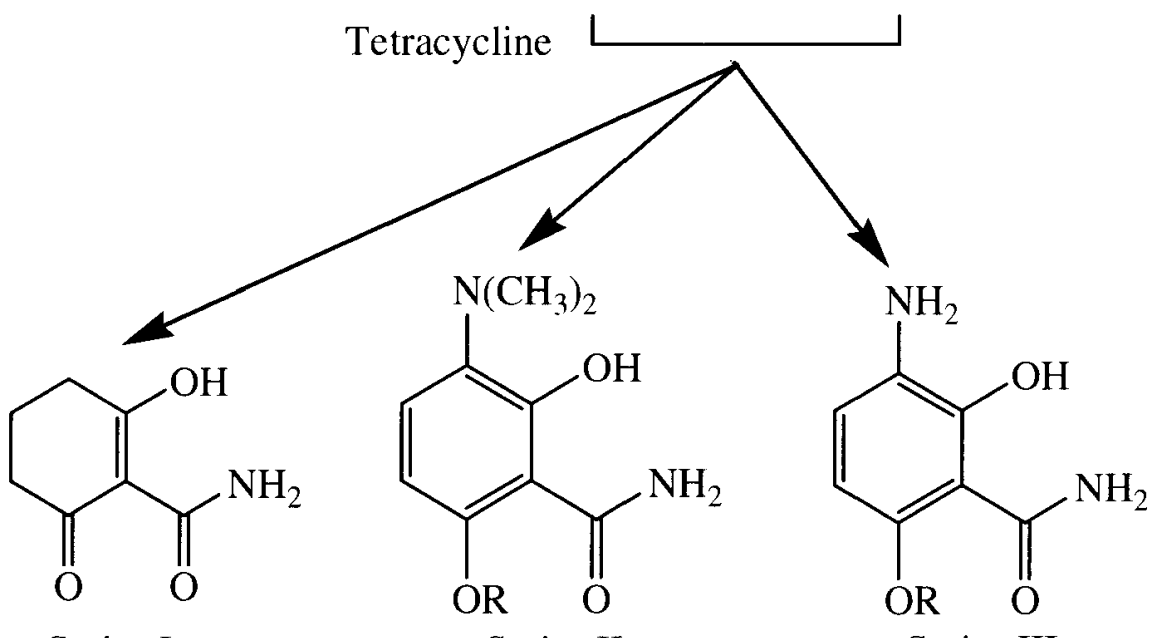

Series I

Series II

Series III

Figure 2: Three series of molecules based on the A ring of tetracycline. The tricarbonyl region of carbons 1-3 has been shown to be essential for calcium binding. $\mathrm{R}=\mathrm{CH}_{3}, \mathrm{Bz}$, or $\mathrm{H}$. 


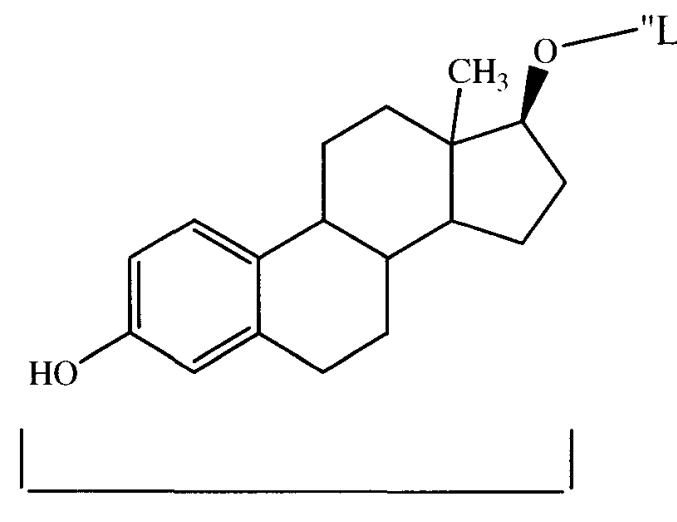

Estrogenic domain<smiles>[R]Oc1ccc(NC(=O)[S-])c(O)c1C(N)=O</smiles>

Series III bone-targeting agent

\begin{tabular}{|c|c|c|c|c|}
\hline Compound & $\begin{array}{c}\text { Estrogenic } \\
\text { domain }\end{array}$ & $\begin{array}{c}\text { "L" } \\
\text { linkage }\end{array}$ & $\begin{array}{c}\text { "S" } \\
\text { spacer }\end{array}$ & $\mathrm{R}$ \\
\hline $\mathrm{BTE}_{2}-\mathrm{A} 1$ & $17 \beta$-estradiol & Ester & $-\left(\mathrm{CH}_{2}\right)_{2^{-}}$ & $-\mathrm{H}$ \\
\hline $\mathrm{BTE}_{2}-\mathrm{A} 2$ & $17 \beta$-estradiol & Ester & $-\left(\mathrm{CH}_{2}\right)_{2}-$ & $-\mathrm{CH}_{3}$ \\
\hline $\mathrm{BTE}_{2}-\mathrm{B} 2$ & $17 \beta$-estradiol & Ester & $-\left(\mathrm{CH}_{2}\right)_{4^{-}}$ & $-\mathrm{CH}_{3}$ \\
\hline $\mathrm{BTE}_{2}-\mathrm{C} 2$ & $17 \beta$-estradiol & ------ & ------ & $-\mathrm{CH}_{3}$ \\
\hline $\mathrm{BTE}_{2}-\mathrm{D} 1$ & $17 \beta$-estradiol & Ether & $-\left(\mathrm{CH}_{2}\right)_{2}-$ & $-\mathrm{H}$ \\
\hline $\mathrm{BTE}_{2}-\mathrm{D} 2$ & $17 \beta$-estradiol & Ether & $-\left(\mathrm{CH}_{2}\right)_{2-}$ & $-\mathrm{CH}_{3}$ \\
\hline $\mathrm{BTE}_{2}-\mathrm{D} 3$ & $17 \beta$-estradiol & Ether & $-\left(\mathrm{CH}_{2}\right)_{2-}$ & - benzyl \\
\hline $\mathrm{BTE}_{2}-\mathrm{E} 2$ & $17 \beta$-estradiol & Ureido & $-\left(\mathrm{CH}_{2}\right)_{2-}$ & $-\mathrm{CH}_{3}$ \\
\hline
\end{tabular}

Figure 3: Structure-activity relationship variables of bone-targeted estrogens.

domains was varied from zero to two to four methylene groups to evaluate the effects on hydroxyapatite affinity, hydrolytic susceptibility, and, possibly, estrogenic properties. Incorporating different substituents at the C6 position diversified the bone-targeted portion of the molecule. After modifying the BTA to include a methoxyl, benzyloxyl, or hydroxyl substituent at the $\mathrm{C} 6$ position, changes in bone-affinity could be observed.

The conjugates were first screened via a hydroxyapaptite-binding assay. The affinity of the compounds for HA was compared to that of tetracycline. It was discovered that the compounds containing a BTA with a methoxyl or benzyloxyl group at C6 bound to 
HA at significantly higher level (150-200\% better) than tetracycline (see Figure 4). It was found that conjugating the BTAs to 17- $\beta$-estradiol improved the affinity for HA considerably compared to the BTAs alone.

Since the main disadvantage associated with current hormone-replacement therapy is the dual estrogenic effects on the bone and the uterus, the conjugates were tested in vivo for improvements in tissue selectivity. As anticipated, estradiol itself was found to have virtually no selectivity between the two tissues, with a ratio of femur to uterus stimulation of 0.90. In vivo studies of the bone-targeted conjugates revealed that three of the bonetargeted estradiols, $\mathrm{BTE}_{2}-\mathrm{A} 1, \mathrm{BTE}_{2}-\mathrm{D} 2$, and $\mathrm{BTE}_{2}-\mathrm{D} 3$ (see Figure 3 for structures), had the highest ratios of femur: uterine tissue selectivity, at ratios of $3.00,3.34$, and 2.43 , respectively.

Compound $\mathrm{BTE}_{2}-\mathrm{A} 1$ was found to be active when administered orally. The doses necessary for bone mass preservation, however, exceeded those necessary when subcutaneous administration was used. These results indicated that the conjugate might have been incompletely absorbed, possibly due to hydrolysis of the ester linkage during metabolism.

One other noteworthy observation from the in vivo assessment of the bone-targeted conjugates is that two of the most highly selective compounds, $\mathrm{BTE}_{2}-\mathrm{D} 2$ and $\mathrm{BTE}_{2}-\mathrm{D} 3$, were discovered not only to preserve, but also to increase bone density. BTE 2 -D2 preserved bone density at a level of $250 \%$ compared to sham animals; $\mathrm{BTE}_{2}-\mathrm{D} 3$ preserved it at $300 \%$. These increases in bone density signify that the bone-targeted estradiol conjugates may be anabolic in nature, helping to build bone tissue, rather than simply slowing resorption. To date, the most widely prescribed pharmaceutical available 
for osteoporosis treatment that has anabolic properties is parathyroid hormone (marketed as Forteo $\left.{ }^{\circledR}\right)$. Although parathyroid hormone and related compounds build bone, they are not used long term and require frequent injections.

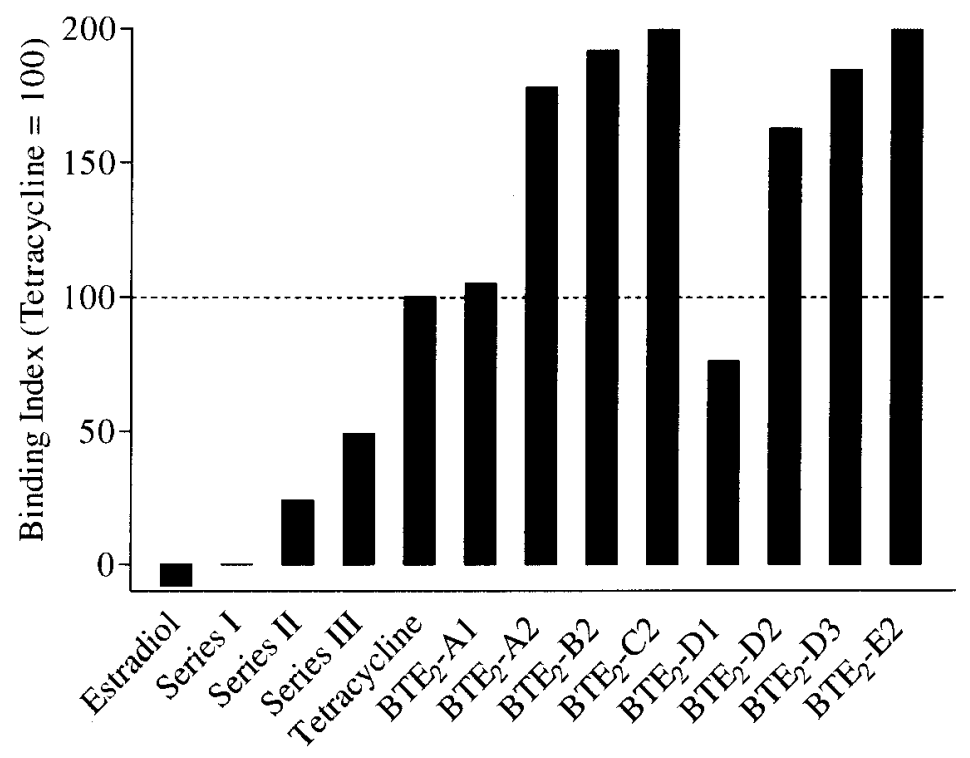

Figure 4: Comparative hydroxyapatite binding of bone-targeted estrogens. Tetracycline is defined as having a relative binding index of 100 . 


\section{GOALS OF THIS PROJECT}

\section{A. Develop a "Shelf-Stable" Bone-Targeting Entity}

In order to fully realize the potential of the newly discovered line of bone-targeting agents, it became evident that "universal" BTA would be invaluable. In the previous synthetic work, the spacer was attached to $17-\beta$-estradiol before conjugation to the BTA. This approach worked well when only bone-targeted estrogens were being studied, but if other drug conjugates were to be made, a more rational approach would be to attach the spacer to the BTA. With such a compound in hand, a seemingly endless number of drugs could be targeted to bone tissue by simply attaching them to the BTA-spacer molecule. Hence, one of the goals of this project was to synthesize a number of the BTA-spacer compounds and to assess their use and versatility as "shelf" reagents for making bonetargeted drugs.

Previous patented work was done attempting to make such a bone-targeted compound. A succinic acid linker arm was attached to the bone-targeting agents via the amino position. Unfortunately, further couplings with these linked compounds were unsuccessful. It was speculated that the succinic linker, rather than reacting with the desired molecule to make a bone-targeted conjugate, underwent an intramolecular cyclization (see Figure 5). The next generation of linkers will be carefully selected to avoid such a problem. Given that the estradiol conjugates of BTAs "D2" and "D3" (see Figure 6) were found to be the most biologically active and tissue selective compounds from the first series of studies, the universal BTA will be developed from one of these two bone-targeting agents. 

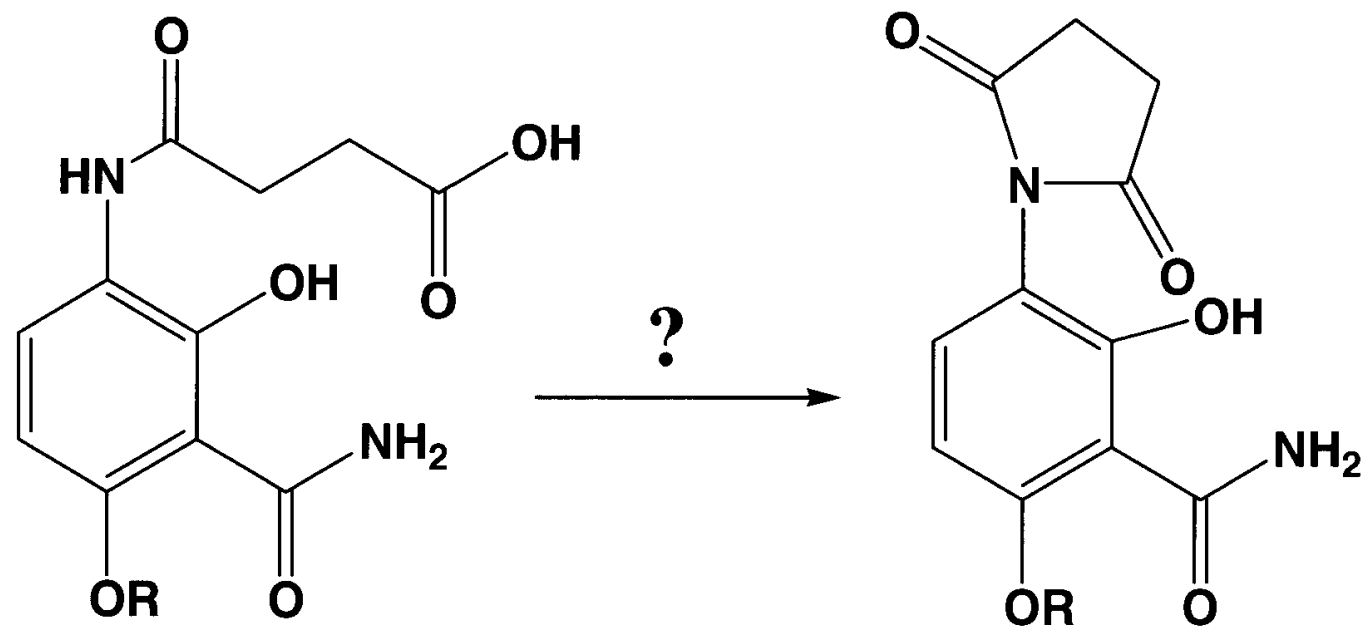

Figure 5: Postulated intramolecular cyclization of previous bone-targeting agents with linker arms.

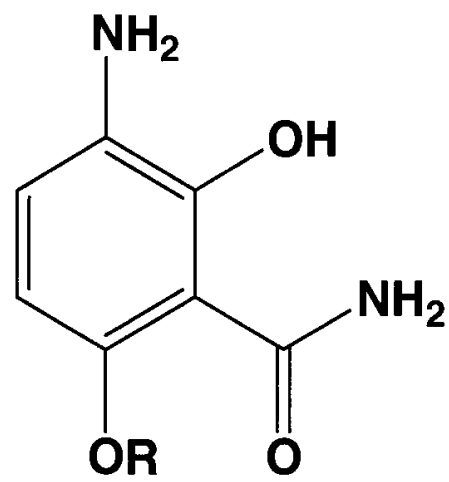

Figure 6: Bone-targeting agents "D2" (1: $\left.\mathbf{R}=\mathbf{C H}_{\mathbf{3}}\right)$ and "D3" (2: $\left.\mathbf{R}=\mathbf{B z}\right)$ were found to result in the most potent and selective estradiol conjugates

\section{B. Further Investigate the Effect of the Spacer ("S") on Oral Activity}

A secondary goal of the project was to determine if variations of the spacer had a substantial effect on the oral bioavailability of the bone-targeted estrogens. As discussed in Part I Section $\mathrm{H}$, the oral availability of the BTA-estradiol compounds may have been limited by the adsorption of the molecules into the bone tissue. One strategy for possibly 
enhancing cell uptake of the bone-targeted species is to make the spacer more amphiphilic.

The first series of bone-targeted estrogens contained hydrophobic spacers, composed mostly of methylene groups. The next series of compounds in this study will utilize spacers of varied lengths and varied compositions. The bifunctional linker 8-amino-3,6dioxaoctanoic acid ("mini-PEG”) and the longer version 11-amino-3,6,9trioxaundecanoic acid, because of their hydrophilic nature and flexibility, were chosen to be the spacers incorporated into the new series of bone-targeted estrogens.

\section{Design and Synthesize New Bone-Targeted Conjugates}

Because of its structural similarity to $17 \beta$-estradiol and ability to bind to the estrogen receptor, genistein, an isoflavone isolated from soybeans, falls into a class of compounds known as "phytoestrogens." Genistein actually exists almost exclusively as the $\beta$ glucoside "genistin" until it is hydrolyzed in the gastrointestinal system, as shown in Figure 7.

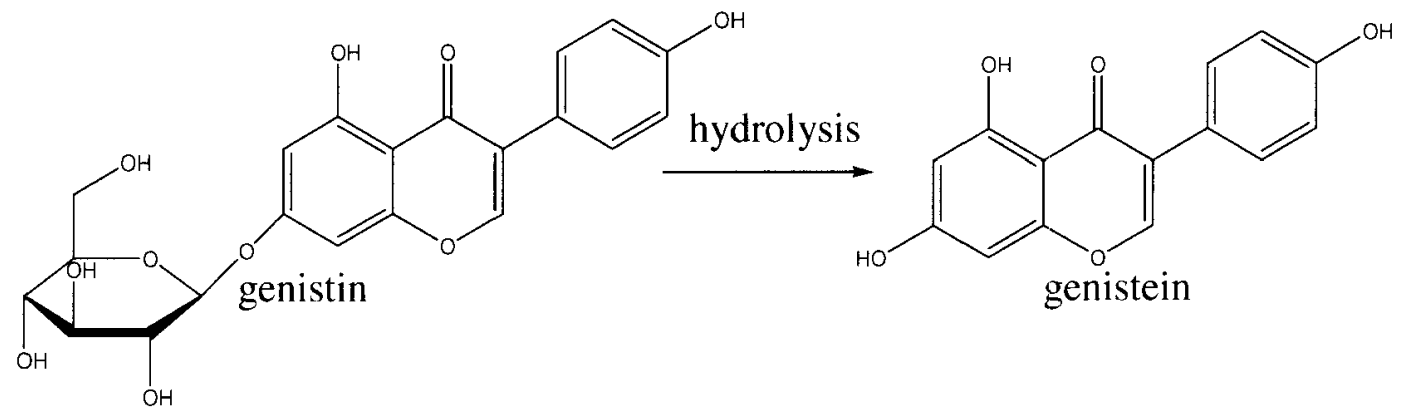

Figure 7: Genistin is hydrolyzed by a $\beta$-glucosidase during digestion to yield genistein. 
Genistein has been found to have an anabolic effect on bone tissue and to inhibit bone resorption (Yamaguchi, 2002). However, unlike hormone-replacement therapy, genistein appears to be selective for bone tissue and bone marrow, not having notable effects on reproductive tissues (Ishimi, et al, 1999; Wang, et al 2005). Hence, to further reduce the potential adverse estrogenic effects, a bone-targeted genistein compound became an attractive target for our current project.

In addition to bone-targeted estrogens/estrogen mimics, other molecules can be linked to the BT compounds. Doxorubicin, an anticancer drug, has been conjugated to a bisphosponate via a polymeric linker and was found to retain affinity for hydroxyapatite (Hruby, et al, 2006). Because of the potential for a targeted treatment for bone metastases, bone-targeted conjugates of doxorubicin are of interest for this project.

Fluorescein isothiocyanate (FITC) was conjugated to a bisphosphonate and a small, acidic peptide known to have bone-seeking properties (Wang, et al, 2003). The fluorescence of the conjugates was studied in vitro and in vivo and both compounds were found to bind to bone. Similarly, we would like to conjugate our BTAs to a fluorescent marker to be able to study the tissue distribution in vivo. 


\section{EXPERIMENTAL}

General Methods. Benzotriazole-1-yl-oxy-tris-(dimethylamino) phosphonium hexafluorophosphate (BOP) and 1-ethyl-3-(3-dimethylaminopropyl) carbodiimide hydrochloride (EDC) were purchased from Advanced ChemTech, 1hydroxybenzotriazole (HOBt) from Quantum Technologies, and 9fluorenylmethoxycarbonyl (Fmoc-) and tert-butyloxycarbonyl-miniPEGs (BocminiPEGs) from Peptides International. 3-amino-2-hydroxy-6-methoxybenzamide and 3amino-6-benzyloxy-2-hydroxybenzamide hydrochloride were purchased in bulk from Ricerca Biosciences, Concord, OH. All solvents and other reagents were purchased from either Fisher Scientific or Sigma-Aldrich. Reagent grade solvents were either purchased and used immediately or were freshly distilled before use. Varian Bond-Elut cartridges packed with $\mathrm{C} 18$ bound to silica gel were employed for reverse-phase chromatographic separation.

High-resolution mass spectrometry was performed by Dr. Jian Cai in the Department of Pharmacology and Toxicology at the University of Louisville School of Medicine. The instrument used was a Q-TOF API US from Waters. The samples were dissolved in $50 \% \mathrm{ACN} / 0.1 \%$ formic acid and analyzed by ESI in positive ion mode. The capillary voltage was $3.25 \mathrm{kV}$ and the mass resolution was 8500 .

NMR experiments were performed on a Varian INOVA $500 \mathrm{MHz}$ spectrometer. Fluorescence spectroscopy was performed by Dr. Daxin Tang in the Department of Ophthalmology at the University of Louisville on an ISS PC1 photon counting fluorimeter. 
1. Synthesis of Bone-Targeting Agent 1: 3-amino-2-hydroxy-6-methoxybenzamide (Scheme 1)

a. Esterification of 2, 6-dihydroxybenzoic acid (DHBA): methyl 2,6dihydroxybenzoate (3)

DHBA (10.00 g, $65 \mathrm{mmol})$, potassium bicarbonate $(6.51 \mathrm{~g}, 65 \mathrm{mmol})$, and 18-crown-6 ether $(90 \mathrm{mg}, 0.33 \mathrm{mmol})$ were mixed in dry acetone $(100 \mathrm{~mL})$. The solution stirred at room temperature for 10 minutes before dimethylsulfate $(7.00 \mathrm{~mL}, 72 \mathrm{mmol})$ was added. The reaction stirred for 18 hours at room temperature before being evaporated under vacuum to give a solid. The solid was taken up in $\mathrm{CHCl}_{3}(50 \mathrm{~mL})$, stirred for 5 minutes, and then treated with solid $\mathrm{NaHCO}_{3}$ and filtered. The resulting filtrate was washed with water $2 \mathrm{X}$ and brine $2 \mathrm{X}$. The organic layer was dried over $\mathrm{Na}_{2} \mathrm{SO}_{4}$, filtered, and evaporated to dryness to give an oil. A precipitate formed upon trituration. The mixture was recrystallized from EtOH/water to give white solid $\mathbf{3}$, collected by vacuum filtration. Yield: $8.24 \mathrm{~g}, \mathbf{7 5 \%} .{ }^{\mathrm{I}} \mathrm{H}\left(500 \mathrm{MHz}, \mathrm{DMSO}_{\mathrm{d}}\right)$ : $\delta 3.78, \mathrm{~s}, 3 \mathrm{H}, \mathrm{OCH}_{3} ; 66.34 \mathrm{~d}$, J $8.05 \mathrm{~Hz}, 2 \mathrm{H}, \mathrm{C} 3 \mathrm{H} / \mathrm{C} 5 \mathrm{H} ; \delta 7.09$, t, J $8.17 \mathrm{~Hz}, 1 \mathrm{H}, \mathrm{C} 4 \mathrm{H}$.

b. Aminolysis of 3: 2,6-dihydroxybenzamide (4)

Product 3 ( $3.00 \mathrm{~g}, 18 \mathrm{mmol}$ ) was dissolved in $75 \mathrm{~mL}$ methanol (freshly distilled from $\mathrm{Mg}$ turnings). The solution was cooled in an ice bath and anhydrous ammonia was bubbled through until approximately $5 \mathrm{~g}$ had transferred. The reaction was kept in an ice bath and stirred. After 5 hours, the green solution was evaporated to yield a green solid. The solid was dissolved in hot $\mathrm{MeOH}$ and treated with charcoal. After filtering, the filtrate was cooled to $4^{\circ} \mathrm{C}$ to give a sticky solid. The solid was dissolved in hot ethanol and filtered through Celite. After cooling, white solid 4 was collected. Yield: 1.64 g, 55\%. ${ }^{1} \mathrm{H}$ (500 
MHz, DMSO-d 6 ): $\delta 6.34$, d, J $8.05 \mathrm{~Hz}, 2 \mathrm{H}, \mathrm{C} 3 \mathrm{H} / \mathrm{C} 5 \mathrm{H} ; \delta 7.15, \mathrm{t}, \mathrm{J} 8.30 \mathrm{~Hz}, 1 \mathrm{H}, \mathrm{C} 4 \mathrm{H}$; $\delta 8.05, \mathrm{~s}, 1 \mathrm{H}, \mathrm{C} 1$ amide $\mathrm{H} ; \delta 8.33, \mathrm{~s}, 1 \mathrm{H}, \mathrm{C} 1$ amide $\mathrm{H} ; \delta 12.63, \mathrm{~s}, 2 \mathrm{H}$, phenolic $\mathrm{H}$.

c. Methylation of 4: 2-hydroxy-6-methoxybenzamide (5)

Product $4(2.6 \mathrm{~g}, 17 \mathrm{mmol})$ was dissolved in dry acetone $(100 \mathrm{~mL})$ in a 3 -neck roundbottom flask. To the solution was added $\mathrm{K}_{2} \mathrm{CO}_{3}(4.67 \mathrm{~g}, 34 \mathrm{mmol})$ and the solution was stirred for 30 minutes at room temperature under nitrogen. Dimethylsulfate $(1.9 \mathrm{~mL}, 20$ mmol) was added dropwise to the stirring solution over a period of 10 minutes. The solution was brought to reflux and held there for 18 hours. A significant amount of white precipitate was noted. The flask was allowed to cool to room temperature and then in an ice bath for 30 minutes. The solid was filtered off and washed with acetone $3 \mathrm{X}$. The filtrate was evaporated to give white solid 5. Yield: $1.76 \mathrm{~g}, 62 \% .{ }^{1} \mathrm{H}(500 \mathrm{MHz}$, DMSO-d $)_{6}: \delta 3.88, \mathrm{~s}, 3 \mathrm{H}, \mathrm{C} 6 \mathrm{OCH}_{3} ; \delta 6.48, \mathrm{~d}, \mathrm{~J} 8.30 \mathrm{~Hz}, 1 \mathrm{H}, \mathrm{C} 3 \mathrm{H} ; \delta 6.53, \mathrm{~d}, \mathrm{~J} 8.05 \mathrm{~Hz}$, 1H, C5 H; $\delta 7.32, \mathrm{t}, \mathrm{J} 8.42 \mathrm{~Hz}, 1 \mathrm{H}, \mathrm{C} 4 \mathrm{H} ; \delta 8.12$, s, $1 \mathrm{H}, \mathrm{C} 1$ amide $\mathrm{H} ; \delta 8.18, \mathrm{~s}, 1 \mathrm{H}, \mathrm{C} 1$ amide $\mathrm{H}$.

d. Nitration of 5: 2-hydroxy-6-methoxy-3-nitrobenzamide (6) Product $5(3.00 \mathrm{~g}, 18 \mathrm{mmol})$ was dissolved in $150 \mathrm{~mL}$ of glacial acetic acid. The solution was cooled in an ice bath and concentrated nitric acid $(12 \mathrm{~mL})$ was added. The reaction was stirred at room temperature for 18 hours. The reaction was quenched with cold water and the product, 6, was collected via vacuum filtration. Yield: $56 \%$. ${ }^{1} \mathrm{H}(500 \mathrm{MHz}$, DMSO-d $)_{6}: \delta 4.00$, s, 3H, C6 OCH $; \delta 6.75$, d, J $9.39 \mathrm{~Hz}, 1 \mathrm{H}, \mathrm{C} 5 \mathrm{H} ; \delta 8.15, \mathrm{~d}, \mathrm{~J} 9.39 \mathrm{~Hz}$, $1 \mathrm{H}, \mathrm{C} 4 \mathrm{H} ; \delta 8.34, \mathrm{~s}, 1 \mathrm{H}, \mathrm{C} 1$ amide $\mathrm{H} ; \delta 8.47, \mathrm{~s}, 1 \mathrm{H}, \mathrm{C} 1$ amide $\mathrm{H}$. 
e. Reduction of 6: 3-amino-2-hydroxy-6-methoxybenzamide (1)

Product $6(1.00 \mathrm{~g}, 5 \mathrm{mmol})$ was taken up in $100 \mathrm{~mL}$ of $\mathrm{MeOH}$ along with $\mathrm{Pd}-\mathrm{C}(5 \% \mathrm{Pd}$; $600 \mathrm{mg})$. The mixture was brought to reflux and hydrazine-hydrate $\left(\mathrm{N}_{2} \mathrm{H}_{4} 50-60 \%, 1.6\right.$ $\mathrm{mL}$ ) was added via a dropping funnel. The mixture was allowed to reflux overnight. The reaction mixture was filtered through Celite and the filtrate was concentrated in vacuo. The resulting solid was dissolved in hot water and hot gravity filtration was performed. Upon cooling, fine brown crystals of 1 formed. Yield: $610 \mathrm{mg}, \mathbf{6 7 \%} .{ }^{1} \mathrm{H}(500 \mathrm{MHz}$, DMSO-d $\left.\mathrm{d}_{6}\right): \delta 3.79, \mathrm{~s}, 3 \mathrm{H}, \mathrm{C} 6 \mathrm{OCH}_{3} ; \delta 6.33, \mathrm{~d}, \mathrm{~J} 8.54 \mathrm{~Hz}, 1 \mathrm{H}, \mathrm{C} 5 \mathrm{H} ; \delta 6.73, \mathrm{~d}, \mathrm{~J} 8.66 \mathrm{~Hz}$, $1 \mathrm{H}, \mathrm{C} 4 \mathrm{H} ; \delta 8.08, \mathrm{~s}, 1 \mathrm{H}, \mathrm{Cl}$ amide $\mathrm{H} ; \delta 8.21, \mathrm{~s}, 1 \mathrm{H}, \mathrm{Cl}$ amide $\mathrm{H}$.<smiles>COC(=O)c1c(O)ccc(N(C)C(=O)O)c1O</smiles><smiles>COc1cccc(O)c1C(N)=O</smiles>

Scheme 1: Synthesis of Bone-Targeting Agent 1. 


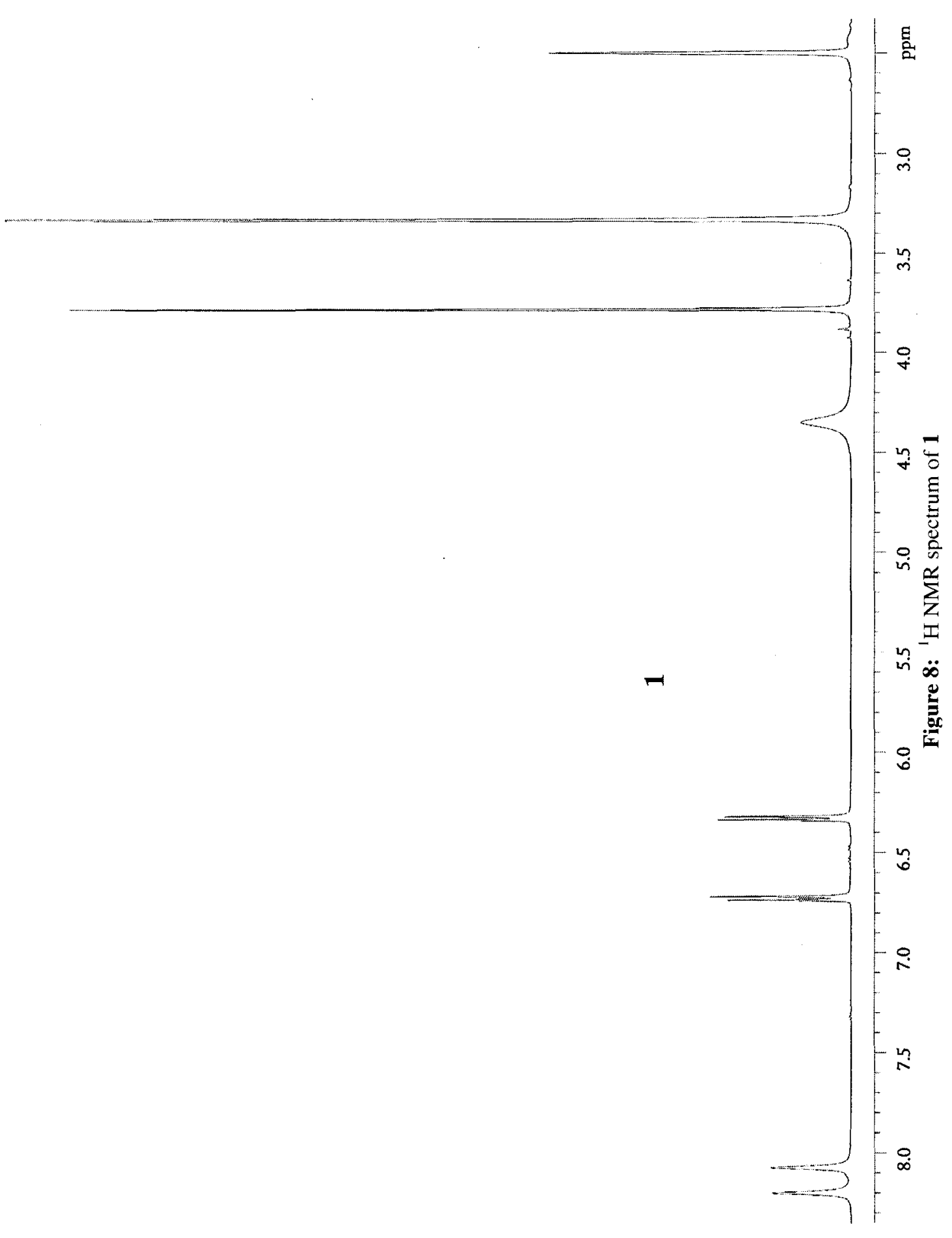


2. Coupling of Fmoc-mini-PEG to Bone-Targeting Agent 1: (9H-fluoren-9-yl)methyl 2-(2-(2-(3-carbamoyl-2-hydroxy-4-methoxyphenylamino)-2oxoethoxy)ethoxy)ethylcarbamate $(7$, Scheme 2$)$

Fmoc-8-amino-3, 6-dioxaoctanoic acid ("Fmoc-mini-PEG”, $2.5 \mathrm{~g}, 6.5 \mathrm{mmol}$ ) along with hydroxybenzatriazole (HOBt; $0.88 \mathrm{~g}, 6.5 \mathrm{mmol}$ ), benzotriazole-1-yl-oxy-tris(dimethylamino)-phosphonium hexafluorophosphate (BOP; $2.87 \mathrm{~g}, 6.5 \mathrm{mmol}$ ), and diisopropylethylamine (DIEA; $1.13 \mathrm{~mL}, 6.5 \mathrm{mmol}$ ) were dissolved in dimethylformamide (DMF; $20 \mathrm{~mL}$ ). In a separate flask, bone-targeting agent 3-amino-2-hydroxy-6methoxybenzamide $(0.89 \mathrm{~g}, 4.9 \mathrm{mmol})$ was dissolved in $20 \mathrm{~mL}$ DMF. After $\sim 3$ minutes, the two solutions were mixed together and stirred at room temperature for 24 hours. The DMF was removed under vacuum and crude product appeared as a brown oil.

The oily product was taken up in ethyl acetate and washed with brine $2 \mathrm{X}, 5 \% \mathrm{HCl} 2 \mathrm{X}$, and saturated $\mathrm{NaHCO}_{3} 2 \mathrm{X}$, then dried over sodium sulfate. It was then concentrated via rotary evaporation and a sticky brown oil resulted. When this oil was dissolved in methanol and triturated, a brownish-white solid precipitated out. The mixture sat at $4{ }^{\circ} \mathrm{C}$ for $\sim 72$ hours and solid product 7 was collected via vacuum filtration. Yield: $1.96 \mathbf{g}$, 73\%. ' ${ }^{1} \mathrm{NMR}\left(500 \mathrm{mHz}, \mathrm{DMSO}-\mathrm{d}_{6}\right): 83.15, \mathrm{~m}, 2 \mathrm{H}, 6{ }^{\prime} \mathrm{CH}_{2} ; 83.44$, t, J $5.98 \mathrm{~Hz}, 2 \mathrm{H}, 5$ ' $\mathrm{CH}_{2} ; \delta 3.60$, br s, $2 \mathrm{H}, 4^{\prime} \mathrm{CH}_{2} ; \delta 3.69$, br s, $2 \mathrm{H}, 3^{\prime} \mathrm{CH}_{2} ; \delta 3.88, \mathrm{~s}, 3 \mathrm{H}, \mathrm{C} 6 \mathrm{OCH}_{3} ; \delta 4.09$, s, 2 H, 2’ $\mathrm{CH}_{2} ; \delta 4.19$, q, J $6.59 \mathrm{~Hz}, 1$ H, 9’ CH; $\delta 4.27$, d, J $6.40 \mathrm{~Hz}, 2 \mathrm{H}, 8^{\prime} \mathrm{CH}_{2} ; \delta 6.54$, d, J $8.97 \mathrm{~Hz}, 1$ H, C5 H; $\delta 7.31$, m, 3 H, C14’ H/C6 amide H; 87.40 , m, 2 H, C12’ H; 87.67 , d, J 7.87 Hz, 2 H, C13’ H; $\delta 7.88$, d, J 7.32 Hz, C11' H; $\delta 8.18$, d, J 8.60 Hz, 1 H, C4 H; $\delta 8.29, \mathrm{~s}, 1 \mathrm{H}, \mathrm{Cl}$ amide $\mathrm{H} ; \delta 8.33, \mathrm{~s}, 1 \mathrm{H}, \mathrm{C} 1$ amide $\mathrm{H} ; \delta 8.85, \mathrm{~s}, 1 \mathrm{H}, \mathrm{C} 3$ amide $\mathrm{H}$. 


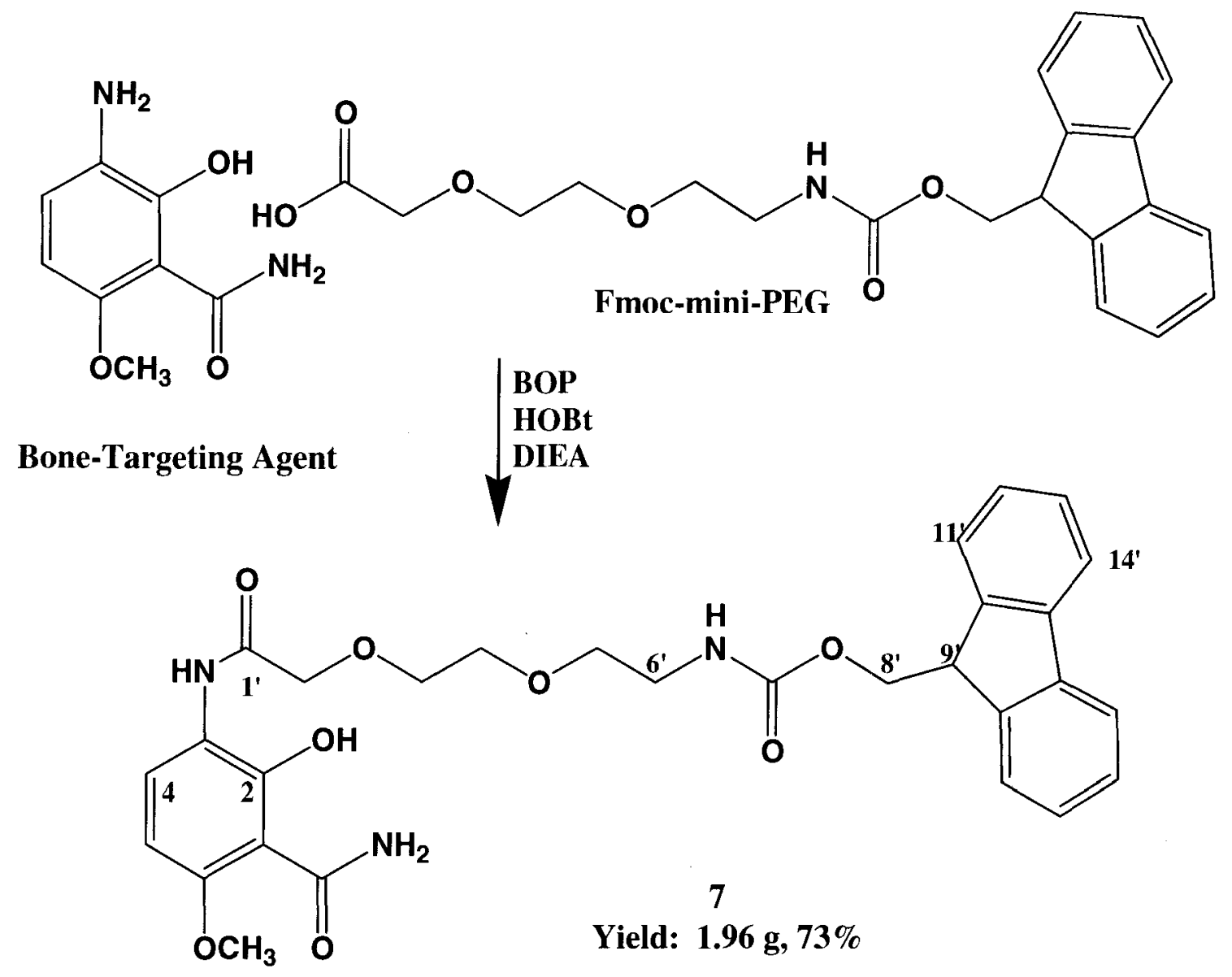

Scheme 2: Coupling of Fmoc-mini-PEG to bone-targeting agent 2-hydroxy-6-methoxy-3-aminobenzamide. 


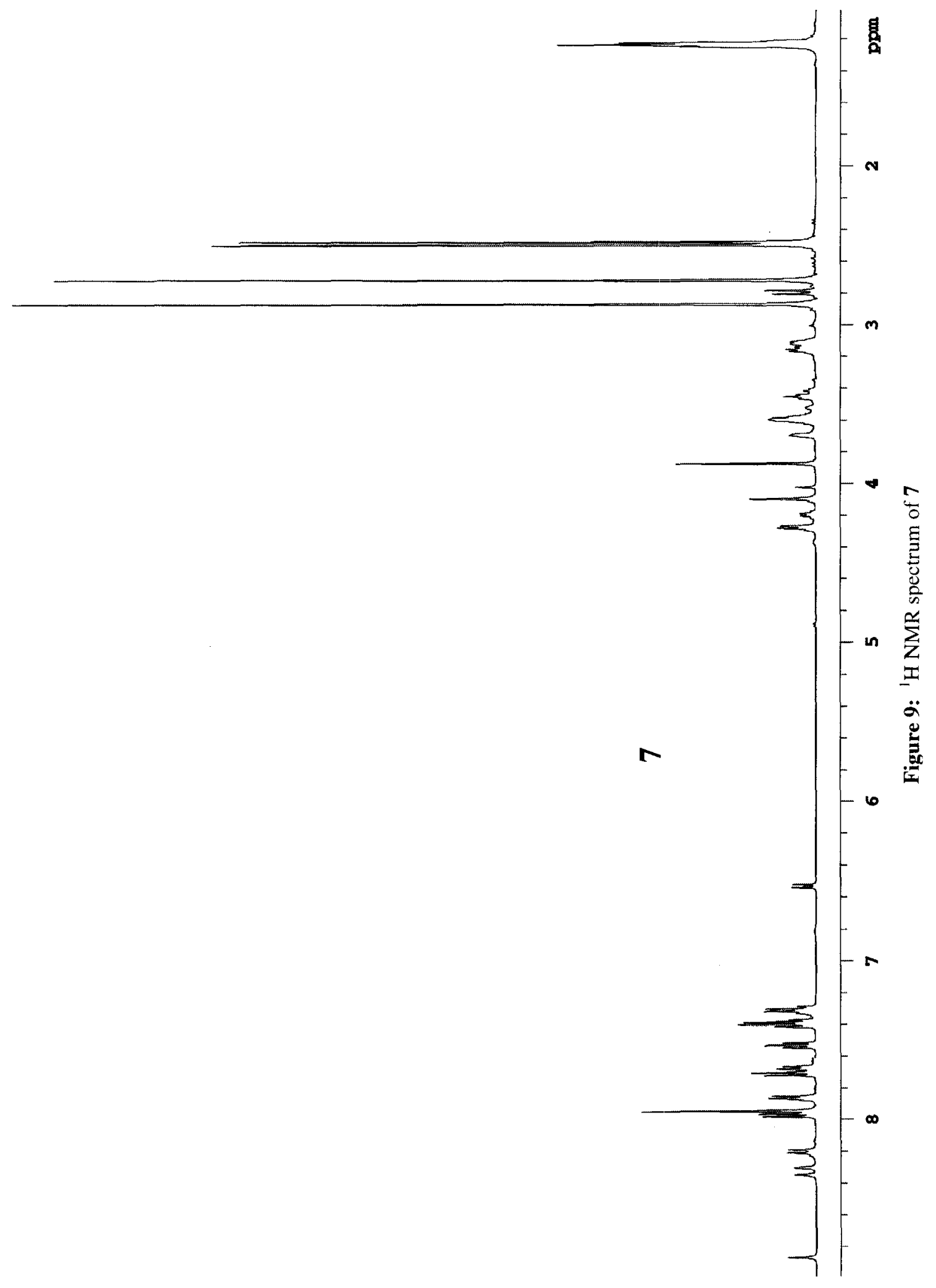


3. Fmoc-Deprotection/Formation of HCl Salt: 2-(2-(2-(3-carbamoyl-2-hydroxy-4methoxyphenylamino)-2-oxoethoxy)ethoxy)ethanaminium chloride (8, Scheme 3) Compound 7 ( $3.5 \mathrm{~g}, 6 \mathrm{mmol}$ ) was dissolved in $20 \%$ piperidine in DMF and stirred for 20 minutes. At that time, the solvent was removed in vacuo and fresh piperidine solution was added to repeat the reaction. Altogether, the deprotection was performed three times. After the third solvent removal, a solid product appeared and diethyl ether was added. The mixture was acidified with $7 \mathrm{~N} \mathrm{HCl}$ in methanol and decanted. A light brown precipitate, $\mathbf{8}$, was collected via vacuum filtration. Yield: $\mathbf{1 . 9 6} \mathbf{g}, \mathbf{9 0 \%} .{ }^{1} \mathrm{H}(500 \mathrm{mHz}$, DMSO-d $\left.{ }_{6}\right): \delta 2.96, \mathrm{t}, 2 \mathrm{H}, 6^{\prime} \mathrm{CH}_{2} ; \delta 3.65, \mathrm{~m}, 4 \mathrm{H}, 4^{\prime} / 5^{\prime} \mathrm{CH}_{2} ; \delta 3.73, \mathrm{~m}, 2 \mathrm{H}, 3^{\prime} \mathrm{CH}_{3}$; $\delta 3.89$, s, 3 H, C6 $\mathrm{OCH}_{3} ; \delta 4.12,2$ H, 2' $\mathrm{CH}_{2} ; \delta 6.56$, d, J $8.91 \mathrm{~Hz}, 1 \mathrm{H}, \mathrm{C} 5 \mathrm{H} ; \delta 8.17$, d, J $9.15 \mathrm{~Hz}, 1 \mathrm{H}, \mathrm{C} 4 \mathrm{H} ; \delta 8.30, \mathrm{~s}, 1 \mathrm{H}, \mathrm{C} 1$ amide $\mathrm{H} ; \delta 8.35, \mathrm{~s}, 1 \mathrm{H}, \mathrm{C} 1$ amide $\mathrm{H} ; \delta 8.87, \mathrm{~s}, 1 \mathrm{H}$, C3 amide H. ${ }^{13} \mathrm{C}\left(500 \mathrm{mHz}, \mathrm{DMSO}-\mathrm{d}_{6}\right): \delta 39.16, \mathrm{C} 6{ }^{\prime} ; \delta 56.86, \mathrm{C} 6-\mathrm{OCH}_{3} ; \delta 67.43, \mathrm{C} 5$; $\delta 70.17, \mathrm{C}^{\prime} ; \delta 70.77, \mathrm{C}^{\prime} ; \delta 70.97, \mathrm{C}^{\prime} ; \delta 100.96, \mathrm{C} 5 ; \delta 156.70, \mathrm{qC} ; \delta 103.21, \mathrm{qC} ; \delta 120.85$, C4; $\delta 124.95, \mathrm{qC} ; \delta 154.94, \mathrm{qC} ; \delta 155.47, \mathrm{qC} ; \delta 168.22, \mathrm{qC} ; \delta 172.54$, qC. Mass calculated: 327.1430; Mass found: $327.1426, \Delta=-1.3 \mathrm{ppm}$. 


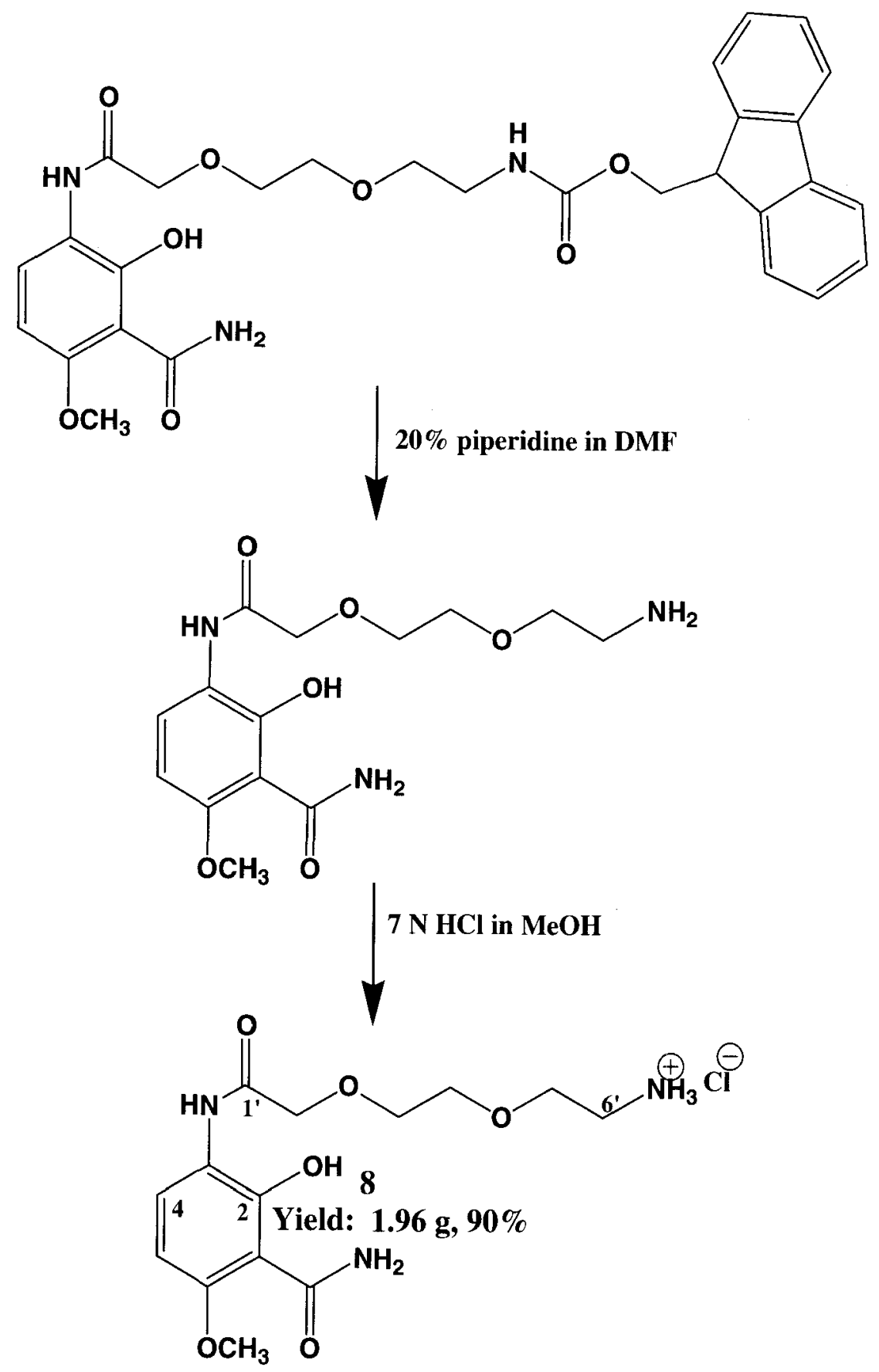

Scheme 3: Fmoc-Deprotection/Formation of $\mathrm{HCl}$ Salt 8. 


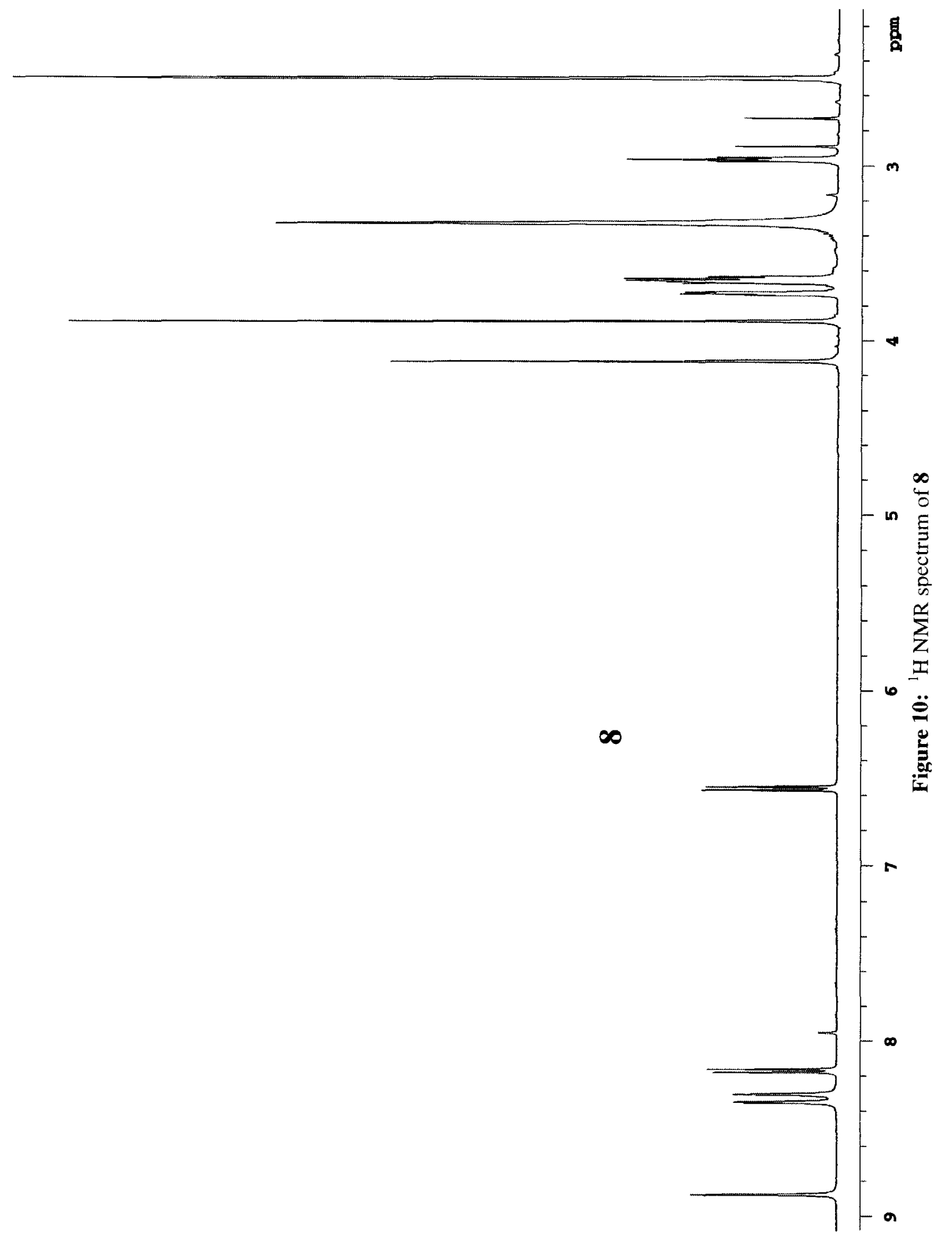




$$
1
$$




\section{4. a. Coupling of Bone-Targeting Agent to Fmoc-11-Amino-3,6,9-Trioxaundecanoic}

Acid: (9H-fluoren-9-yl)methyl 2-(2-(2-(2-(3-carbamoyl-2-hydroxy-4-

ethoxyphenylamino)-2-oxoethoxy)ethoxy)ethoxy)ethylcarbamate b. Fmoc-

Deprotection/Formation of HCl Salt: 2-(2-(2-(2-(3-carbamoyl-2-hydroxy-4-

methoxyphenylamino)-2-oxoethoxy)ethoxy)ethoxy)ethanaminium chloride

\section{(9, Scheme 4)}

Fmoc-11-amino-3,6,9-trioxaundecanoic acid ("Fmoc-mini-PEG-3", from Peptides International, Louisville, KY; $5.00 \mathrm{~g}, 11.6 \mathrm{mmol}$ ) was dissolved in $10 \mathrm{~mL}$ DCM along with DIEA (3 mL, $17.2 \mathrm{mmol})$. A second solution was made with BOP $(5.12 \mathrm{~g}, 11.6$ mmol), HOBt (1.55 g, $11.6 \mathrm{mmol})$, and DIEA ( $2 \mathrm{~mL}, 11.5 \mathrm{mmol})$ in DCM (40 mL). The two solutions were combined and stirred. Finally, 3-amino-2-hydroxy-6-

methoxybenzamide $(2.11 \mathrm{~g}, 11.6 \mathrm{mmol})$ was added to the reaction solution and it was stirred overnight at room temperature.

The solution was diluted with $120 \mathrm{~mL}$ of EtOAc then washed with brine $2 \mathrm{X}, 5 \% \mathrm{HCl}$ $2 \mathrm{X}$, and saturated sodium bicarbonate $2 \mathrm{X}$. The organic layer was dried over sodium sulfate and evaporated to dryness under vacuum to give a brown oil. The oil was taken up in $20 \%$ piperidine in DMF $(20 \mathrm{~mL})$ and stirred. After 10 minutes, a precipitate formed. This white solid (BOP reagent) was collected via vacuum filtration and the filtrate was concentrated in vacuo. The resulting oil was twice more treated with $20 \%$ piperidine in DMF for 15 minutes and the solvent removed under vacuum. Finally, a brown solid was obtained. Immediately, ether was added to the solid and the mixture was acidified with $7 \mathrm{~N} \mathrm{HCl}$ in $\mathrm{MeOH}$. The solvent was removed and once again the product was taken up in ether and acidified. The mixture was allowed to sit at $4^{\circ} \mathrm{C}$ 
overnight. A light brown precipitate, $\mathbf{9}$, was collected via suction filtration. Yield: $\mathbf{2 . 4 8}$ g, 53\%.

${ }^{1} \mathrm{H}\left(500 \mathrm{mHz}\right.$, DMSO-d $\left.\mathrm{d}_{6}\right): \delta 2.92, \mathrm{q}, \mathrm{J} 5.49 \mathrm{~Hz}, 2 \mathrm{H}, \mathrm{C} 8^{\prime} \mathrm{CH}_{2} ; \delta 3.54-3.60, \mathrm{~m}, 6 \mathrm{H}, 5^{\prime}-7^{\prime}$ $\mathrm{CH}_{2} ; \delta 3.62, \mathrm{~m}, 2 \mathrm{H}, 4^{\prime} \mathrm{CH}_{2} ; \delta 3.69, \mathrm{~m}, 2 \mathrm{H}, 3^{\prime} \mathrm{CH}_{2} ; \delta 3.88, \mathrm{~s}, 3 \mathrm{H}, \mathrm{C} 6 \mathrm{OCH}_{3} ; \delta 4.10, \mathrm{~s}, 2 \mathrm{H}$, 2' $\mathrm{CH}_{2} ; \delta 5.50$, br s, $3 \mathrm{H}, \mathrm{NH}_{3}{ }^{+} ; \delta 6.55$, d, J $9.15 \mathrm{~Hz}, 1 \mathrm{H}, \mathrm{C} 5 \mathrm{H} ; \delta 8.17$, d, J $8.97 \mathrm{~Hz}, 1 \mathrm{H}, \mathrm{C} 4$ $\mathrm{H} ; \delta 8.30$, br s, $1 \mathrm{H}, \mathrm{C} 1$ amide $\mathrm{H} ; \delta 8.35$, br s, $1 \mathrm{H}, \mathrm{C} 1$ amide $\mathrm{H} ; \delta 8.87$, br s, $1 \mathrm{H}, \mathrm{C} 3$ amide H. ${ }^{13} \mathrm{C}\left(500 \mathrm{mHz}, \mathrm{DMSO}-\mathrm{d}_{6}\right): \delta 39.17, \mathrm{CH}_{2} ; \delta 56.86, \mathrm{C} 6 \mathrm{OCH}_{3} ; \delta 67.33, \mathrm{CH}_{2} ; \delta 70.36, \mathrm{CH}_{2}$ (int=3); $\delta 70.81, \mathrm{CH}_{2} ; \delta 71.20, \mathrm{CH}_{2} ; \delta 100.97, \mathrm{C} 5 ; \delta 103.19, \mathrm{qC} ; \delta 120.87, \mathrm{qC} ; \delta 124.85, \mathrm{C} 4$; $\delta 154.89, \mathrm{qC} ; \delta 155.44, \mathrm{qC} ; \delta 168.26, \mathrm{qC} ; \delta 172.55, \mathrm{qC}$. Mass calculated: 371.1693 ; Mass found: $371.1684, \Delta=-2.49 \mathrm{ppm}$. 


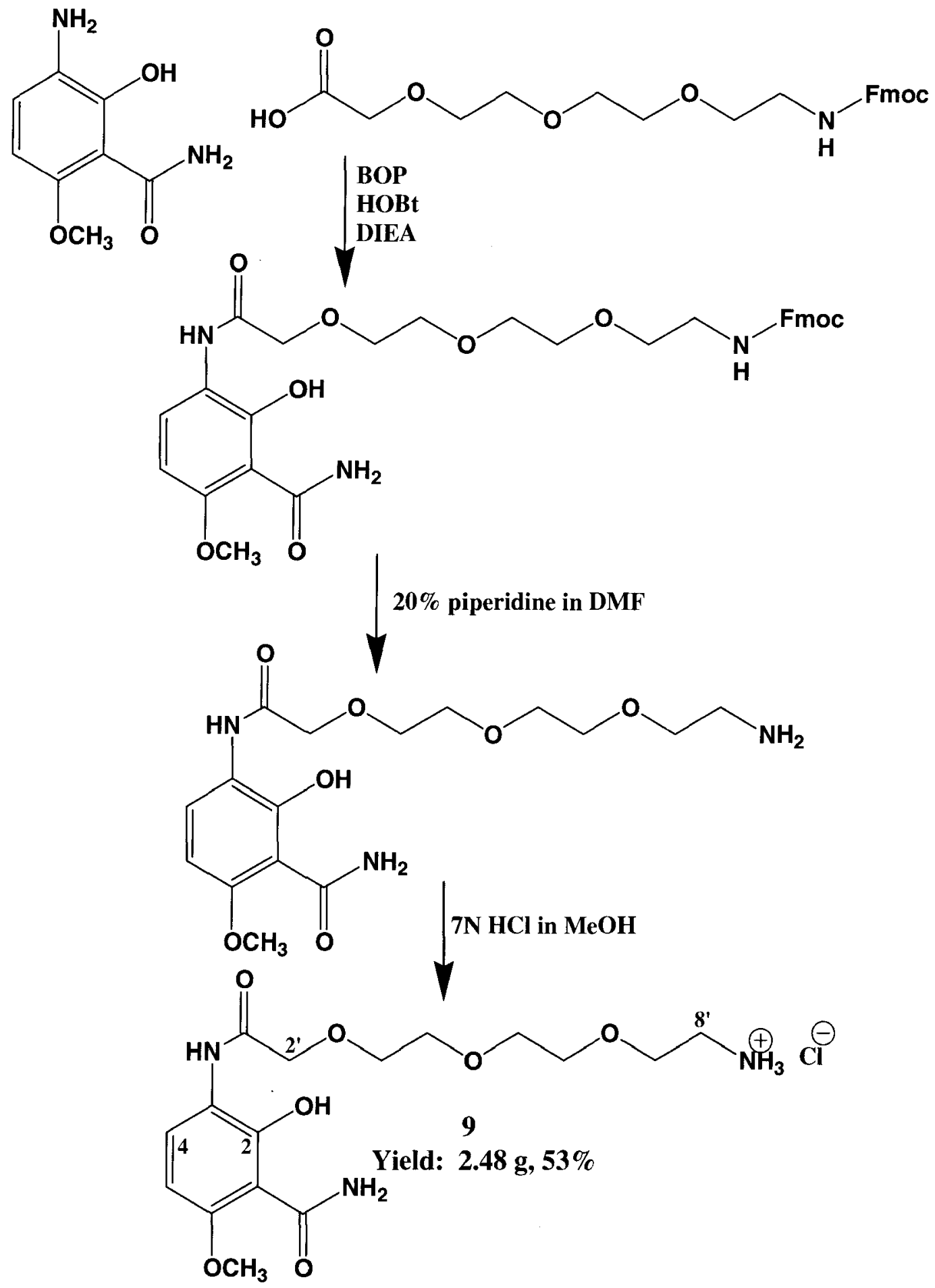

Scheme 4: a. Coupling of bone-targeting agent (2-hydroxy-6-methoxy-3-amino-benzamide) to Fmoc-11amino-3,6,9-trioxaundecanoic acid. b. Fmoc-Deprotection/Formation of $\mathrm{HCl}$ salt 9 


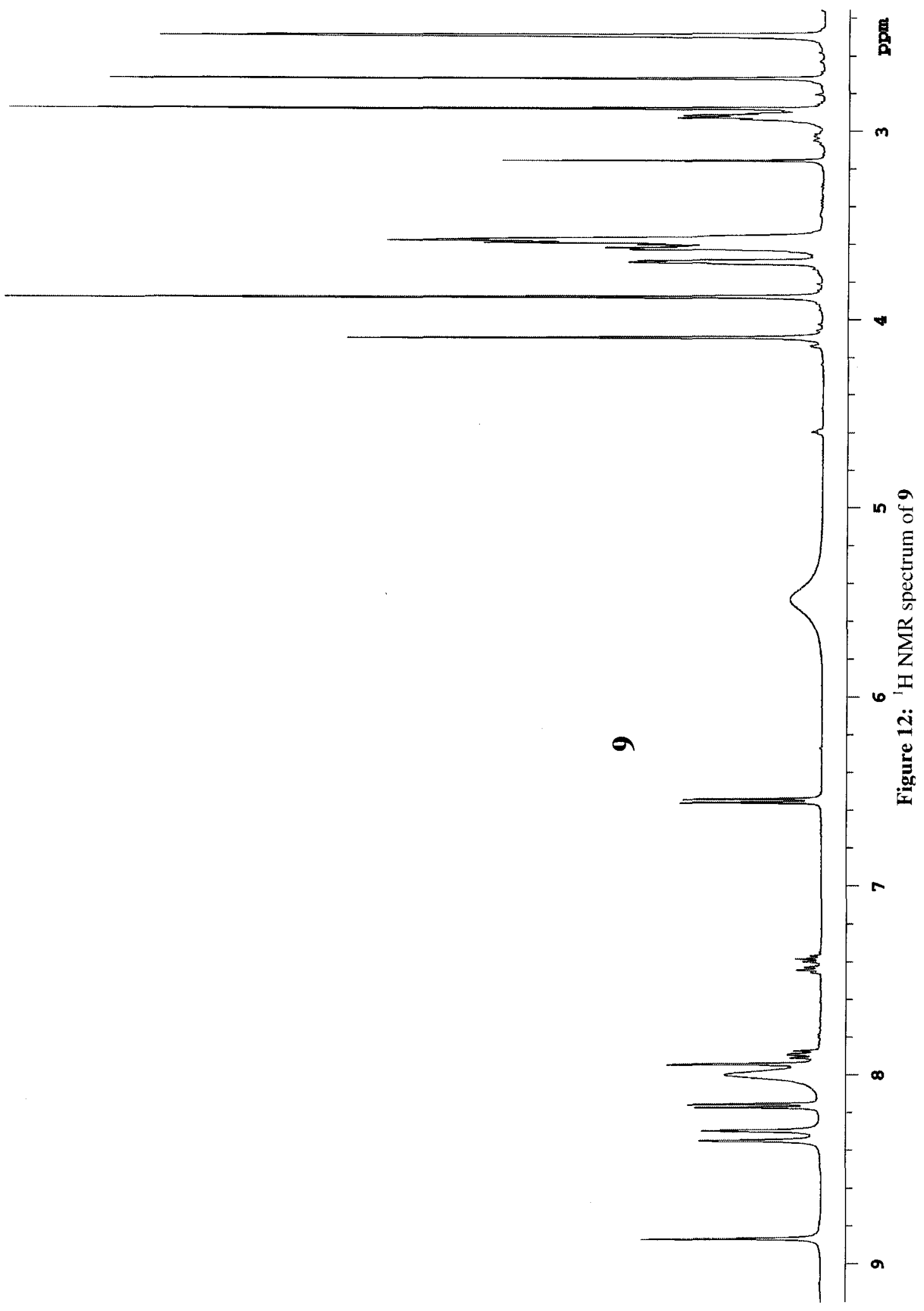




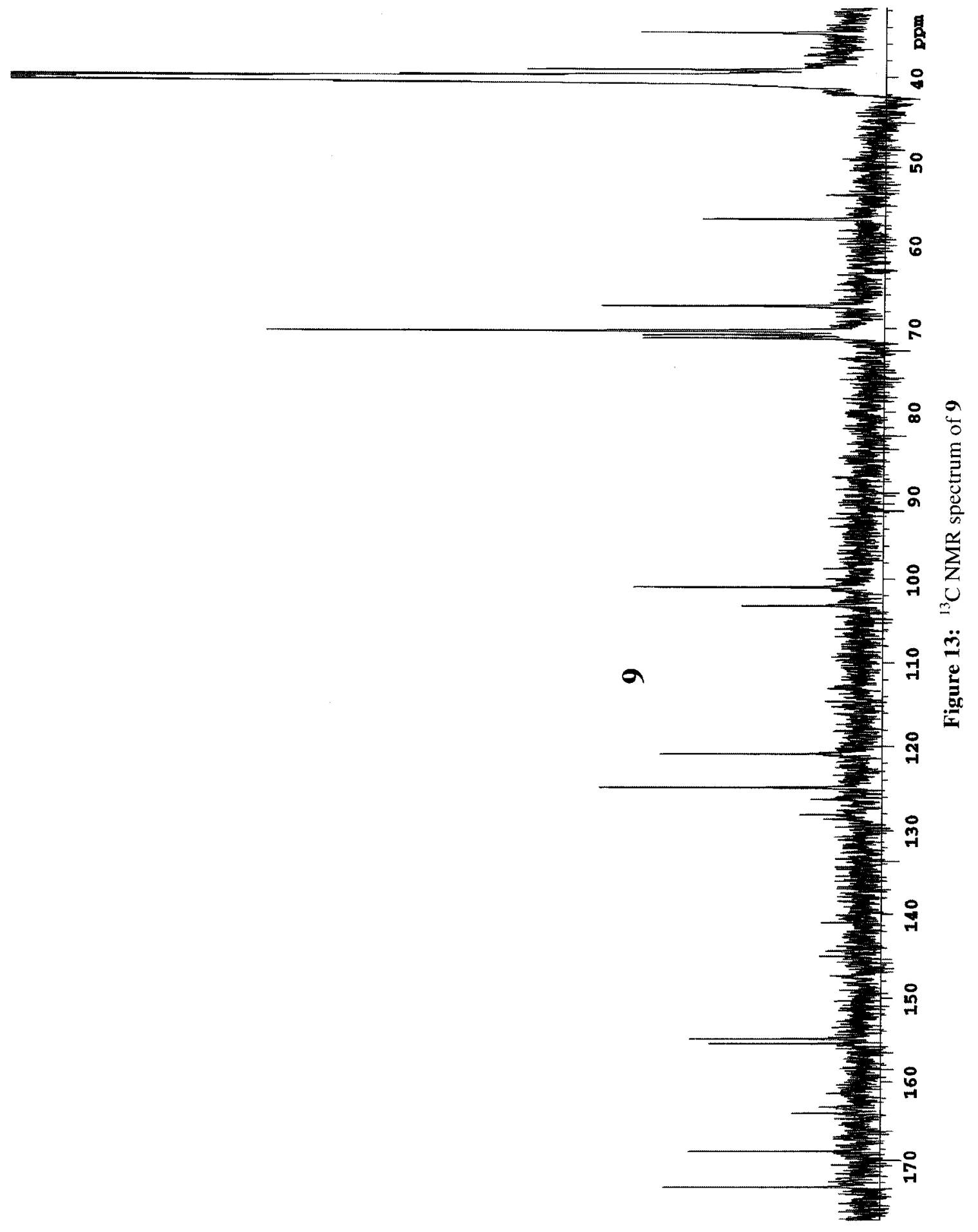




\section{Coupling of Fmoc-mini-PEG to Bone-Targeting Agent 3-amino-6-benzyloxy-2-}

hydroxybenzamide hydrochloride: 4-(1-(9H-fluoren-9-yl)-3-oxo-2,7,10-trioxa-4azadodecanamido)-2-carbamoyl-3-hydroxyphenyl benzoate (10, Scheme 5)

In a $200 \mathrm{~mL}$ round-bottom flask were dissolved Fmoc-mini-PEG (5.00g, (13 mmol), 3-amino-6-benzyloxy-2-hydroxybenzamide hydrochloride (from Ricerca Biosciences, Concord, OH; $2.95 \mathrm{~g}, 10 \mathrm{mmol}), \mathrm{HOBt}(3.51 \mathrm{~g}, 26 \mathrm{mmol}), \mathrm{BOP}(11.5 \mathrm{~g}, 26 \mathrm{mmol})$, and DIEA (4.53 mL, $26 \mathrm{mmol})$, in DMF (70 mL). The homogeneous solution was allowed to stir at room temperature overnight. The DMF was removed under vacuum after $\sim 22$ hours to give a dark brown oil. The oil was dissolved in $100 \mathrm{~mL}$ EtOAc and washed with brine $2 \mathrm{X}, 5 \% \mathrm{HCl} 2 \mathrm{X}$, and saturated $\mathrm{NaHCO}_{3} 2 \mathrm{X}$, then dried over sodium sulfate and concentrated via rotary evaporation to give a sticky brown residue. The residue was taken up in methanol and triturated. An off-white precipitate (10) was collected and washed with $\mathrm{MeOH}$ via vacuum filtration. Yield $\approx \mathbf{4 . 6 7 g}, \mathbf{7 0} \%$. ${ }^{1} \mathrm{H}(500 \mathrm{mHz}$, DMSO$\left.\mathrm{d}_{6}\right): \delta 3.15, \mathrm{t}, \mathrm{J} 5.50 \mathrm{~Hz}, 2 \mathrm{H}, 6^{\prime} \mathrm{CH}_{2} ; \delta 3.44$, t, J $5.73 \mathrm{~Hz}, 2 \mathrm{H}, 5^{\prime} \mathrm{CH}_{2} ; \delta 3.59$, br s, $2 \mathrm{H}, 4$ ' $\mathrm{CH}_{2} ; \delta 3.67$, br s, $2 \mathrm{H}, 3^{\prime} \mathrm{CH}_{2} ; \delta 4.19$, t, J $6.71 \mathrm{~Hz}, 1$ H, C9' H; $\delta 4.27$, d, J $6.83 \mathrm{~Hz}, 2 \mathrm{H}, 2^{\prime}$ ' $\mathrm{CH}_{2} ; \delta 5.27, \mathrm{~s}, 2 \mathrm{H}, \mathrm{C} 6 \mathrm{CH}_{2}$ (benzyl); $\delta 6.64$, d, J $8.78 \mathrm{H}, 1 \mathrm{H}, \mathrm{C} 5 \mathrm{H} ; \delta 7.31, \mathrm{~m}, 3 \mathrm{H}, \mathrm{C} 14$ ' H/benzyl $H_{c} ; \delta 7.36$, d, J 7.32 Hz, 1 H, 6' amide H; $\delta 7.40$, m, 4 H, C12' H/benzyl $H_{b}$; $\delta 7.48$, d, J $7.20 \mathrm{~Hz}, 2 \mathrm{H}$, benzyl Ha $\mathrm{H}_{\mathrm{a}} \delta 7.67$, d, J $7.20 \mathrm{~Hz}, 2 \mathrm{H}, \mathrm{C} 13$ ' H; $\delta 7.87$, d, J $7.69 \mathrm{~Hz}$, $2 \mathrm{H}, \mathrm{C} 11^{\prime}$ H; $\delta 8.13 \mathrm{~Hz}, \mathrm{~d}, \mathrm{~J} 4.52 \mathrm{~Hz}, 1 \mathrm{H}, \mathrm{C} 4 \mathrm{H} ; \delta 8.19, \mathrm{~s}, 1 \mathrm{H}, \mathrm{Cl}$ amide $\mathrm{H} ; \delta 8.36, \mathrm{~s}, 1 \mathrm{H}$, $\mathrm{C} 1$ amide $\mathrm{H} ; \delta 8.86, \mathrm{~s}, 1 \mathrm{H}, \mathrm{C} 3$ amide $\mathrm{H}$. 


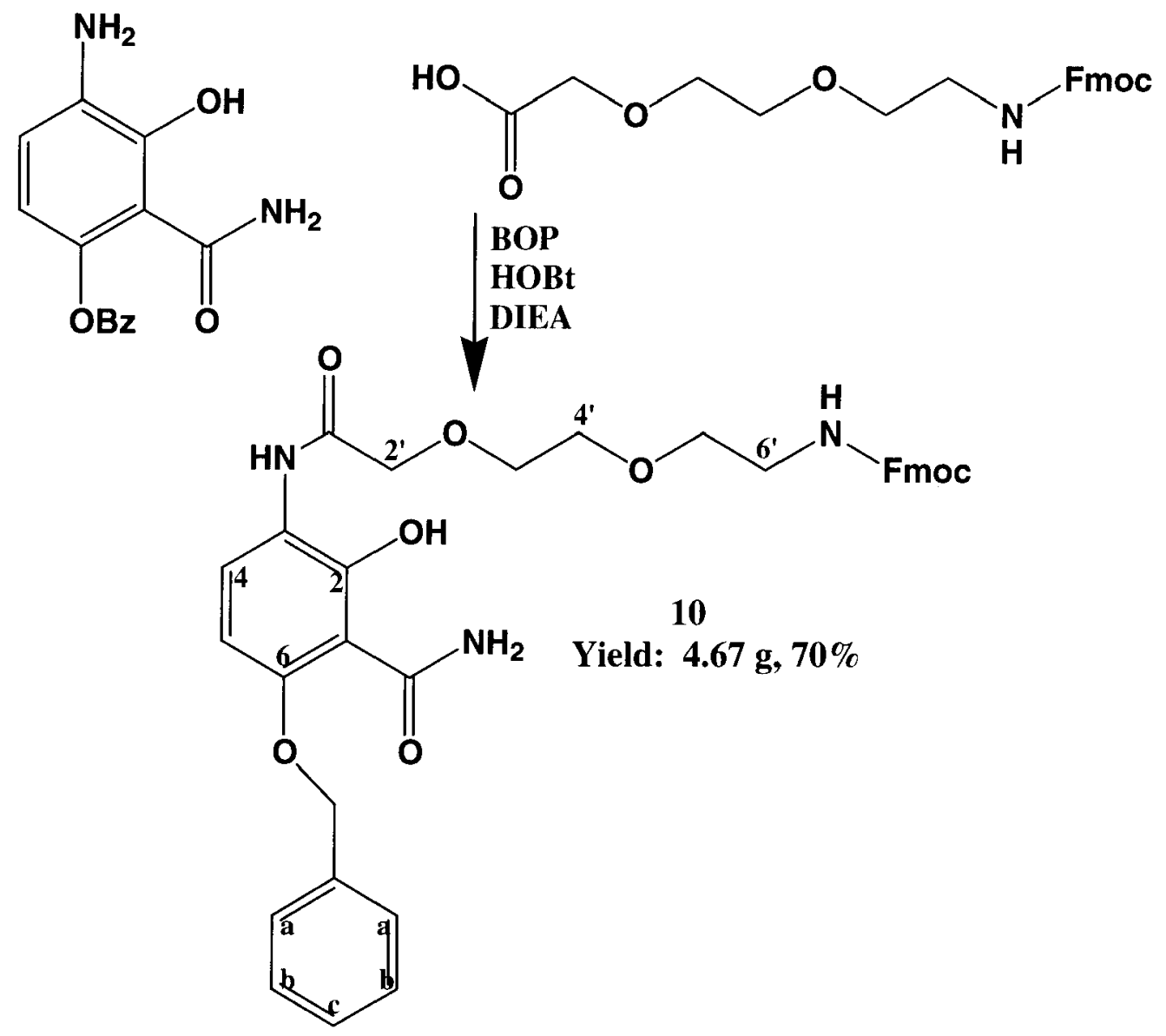

Scheme 5: Coupling of Fmoc-mini-PEG to Bone-Targeting Agent 2-hydroxy-6-benzyloxy-3-aminobenzamide hydrochloride. 


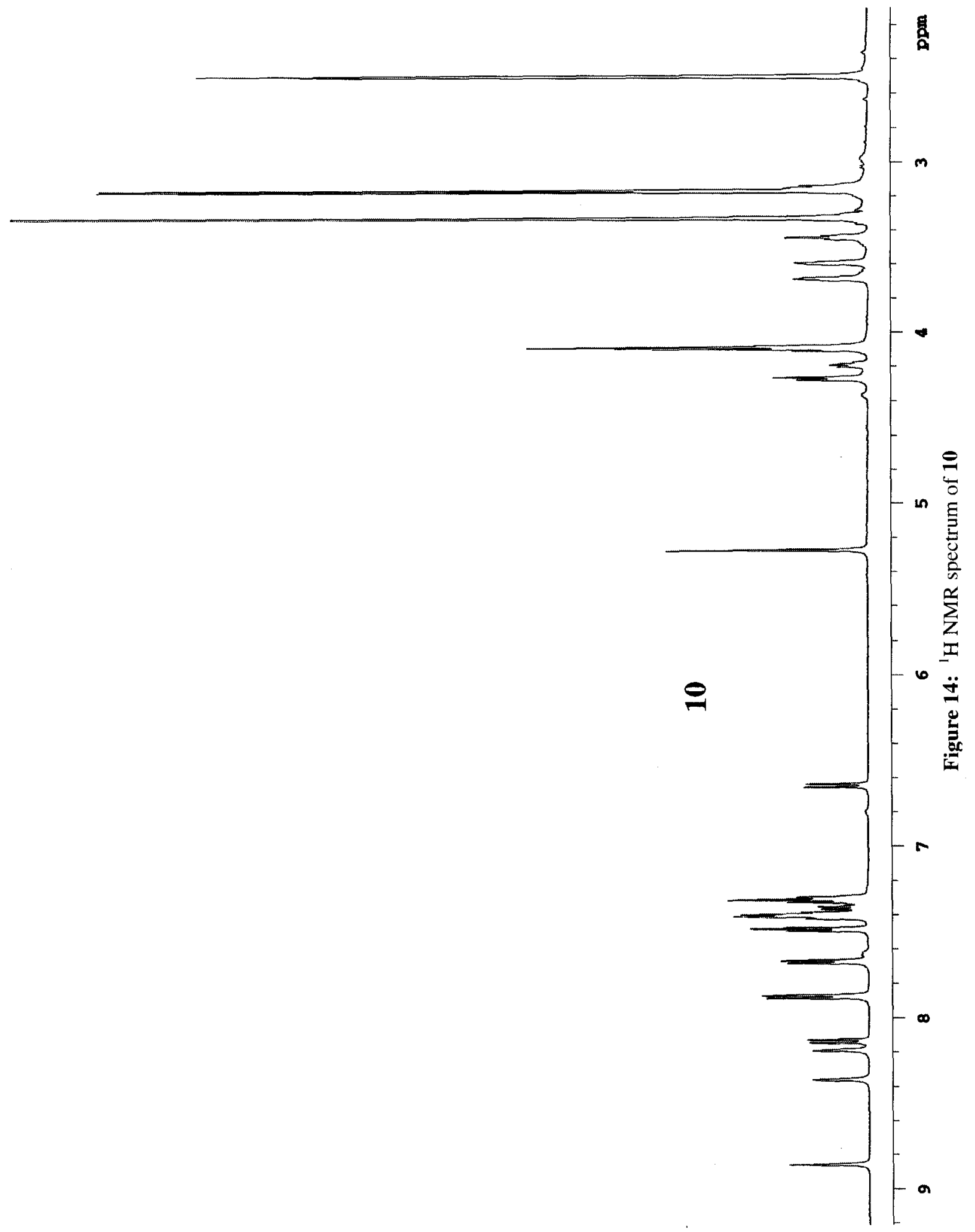


6. Deprotection of 4/Formation of HCl Salt: 2-(2-(2-(4-(benzoyloxy)-3-carbamoyl-2hydroxyphenylamino)-2-oxoethoxy)ethoxy)ethanaminium chloride (11, Scheme 6)

Compound 10 ( $2.50 \mathrm{~g}, 3.8 \mathrm{mmol})$ was dissolved and stirred in $\sim 20 \mathrm{~mL}$ of $20 \%$ piperidine in DMF for 20 minutes before the solvent was removed under vacuum. The piperdine treatment and solvent removal were repeated twice more. After the final solvent removal, the mixture was taken up in ether and acidified with $7 \mathrm{~N} \mathrm{HCl}$ in $\mathrm{MeOH}$. A white precipitate was collected via filtration, however the solid proved to be the Fmoc hydrocarbon. The remaining filtrate was concentrated and taken up in a small amount of methanol. It was then allowed to sit in $\mathrm{MeOH}$ at $4{ }^{\circ} \mathrm{C}$ for 48 hours. A solid/oil mixture resulted. The mixture was dried under vacuum for 1 hour, taken up in ether, then briefly exposed to dry ice-acetone bath and triturated. After some 10 minutes, a light purple precipitate was noted. This solid was collected via vacuum filtration and then recrystallized from methanol/ether to give off-white solid, $\mathbf{1 1}$. Yield: $\mathbf{7 4 0} \mathbf{~ m g , ~ 5 7 \%} .^{1} \mathrm{H}$ (500 mHz, DMSO-d ${ }_{6}$ ): $\delta 2.94$, t, J 5.37 Hz, 2 H, 6' $\mathrm{CH}_{2} ; \delta 3.63, \mathrm{~m}, 4$ H, 4'/5' $\mathrm{CH}_{2} ; \delta 3.71$, m, 3' $\mathrm{CH}_{2} ; \delta^{\prime} 4.11$, s, $2 \mathrm{H}, 2^{\prime} \mathrm{CH}_{2} ; \delta 5.29$, s, $2 \mathrm{H}$, benzyl $\mathrm{CH}_{2} ; \delta 6.65$, d, J $9.15 \mathrm{~Hz}, 1 \mathrm{H}, \mathrm{C} 5$ H; $\delta 7.36$, d, J $7.20 \mathrm{~Hz}, 1 \mathrm{H}$, benzyl $\mathrm{H}_{\mathrm{c}} ; \delta 7.41$, t, J $7.44 \mathrm{~Hz}, 2 \mathrm{H}$, benzyl $\mathrm{H}_{\mathrm{b}} ; \delta 7.49$, d, J $7.69 \mathrm{~Hz}, 2 \mathrm{H}$, benzyl $\mathrm{H}_{\mathrm{a}}$; $\delta 8.12$, d, J $9.03 \mathrm{~Hz}, 1 \mathrm{H}, \mathrm{C} 4 \mathrm{H} ; \delta 8.20, \mathrm{~s}, 1 \mathrm{H}, \mathrm{C} 1$ amide H; $\delta 8.37, \mathrm{~s}, 1 \mathrm{H}, \mathrm{C} 1$ amide $\mathrm{H} ; \delta 8.88, \mathrm{~s}, 1 \mathrm{H}, \mathrm{C} 3$ amide $\mathrm{H} .{ }^{13} \mathrm{C}\left(500 \mathrm{mHz}\right.$, DMSO-d $\left.\mathrm{d}_{6}\right)$ : $\delta 39.18, \mathrm{C}^{\prime} ; \delta 67.61, \mathrm{C}^{\prime} ; \delta 70.16, \mathrm{CH}_{2} ; \delta 70.78, \mathrm{CH}_{2} ; \delta 70.98, \mathrm{CH}_{2} ; \delta 71.08, \mathrm{CH}_{2} ; \delta 102.63$, C5; $\delta 103.82, \mathrm{qC} ; \delta 121.09, \mathrm{qC} ; \delta 124.82, \mathrm{C} 4 ; \delta 128.68$, benzylic C; $\delta 128.99$, benzylic $\mathrm{C}_{\mathrm{c}}$; $\delta 129.36$, benzylic C; $\delta 136.84, \mathrm{qC} ; \delta 154.21, \mathrm{qC} ; \delta 154.90, \mathrm{qC} ; \delta 168.28, \mathrm{qC} ; \delta 172.52$, qC. Mass calculated: 403.1743; Mass found: $403.1738, \Delta=-1.30 \mathrm{ppm}$. 


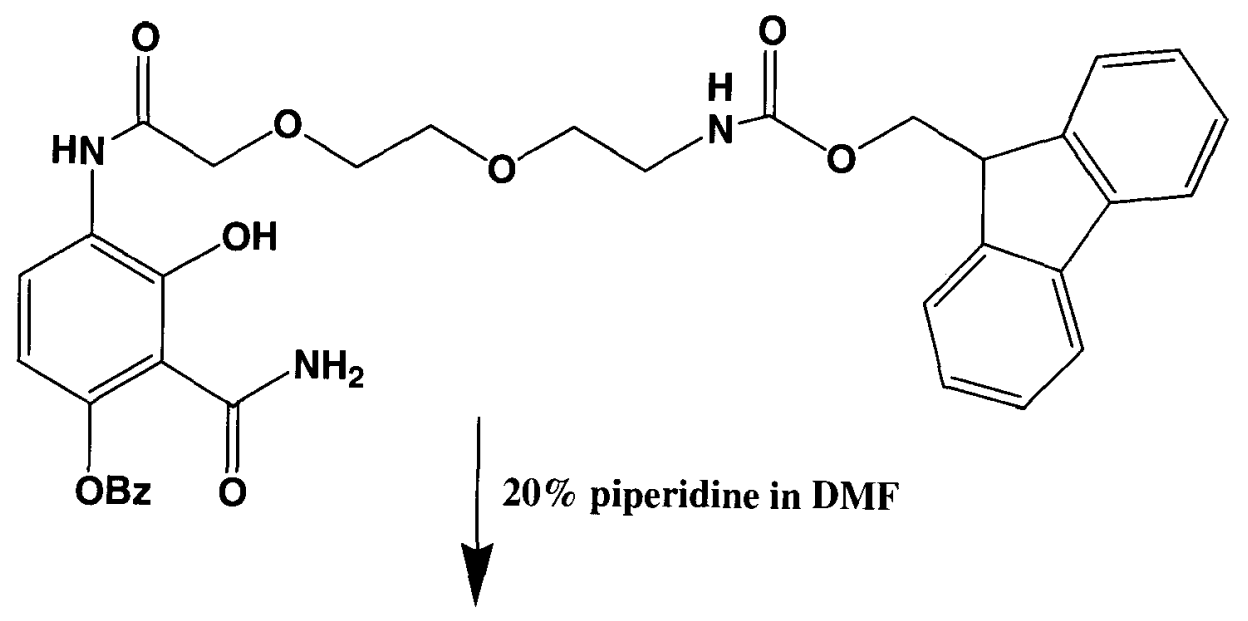<smiles>CC(C)(C)Oc1ccc(NC(=O)COCCOCCN)c(O)c1C(N)=O</smiles>

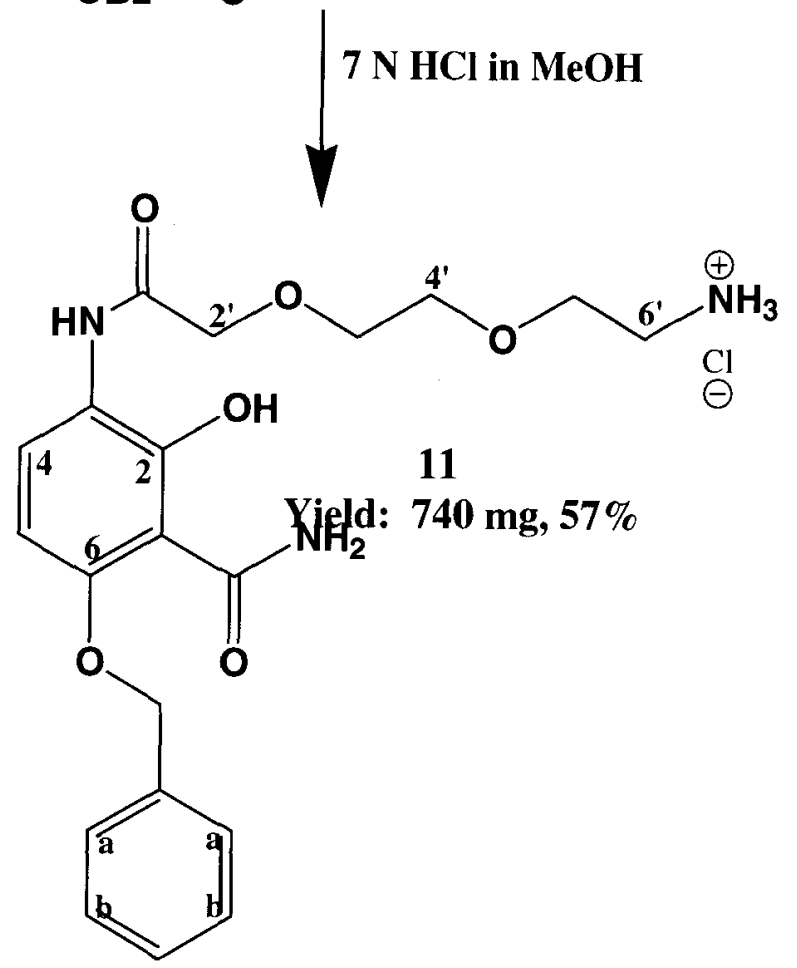

Scheme 6: Deprotection of 10/Formation of HCl Salt 11 


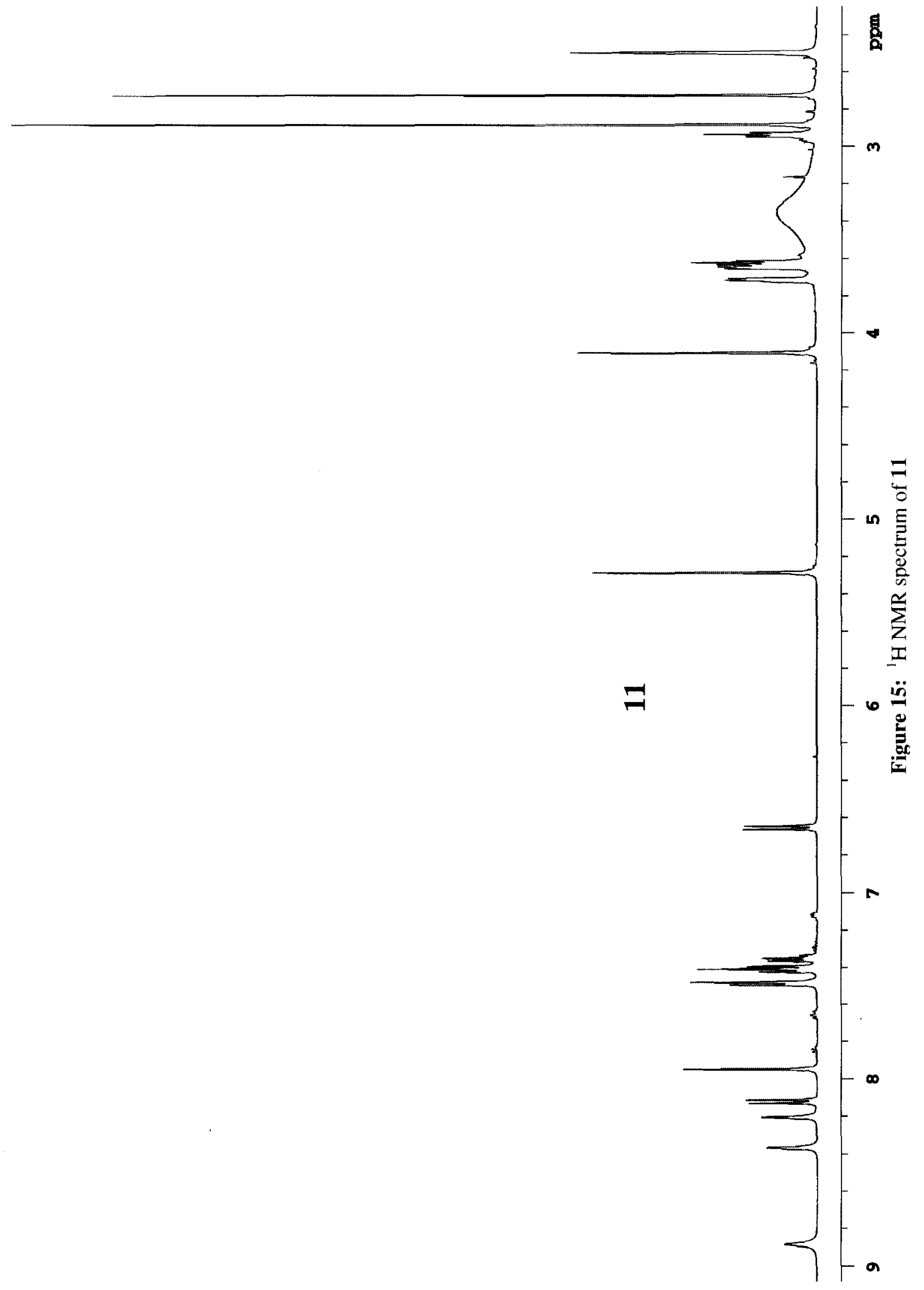




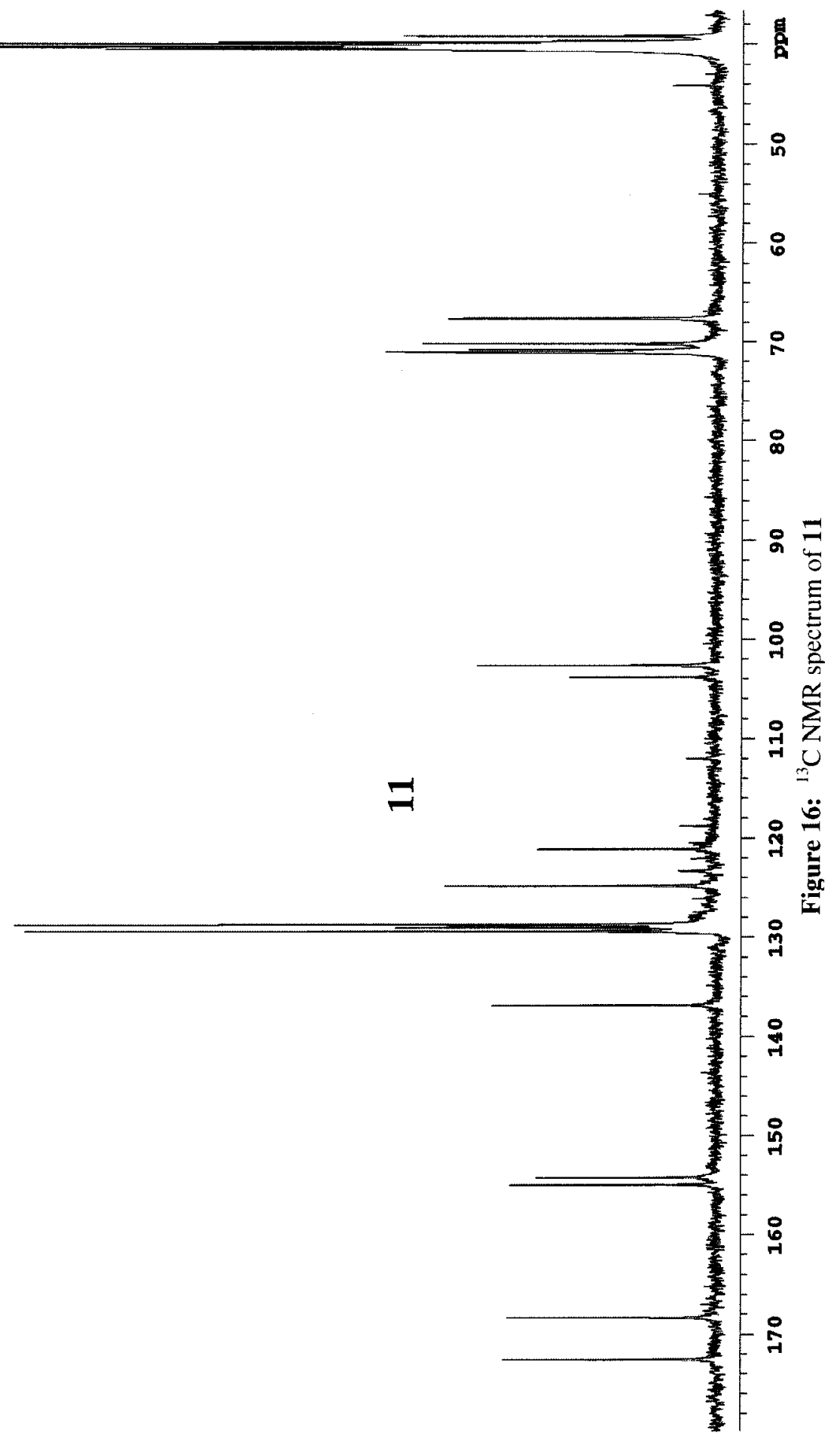


7. Coupling of $\beta$-estro-O-propanoic acid to 8: 2-hydroxy-3-(2-(2-(2-(3-((17R)-3hydroxy-13-methyl-7,8,9,11,12,13,14,15,16,17-decahydro-6H-cyclopenta[a]phenanthren17-yloxy)propanamido)ethoxy)ethoxy)acetamido)-6-methoxybenzamide (12, Scheme 7) In a round-bottom flask were combined the following: $17-\beta$-estro-O-propanoic acid (0.48 g, $1.4 \mathrm{mmol}$ ), HOBt (0.38 g, $2.8 \mathrm{mmol})$, BOP (1.24g, $2.8 \mathrm{mmol}$ ), and 8 (see scheme 3; $0.5 \mathrm{~g}, 1.4 \mathrm{mmol})$. The dry mixture was dissolved in DMF (20 mL) then DIEA (488 $\mu \mathrm{L}, 2.8 \mathrm{mmol}$ ) was added. The reaction was allowed to stir at room temperature for $\sim 48$ hours.

The reaction solvent was removed under vacuum and the resulting yellow oil was taken up in $\sim 50 \mathrm{~mL}$ ethylacetate (EtOAc). It was then washed with brine $2 \mathrm{X}, 5 \% \mathrm{HCl}$ $2 \mathrm{X}$, and saturated sodium bicarbonate $2 \mathrm{X}$ and dried over sodium sulfate. After gravity filtration, the filtrate was condensed via rotary evaporation to yield a sticky oil. Upon trituration of the oil in cold methanol, product 12 precipitated out as an off-white solid. The product was collected via vacuum filtration. Yield: $\mathbf{5 1 0} \mathbf{~ m g , ~ 5 6 \% . ~}{ }^{1} \mathrm{H}(500 \mathrm{mHz}$, DMSO-d $\left.\mathrm{d}_{6}\right): \delta 0.66, \mathrm{~s}, 3 \mathrm{H}$, angular methyl; $\delta 1.10, \mathrm{~m} ; \delta 1.16-1.32, \mathrm{~m} ; \delta 1.35, \mathrm{~m} ; \delta 1.55, \mathrm{~m}$; $\delta 1.73, \mathrm{~m} ; \delta 1.86-1.97, \mathrm{~m} ; \delta 2.04, \mathrm{t} ; \delta 2.19, \mathrm{~d} ; \delta 2.27, \mathrm{t}, \mathrm{J} 6.47 \mathrm{~Hz}, 2 \mathrm{H}, 8^{\prime} \mathrm{CH}_{2} ; \delta 2.68, \mathrm{~m}, 2$ H; $\delta 3.21$, q, J 5.61 Hz, 2 H, 6' $\mathrm{CH}_{2} ; \delta 3.44$, t, J $5.86 \mathrm{~Hz}, 2$ H, 5' $\mathrm{CH}_{2} ; \delta 3.55, \mathrm{~m}, 1 \mathrm{H}, \mathrm{C} 9^{\prime}$ $\mathrm{H}_{1} ; \delta 3.60, \mathrm{~m}, 2 \mathrm{H}, 4^{\prime} \mathrm{CH}_{2} ; \delta 3.69, \mathrm{~m}, 2 \mathrm{H}, 3^{\prime} \mathrm{CH}_{2} ; \delta 3.63, \mathrm{~m}, 1 \mathrm{H}, \mathrm{C}^{\prime} \mathrm{H}_{2} ; \delta 3.87, \mathrm{~s}, 3 \mathrm{H}$, $\mathrm{C} 6 \mathrm{OCH}_{3} ; \delta 4.09, \mathrm{~s}, 2 \mathrm{H}, 2^{\prime} \mathrm{CH}_{2} ; \delta 6.42$, br s, 1 H, C18' H; $\delta 6.49$, dd, J $18.54 \mathrm{~Hz}, \mathrm{~J}_{2} 2.20$ Hz, 1 H, C20’ H; $\delta 6.54$, d, J 9.03 Hz, 1 H, C5 H; 87.01 , J 8.54 Hz, 1 H, C21' H; $\delta 7.81$, t, J $5.61 \mathrm{~Hz}, 1$ H, C6' amide H; $\delta 8.19$, d, J $9.03 \mathrm{~Hz}, 1$ H, C4 H; $\delta 8.29$, s, 1 H, C1 amide H; 88.33, s, $1 \mathrm{H}, \mathrm{C} 1$ amide $\mathrm{H} ; \delta 8.85$, s, $1 \mathrm{H}, \mathrm{C} 3$ amide $\mathrm{H} ; \delta 8.96, \mathrm{~s}, 1 \mathrm{H}, \mathrm{C} 19^{\prime} \mathrm{OH} .{ }^{13} \mathrm{C}$ :

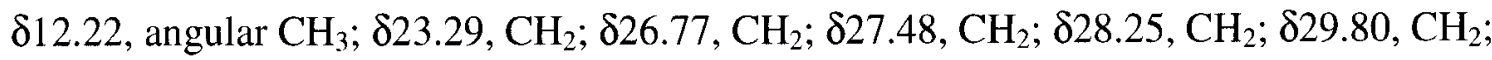




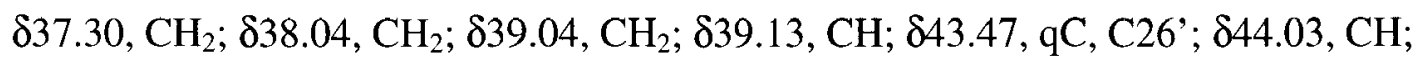
$\delta 56.80, \mathrm{C} 6 \mathrm{OCH}_{3} ; \delta 66.49, \mathrm{CH}_{2} ; \delta 69.94, \mathrm{CH}_{2} ; \delta 70.05, \mathrm{CH}_{2} ; \delta 70.78, \mathrm{CH}_{2} ; \delta 71.14, \mathrm{CH}_{2}$; $\delta 88.87, \mathrm{CH} ; \delta 100.89, \mathrm{CH} ; \delta 103.15, \mathrm{qC} ; \delta 113.40, \mathrm{CH} ; \delta 115.59, \mathrm{CH} ; \delta 120.92, \mathrm{qC}$; $\delta 124.69, \mathrm{CH} ; \delta 126.75, \mathrm{CH} ; \delta 130.97, \mathrm{qC} ; \delta 137.78, \mathrm{qC} ; \delta 154.84, \mathrm{qC} ; \delta 155.39, \mathrm{qC}$; $\delta 155.55, \mathrm{qC} ; \delta 168.17, \mathrm{qC} ; \delta 171.00, \mathrm{qC} ; \delta 172.56, \mathrm{qC}$. Mass calculated: $653.3312 ;$ Mass found: $653.3313, \Delta=0.11 \mathrm{ppm}$. 


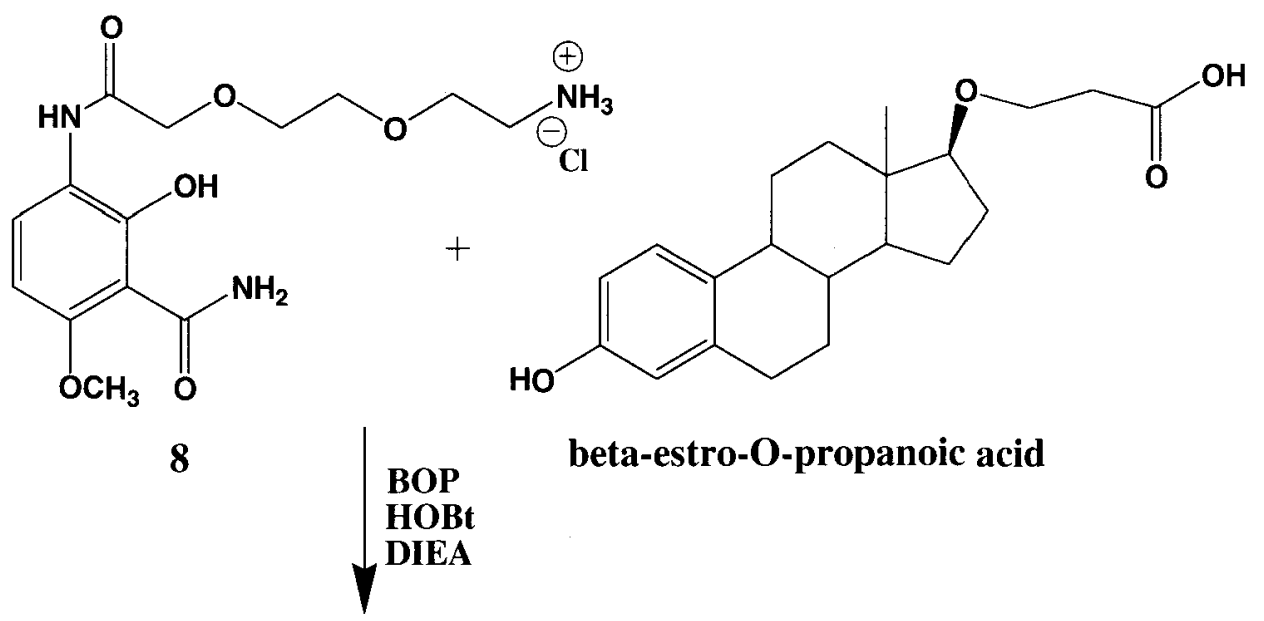<smiles>COc1ccc(NC(=O)COCCOCCNC(=O)CCO[C@H]2CC[C@H]3C4CCc5cc(O)ccc5C4C=C[C@@]23C)c(O)c1C(N)=O</smiles>

Scheme 7: Coupling of $\beta$-estro-O-propanoic acid to 8 . 


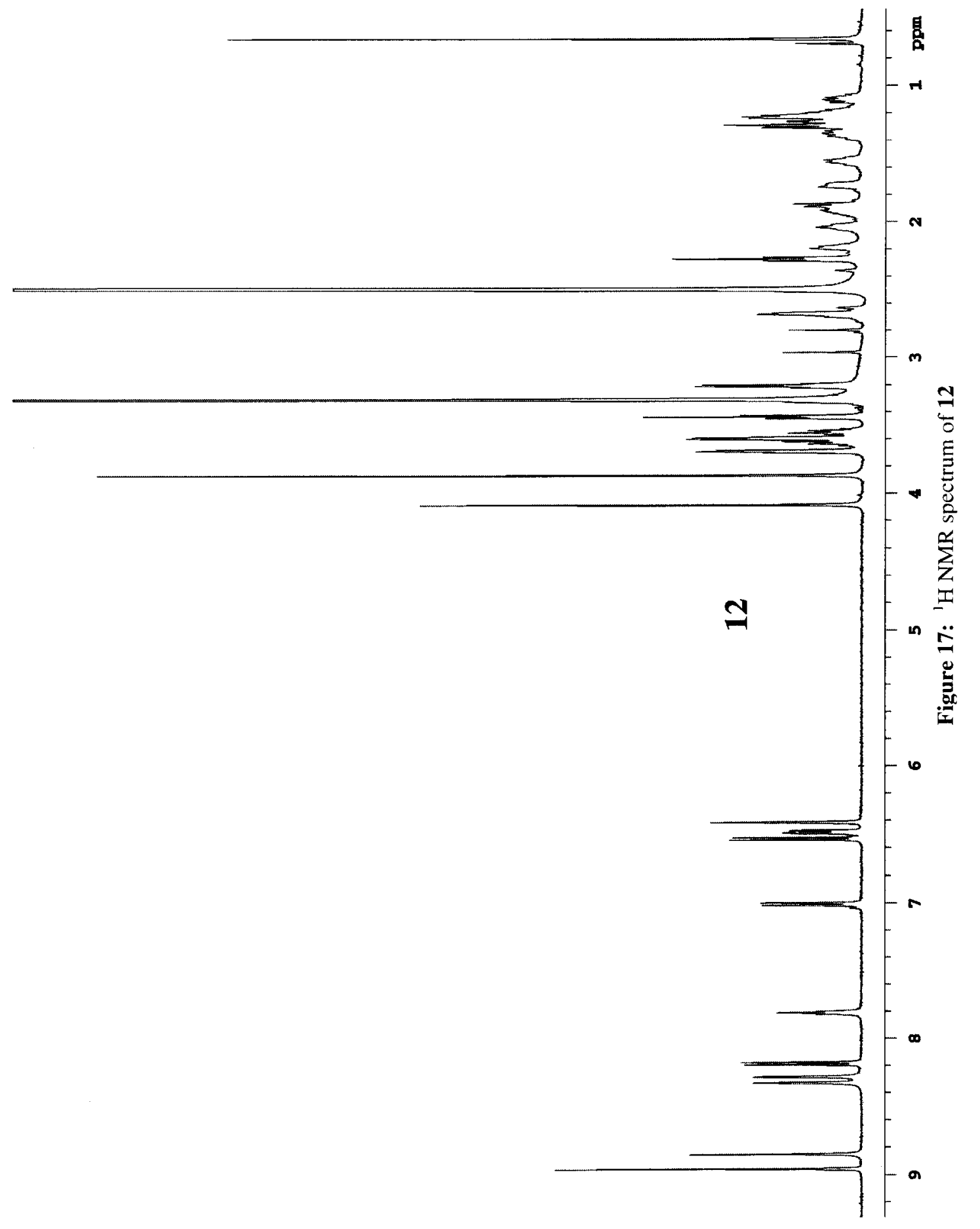




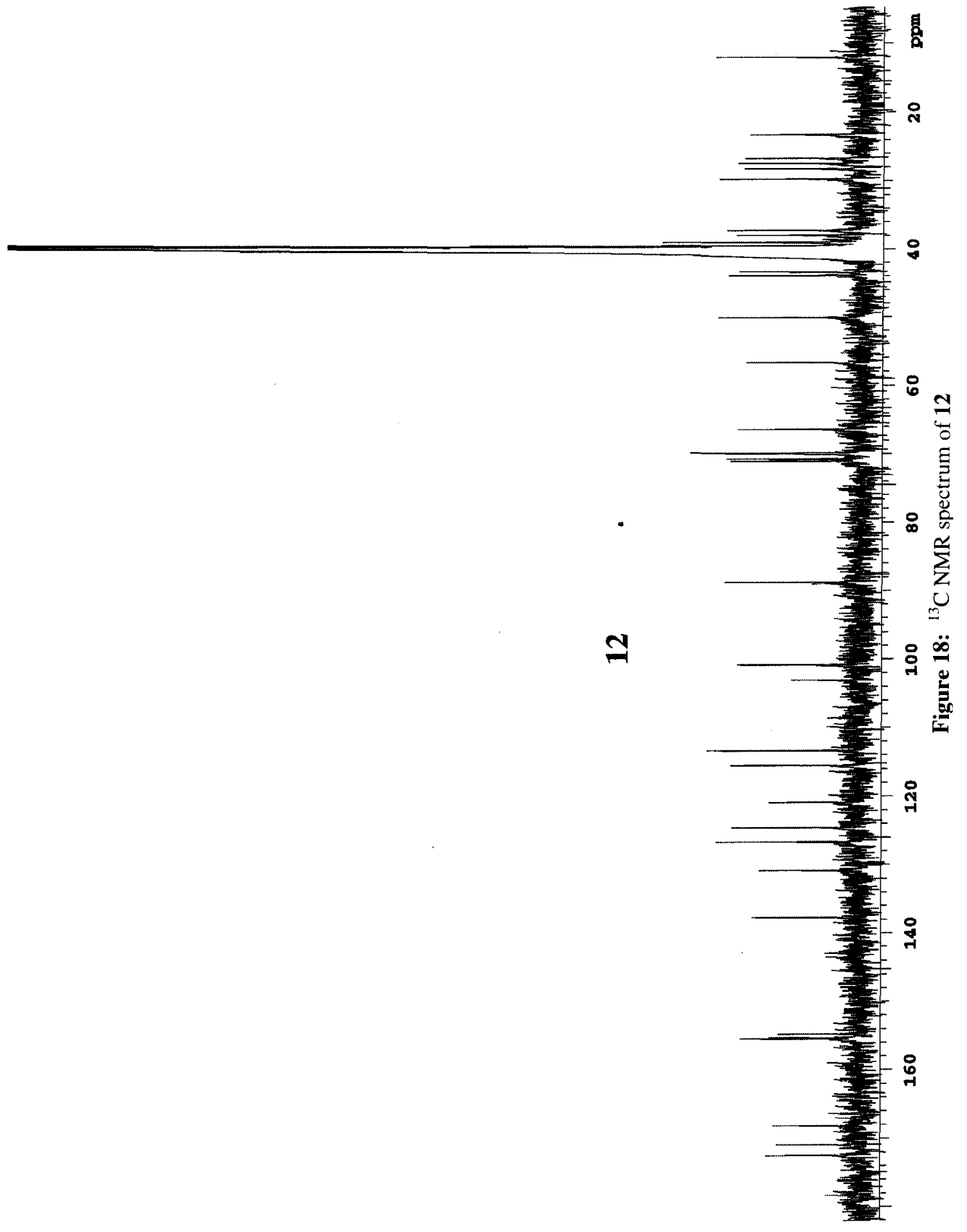




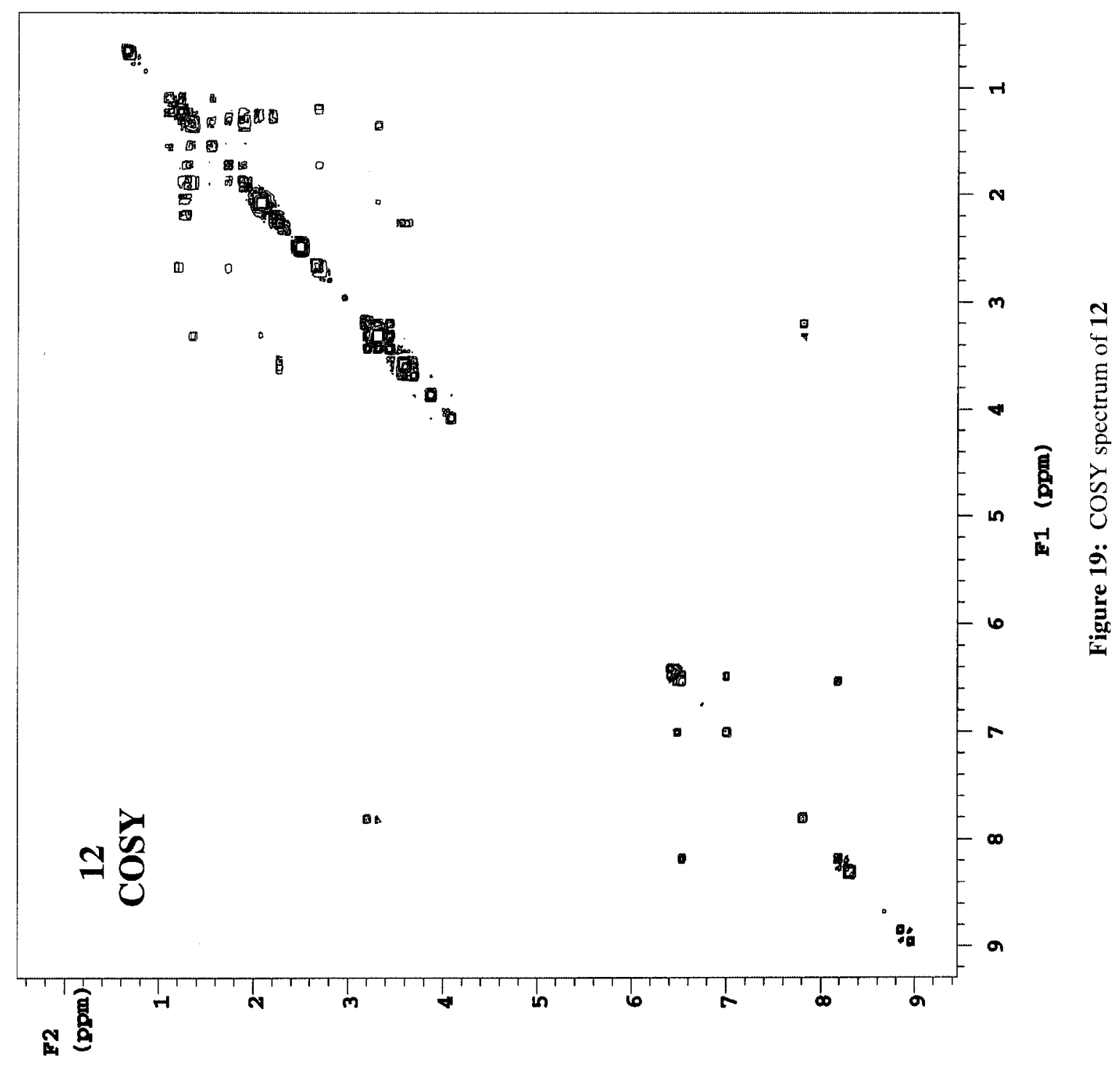


8. Isolation of BTA-MP3-steroid: 2-hydroxy-3-(15-((17R)-3-hydroxy-13-methyl-

7,8,9,11,12,13,14,15,16,17-decahydro-6H-cyclopenta[a]phenanthren-17-yloxy)-13-oxo3,6,9-trioxa-12-azapentadecanamido)-6-methoxybenzamide (13)

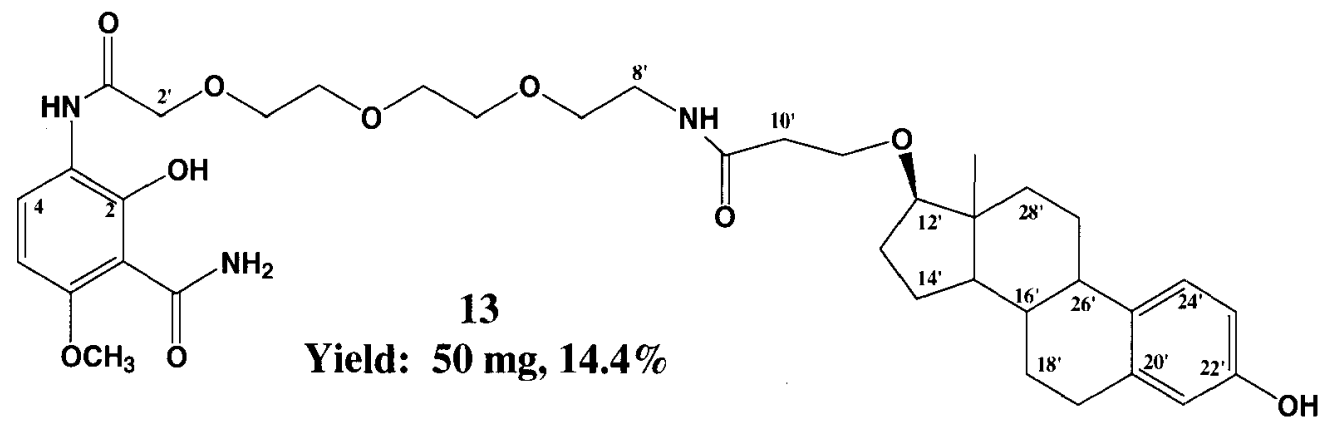

The crude estradiol conjugate was formed as described in 6 using $0.5 \mathrm{mmol}(348 \mathrm{mg})$ of 8, 17- $\beta$-estro-O-propanoic acid ( $175 \mathrm{mg}, 0.5 \mathrm{mmol}), \mathrm{HOBt}$ ( $68 \mathrm{mg}, 0.5 \mathrm{mmol})$, BOP (221 mg, $0.5 \mathrm{mmol})$, and DIEA ( $131 \mu \mathrm{L}, 0.8 \mathrm{mmol})$. The product was oily, but after sitting in hexane at $4^{\circ} \mathrm{C}$ for some 8 weeks, a light gray precipitate could be collected via vacuum filtration. This solid, $\mathbf{1 3}$, was subjected to thin-layer chromatography and ${ }^{1} \mathrm{H}$ NMR for characterization. Yield $\approx \mathbf{5 0} \mathbf{~ m g}, \mathbf{1 4 . 4 \%} .{ }^{\mathrm{I}} \mathrm{H}\left(500 \mathrm{mHz}, \mathrm{DMSO}-\mathrm{d}_{6}\right): \delta 0.66, \mathrm{~s}$, $3 \mathrm{H}$, angular $\mathrm{CH}_{3} ; \delta 1.12, \mathrm{~m} ; \delta 1.16-1.33, \mathrm{~m} ; \delta 1.35, \mathrm{~m} ; \delta 1.57, \mathrm{~m} ; \delta 1.74, \mathrm{~m} ; \delta 1.86-1.99, \mathrm{~m}$; $\delta 2.05, \mathrm{t} ; \delta 2.21, \mathrm{~m} ; \delta 2.28, \mathrm{t}, \mathrm{J} 6.22 \mathrm{~Hz}, 2 \mathrm{H}, 10^{\prime} \mathrm{CH}_{2} ; \delta 2.68, \mathrm{~m} ; \delta 3.17, \mathrm{~m}, 2 \mathrm{H}, 8^{\prime} \mathrm{CH}_{2}$; $\delta 3.38, \mathrm{~m}, 2 \mathrm{H}, 7^{\prime} \mathrm{CH}_{2} ; \delta 3.50, \mathrm{~m}, 2 \mathrm{H}, 6^{\prime} \mathrm{CH}_{2} ; \delta 3.56, \mathrm{~m}, 3 \mathrm{H}, 5^{\prime} \mathrm{CH}_{2}, \mathrm{C}_{11}^{\prime} \mathrm{H}_{\mathrm{b}}{ }^{\prime} \delta 3.62, \mathrm{~m}$, $3 \mathrm{H}, 4^{\prime} \mathrm{CH}_{2}, \mathrm{C}_{1} 1^{\prime} \mathrm{H}_{\mathrm{a}} ; \delta 3.70, \mathrm{~m}, 2 \mathrm{H}, 3^{\prime} \mathrm{CH}_{2} ; \delta 3.87, \mathrm{~s}, 3 \mathrm{H}, \mathrm{C} 6 \mathrm{OCH}_{3} ; \delta 4.08, \mathrm{~s}, 2 \mathrm{H}, 2^{\prime}$ $\mathrm{CH}_{2} ; \delta 6.41, \mathrm{~s}, 1 \mathrm{H}, \mathrm{C} 21^{\prime} \mathrm{H} ; \delta 6.48, \mathrm{dd}, \mathrm{J}_{1} 8.42 \mathrm{~Hz}, \mathrm{~J}_{2} 2.56 \mathrm{~Hz}, 1 \mathrm{H}, \mathrm{C} 23{ }^{\prime} \mathrm{H} ; \delta 6.54$, d, J 9.15 Hz, 1H, C5 H; $\delta 7.02$, m, 1H, C24' H; $\delta 7.82$, t, J 5.12 Hz, 1H, C8' amide H; $\delta 8.18$, d, J $9.15 \mathrm{~Hz}, 1 \mathrm{H}, \mathrm{C} 4 \mathrm{H} ; \delta 8.29, \mathrm{~s}, 1 \mathrm{H}, \mathrm{Cl}$ amide $\mathrm{H} ; \delta 8.34, \mathrm{~s}, 1 \mathrm{H}, \mathrm{C} 1$ amide $\mathrm{H} ; \delta 8.85, \mathrm{~s}, 1 \mathrm{H}$, C3 amide H; 88.97 , s, 1H, C19’ OH. Mass calculated: 697.3574; Mass found: $697.3568, \Delta=-0.90 \mathrm{ppm}$. 


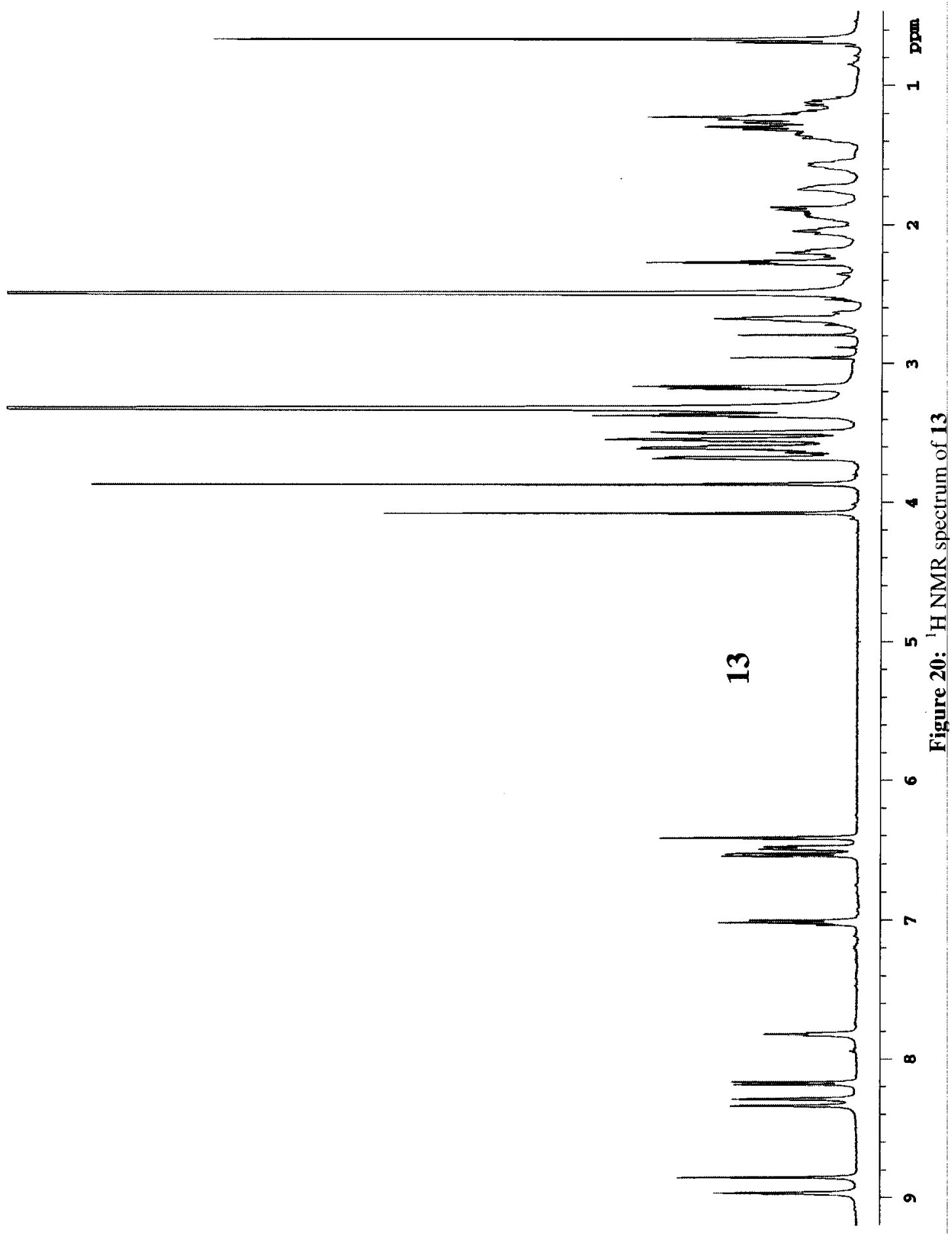




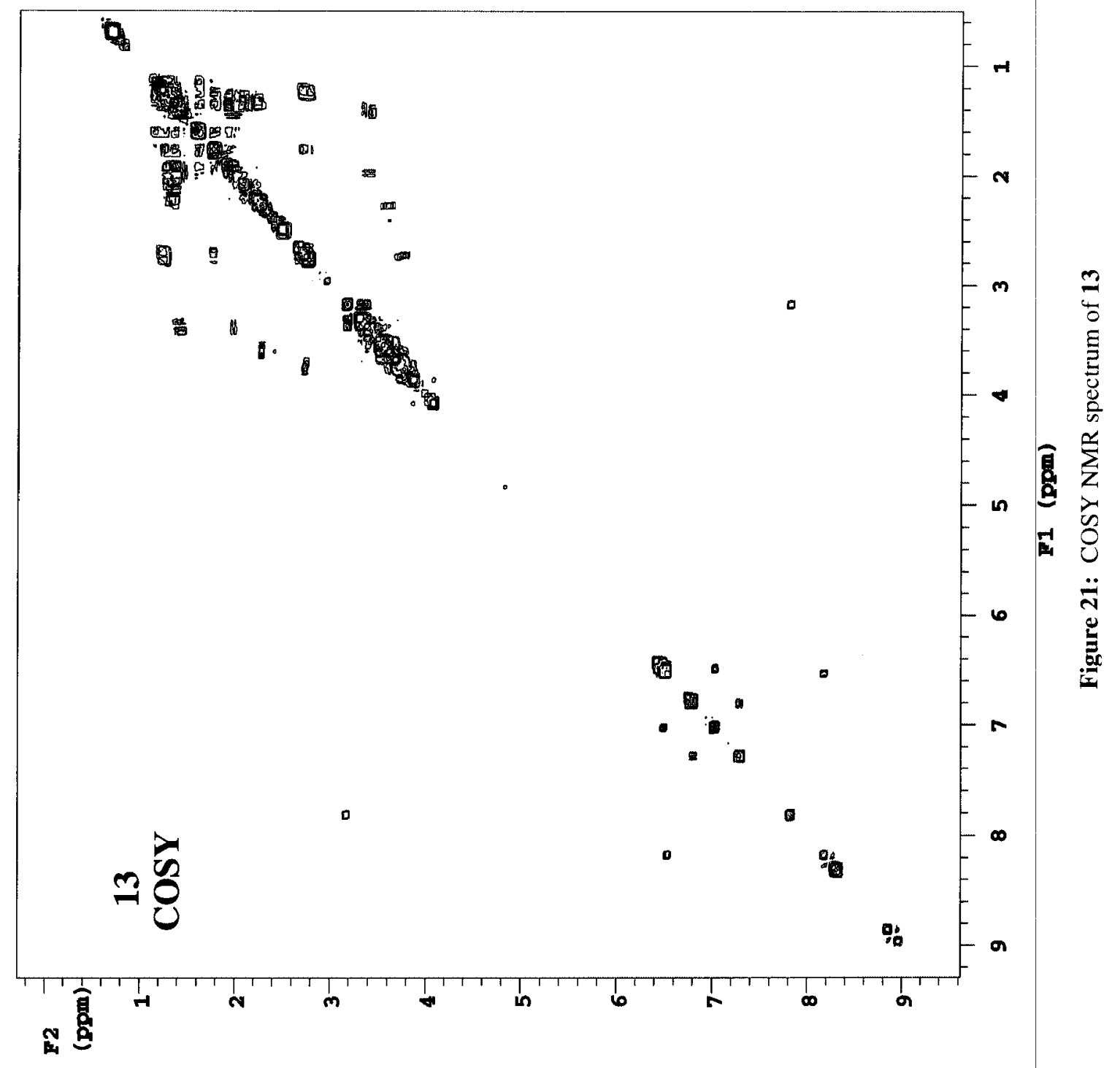


9. Coupling of $\beta$-estro-O-propanoic acid to 11: 6-(benzyloxy)-2-hydroxy-3-(2-(2-(2(3-((17R)-3-hydroxy-13-methyl-7,8,9,11,12,13,14,15,16,17-decahydro-6Hcyclopenta[a]phenanthren-17-yloxy)propanamido)ethoxy)ethoxy)acetamido)benzamide

\section{(14, Scheme 8)}

In a $25 \mathrm{~mL}$ round-bottom flask was dissolved 11 (300 mg, $0.7 \mathrm{mmol}), \beta$-estropropanoic acid (250 mg, $0.7 \mathrm{mmol})$, BOP (620 mg, 1.4mmol), HOBt (189 mg, $1.4 \mathrm{mmol})$, and DIEA (244 $\mu \mathrm{l}, 1.4 \mathrm{mmol})$ in $15 \mathrm{~mL}$ of DMF. The reaction was allowed to stir at room temperature for two days, after which time the solvent was removed under vacuum. The resulting oil was taken up in ethyl acetate and washed with brine $2 \mathrm{X}, 5 \% \mathrm{HCl} 2 \mathrm{X}$, and saturated $\mathrm{NaHCO}_{3} 2 \mathrm{X}$. The organic layer was then dried over $\mathrm{Na}_{2} \mathrm{SO}_{4}$, filtered, and concentrated. The product resulted as an oil. The product was combined with another oily product obtained from a previous experiment, then subjected to column chromatography (solvent system $=$ EtOAc:Acetone, 9:1). After the appropriate fractions were pooled and concentrated, sticky gray oil 14 was obtained. Yield: $300 \mathbf{m g}, \mathbf{5 8 \%}$. ${ }^{1} \mathrm{H}$ $\left(500 \mathrm{mHz}\right.$, DMSO-d $\left.\mathrm{d}_{6}\right): \delta 0.66, \mathrm{~s}, 3 \mathrm{H}$, angular methyl; $\delta 1.09, \mathrm{~m} ; \delta 1.16-1.32, \mathrm{~m} ; \delta 1.35, \mathrm{~m}$; $\delta 1.55, \mathrm{~m} ; \delta 1.73, \mathrm{~m} ; \delta 1.85-1.96, \mathrm{~m} ; \delta 2.04, \mathrm{t} ; \delta 2.19, \mathrm{~d} ; \delta 2.28, \mathrm{t}, \mathrm{J} 6.47 \mathrm{~Hz}, 2 \mathrm{H}, 8^{\prime} \mathrm{CH}_{2}$; $\delta 2.68, \mathrm{~m}, 2 \mathrm{H} ; \delta 3.21, \mathrm{q}, \mathrm{J} 5.61 \mathrm{~Hz}, 2 \mathrm{H}, 6^{\prime} \mathrm{CH}_{2} ; \delta 3.44, \mathrm{t}, \mathrm{J} 5.61 \mathrm{~Hz}, 2 \mathrm{H}, 5^{\prime} \mathrm{CH}_{2} ; \delta 3.55, \mathrm{~m}$, $1 \mathrm{H}, \mathrm{C}^{\prime} \mathrm{H}^{1} ; \delta 3.60, \mathrm{~m}, 2 \mathrm{H}, 4^{\prime} \mathrm{CH}_{2} ; \delta 3.63, \mathrm{~m}, 1 \mathrm{H}, \mathrm{C}^{\prime} \mathrm{H}_{2} ; \delta 3.69, \mathrm{~m}, 2 \mathrm{H}, 3^{\prime} \mathrm{CH}_{2} ; \delta 4.10$, s, ${ }^{\prime}{ }^{\prime} \mathrm{CH}_{2} ; \delta 5.26, \mathrm{~s}, 2 \mathrm{H}, \mathrm{C} 6 \mathrm{OCH}_{2} ; \delta 6.42$, br s, $1 \mathrm{H}, \mathrm{C} 18^{\prime} \mathrm{H} ; \delta 6.49$, dd, J $8.67 \mathrm{~Hz}, \mathrm{~J}_{2} 1.95$ Hz, 1H, C20’ H; $\delta 6.65$, d, J 9.15 Hz, 1H, C5 H; $\delta 7.01$, d, J 8.54 Hz, 1 H, C21' H; $\delta 7.36$, d, J $7.44 \mathrm{~Hz}, 1 \mathrm{H}, \mathrm{H}_{\mathrm{c}} ; \delta 7.40$, t, J $7.50 \mathrm{~Hz}, 2 \mathrm{H}, \mathrm{H}_{\mathrm{b}} ; \delta 7.47$, d, J $7.81 \mathrm{~Hz}, 2 \mathrm{H}, \mathrm{H}_{\mathrm{a}} ; 87.82$, t, J $5.37 \mathrm{~Hz}, 1 \mathrm{H}, \mathrm{C} 6$ ' amide $\mathrm{H} ; \delta 8.15$, d, J $9.15 \mathrm{~Hz}, 1 \mathrm{H}, \mathrm{C} 4 \mathrm{H} ; \delta 8.18$, br s, $1 \mathrm{H}, \mathrm{C} 1$ amide $\mathrm{H}$; $\delta 8.36$, br s, $1 \mathrm{H}, \mathrm{Cl}$ amide $\mathrm{H} ; \delta 8.86, \mathrm{~s}, 1 \mathrm{H}, \mathrm{C} 3$ amide $\mathrm{H} ; \delta 8.97,1 \mathrm{H}, \mathrm{C} 19{ }^{\prime} \mathrm{OH} .{ }^{13} \mathrm{C}(500$ 
mHz, DMSO-d $\mathrm{d}_{6}$ ): $\delta 12.13$, angular $\mathrm{CH}_{3} ; \delta 23.30, \mathrm{CH}_{2} ; \delta 26.78, \mathrm{CH}_{2} ; \delta 27.50, \mathrm{CH}_{2} ; \delta 28.28$, $\mathrm{CH}_{2} ; \delta 29.81, \mathrm{CH}_{2} ; \delta 37.33, \mathrm{CH}_{2} ; \delta 38.05, \mathrm{CH} ; \delta 39.05, \mathrm{CH} ; \delta 43.48, \mathrm{C} 26 ’ ; \delta 44.04, \mathrm{CH}$; $\delta 50.20, \mathrm{CH} ; \delta 66.51, \mathrm{CH}_{2} ; \delta 69.95, \mathrm{CH}_{2} ; \delta 70.05, \mathrm{CH}_{2} ; \delta 70.79, \mathrm{CH}_{2} ; \delta 71.13, \mathrm{CH}_{2}$ (int=2); $\delta 88.89, \mathrm{CH} ; \delta 102.57, \mathrm{CH} ; \delta 113.41, \mathrm{CH} ; \delta 115.60, \mathrm{CH} ; \delta 121.17, \mathrm{qC} ; \delta 124.54, \mathrm{CH}$ $\delta 126.73, \mathrm{CH} ; \delta 128.69, \mathrm{CH}$ (int=2); $\delta 129.00, \mathrm{CH} ; \delta 129.37, \mathrm{CH}(\mathrm{int}=2) ; \delta 130.97, \mathrm{qC}$; $\delta 136.79, \mathrm{qC} ; \delta 137.77, \mathrm{qC} ; \delta 154.15, \mathrm{qC} ; \delta 154.76, \mathrm{qC} ; \delta 155.59, \mathrm{qC} ; \delta 168.19, \mathrm{qC} ;$ $\delta 170.93, \mathrm{qC} ; \delta 172.56, \mathrm{qC}$. Mass calculated: $729.3625 ;$ Mass found: $729.3635, \Delta=1.34$ ppm. 


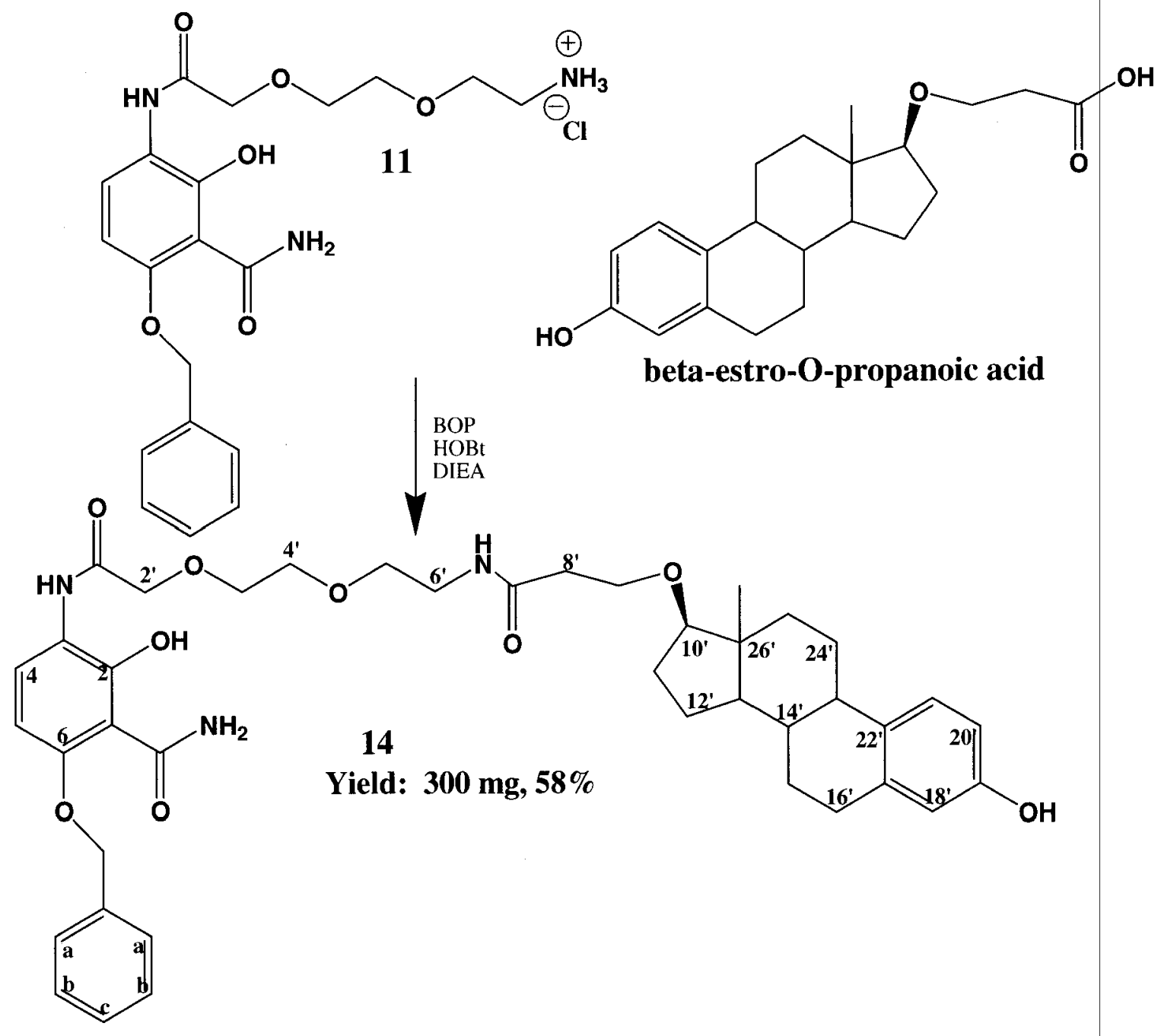

Scheme 8: Coupling of $\beta$-estro-O-propanoic acid to 11. 


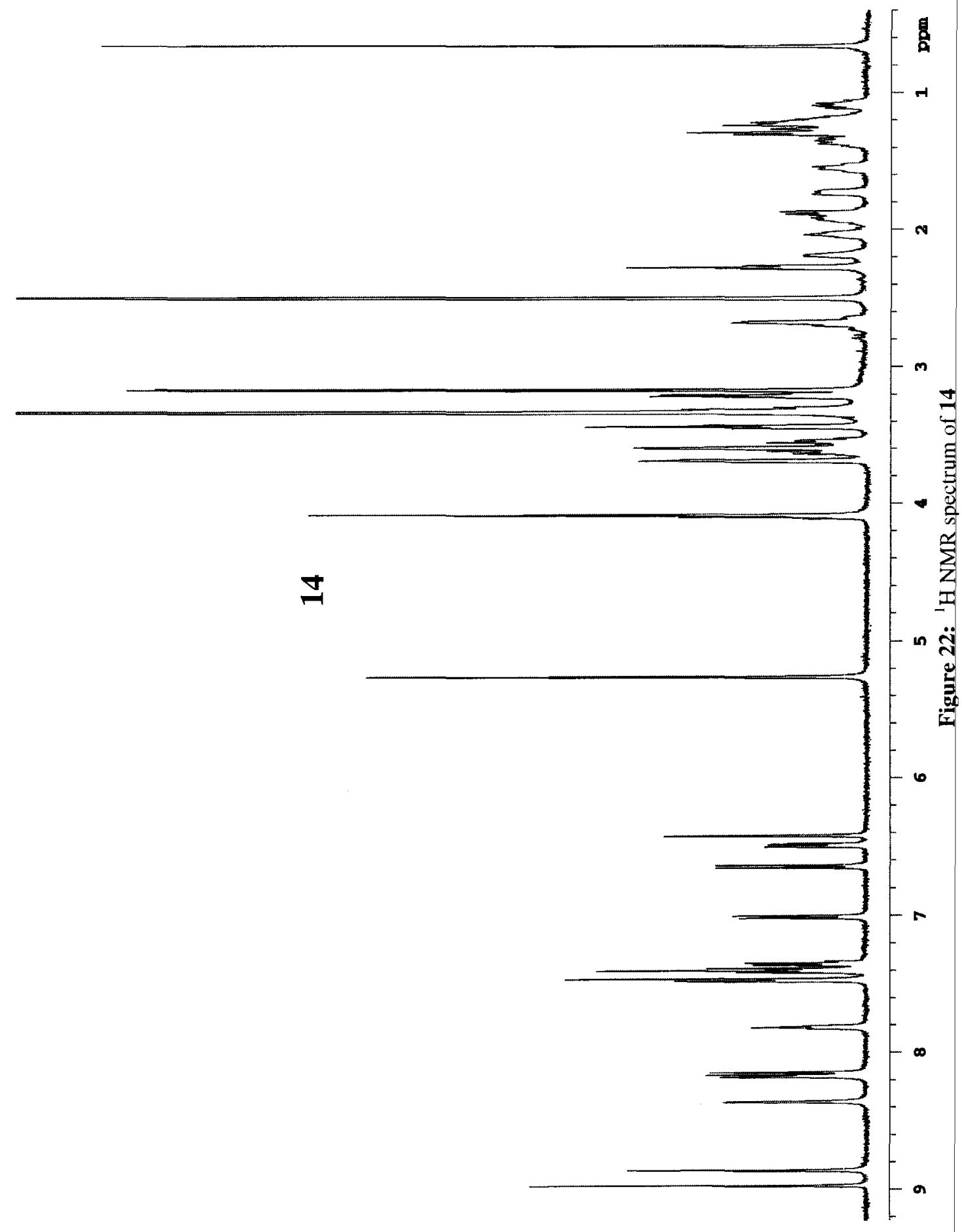




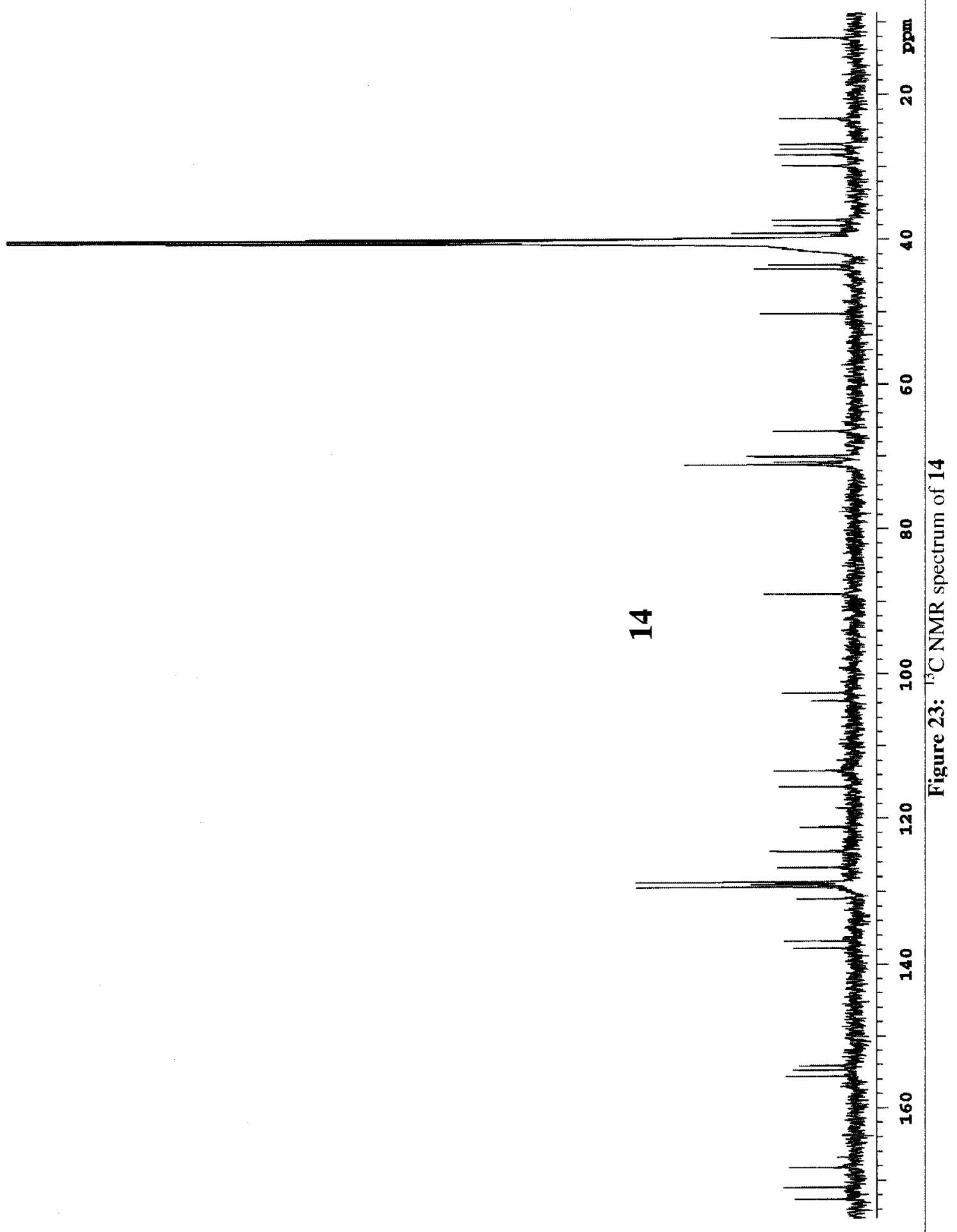




$$
y^{2}
$$


10. Coupling of Glutaric Anhydride to 8: 5-(2-(2-(2-(3-carbamoyl-2-hydroxy-4methoxyphenylamino)-2-oxoethoxy)ethoxy)ethylamino)-5-oxopentanoic acid (15,

\section{Scheme 9)}

In a $100 \mathrm{~mL}$ round-bottom flask was combined $8(500 \mathrm{mg}, 1.4 \mathrm{mmol})$, glutaric anhydride (155 mg, $1.4 \mathrm{mmol})$, DIEA (590 $\mu \mathrm{l}, 3.4 \mathrm{mmol})$ and DMF (40 mL). A homogeneous solution formed and it was stirred overnight at room temperature. Approximately $20 \mathrm{~mL}$ of $50 \%$ aq. $\mathrm{MeOH}$ was then added to the reaction solution and it was allowed to stir for 30 minutes more. The solvent was removed under vacuum to give a sticky brown solid. When triturated in methanol, off-white precipitate 15 was noted and collected via suction filtration. Yield: $495 \mathbf{~ m g , ~ 8 3 \%}$. ${ }^{1} \mathrm{H}\left(500 \mathrm{mHz}, \mathrm{DMSO}-\mathrm{d}_{6}\right)$ : $\delta 1.68$, quintet, J $7.56 \mathrm{~Hz}, 2 \mathrm{H}, 9^{\prime} \mathrm{CH}_{2} ; \delta 2.08$, t, J 7.44, 2H, 10' $\mathrm{CH}_{2} ; \delta 2.18$, t, J $7.56 \mathrm{~Hz}, 8^{\prime}$ $\mathrm{CH}_{2} ; \delta 3.19, \mathrm{~m}, 2 \mathrm{H}, 6^{\prime} \mathrm{CH}_{2} ; \delta 3.43, \mathrm{t}, \mathrm{J} 5.61 \mathrm{~Hz}, 2 \mathrm{H}, 5^{\prime} \mathrm{CH}_{2} ; \delta 3.60, \mathrm{~m}, 2 \mathrm{H}, 4^{\prime} \mathrm{CH}_{2} ; \delta 3.69$, m, 2H, 3' $\mathrm{CH}_{2} ; \delta 3.89$, s, 3H, C6 OCH $3 ; \delta 4.09$, s, $2^{\prime} \mathrm{CH}_{2} ; \delta 6.56$, d, J $9.03 \mathrm{~Hz}, 1 \mathrm{H}, \mathrm{C} 4 \mathrm{H}$; $\delta 7.83$, m, 1H, C6' amide H; $\delta 8.18$, d, J $9.39 \mathrm{~Hz}, 1 \mathrm{H}, \mathrm{C} 5 \mathrm{H} ; \delta 8.30$, s, $1 \mathrm{H}, \mathrm{Cl}$ amide $\mathrm{H}$; $\delta 8.34, \mathrm{~s}, 1 \mathrm{H}, \mathrm{C} 1$ amide $\mathrm{H} ; \delta 8.85, \mathrm{~s}, 1 \mathrm{H}, \mathrm{C} 3$ amide $\mathrm{H} ; \delta 12.01, \mathrm{~s}, 1 \mathrm{H}, \mathrm{C} 11{ }^{\prime} \mathrm{OH} .{ }^{13} \mathrm{C}(500$ mHz, DMSO-d $\left.{ }_{6}\right): \delta 21.33, \mathrm{C}^{\prime} ; 33.66, \mathrm{C}^{\prime} 0^{\prime} ; \delta 35.01, \mathrm{C}^{\prime} ; \delta 39.06, \mathrm{C}^{\prime} ; \delta 56.82, \mathrm{C}^{\prime} \mathrm{OCH}_{3}$;

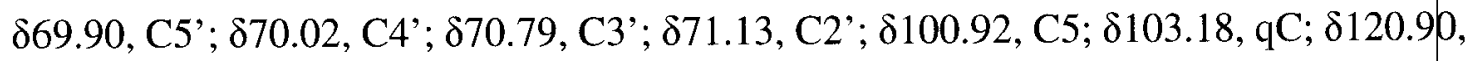
qC; $\delta 124.80, \mathrm{C} 4 ; \delta 154.88, \mathrm{qC} ; \delta 155.42, \mathrm{qC} ; \delta 168.20, \mathrm{qC} ; \delta 172.38, \mathrm{qC} ; \delta 172.56, \mathrm{qC}$; $\delta 174.89$, qC. Mass calculated: 441.1747; Mass found: $441.1743, \Delta=-0.96 \mathrm{ppm}$. 

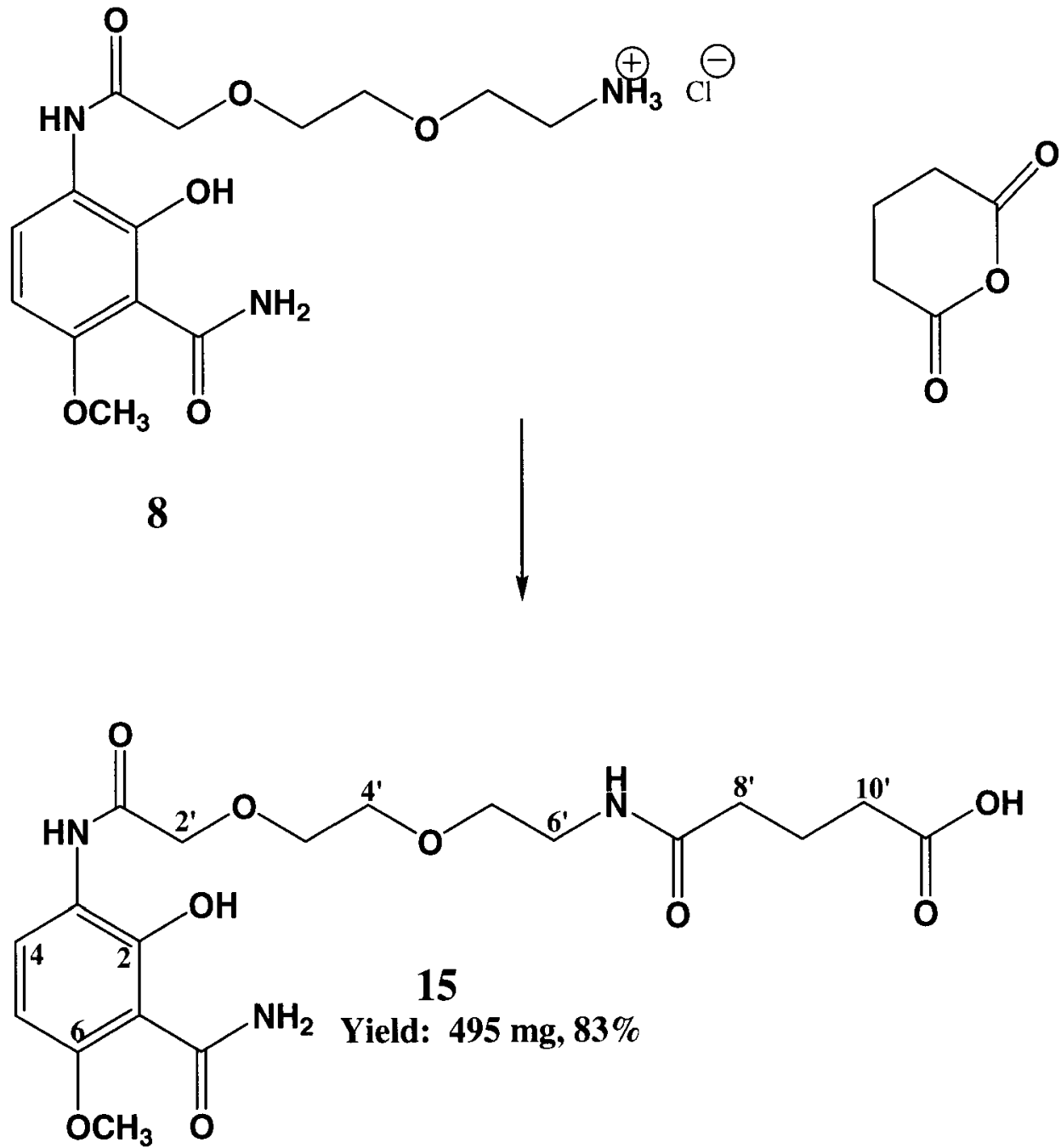

Scheme 9: Coupling of Glutaric Anhydride to 8. 


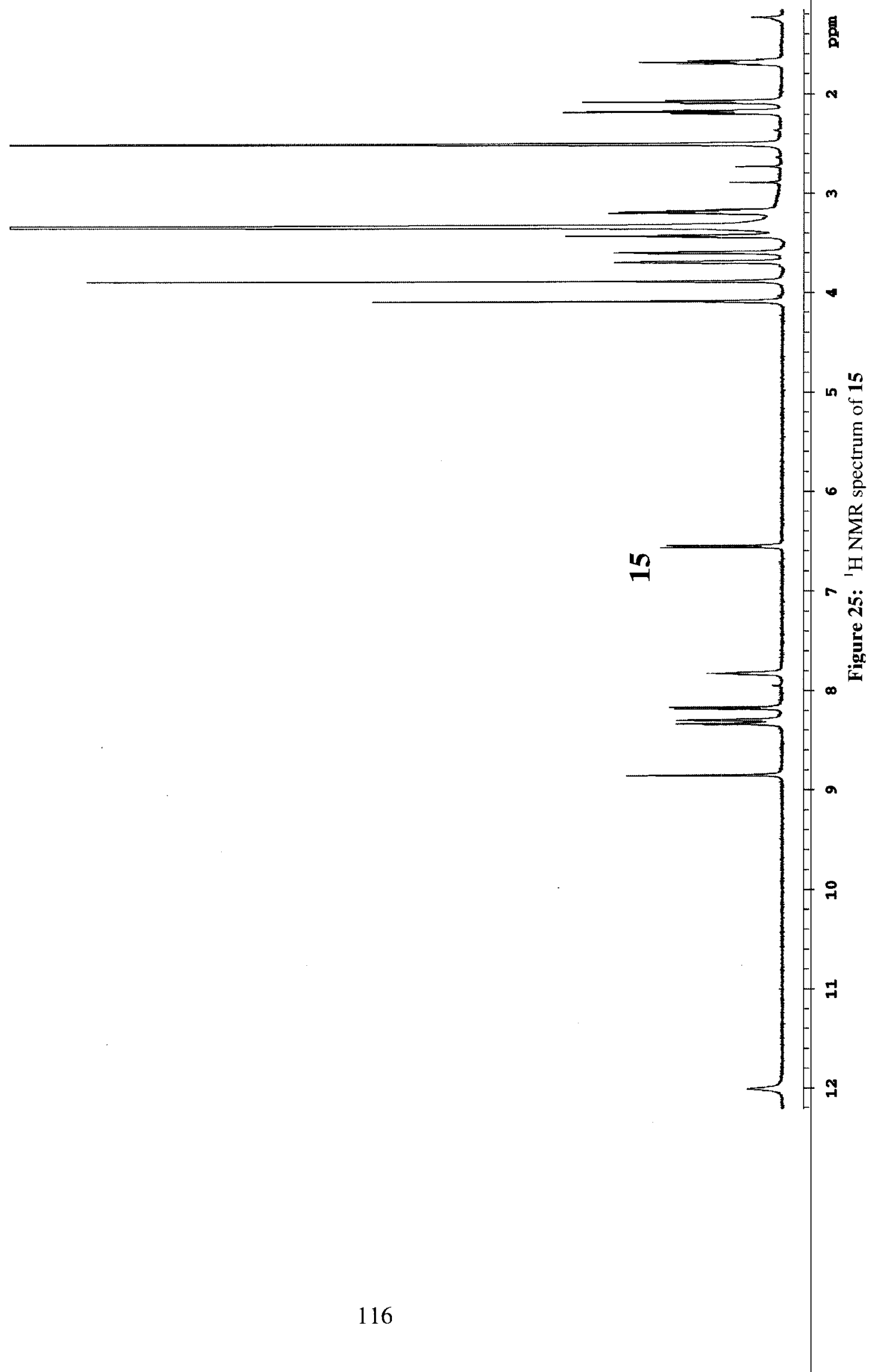




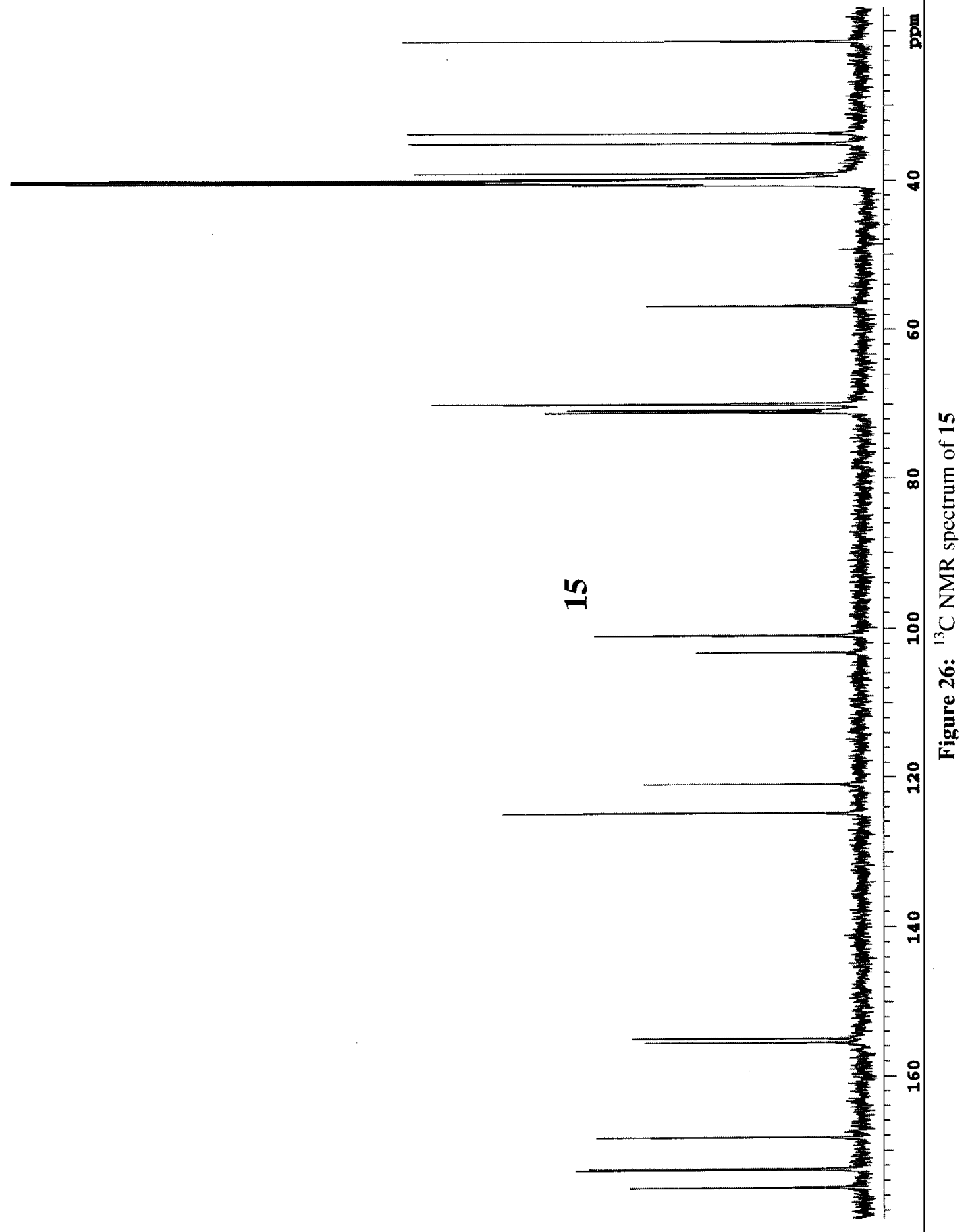


11. Coupling of 9 to Doxorubicin॰HCl: N1-(2-(2-(2-(3-carbamoyl-2-hydroxy-4methoxyphenylamino)-2-oxoethoxy)ethoxy)ethyl)-N5-((2S,3S,4S,6S)-3-hydroxy-2methyl-6-((1R,3S)-3,5,12-trihydroxy-3-(2-hydroxyacetyl)-10-methoxy-6,11-dioxo1,2,3,4,6,11-hexahydrotetracen-1-yloxy)tetrahydro-2H-pyran-4-yl)glutaramide (16,

\section{Scheme 10)}

Compound 15 (286 mg, $0.65 \mathrm{mmol}$ ), along with $\mathrm{HOBt}$ (174 mg, $1.3 \mathrm{mmol}$ ), BOP ( 571 $\mathrm{mg}, 1.3 \mathrm{mmol})$, and DIEA (225 $\mu \mathrm{l}, 1.3 \mathrm{mmol})$ were dissolved in $25 \mathrm{~mL} \mathrm{DMF}$. After 5 minutes, doxorubicin $\bullet \mathrm{HCl}(250 \mathrm{mg}, 0.4 \mathrm{mmol})$ was added to the stirring solution. The reaction flask was wrapped in foil and purged with $\mathrm{N}_{2}$. The flask was sealed and the reaction left stirring overnight. After $\sim 21$ hours, the DMF was removed under vacuun to give a red oil. The oil was taken up in EtOAc and triturated. A red solid precipitated. The mixture was centrifuged and the supernatant removed. The solid was washed with EtOAc twice more, each time removing the solvent by centrifugation/decanting. The red product was purified via reverse-phase column chromatography (Varian Mega Bond Elut column) using an acetonitrile/water stepwise elution (10\%, 20\%, 30\%, 40\%, 50\% $\mathrm{CH}_{3} \mathrm{CN}$ ). Product 16 was obtained after the chromatographic separation. Yield: 270 mg, 65\%. ' $\mathrm{H}\left(500 \mathrm{mHz}, \mathrm{DMSO}-\mathrm{d}_{6}\right): \delta 1.12, \mathrm{~d}, \mathrm{~J} 5.49 \mathrm{~Hz}, 3 \mathrm{H}, \mathrm{C} 16{ }^{\prime} \mathrm{OCH}_{3} ; \delta 1.42, \mathrm{~d} ; \delta 1.63$, $2 \mathrm{H}, \mathrm{m}, 9^{\prime} \mathrm{CH}_{2} ; \delta 1.83, \mathrm{t} ; \delta 2.00, \mathrm{~m} ; \delta 2.09, \mathrm{~m}, 1 \mathrm{H}, 10^{\prime} \mathrm{CH}_{2} ; \delta 2.20, \mathrm{~m} ; \delta 2.95, \mathrm{q} ; \delta 3.15$, m, $2 \mathrm{H}, 6^{\prime} \mathrm{CH}_{2} ; \delta 3.39, \mathrm{~m}, 2 \mathrm{H}, 5^{\prime} \mathrm{CH}_{2} ; \delta 3.57$, br s, $2 \mathrm{H}, 4^{\prime} \mathrm{CH}_{2} ; \delta 3.66$, br s, $2 \mathrm{H}, 3^{\prime} \mathrm{CH}_{2}$; 83.87, s, $3 \mathrm{H}, \mathrm{C} 6 \mathrm{OCH}_{3} ; \delta 3.97$, s, 3H, C29' $\mathrm{OCH}_{3} ; \delta 4.06$, s, 2H, 2' $\mathrm{CH}_{2} ; \delta 4.16$, m; $\delta 4.57, \mathrm{~m} ; \delta 4.73, \mathrm{~d} ; \delta 4.85, \mathrm{t} ; \delta 4.92$, br s; $\delta 5.22$, br s; $\delta 5.43, \mathrm{~s} ; \delta 6.52$, d, J $8.54 \mathrm{~Hz}, 1 \mathrm{H}, \mathrm{C5}$ $\mathrm{H} ; \delta 7.47, \mathrm{~d} ; \delta 7.62$, br s; $\delta 7.75, \mathrm{~s}, 1 \mathrm{H}, \mathrm{C} 11$ ' amide; $\delta 7.87, \mathrm{~s} ; \delta 8.15, \mathrm{~d}, \mathrm{~J} 9.15 \mathrm{~Hz}, 1 \mathrm{H}, \mathrm{C} 4$ $\mathrm{H} ; \delta 8.27, \mathrm{~s}, 1 \mathrm{H}, \mathrm{Cl}$ amide $\mathrm{H} ; \delta 8.31, \mathrm{~s}, 1 \mathrm{H}, \mathrm{Cl}$ amide $\mathrm{H} ; \delta 8.81, \mathrm{~s}, 1 \mathrm{H}, \mathrm{C} 3$ amide $\mathrm{H}$; 
$\delta 13.25, \mathrm{~s}, 1 \mathrm{H}, \mathrm{C} 38^{\prime} \mathrm{OH} .{ }^{13} \mathrm{C}\left(500 \mathrm{mHz}, \mathrm{DMSO}-\mathrm{d}_{6}\right): \delta 17.72, \mathrm{C}^{\prime}{ }^{\prime} \mathrm{CH}_{3} ; \delta 22.22, \mathrm{CH}_{2}$; $\delta 30.38, \mathrm{CH}_{2} ; \delta 32.73, \mathrm{CH}_{2} ; \delta 35.30, \mathrm{CH}_{2} ; \delta 35.35, \mathrm{CH}_{2} ; 837.25, \mathrm{CH}_{2} ; \delta 39.03, \mathrm{CH}_{2} ; \delta 45.58$, $\mathrm{CH} ; \delta 56.80, \mathrm{OCH}_{3} ; \delta 57.23, \mathrm{OCH}_{3} ; \delta 64.39, \mathrm{CH}_{2} ; \delta 67.36, \mathrm{CH}_{2} ; \delta 68.76, \mathrm{CH} ; \delta 69.89, \mathrm{CH}_{2} ;$ $\delta 70.02, \mathrm{CH}_{2} ; \delta 70.78, \mathrm{CH}, \mathrm{CH}_{2} ; \delta 71.10, \mathrm{CH}_{2} ; \delta 75.65, q \mathrm{qC} ; \delta 100.89, \mathrm{CH} ; \delta 101.13, \mathrm{CH} ;$ $\delta 103.15, \mathrm{qC} ; \delta 111.26, \mathrm{qC} ; \delta 119.62, \mathrm{CH} ; \delta 120.61, \mathrm{CH} ; \delta 120.88, \mathrm{qC} ; \delta 124.69, \mathrm{CH}$; $\delta 134.72, \mathrm{qC} ; \delta 135.30, \mathrm{qC} ; \delta 136.14, \mathrm{qC} ; \delta 136.82, \mathrm{CH} ; \delta 154.82, \mathrm{qC} ; \delta 155.37, \mathrm{qC}$; $\delta 156.78, \mathrm{qC} ; \delta 161.42, \mathrm{qC} ; \delta 168.16, \mathrm{qC} ; \delta 171.77, \mathrm{qC} ; \delta 172.52$, qC (int $=2) ; \delta 187.02$, qC. Mass calculated: 966.3382 ; Mass found: $966.3381, \Delta=-0.13 \mathrm{ppm}$. 
<smiles>COc1ccc(NC(=O)COCCOCCNC(=O)CCCC(=O)O)c(O)c1C(N)=O</smiles><smiles>C[C@H]1C[C@H](C)[C@H](O)[C@@H](C)O1</smiles><smiles>C=C(C(=O)c1ccccc1)/C(O)=C(\C)C[C@](C)(O)C(=O)CO</smiles><smiles>C/C=C\C(=C/C)NC(=O)COC[CH]OCCNC(=O)[C@H](I)CCC(=O)N[C@H]1C[C@H](C)O[C@H](C)[C@H]1O</smiles>

Yield; $270 \mathrm{mg}, \mathbf{6 5 \%}$

Scheme 10: Coupling of 15 to Doxorubicin $\bullet \mathrm{HCl}$. 


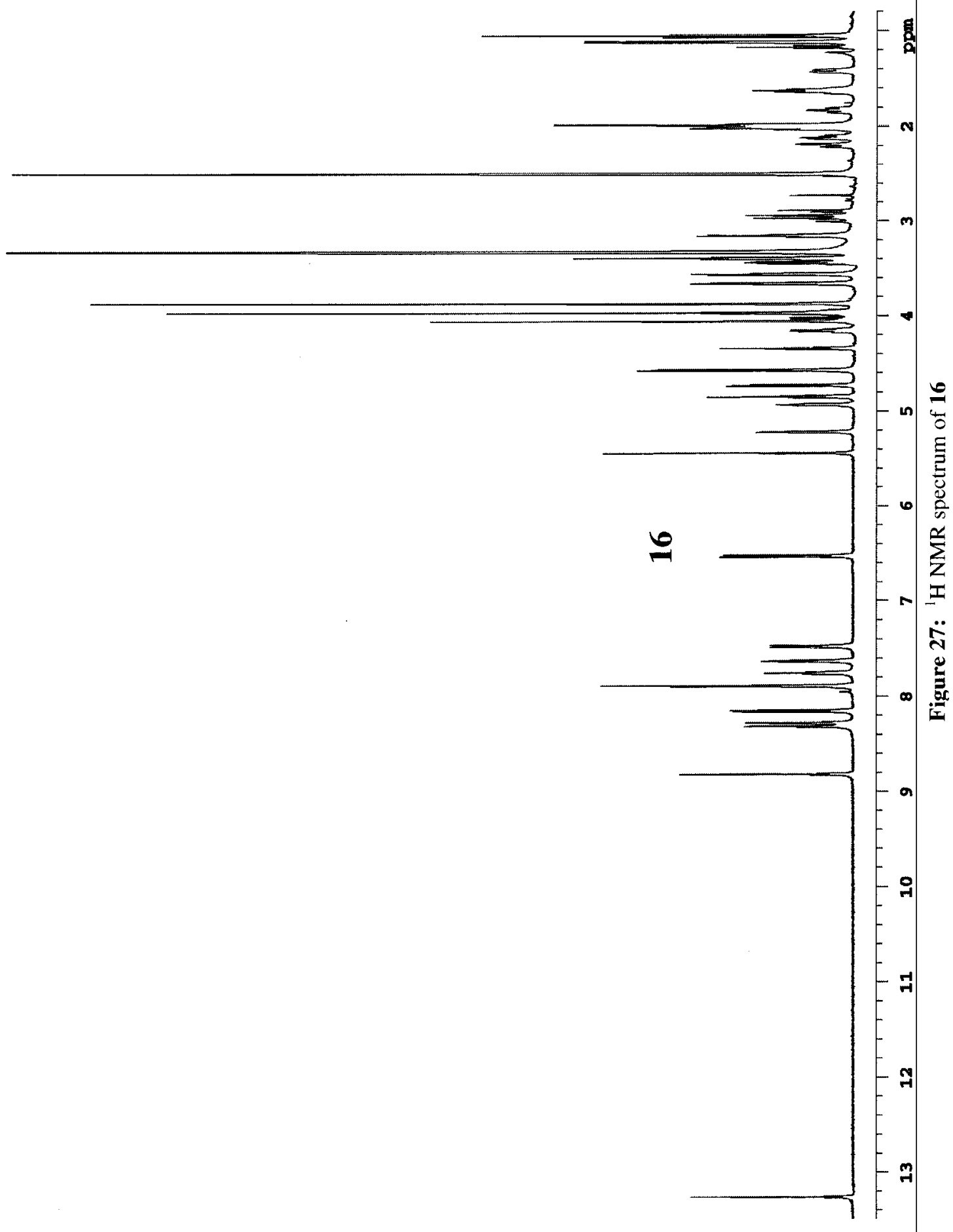




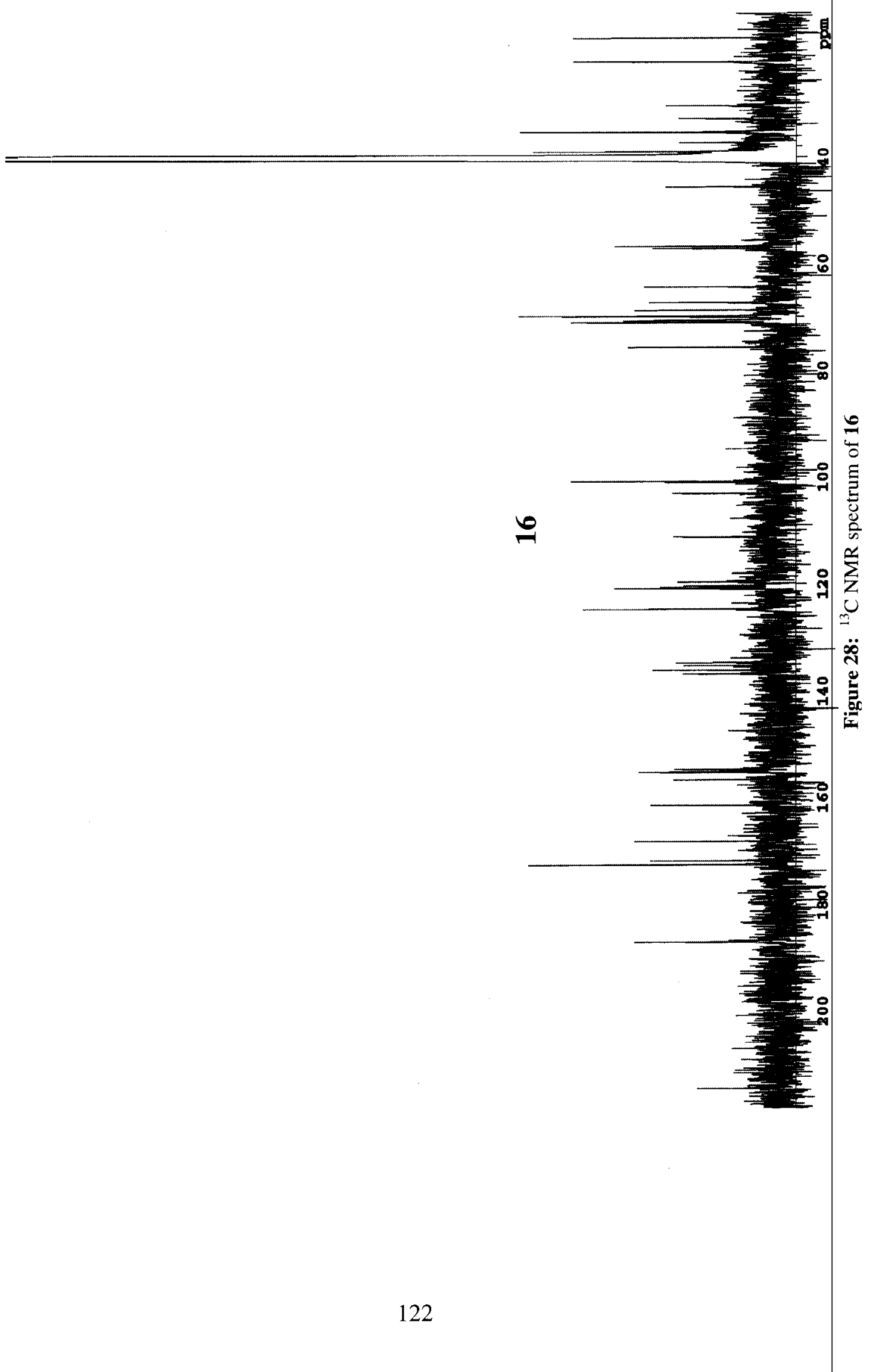




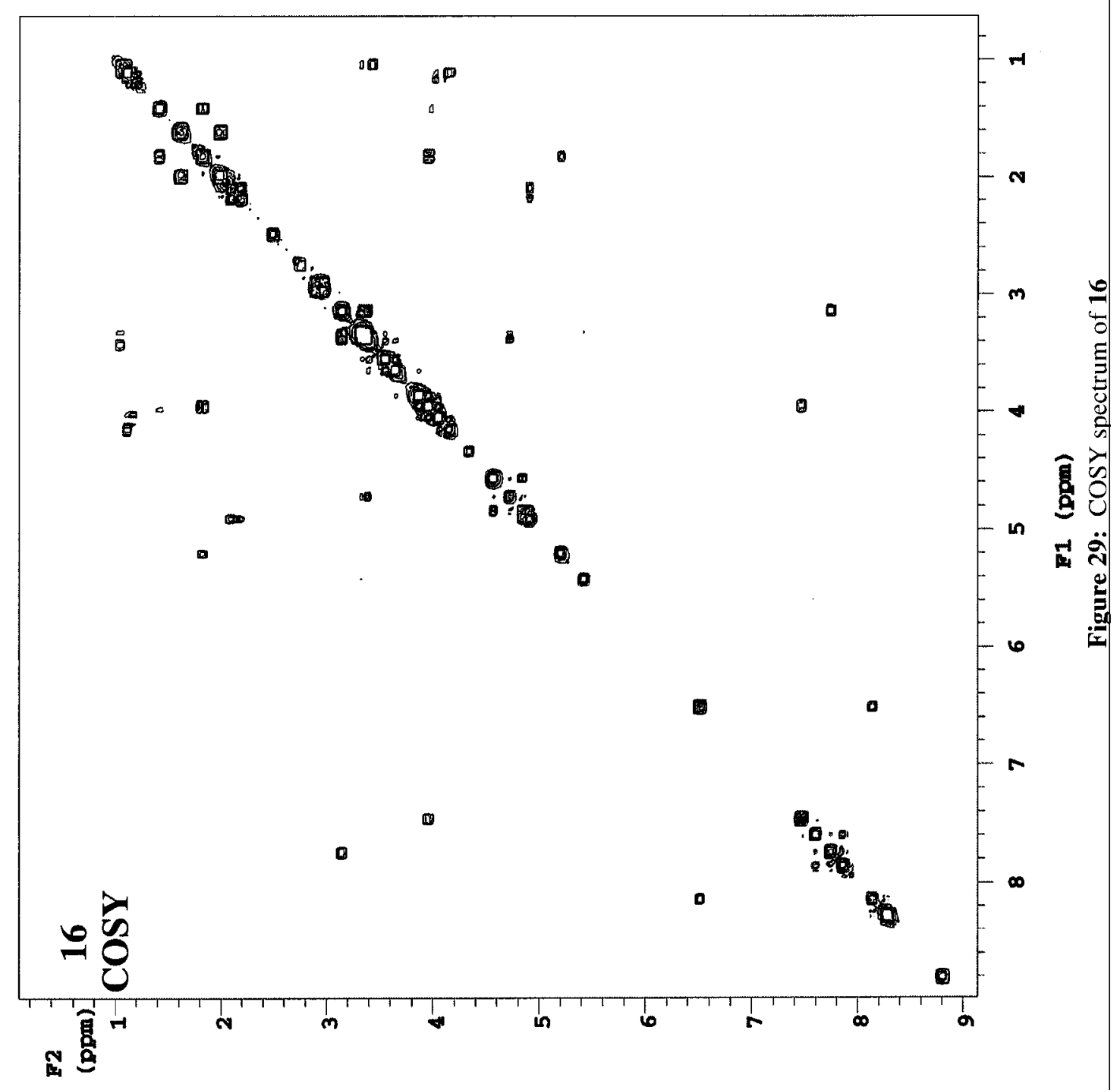


12. Coupling of Fluorescein Isothiocyanate to 8: 3-(2-(2-(2-(3-(3',6'-dihydroxy-3-oxo3H-spiro[isobenzofuran-1,9'-xanthene]-5-yl)thioureido)ethoxy)ethoxy)acetamido)-2hydroxy-6-methoxybenzamide (17, Scheme 11)

Product $8(327 \mathrm{mg}, 0.9 \mathrm{mmol})$ was stirred in DMF $(30 \mathrm{~mL})$ then DIEA $(471 \mu \mathrm{L}, 2.7$ mmol) was added. After 5 minutes, a homogeneous solution formed and fluorescein isothiocyanate (FITC; $350 \mathrm{mg}, 0.9 \mathrm{mmol}$ ) was added. The reaction stirred at room temperature for two hours. The solvent was removed under vacuum to leave an orange residue. To the residue was added $5 \% \mathrm{HCl}$ (aq) and an orange precipitate immediately formed. The solid was collected via vacuum filtration and rinsed with $5 \% \mathrm{HCl}$ then water. The product was dried over $\mathrm{CaSO}_{4}$ overnight. Crude Yield: $330 \mathbf{~ m g , ~ 5 1 \% . ~}$ Approximately $70 \mathrm{mg}$ of crude material was dissolved in methanol, stirred with a small amount of Dowex $50 \times 8$ resin for 5 hours, filtered, and finally evaporated to dryness to give product $\mathbf{1 7}$ as an orange powder. Yield: $\mathbf{5 0} \mathbf{~ m g}, \mathbf{7 1 \%}$. ${ }^{1} \mathrm{H}\left(500 \mathrm{mHz}, \mathrm{DMSO}-\mathrm{d}_{6}\right)$ : $\delta 3.68, \mathrm{~m}, 8 \mathrm{H}, 3^{\prime} \mathrm{CH}_{2} / 4^{\prime} \mathrm{CH}_{2} / 5^{\prime} \mathrm{CH}_{2}, / 6^{\prime} \mathrm{CH}_{2} ; \delta 3.87, \mathrm{~s}, 3 \mathrm{H}, \mathrm{C} 6 \mathrm{OCH}_{3} ; \delta 4.11, \mathrm{~s}, 2 \mathrm{H}, 2^{\prime}$ $\mathrm{CH}_{2} ; \delta 6.55, \mathrm{~d}, \mathrm{~J} 9.03 \mathrm{~Hz}, 1 \mathrm{H}, \mathrm{C} 5 \mathrm{H} ; \delta 6.56$, d, J $8.66 \mathrm{~Hz}, 2 \mathrm{H}, \mathrm{C} 17$ ' H; $\delta 6.60$, d, J 8.66, 2H, C18’ H; $\delta 6.67$, d, J 2.10, 2H, C20’ H; $\delta 7.16$, d, J 8.30 Hz, 1H, C10’ H; $\delta 7.73$, d J 8.30 Hz, 1H, C9'H; $\delta 8.10$, br s, $1 \mathrm{H}, \mathrm{C} 13^{\prime}{ }^{H} ; \delta 8.16$, d, J 9.03, 1H, C4 H; $\delta 8.28$, s, 2H, C6' $\mathrm{NH} / \mathrm{Cl}$ amide $\mathrm{H} ; \delta 8.32, \mathrm{~s}, 1 \mathrm{H}, \mathrm{C} 1$ amide $\mathrm{H} ; \delta 8.88, \mathrm{~s}, 1 \mathrm{H}, \mathrm{C} 3$ amide $\mathrm{H} ; \delta 10.04$, s, phenolic $\mathrm{H} ; \delta 10.12$, br s, phenolic $\mathrm{H} .{ }^{13} \mathrm{C}(500 \mathrm{mHz}$, DMSO-d 6 ): $\delta 44.30, \mathrm{C} 6 ; \delta 56.80$. C6 $\mathrm{OCH}_{3} ; \delta 69.24, \mathrm{C}^{\prime} ; \delta 70.13, \mathrm{C}^{\prime} ; \delta 870.81, \mathrm{C}^{\prime} ; \delta 71.18, \mathrm{C}^{\prime} ; \delta 100.92, \mathrm{C} 5 ; \delta 102.92$, $\mathrm{CH} ; \delta 103.19, \mathrm{qC} ; \delta 110.42, \mathrm{qC} ; \delta 113.30, \mathrm{CH} ; \delta 117.01, \mathrm{CH} ; \delta 120.87, \mathrm{qC} ; \delta 124.88, \mathrm{C} 4 ;$ $\delta 127.20, \mathrm{qC} ; \delta 129.76, \mathrm{CH} ; \delta 130.10, \mathrm{CH} ; \delta 152.57, \mathrm{qC} ; \delta 154.94, \mathrm{qC} ; \delta 155.43, \mathrm{qC}$; 
$\delta 160.20, \mathrm{qC} ; \delta 168.21, \mathrm{qC} ; \delta 169.22, \mathrm{qC} ; \delta 172.54, \mathrm{qC} ; \delta 181.23$, qC. Mass calculated:

716.1782; Mass found: $716.1788, \Delta=-0.87 \mathrm{ppm}$.
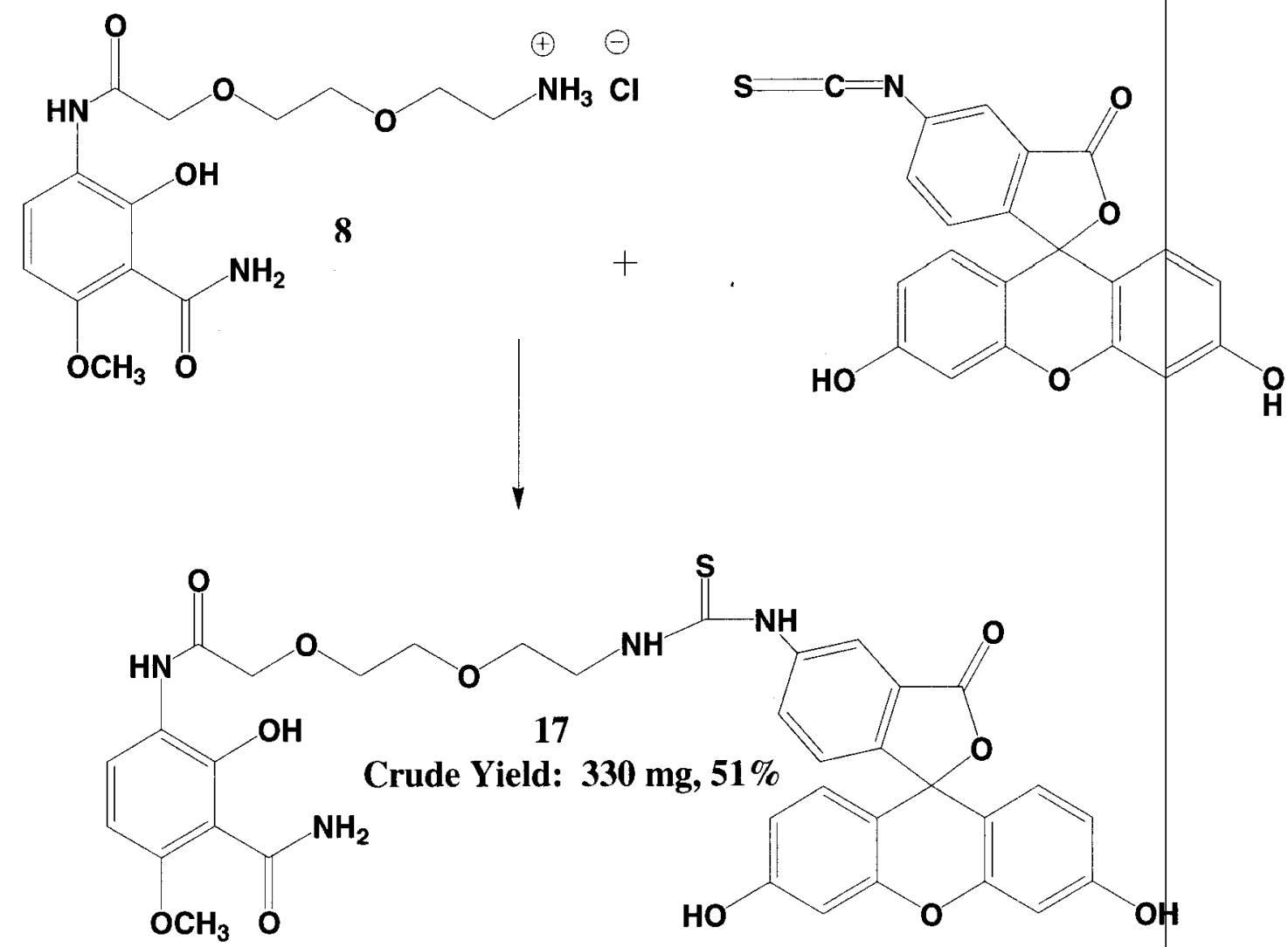

Scheme 11: Coupling of fluorescein isothiocyanate to 8 . 


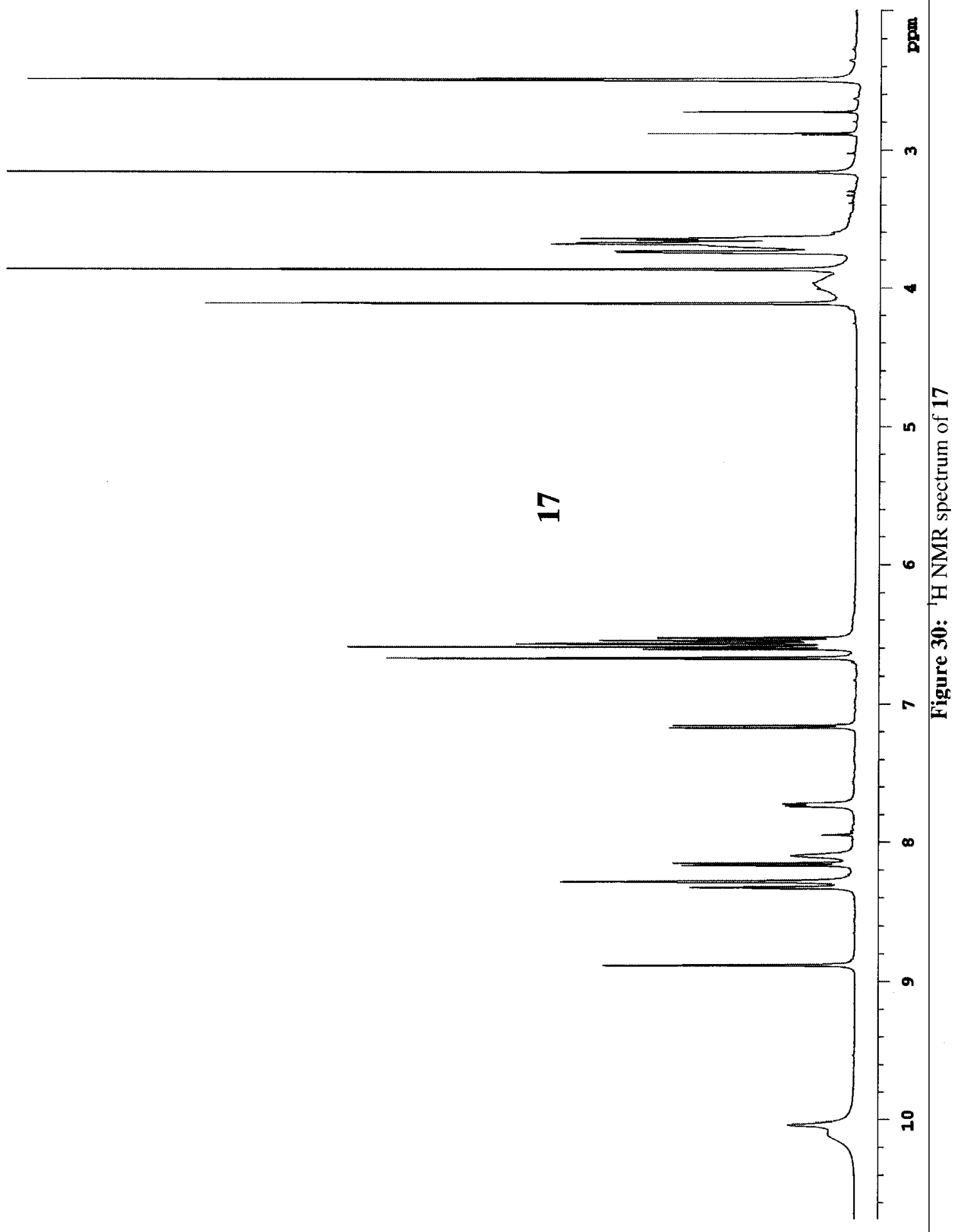




$$
1
$$


13. Carboxyalkylation of Genistein: tert-butyl 2-(4-(5,7-dihydroxy-4-oxo-4Hchromen-3-yl)phenoxy)acetate (18, Scheme 12)

Genistein $(2.00 \mathrm{~g}, 7.6 \mathrm{mmol})$ was dissolved in $160 \mathrm{~mL}$ of DMF along with potassium tert-butoxide ( $880 \mathrm{mg}, 7.6 \mathrm{mmol})$, potassium iodide ( $64 \mathrm{mg}, 5 \mathrm{~mol} \%$ ), and 18-crown- 6 ether $(20 \mathrm{mg}, 1 \mathrm{~mol} \%)$. The reaction solution was stirred at $40^{\circ} \mathrm{C}$ under argon for 2 hours before adding tert-butyl bromoacetate $(2.81 \mathrm{~mL}, 19 \mathrm{mmol})$. The reaction was left stirring under argon at $40^{\circ} \mathrm{C}$ for 2 days. The solvent was then removed under vacuum to give a brown oil. The oil was diluted with water and then acidifies with $5 \%$ aqueous hydrochloric acid. A mixture of white precipitate and sticky yellow solid was obtained as product 18. The product was used immediately in the next step without purification. ${ }^{4} \mathrm{H}$ (500 mHz, DMSO-d $\left.{ }_{6}\right): \delta 1.43$, s, 9H, 3' t-butyl; $\delta 4.81, \mathrm{~s}, 2 \mathrm{H}, 1^{\prime}$ ' $\mathrm{CH}_{2} ; \delta 6.38$, d, J $1.83 \mathrm{~Hz}$, 1H, C6 H; $\delta 6.61$, d, J 1.83 Hz, 1H, C8 H; $\delta 6.83$, d, J 8.30 Hz, 2H, C3’ H /C5' H; $\delta 7.38$, d, J 8.30 Hz, 2H, C2' H/C6' H; $\delta 8.38$, s, 1H, C2 H; $\delta 9.61$, C4”OH; $\delta 12.95, \mathrm{C} 5 \mathrm{OH}$. ${ }^{13} \mathrm{C}(500 \mathrm{mHz}$, DMSO-d 6 , determined from HMBC/HMQC data): $\delta 28.39$, t-butyl; $\delta 65.97$,

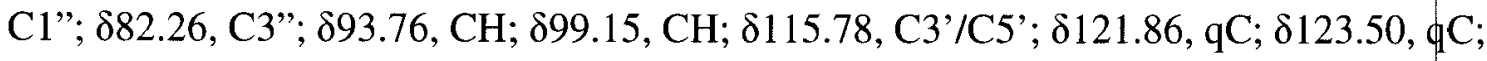
$\delta 130.88, \mathrm{C}^{\prime} / \mathrm{C}^{\prime} ; \delta 155.26, \mathrm{CH} ; \delta 158.19, \mathrm{C} 8 \mathrm{a} / \mathrm{C} 4 ; \delta 162.64, \mathrm{qC} ; \delta 164.28, \mathrm{C} 7 ; \delta 167.80$, C2"; $\delta 181.63$, C3. Mass calculated: 384.1209 ; Mass found: $384.1214, \Delta=1.24 \mathrm{ppm}$. 

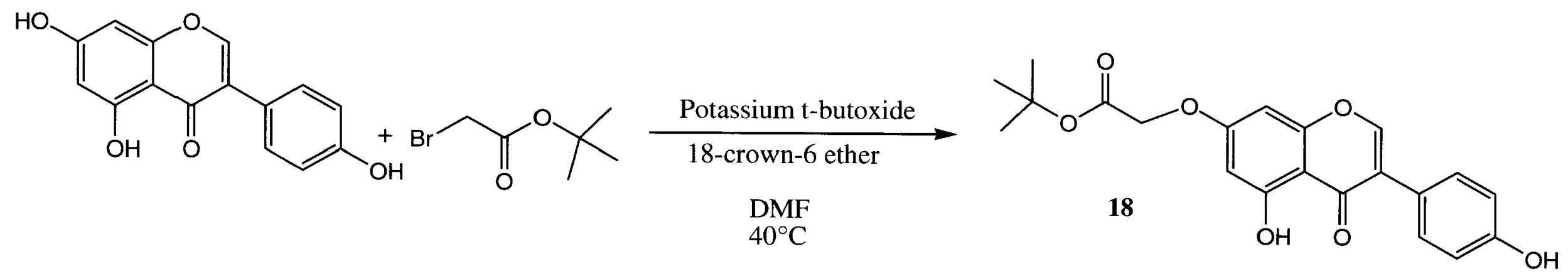

స్

Scheme 12: Regioselective carboxyalkylation of genistein. 


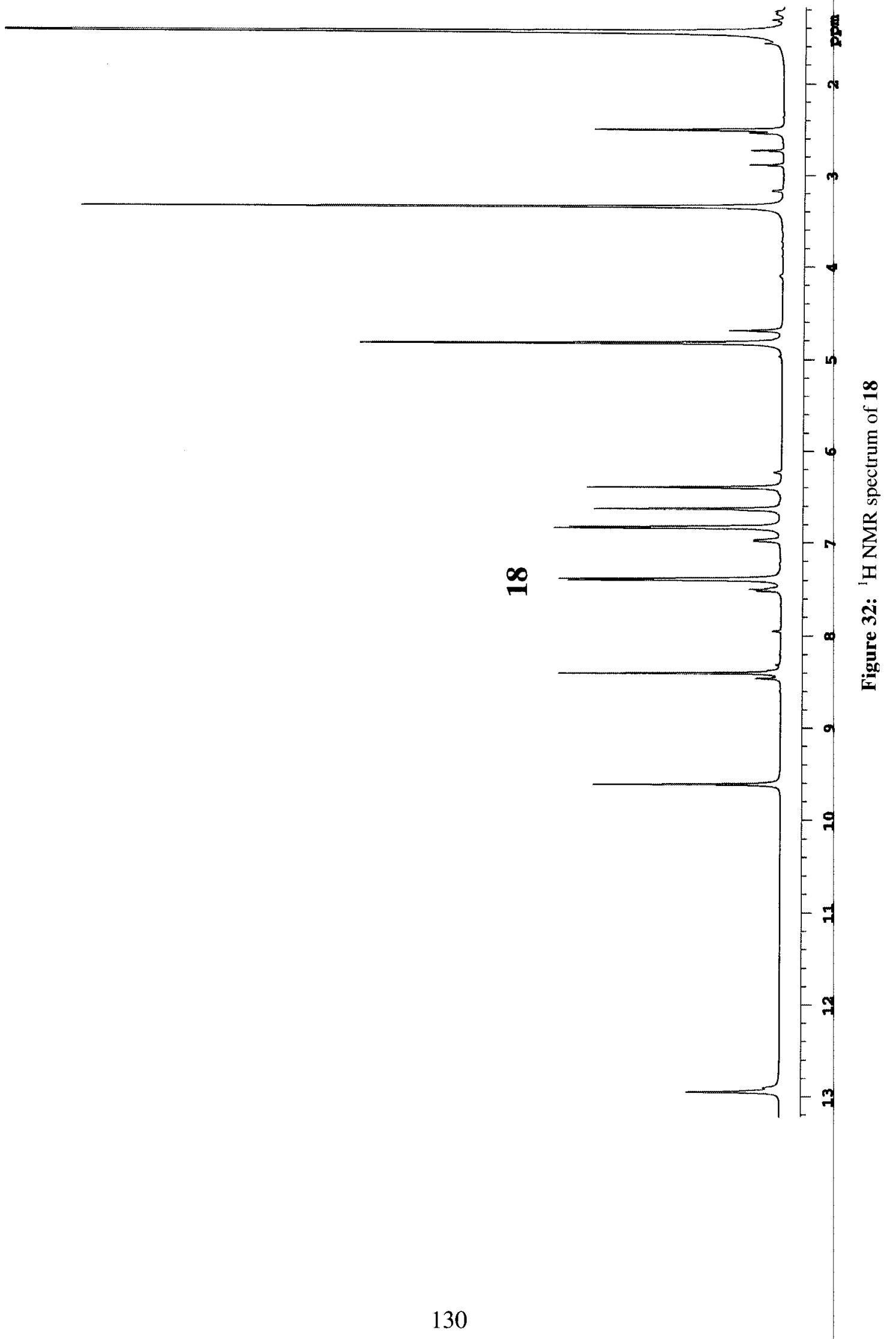




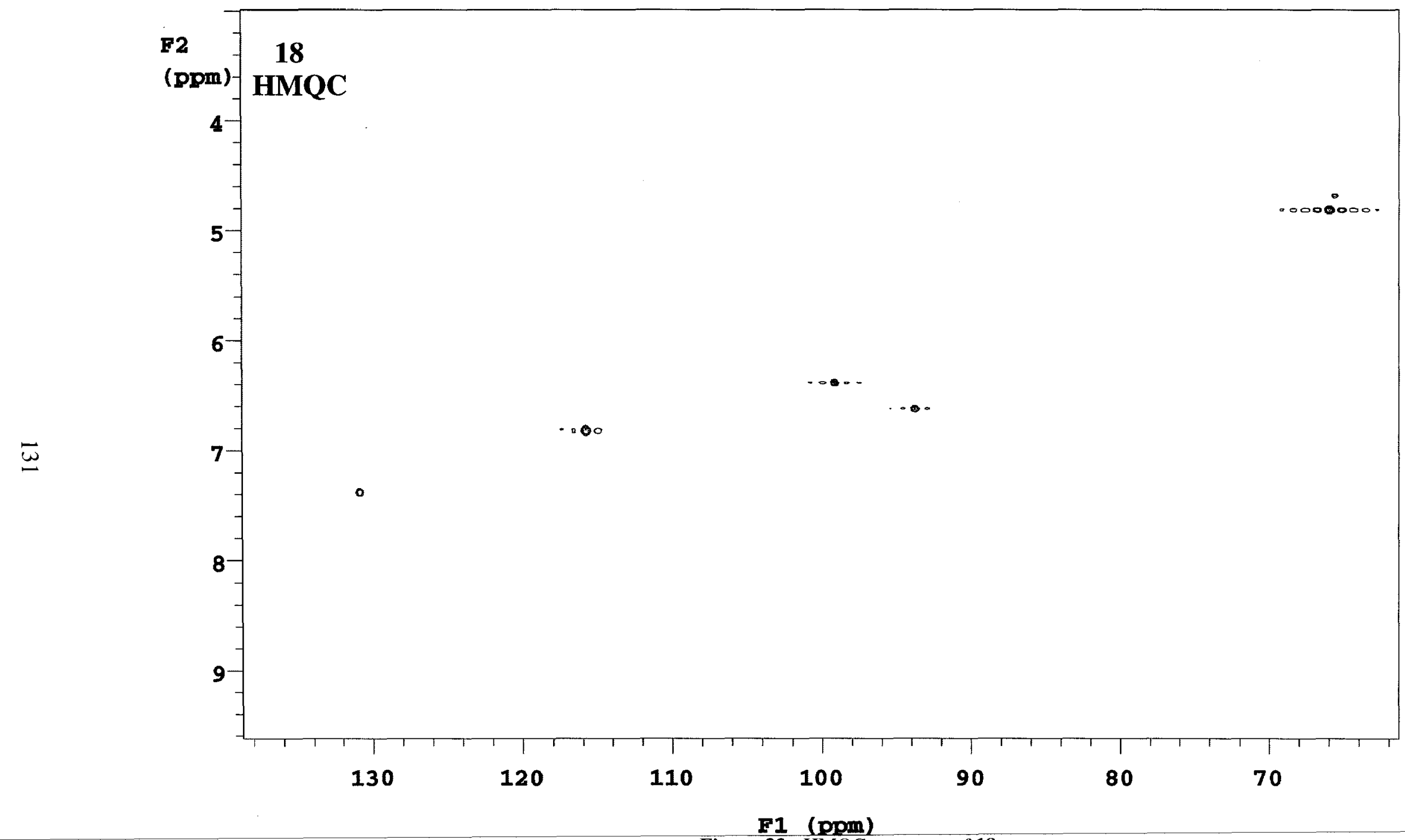

Figure 33: HMQC spectrum of 18 


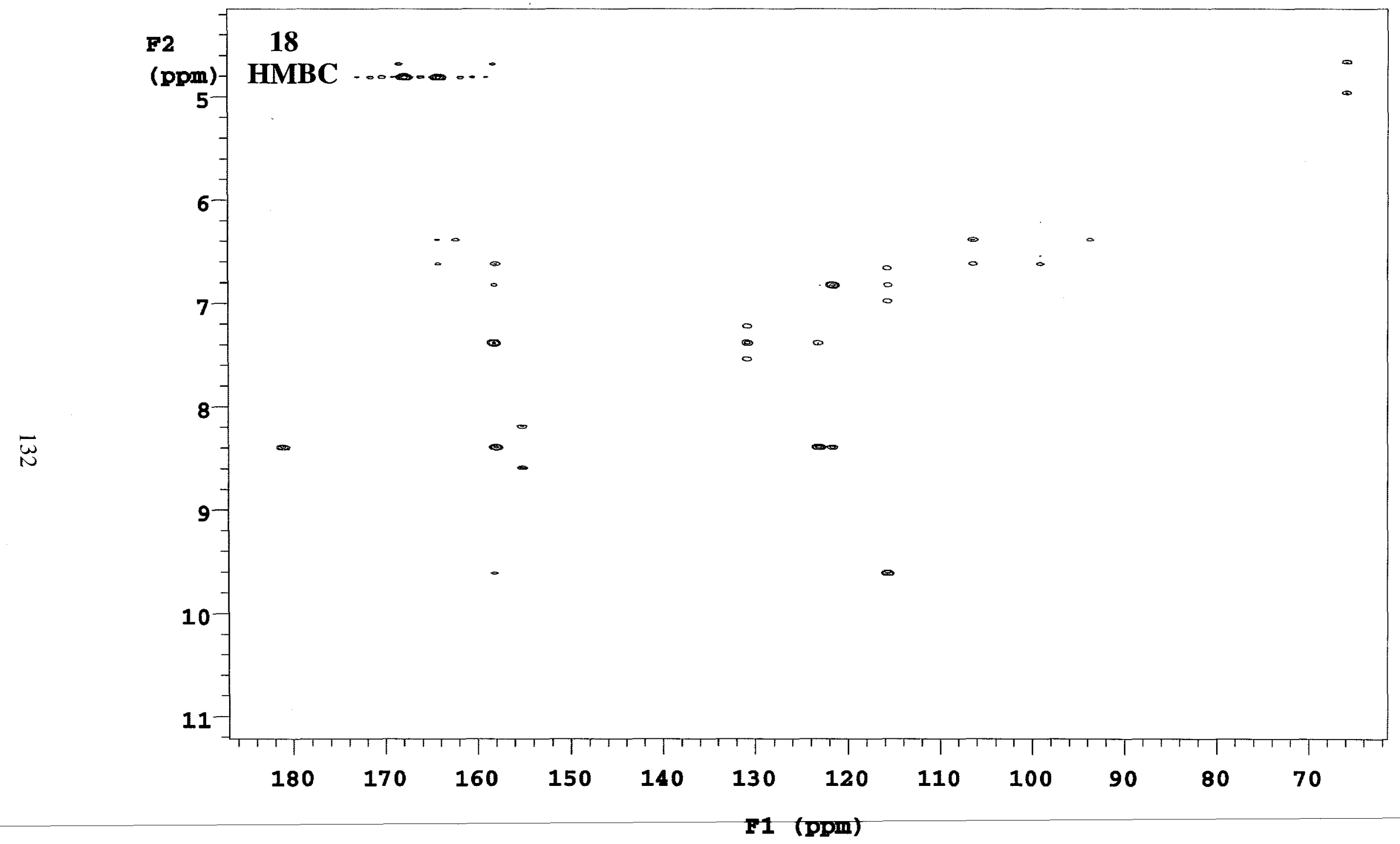

Figure 34: HMBC spectrum of 18 
14. Acidolysis of 18: 2-(5-hydroxy-3-(4-hydroxyphenyl)-4-oxo-4H-chromen-7yloxy)acetic acid (19, Scheme 13)

Product 18 was stirred in $15 \mathrm{~mL}$ of DCM/TFA (2:1) for 2 hours. An off-white precipitate was noted. The solvent was removed via rotary evaporation and the resulting solid was once again treated with the DCM/TFA solution, this time for 1 hour. After the solvent was removed a second time, the solid was stirred in DCM and subjected to rotary evaporation once more. An off-white solid was collected. To remove some impurities, the solid product was stirred in a minimal amount of $10 \%$ methanol in chloroform, gently heated, and filtered to give a white solid product, 19. Yield: $\mathbf{5 8 0} \mathbf{~ m g , 2 3 . 3 \%} .{ }^{1} \mathrm{H} 500$ mHz, DMSO-d d $_{6}: \delta 4.85$, s, $2 \mathrm{H}, \mathrm{C1}{ }^{\prime}{ }^{\mathrm{H}} \mathrm{H} ; \delta 6.41$, d, J $2.10 \mathrm{~Hz}, 1 \mathrm{H}, \mathrm{C} 6 \mathrm{H} ; \delta 6.66$, d, J 2.20 Hz, 1H, C8 H; $\delta 6.83$, d, J 8.54 Hz, 2H, C3' H /C5' H; 87.39 , d, J 8.42 Hz, 2H, C2' H/C6' $\mathrm{H} ; \delta 8.41, \mathrm{~s}, 1 \mathrm{H}, \mathrm{C} 2 \mathrm{H} .{ }^{13} \mathrm{C}\left(500 \mathrm{mHz}, \mathrm{DMSO}-\mathrm{d}_{6}\right): \delta 65.58, \mathrm{Cl} " ; \delta 93.80, \mathrm{CH} ; \delta 99.11$, $\mathrm{CH} ; \delta 106.37, \mathrm{qC} ; \delta 115.77, \mathrm{C}^{\prime} / \mathrm{C}^{\prime} ; \delta 121.70, \mathrm{qC} ; \delta 123.22, \mathrm{qC} ; \delta 130.87, \mathrm{C}^{\prime} / \mathrm{C}^{\prime} ;$ $\delta 155.22, \mathrm{C} 2 ; \delta 158.02, \mathrm{qC} ; \delta 158.18, \mathrm{qC} ; \delta 162.41, \mathrm{qC} ; \delta 164.33, \mathrm{qC} ; \delta 170.17, \mathrm{qC} ; \delta 181.12$, qC. Mass calculated: 328.0583 ; Mass found: $328.0575, \Delta=-2.51 \mathrm{ppm}$. 


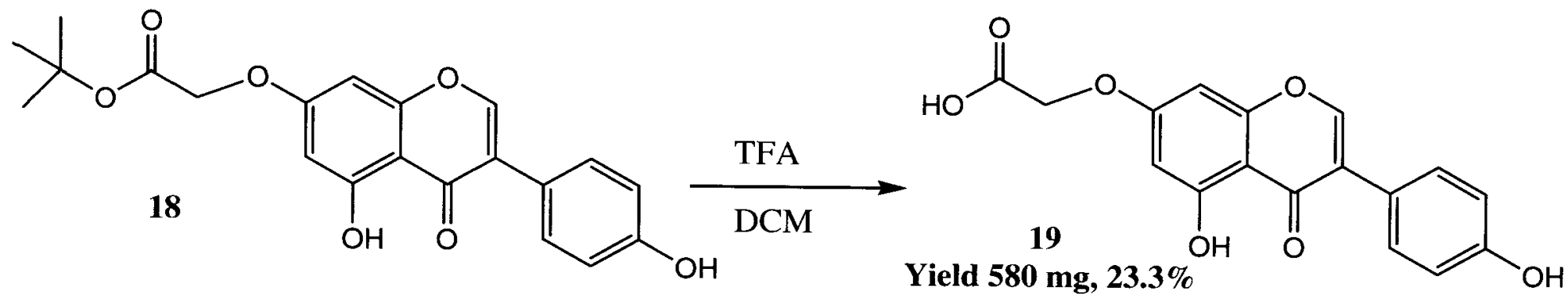

Scheme 13: Acidolysis of $\mathbf{1 8}$ yields an acidic genistein derivative. 


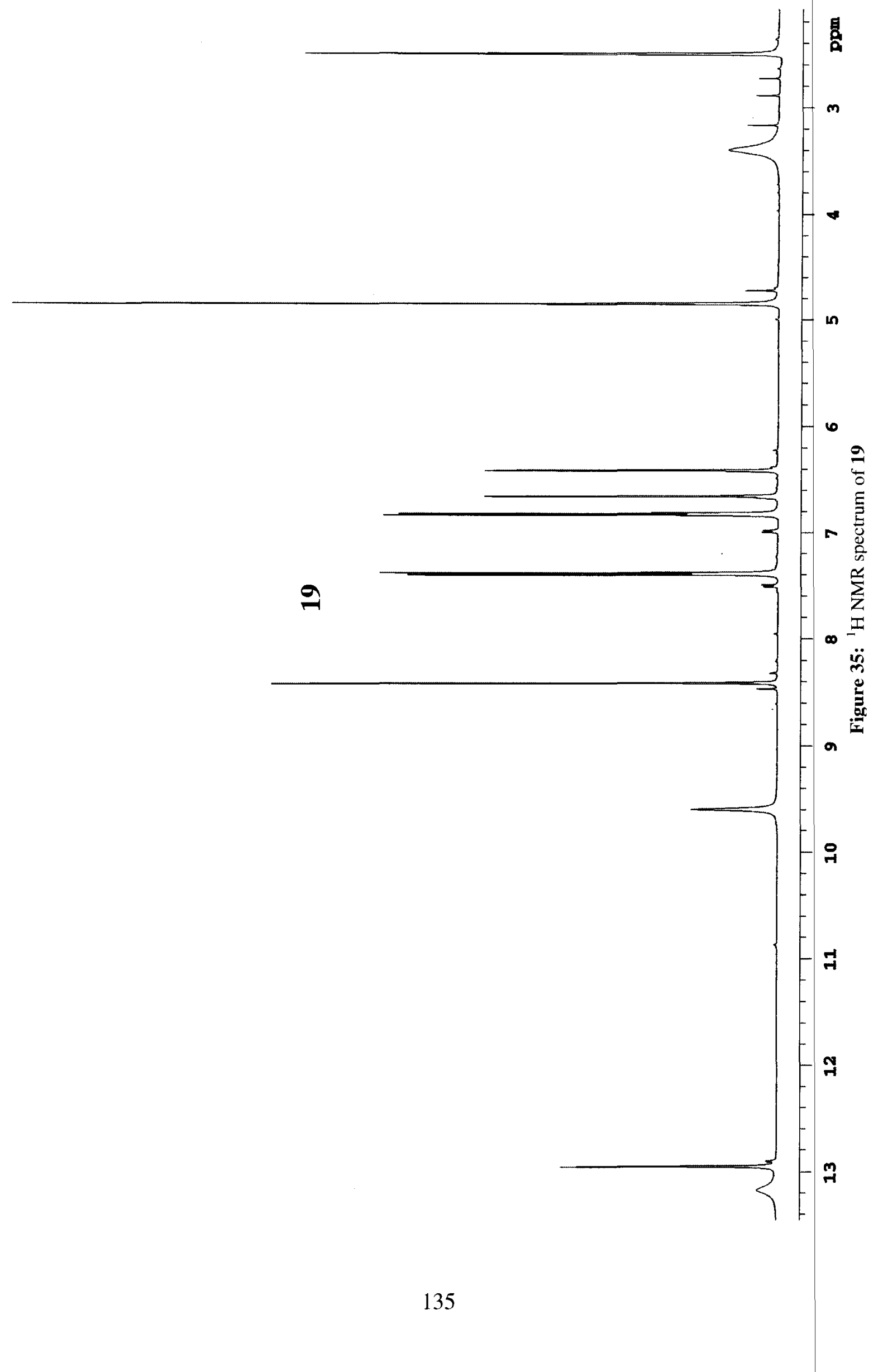




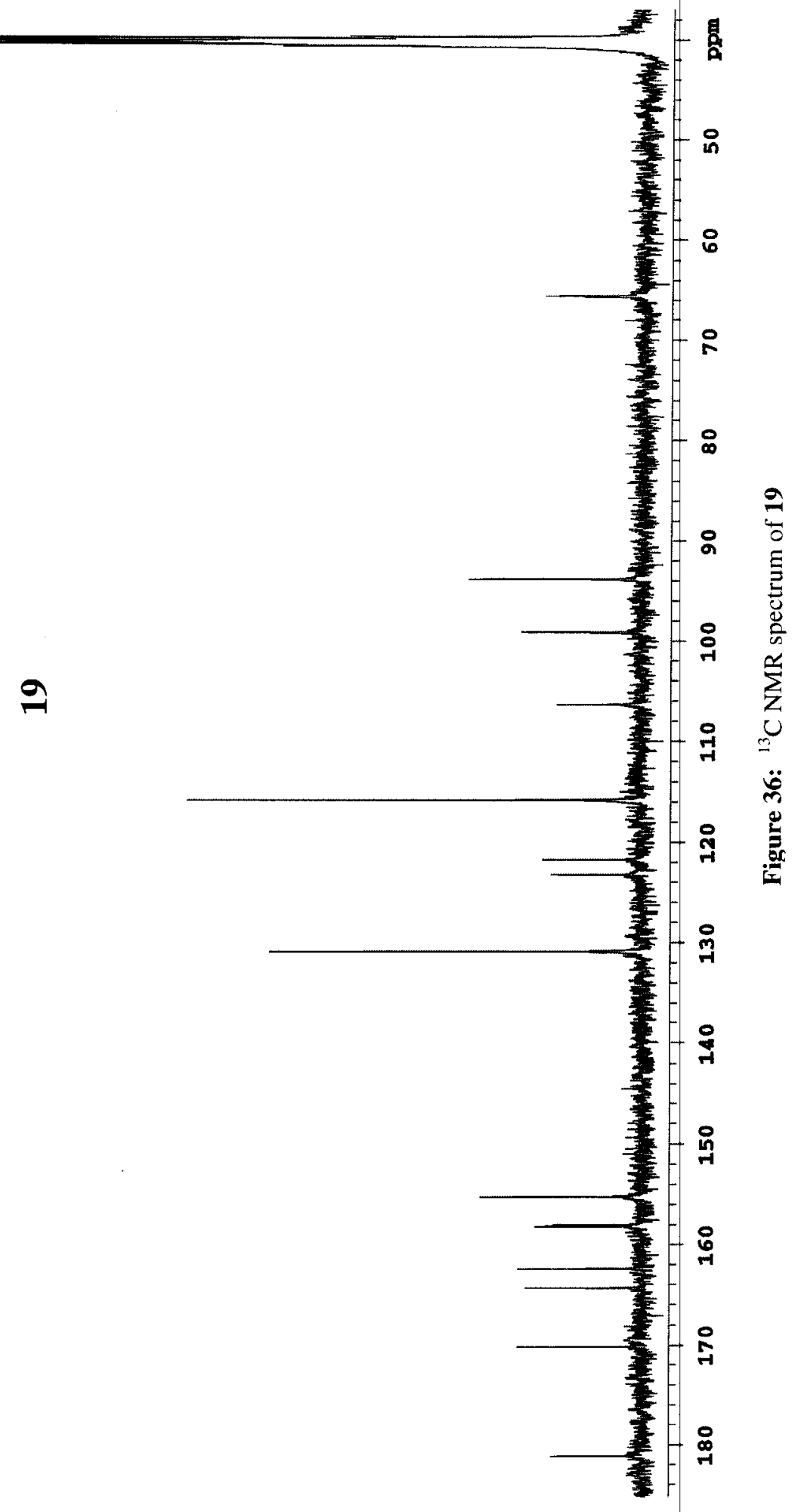


15. Coupling of 19 to Bone-Targeted miniPEG: 2-hydroxy-3-(2-(2-(2-(2-(5-hydroxy-

3-(4-hydroxyphenyl)-4-oxo-4H-chromen-7-

yloxy)acetamido)ethoxy)ethoxy)acetamido)6-methoxybenzamide (20, Scheme 14)

Product 19 (250 mg, $0.8 \mathrm{mmol}$ ), compound 8 (see scheme 3; $273 \mathrm{mg}, 0.8 \mathrm{mmol}$ ), and 1ethyl-3-(3-dimethylaminopropyl) carbodiimide hydrochloride ("EDC", $230 \mathrm{mg}, 1.2$ mmol) were dissolved in $20 \mathrm{~mL}$ DMF. To the stirring solution was added DIEA (557 $\mu \mathrm{L}$, $3.2 \mathrm{mmol})$. The reaction was allowed to proceed at room temperature for 18 hours. The mixture was evaporated to dryness in vacuo to leave a brown oil. The oil was diluted with water, acidified with $5 \%$ aqueous $\mathrm{HCl}$, and extracted into ethyl acetate three times. The organic extracts were combined then dried over sodium sulfate, filtered, and concentrated via rotary evaporation to yield a cloudy yellow oil. Upon trituration in methanol, a white solid (20) precipitated out and was collected via vacuum filtration. Yield: $90 \mathrm{mg}, 22 \% .{ }^{1} \mathrm{H}\left(500 \mathrm{mHz}, \mathrm{DMSO}-\mathrm{d}_{6}\right): \delta 3.33, \mathrm{~m}, 6{ }^{\prime} \mathrm{CH}_{2} ; \delta 3.51, \mathrm{t}, \mathrm{J} 5.61 \mathrm{~Hz}$, $2 \mathrm{H}, 5^{\prime} \mathrm{CH}_{2} ; \delta 3.62, \mathrm{~m}, 2 \mathrm{H}, 4^{\prime} \mathrm{CH}_{2} ; \delta 3.70, \mathrm{~m}, 2 \mathrm{H}, 3^{\prime} \mathrm{CH}_{2} ; \delta 3.86, \mathrm{~s}, 3 \mathrm{H}, \mathrm{C} 6 \mathrm{OCH}_{3} ; \delta 4.09$, s, $2 \mathrm{H}, 2^{\prime} \mathrm{CH}_{2} ; \delta 4.61, \mathrm{~s}, 2 \mathrm{H}, 8^{\prime} \mathrm{CH}_{2} ; \delta 6.41$, d, J $1.83 \mathrm{~Hz}, 1 \mathrm{H}, \mathrm{C} 10$ ' H; $\delta 6.51$, d, J $9.27 \mathrm{~Hz}$, 1H, C5 H; $\delta 6.61$, d, J 1.83 Hz, C18’ H; $\delta 6.82$, d, J 8.66 Hz, 2H, C22’'H/C24’'H; $\delta 7.39$, d, J $8.42 \mathrm{~Hz}, 2 \mathrm{H}, \mathrm{C} 21^{\prime} \mathrm{H} / \mathrm{C} 23^{\prime} \mathrm{H} ; \delta 8.16, \mathrm{~m}, 2 \mathrm{H}, \mathrm{C} 4 \mathrm{H} / \mathrm{C} 6$ ' amide $\mathrm{H} ; \delta 8.27, \mathrm{~s}, 1 \mathrm{H}, \mathrm{C} 1$ amide $\mathrm{H} ; \delta 8.32, \mathrm{~s}, 1 \mathrm{H}, \mathrm{C} 1$ amide $\mathrm{H} ; \delta 8.39, \mathrm{~s}, 1 \mathrm{H}, \mathrm{C} 3$ amide $\mathrm{H} ; \delta 9.60, \mathrm{~s}, 1 \mathrm{H}, \mathrm{C} 23^{\prime} \mathrm{OH} ; \delta 12.93$, s, $1 \mathrm{H}, \mathrm{C} 11$ ' OH. ${ }^{13} \mathrm{C}\left(500 \mathrm{mHz}, \mathrm{DMSO}-\mathrm{d}_{6}\right): \delta 38.96, \mathrm{CH}_{2} ; \delta 56.78, \mathrm{C} 6 \mathrm{OCH}_{3} ; \delta 67.80$, $\mathrm{CH}_{2} ; \delta 69.55, \mathrm{CH}_{2} ; \delta 70.03, \mathrm{CH}_{2} ; \delta 70.76, \mathrm{CH}_{2} ; \delta 71.09, \mathrm{CH}_{2} ; \delta 93.81, \mathrm{CH} ; \delta 94.44, \mathrm{qC}$; $\delta 99.34, \mathrm{CH} ; \delta 100.84, \mathrm{C} 5 ; \delta 115.78, \mathrm{C}_{2} 2^{\prime} / 24^{\prime} ; \delta 116.39, \mathrm{qC} ; \delta 124.65, \mathrm{C} 4 ; \delta 130.87$, C21'/C23'; $\delta 131.52, \mathrm{qC} ; \delta 154.36, \mathrm{qC} ; \delta 154.85, \mathrm{qC} ; \delta 155.19, \mathrm{CH} ; \delta 155.94, \mathrm{qC} ; \delta 158.18$, 
qC; $\delta 162.33, \mathrm{qC} ; \delta 164.08, \mathrm{qC} ; \delta 167.50, \mathrm{qC} ; \delta 168.14, \mathrm{qC} ; \delta 172.56, \mathrm{qC} ; \delta 181.08, \mathrm{qC}$. Mass calculated: 637.1908; Mass found: $637.1908, \Delta=-0.04 \mathrm{ppm}$. 


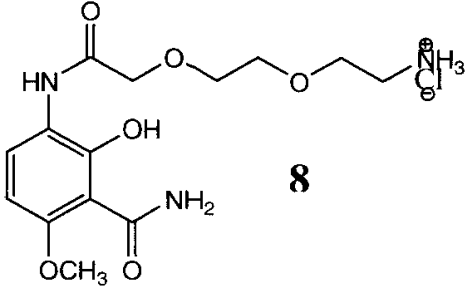

$\bar{\Xi}$
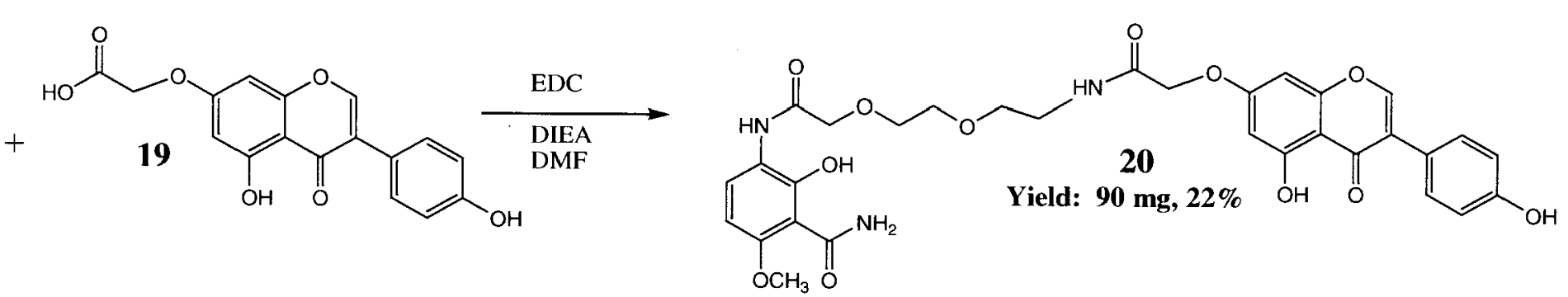

Scheme 14: Formation of bone-targeted genistein. 


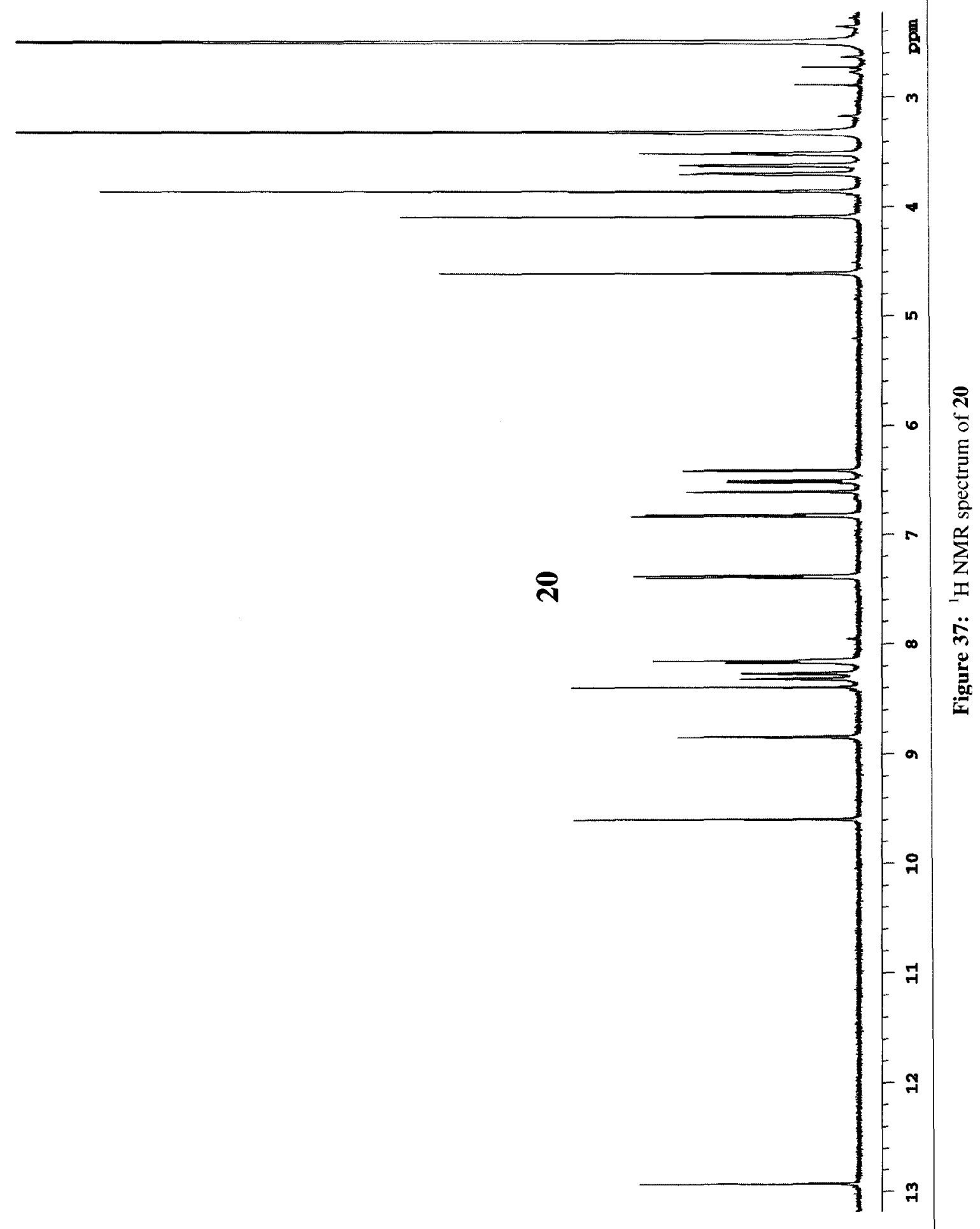




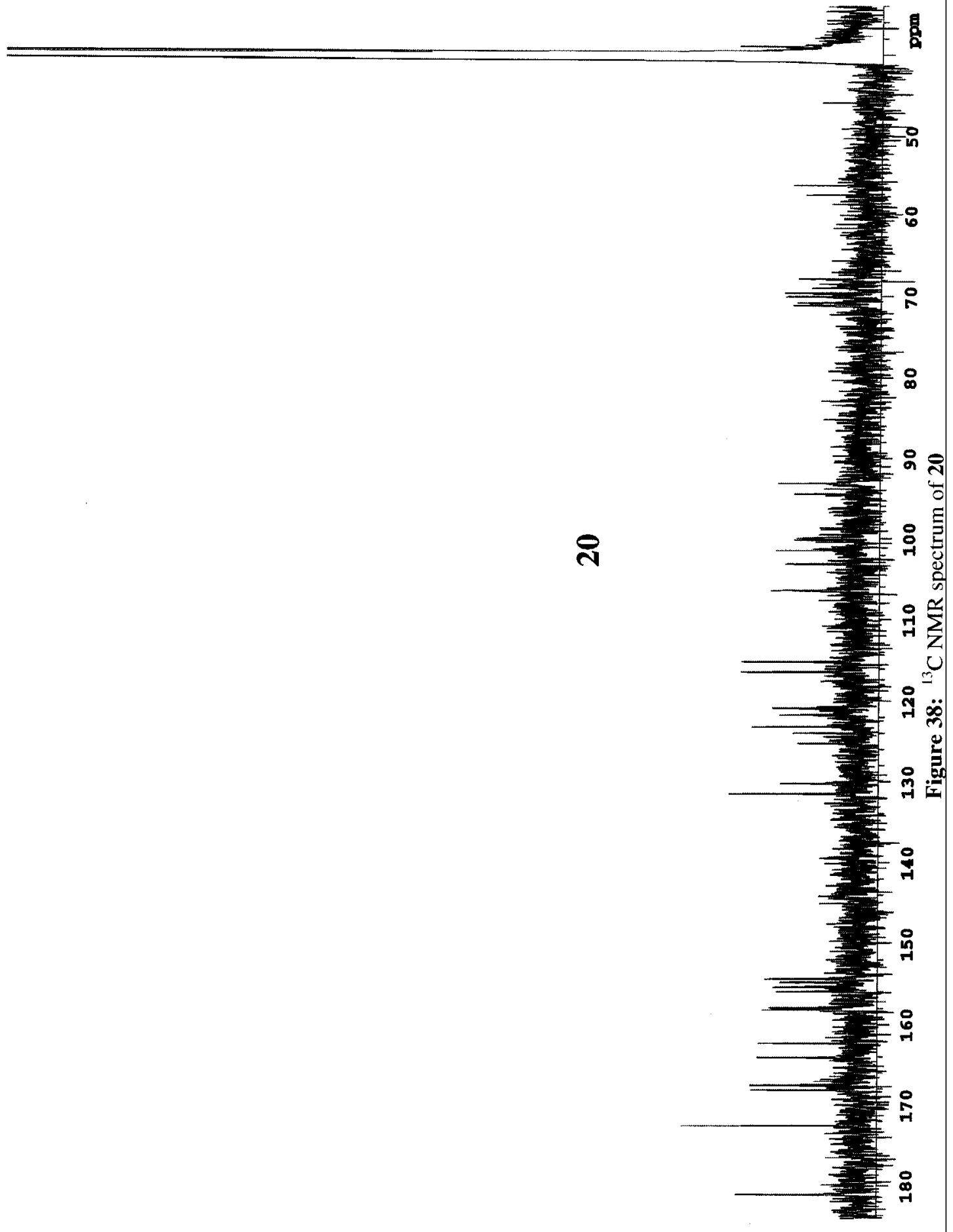




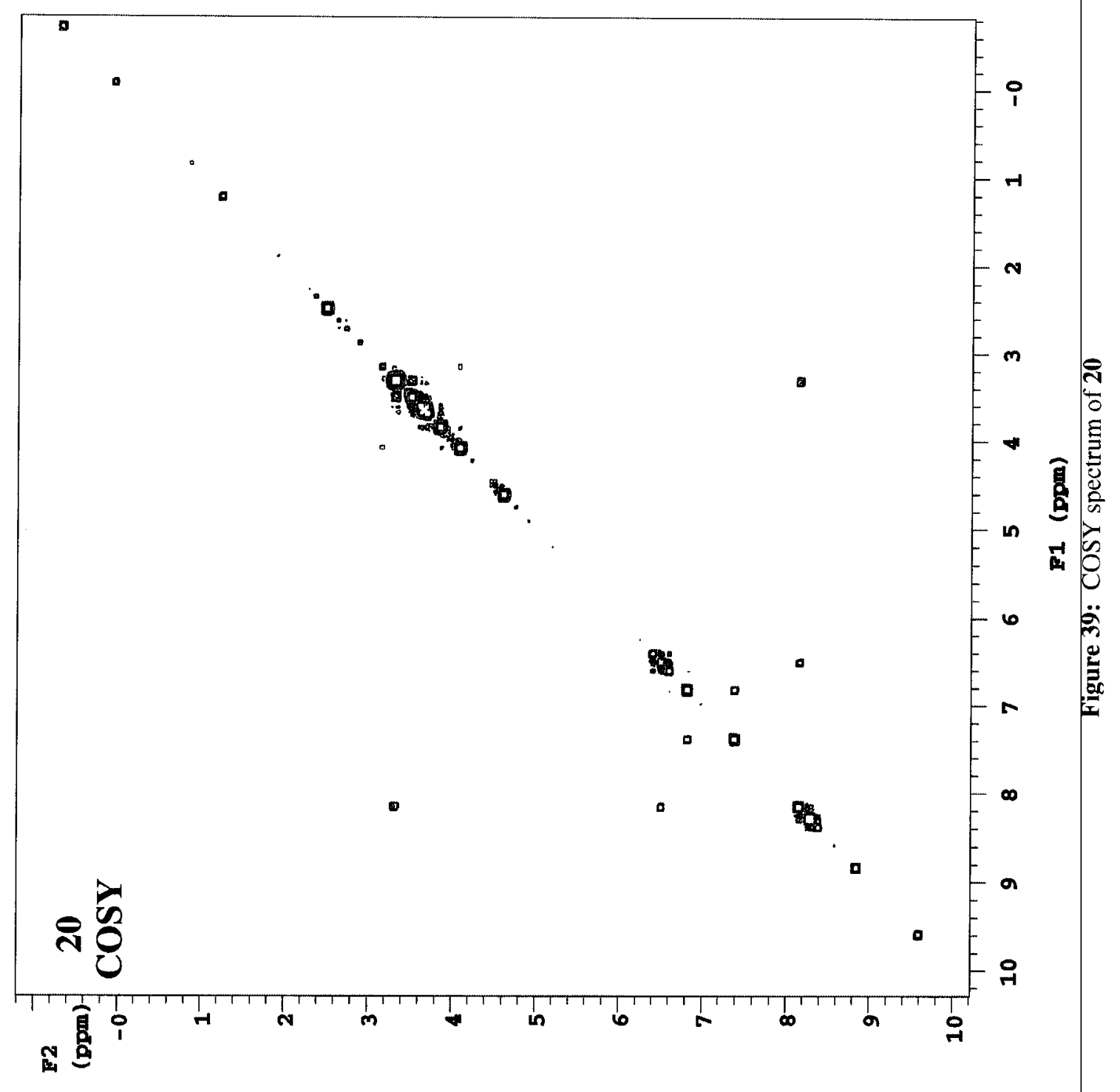




\section{RESULTS AND DISCUSSION}

\section{A. Synthesis}

All of the novel bone-targeted compounds synthesized for this project are summarized in Table $\mathbf{1}$.

The two most selective and potent bone-targeted estrogen conjugates from the first studies were found to be BTE2-D2 and BTE2-D3 (Figure 40). Therefore, we used these molecules as the starting point for this project. Drs. K. Grant Taylor and Sujan Singh developed the synthetic methodology for the bone-targeting agents. The modified synthesis of bone-targeting agent $\mathbf{1}$ (previously labeled "D2") is described in the Experimental section. Bone-targeting agent 2 (previously labeled "D3") was purchased from Ricerca Biosciences, Concord, OH. The 'H NMR spectra of $\mathbf{1}$ and $\mathbf{2}$ are shown in Figure 41.<smiles>COc1ccc(NC(=O)CCO[C@H]2CCC3C4CCc5cc(O)ccc5C4CCC32C)c(O)c1C(N)=O</smiles><smiles>CC12CCC3c4ccc(O)cc4CCC3C1CC[C@@H]2OCCC(=O)Nc1ccc(OCc2ccccc2)c(C(N)=O)c1O</smiles>

Figure 40: Bone-targeted estrogen conjugates BTE2-D2 (left) and BTE2-D3 (right) were the lead compounds from the studies prior to the current project. 


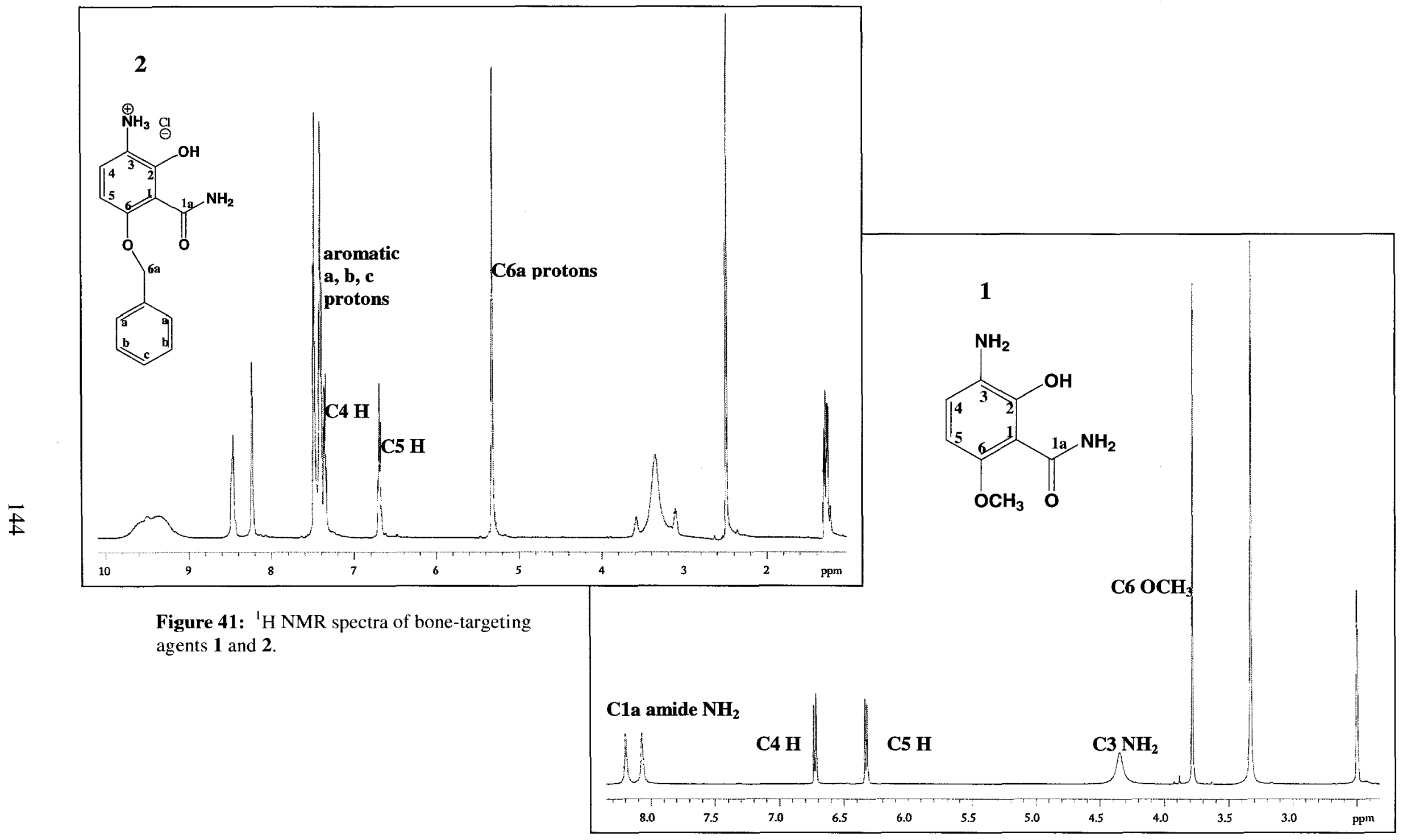


Table 1: Novel bone-targeted compounds synthesized for this project

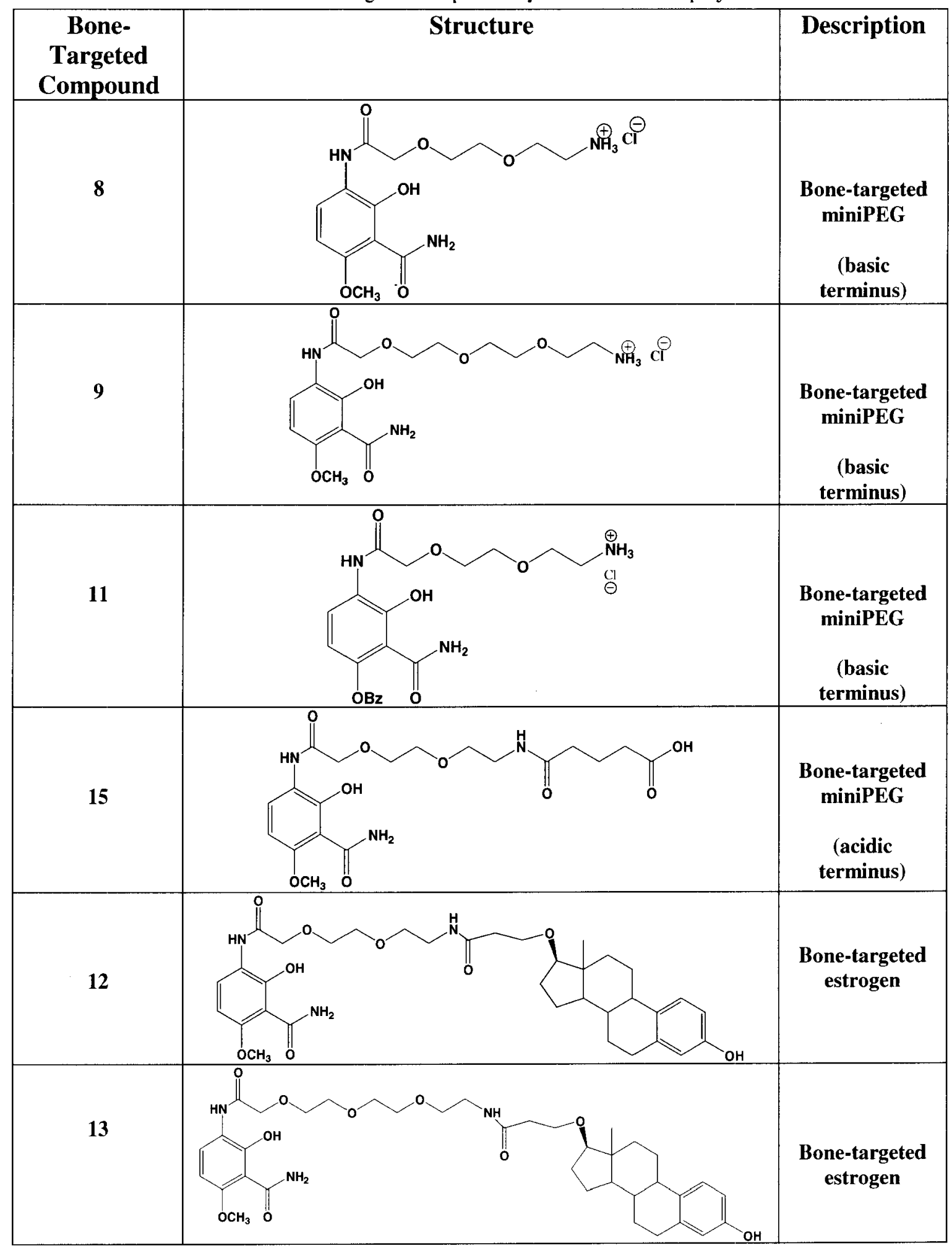

(continues) 


(1)




\section{Bone-Targeted mini-PEG Compounds}

To investigate the effects that new "spacers," or "linkers," would have on the bonetargeted estrogens, linkers that were more hydrophilic and flexible than those previously used were incorporated into the conjugates. As stated in the Background section, the linkers of choice for this project were chosen to be 8-amino-3,6-dioxaoctanoic acid ("mini-PEG") and its longer derivative 11-amino-3,6,9-trioxaundecanoic acid ("miniPEG-3"). Couplings utilizing both fluorenylmethyloxycarbonyl- ("Fmoc-") and tertbutyloxycarbonyl- ("Boc-") protected mini-PEGs were explored. Due to the volatility of the side-products (isobutylene and carbon dioxide) formed during Boc-deprotection, it was originally thought that Boc-mini-PEG would be the more logical choice for use in these syntheses. Unexpectedly, the Fmoc-mini-PEGs gave more consistent and satisfactory results. Use of the Boc-protected compounds was complicated by a necessary dicyclohexylammonium ("DCHA") desalting process and it was difficult to remove the all of the DCHA. Consequently, Fmoc-chemistry was employed in the synthesis of all of the bone-targeted mini-PEG compounds (henceforth referred to as “BT-MPs").

Four new potential "shelf-stable" bone-targeted compounds were synthesized as potential "universal" linkers. Figure $\mathbf{4 2}$ summarizes the BT-MPs. In the case of BTA 1, both the mini-PEG and mini-PEG-3 were effectively coupled to the bone-targeting agent. The attempts to couple the mini-PEG-3 linker to BTA 2 were unsuccessful.

Three of the four new bone-targeted compounds have basic termini through which a drug-conjugate could be formed. The most synthetically facile of these three compounds was found to be 2-(2-(2-(3-carbamoyl-2-hydroxy-4-methoxyphenylamino)-2- 
oxoethoxy)ethoxy)ethanaminium chloride (8, Figure 42). Therefore, glutaric anhydride was coupled to the end of that compound to give a bone-targeted entity with an acidic terminus (Figure $\mathbf{4 3}$ ).
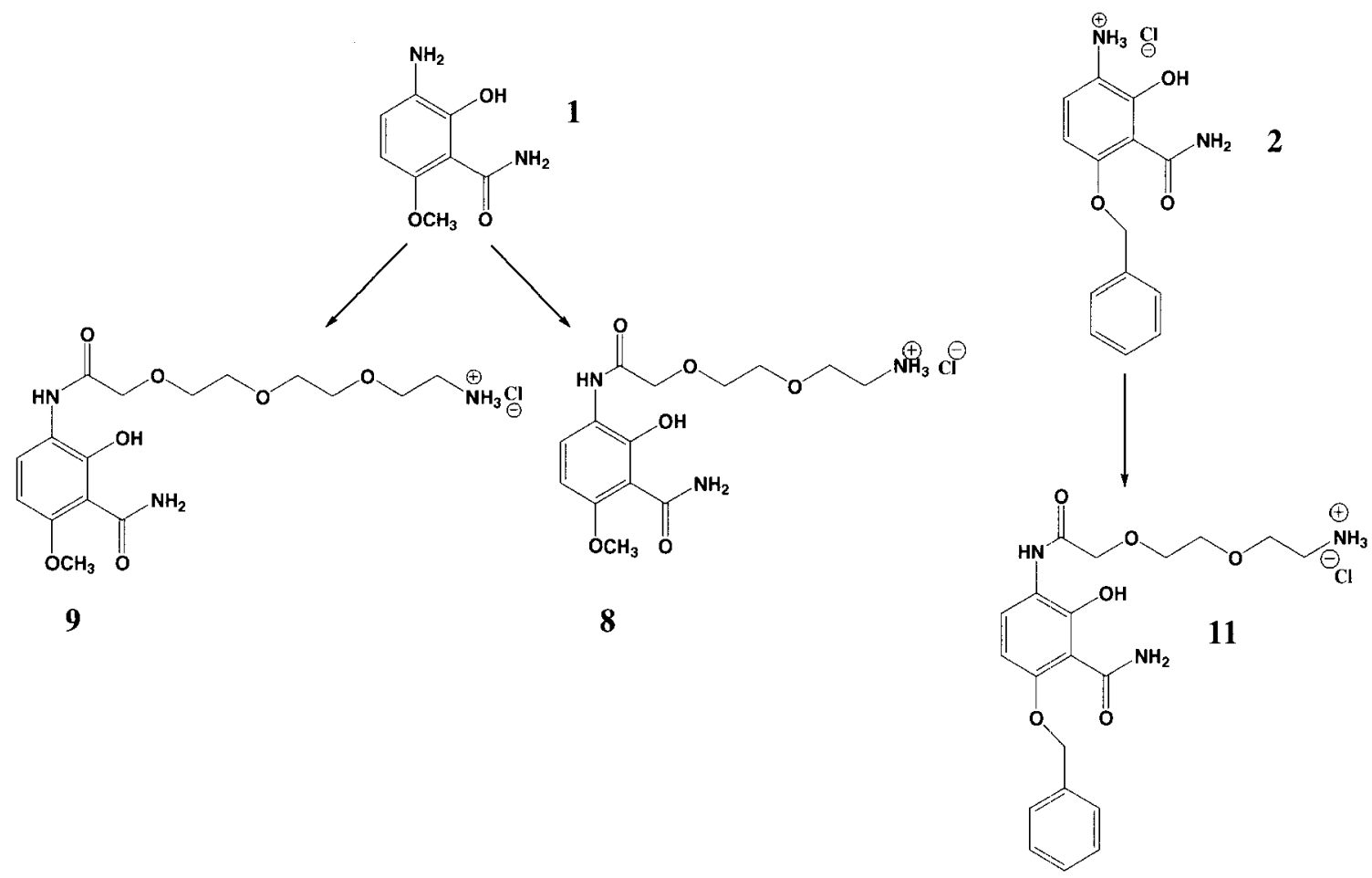

Figure 42: Bone-targeting agents 3-amino-2-hydroxy-6-methoxybenzamide (1) and 3-amino-6-benzyloxy2-hydroxybenzamide hydrochloride (2) were linked to mini-PEG molecules. 
<smiles>COc1ccc(NC(=O)COCCOCCNC(=O)CCCC(=O)O)c(O)c1C(N)=O</smiles>

Figure 43: Product 15. Glutaric anhydride was coupled to compound 8 (figure 9) to give a bone-targeted molecule with an acidic terminus.

As shown in Table 2 of the BT-MPs, the compound arising from 3-amino-2hydroxy-6-methoxybenzamide (1) and Fmoc-mini-PEG gave the most acceptable results. Relatively high yields were accomplished for both the coupling and Fmoc-deprotection processes. Most importantly, no chromatographic purification was necessary for either of these products. Instead, all of the products precipitated nicely out of methanol. 


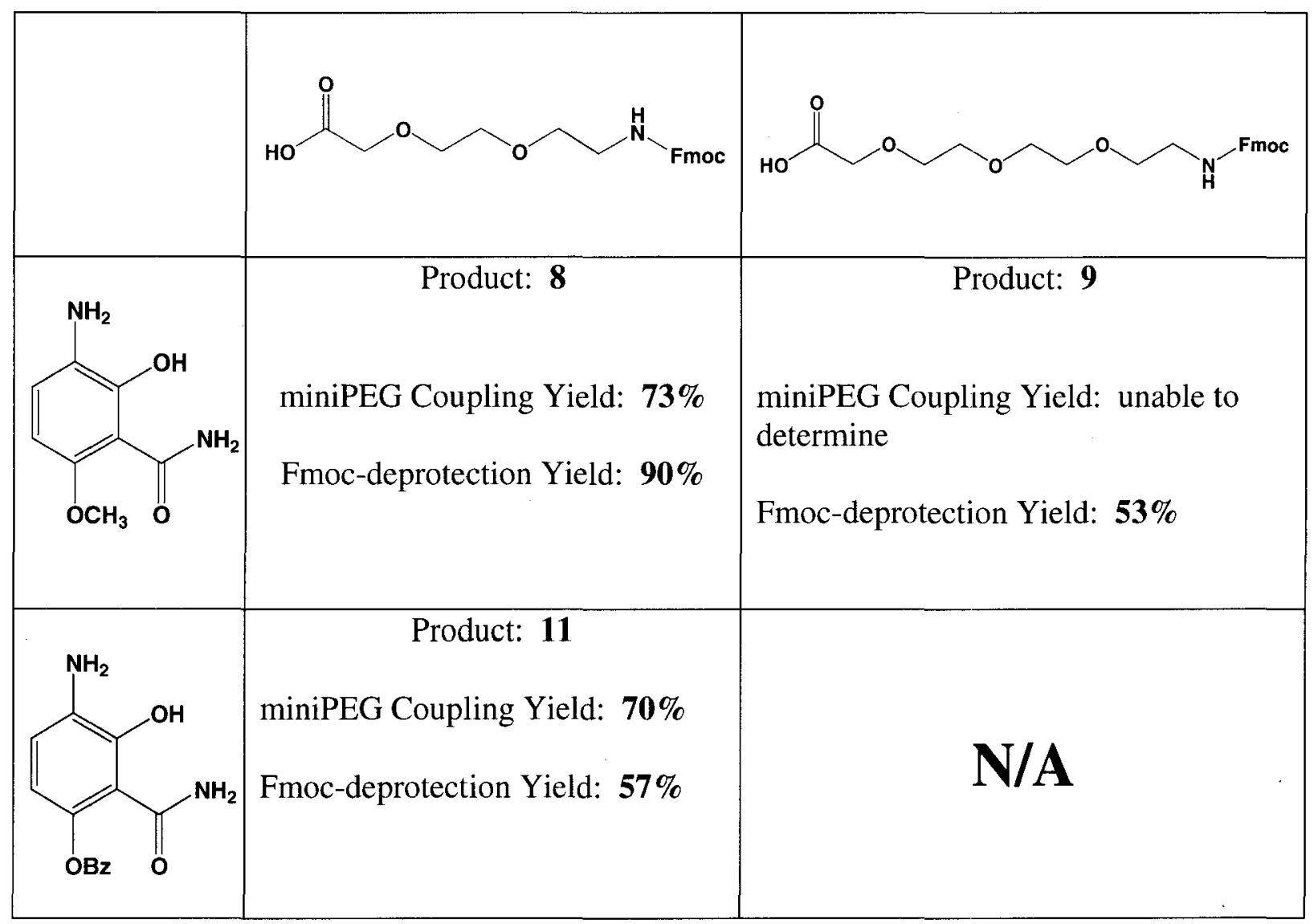

Table 2: Summary of synthetic results from bone-targeted mini-PEGS and estradiol conjugates

All of the amide couplings were performed with the condensing agents hydroxybenzotriazole ("HOBt”) and benzotriazole-1-yl-oxy-tris-(dimethylamino)phosphonium hexafluorophosphate ("BOP") in DMF using diisopropylethylamine ("DIEA") as a base. Equimolar amounts of carboxylic acid and amine seemed to be sufficient for the couplings, while an excess of coupling agents (1.3-2 times) and a twofold excess of base gave satisfactory yields in most cases. It was noted that after the reaction, complete removal of DMF was imperative for successful product isolation. Most completed reaction mixtures were left under vacuum $(<10 \mathrm{~mm} \mathrm{Hg})$ while on a 
rotary evaporator set at $35-40^{\circ} \mathrm{C}$ for one hour before and after reaction work-up. Only after all of the DMF was removed would the products precipitate from methanol.

Although the formation of amide bonds can sometimes be troubled by the presence of water due to its role as a competing nucleophile, rigorously anhydrous conditions were found not to be necessary for these particular couplings. The use of reagent grade solvents and fresh reagents appeared to be adequate for acceptable yields. No difference was observed when the reactions were performed under an inert atmosphere.

Figure 44 shows the 1-dimensional ${ }^{1} \mathrm{H}$ NMR spectra obtained from products 8,9 , and 11. The new amide proton is in red. 

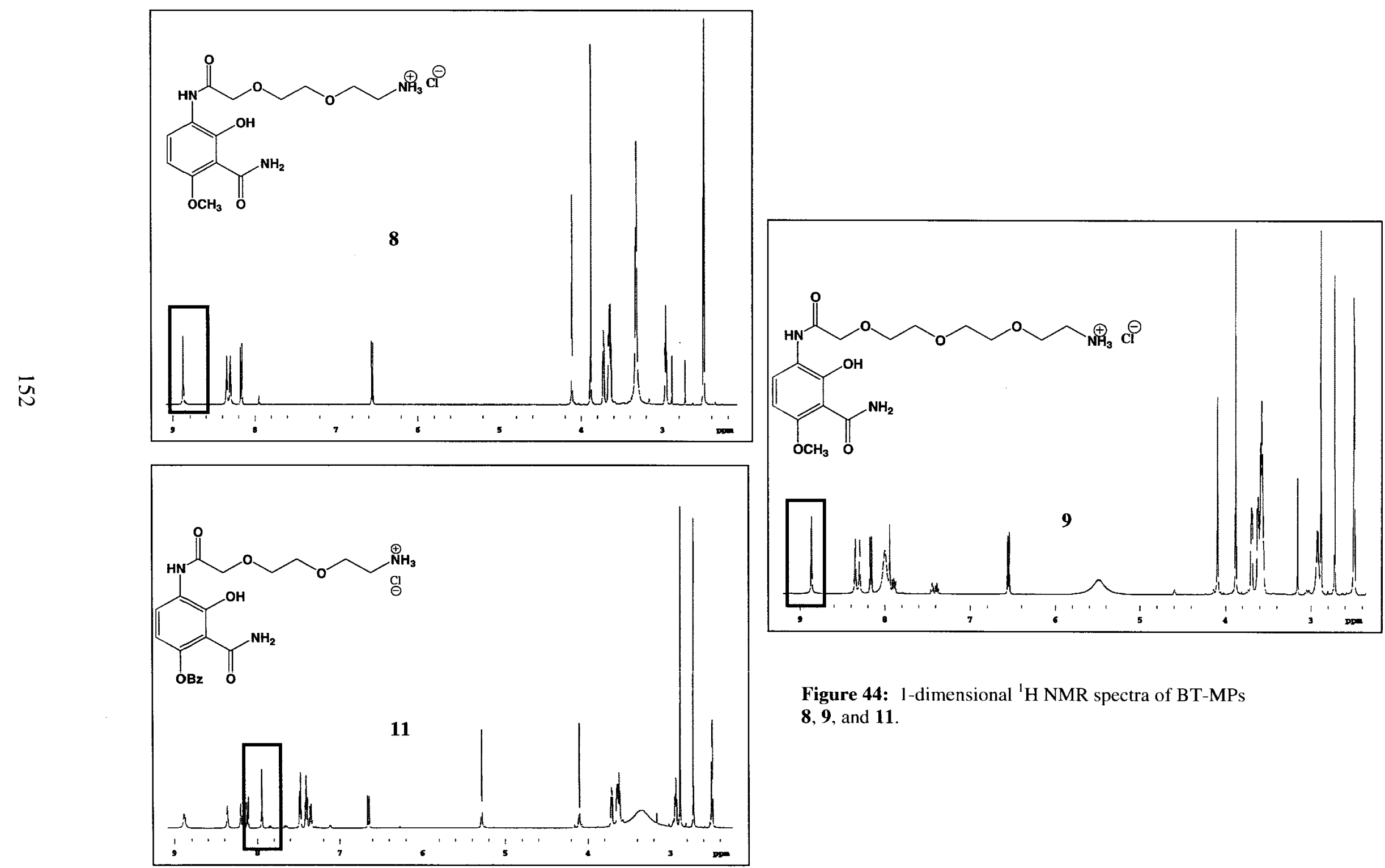

Figure 44: 1-dimensional ${ }^{1} \mathrm{H}$ NMR spectra of BT-MPs $\mathbf{8 , 9}$, and 11 . 


\section{Bone-Targeted Estrogen Conjugates}

Three novel bone-targeted estrogens (Table 3 ) were synthesized as described in the experimental section.

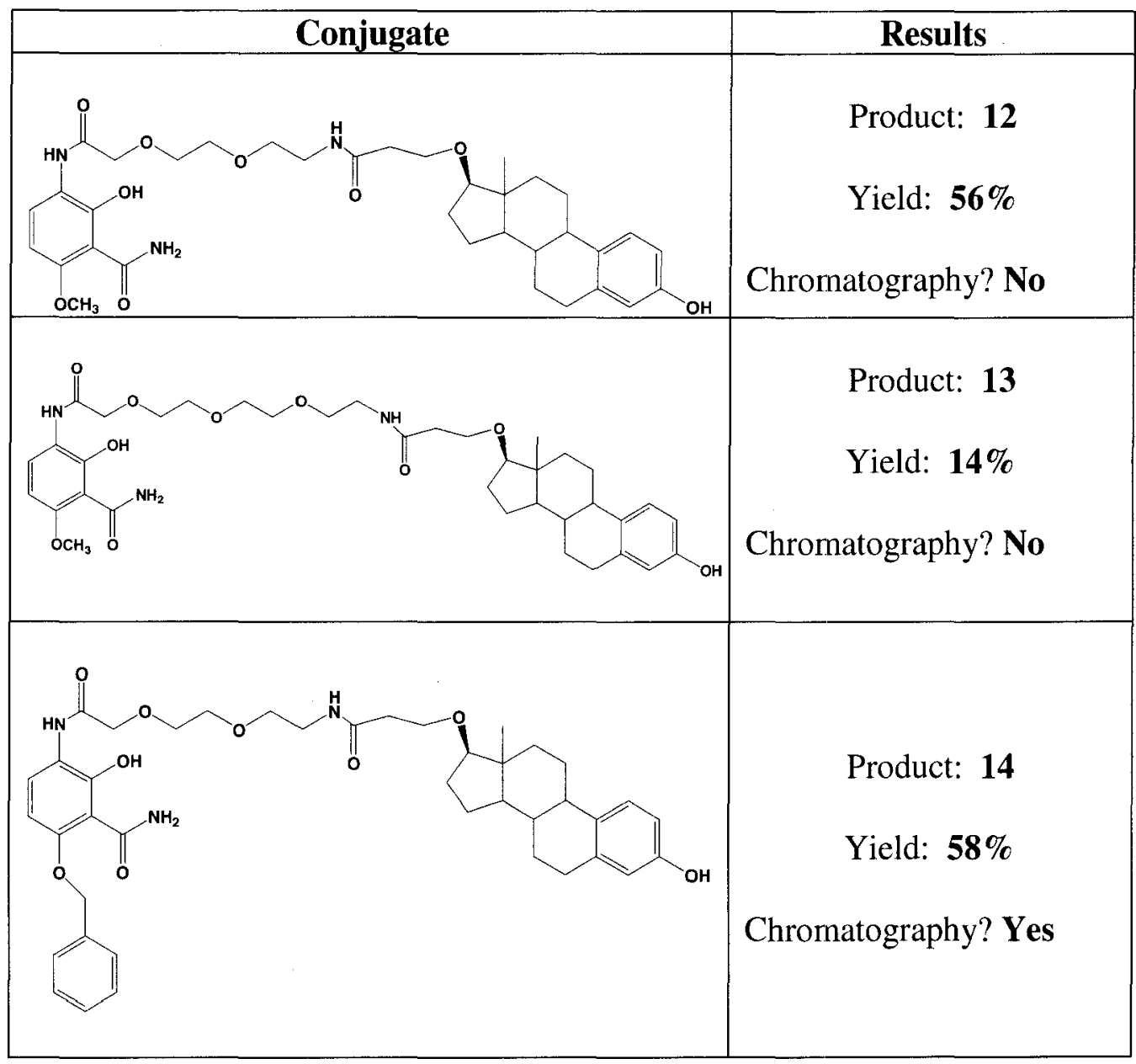

Table 3: Bone-targeted estradiol conjugates

The same reaction and work-up conditions were used for these couplings as employed for making the BT-MPs. Although all three of the BT-MPs did yield a novel drug conjugate when coupled to $\beta$-estro-O-propanoic acid, product $\mathbf{1 2}$ was synthetically less complicated to isolate than products $\mathbf{1 3}$ and $\mathbf{1 4}$. After work-up, $\mathbf{1 2}$ precipitated immediately when triturated in methanol, giving a clean solid product. Product $\mathbf{1 3}$ could 
only be collected after sitting in hexane for some length of time, on the order of weeks, at $4^{\circ} \mathrm{C}$. Although it precipitated out purely, the yield was very poor - only $14 \%$. Finally, 14 was produced in a moderate yield, but did require chromatographic separation.

The couplings were monitored by ${ }^{1} \mathrm{H}$ NMR spectroscopy. Upon the formation of the amide bond, a correlation could be observed in the COSY spectrum between the terminal $\mathrm{NH}$ proton of the BT-MP and its neighboring methylene protons. Also, a downfield shift could be noted in the terminal methylene protons in the 1-dimensional spectrum when the amide formed. Figures $\mathbf{4 5}$ and $\mathbf{4 6}$ outline the spectral observations in product $\mathbf{1 2}$.
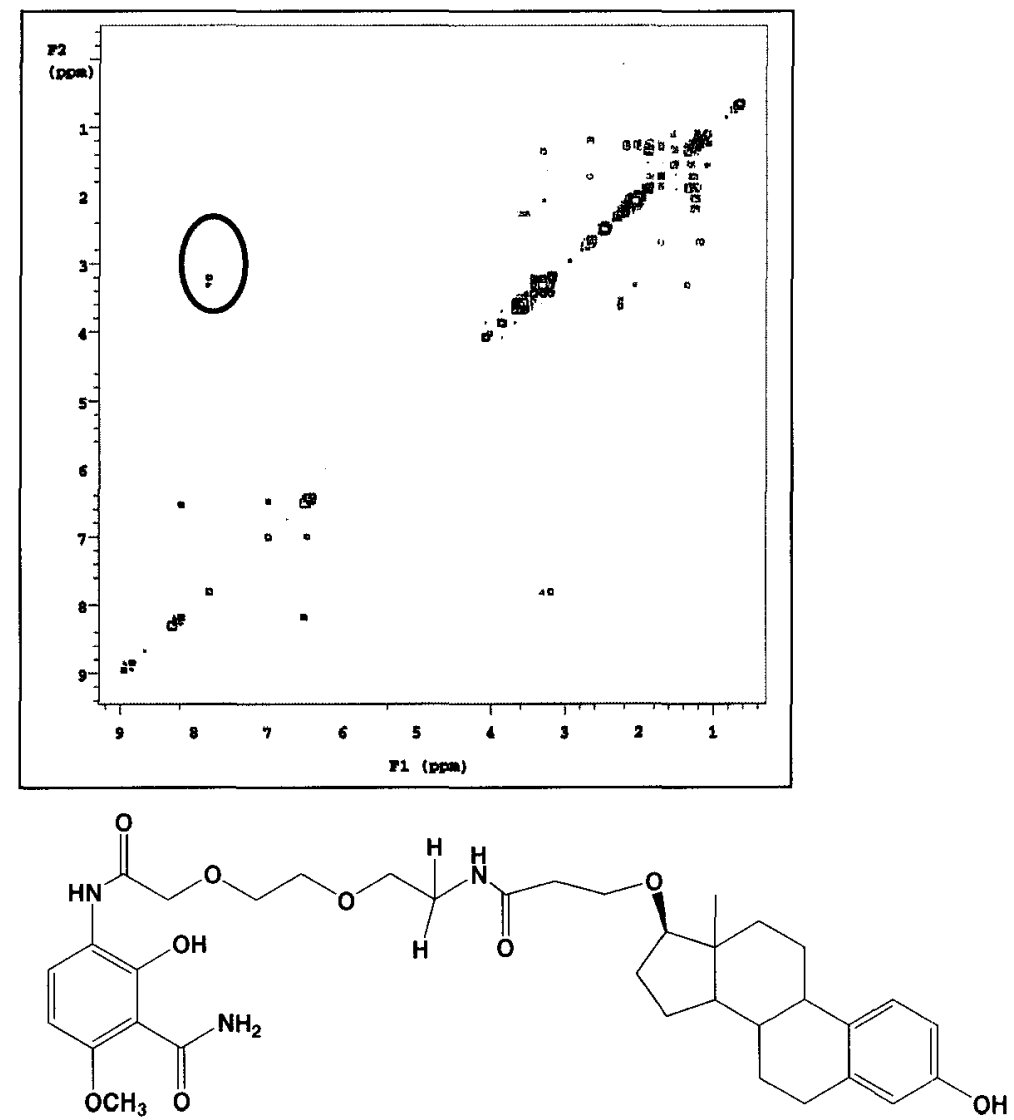

Figure 45: The through-bond coupling interaction between the protons highlighted in red can be observed in the COSY spectrum of the newly formed conjugate. 

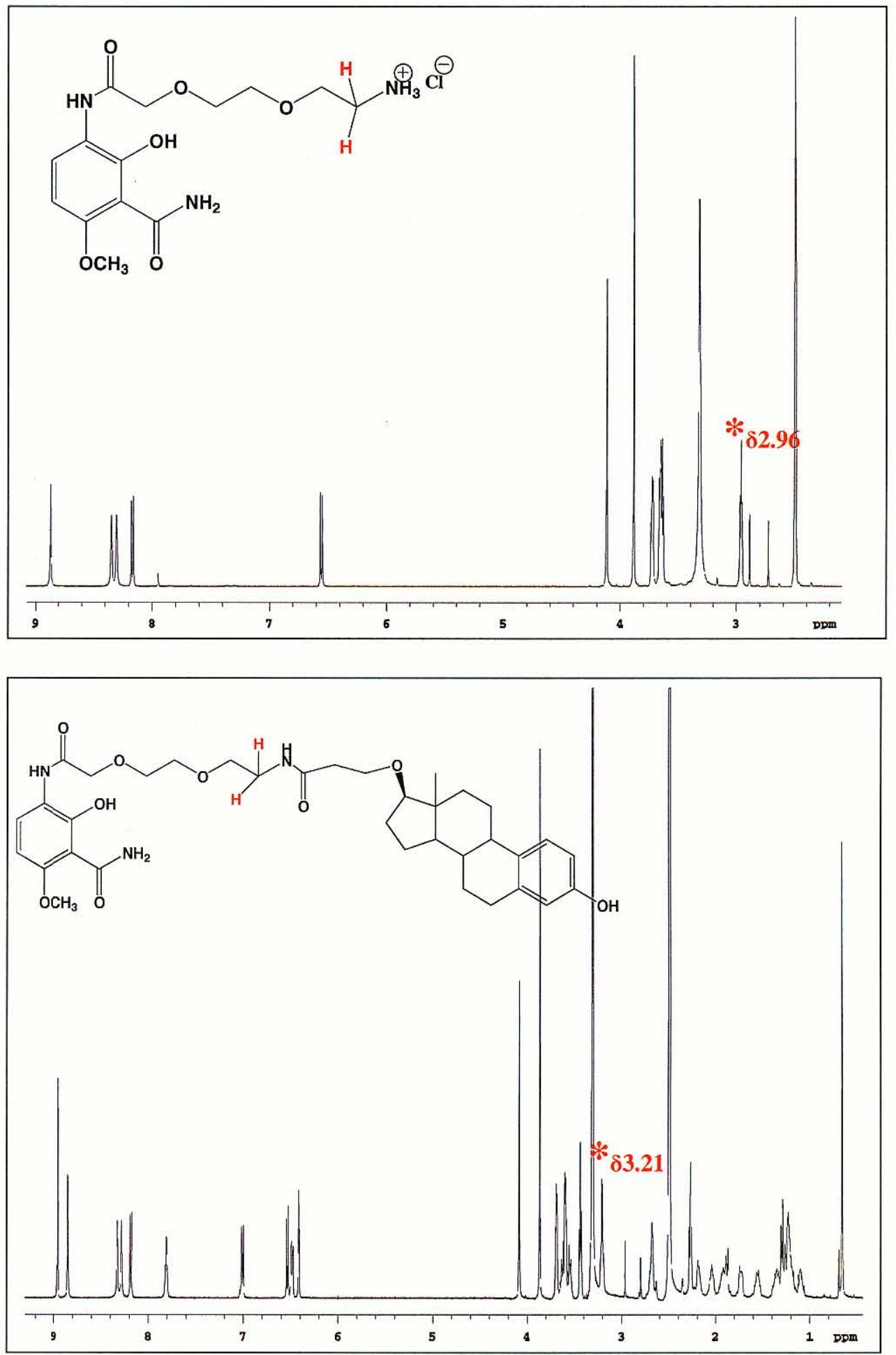

Figure 46: A downfield shift could be noted in the terminal methylene protons (red) in the 1-dimensional spectrum when the amide formed. 
It was discovered that the replacement of the O-methyl group at carbon 6 (as in 1) with an O-benzyl (as in 2) gave no significant advantage to the biological activity of the estradiol conjugates (discussed in next section). That information, coupled with the pleasing synthetic outcomes, led to the decision that future drug conjugates would be made from the bone-targeting agent 1 and mini-PEG scaffold. Thus, compound 8 (below) became the sought-after "shelf-stable" bone-targeting entity.<smiles>COc1ccc(NC(=O)COCCOCC[NH3+])c(O)c1C(N)=O</smiles>

Figure 47: Because of the successful synthetic outcomes from the Fmoc-mini-PEG coupling, the Fmoc-deprotection, and estradiol conjugate formation, compound 8 would be used as the bone-targeting entity for future drug conjugates. 


\section{Bone-Targeted Doxorubicin Conjugate}

In order to synthesize a conjugate of the anticancer drug doxrubicin (see Figure 48), the acidic $\mathbf{1 5}$ shown in Figure $\mathbf{4 3}$ was coupled to the amino sugar of the doxorubicin molecule. The amino group is highlighted in red.

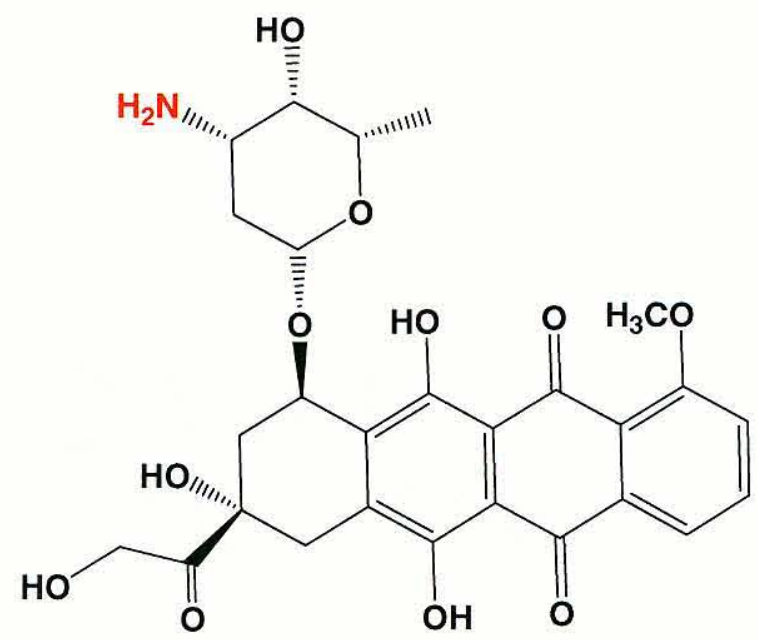

Figure 48: Doxorubicin. The bone-targeted conjugate utilized the amino group highlighted in red.

Although the estradiol conjugate of $\mathbf{8}$ precipitated out nicely from methanol after the reaction work-up, the doxorubicin conjugate of $\mathbf{1 5}$ displayed dramatically different behavior. After the DMF was removed from the reaction mixture, the remaining red residue was found to be insoluble in ethyl acetate and other typical organic extraction solvents. To remove excess coupling agent, the product was stirred in EtOAc, and then centrifuged and the supernatant removed. This process was repeated several times. Finally, reverse-phase column chromatography had to be employed to separate unreacted doxorubicin from the drug conjugate. The described methodology yielded a product of high purity. Analogous to the estradiol conjugates, 1- and 2-dimensional ${ }^{1} \mathrm{H}$ NMR 
spectroscopic analysis was used for to confirm amide bond formation between $\mathbf{8}$ and doxorubicin.

\section{Bone-Targeted Fluorescein}

Making a bone-targeted conjugate of fluorescein proved to be more challenging. Initially, we wanted to use an amide bond to link a BT-MP to a fluorophore. Amide bonds are less susceptible to degradation than esters and easier to form than ethers or esters. The first fluorescent molecule of choice was 5-aminofluorescein ("5AF"; Figure 49). When the standard procedure used for amide bond formation in this project ( $\mathrm{HOBt} / \mathrm{BOP}$ coupling in DMF with DIEA) was attempted with 5AF, a side-reaction between the $\mathrm{BOP}$ reagent and $5 \mathrm{AF}$ was noted. An additional complication arose from the fact that $5 \mathrm{AF}$ exists in an equilibrium between a lactone and an open-chain quinoid (Figure 50). Because this equilibrium is $\mathrm{pH}$ dependent, the solubility properties of the molecule also change with $\mathrm{pH}$. When the coupling reaction was worked-up as usual, the product was distributed between the aqueous and organic layers. To avoid this difficulty, a new synthetic scheme was proposed (see Scheme 15). First, esterification of the openchain tautomer of the 5AF molecule as described in the literature (Burchak, et al, 2006), would "lock" the molecule into one tautomeric form (it happens that the open-chain quinoid form of $5 \mathrm{AF}$ is the form in which the molecule is fluorescent.) Subsequently, amide bond formation could take place at the 5-amino position using acidic BT-MP 15 . 


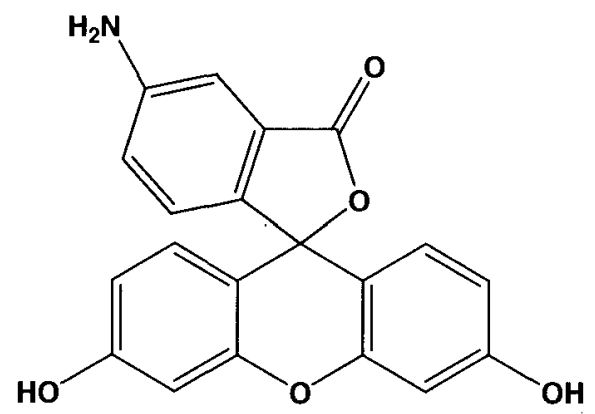

Figure 49: 5-aminofluorescein.

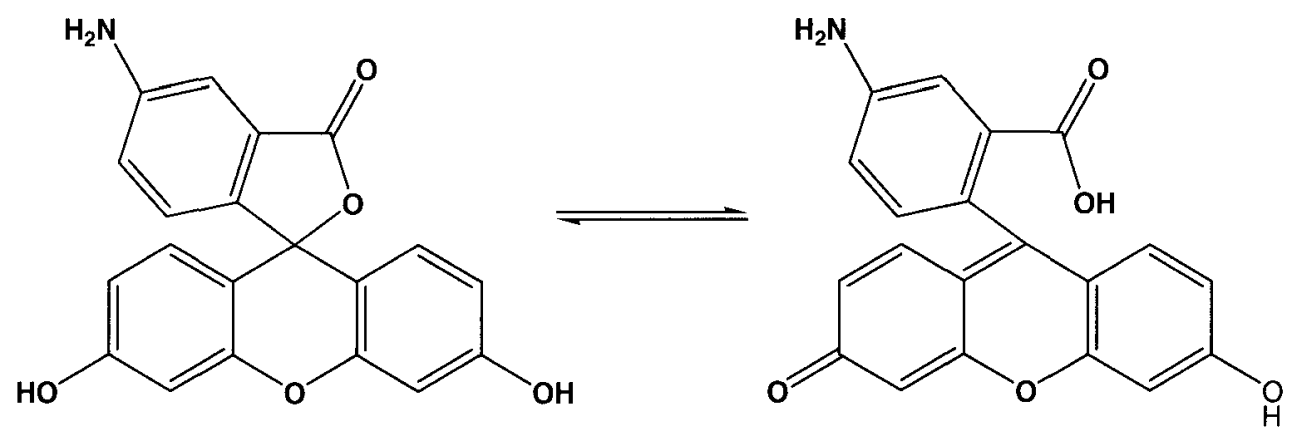

Figure 50: 5-aminofluorescein exists as in equilibrium between a lactone and an open-chain acid. 

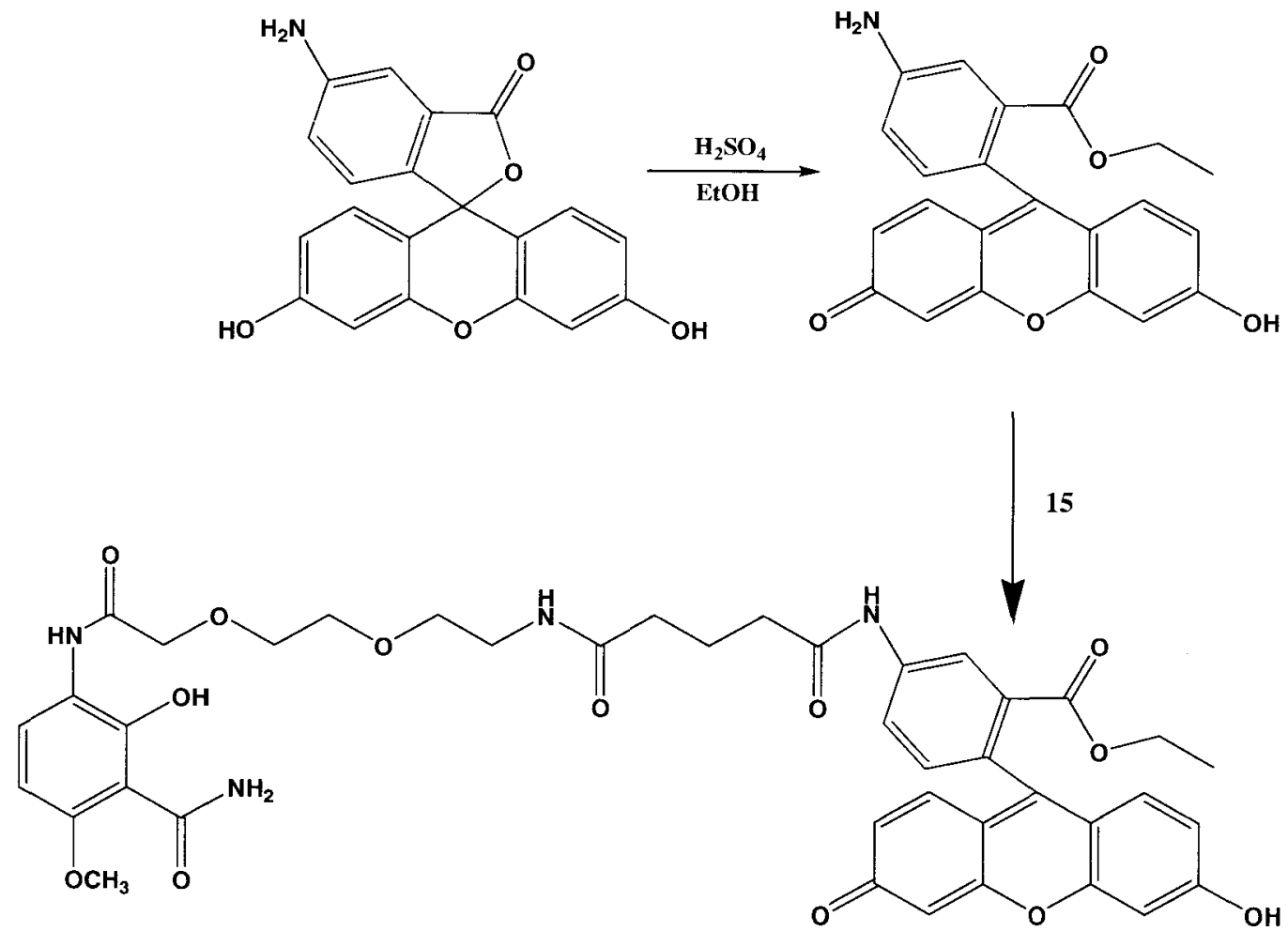

Scheme 15: Proposed synthetic strategy for making bone-targeted fluorophore. 
While the esterification was accomplished with moderate success (65\% yield), the coupling step seemed to yield some undesired ester product at the remaining phenolic position. Instead of trying to block the phenolic position after esterification, it was decided to try alkylating that position with t-butyl bromoacetate and then cleaving the ester to get a carboxylic acid functionality (Scheme 16). Since the second strategy would not make use of the amino group on the $5 \mathrm{AF}$ molecule, it was proposed to try the synthesis on fluorescein itself. However, the new synthetic scheme was quickly abandoned after the esterification of fluorescein lead to an alkylated product at the phenolic position.

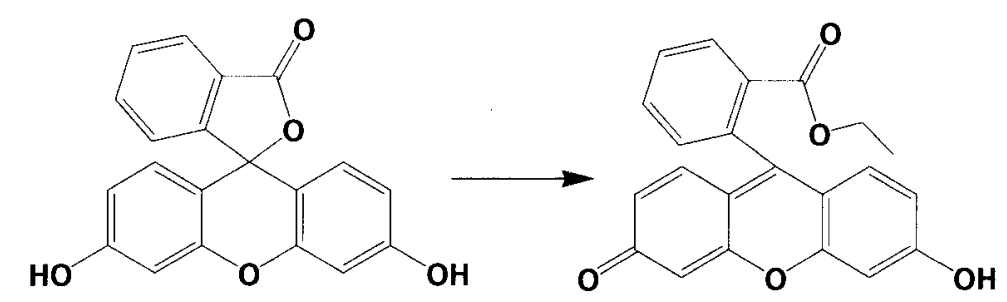

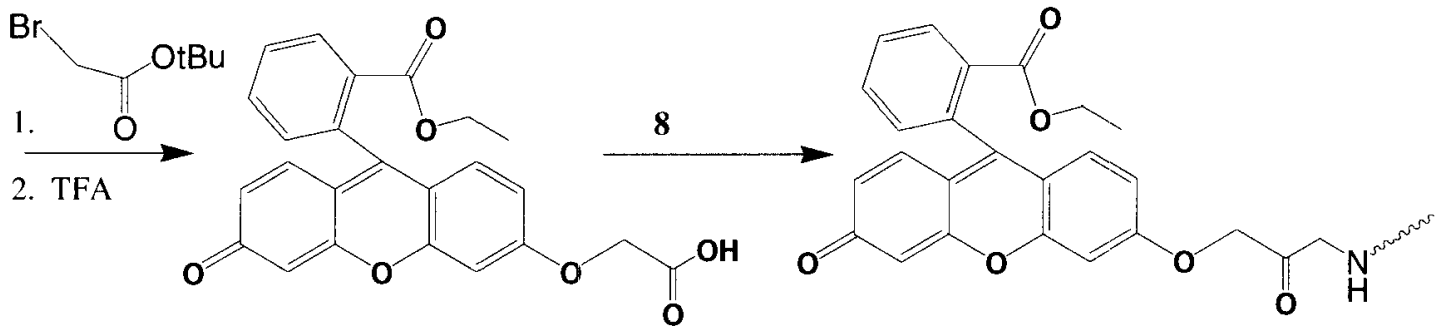

Scheme 16: Strategy 2. Esterify fluorescein, alkylate at phenolic position, then finally conjugate through acidic functionality. 
Once again, the synthetic approach was modified. Employing the commonly used fluorescein isothiocyanate (FITC), a bone-targeted fluorophore was quickly synthesized, as described in the Experimental section. The FITC conjugate of $\mathbf{8}$ is linked via a thiourea bond, a more labile bond than an amide. However, Wang, et al (2003) published a study in which a FITC-labeled bone-targeted conjugate was investigated in vivo and biodegradation was not a problem.

Although the coupling of the bone-targeted miniPEG went quickly and resulted in an acceptable crude yield (51\%), it was obvious from ${ }^{\mathrm{I}} \mathrm{H}$ NMR characterization that a significant amount of diisopropylethylamine was still present in the crude material. Subjecting the solid to strong vacuum, even for long periods of time, did not eliminate the residual base. With the hopes of removing the DIEA via ionic interactions, the crude substance was dissolved in methanol, stirred with Dowex 50x8 resin for several hours, and then filtered. After the methanol was removed, the orange powder that resulted appeared to be free of DIEA.

While the NMR spectra of product $\mathbf{1 7}$ do show a small amount of DMF and methanol left in the solid, the removal of these solvents is much more straightforward than is DIEA removal. Also, the relative amount of DIEA left after the reaction compared to DMF is much greater. Collectively, the chemical investigations with fluorescein resulted in the development of synthetic and purification protocols for a bone-targeted fluorophore. Fluorescence spectra of $\mathbf{1 7}$ revealed maximum excitation occurred at $\lambda=495 \mathrm{~nm}$ and maximum emission at $\lambda=520 \mathrm{~nm}$ (see Figure 51). 


\section{Excitation Spectrum}

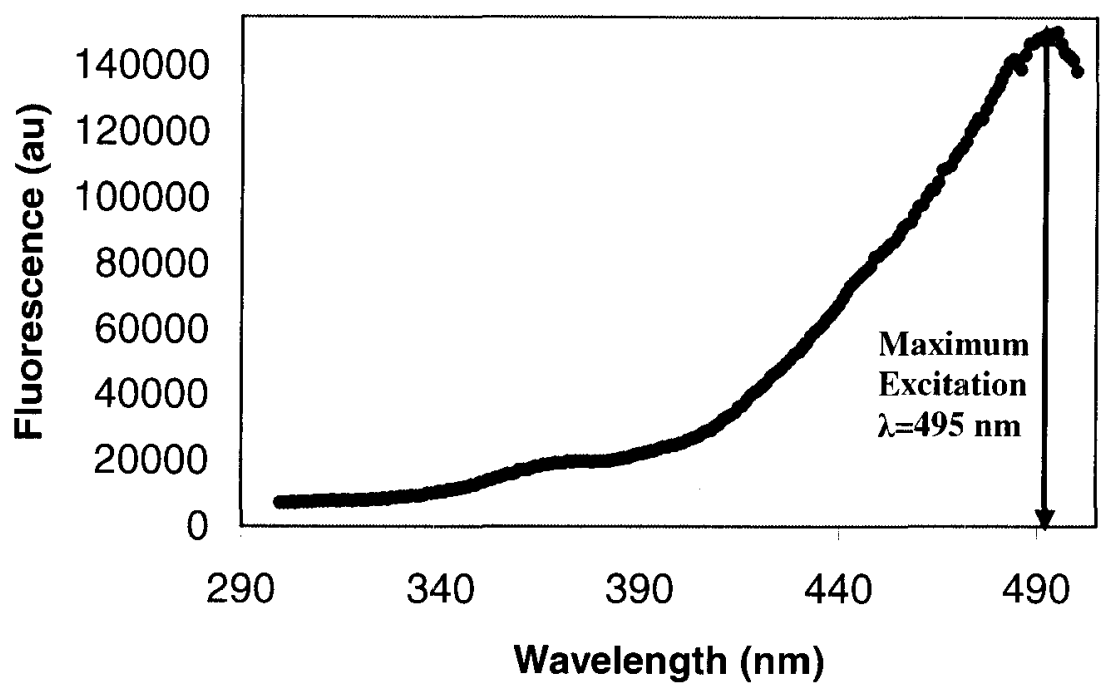

Emission Spectrum

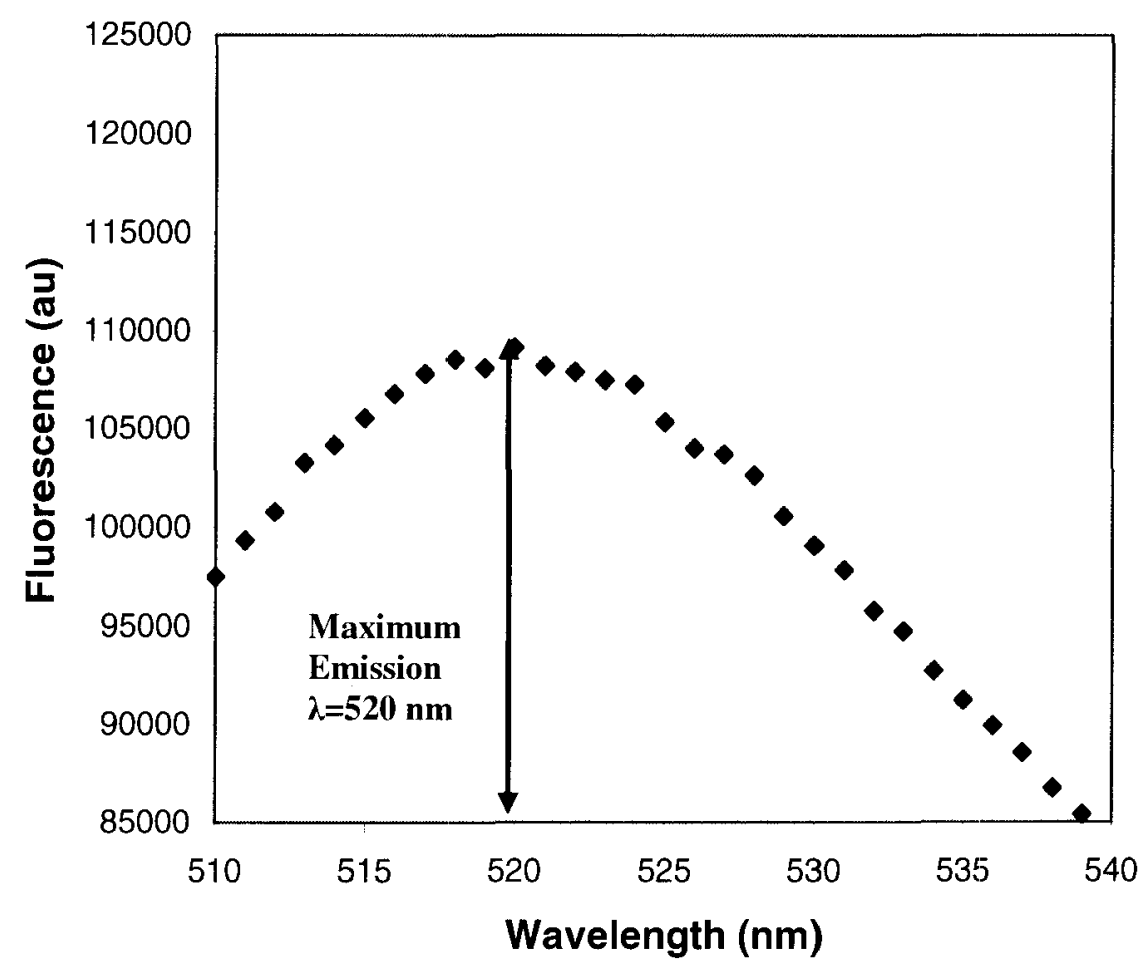

Figure 51: Fluorescence excitation (top) and emission (bottom) spectra of product 17. Emission spectrum obtained by excitation at $\lambda=495 \mathrm{~nm}$. 


\section{Bone-Targeted Genistein}

To make genistein (Figure $\mathbf{5 2}$ ) compatible for coupling to $\mathbf{8}$, a regioselective alkylation of the tri-phenolic molecule was first needed. Of the three phenol groups that genistein possesses, the 7-OH is the most acidic. Lewis, et al (2000) report that this hydroxyl group is 100 fold more acidic than the 4'-OH due to the electron withdrawing effect of the carbonyl at $\mathrm{C} 4$. By exploiting this difference in $\mathrm{pK}_{\mathrm{a}}$, genistein and other isoflavones have been selectively alkylated (Lewis, et al 2000; Al-Maharik, Kaltia, and Wähälä, 1999; Wang, et al 2005). The phenolic proton at the 5-position is typically not reactive due to the hydrogen bonding interactions with the adjacent carbonyl.

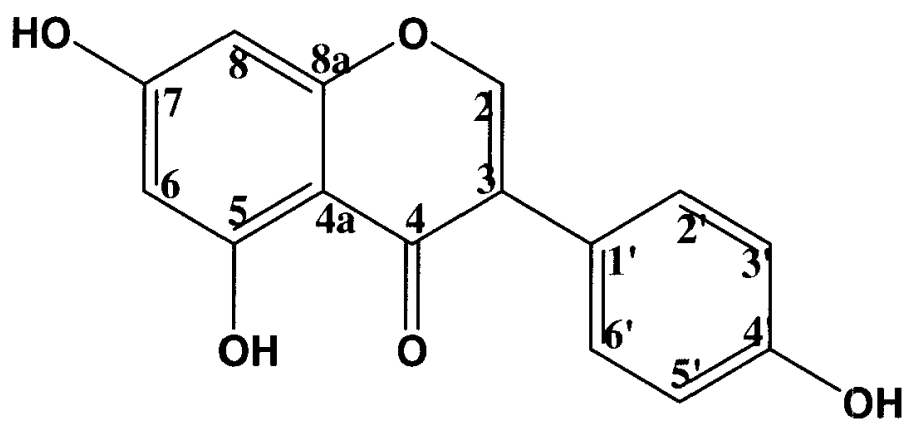

Figure 52: Genistein.

Since the $7-\mathrm{OH}$ is substantially more acidic than the $4^{\prime}-\mathrm{OH}$, the addition of one equivalent of base should only deprotonate the 7-OH. Simultaneous addition of the alkylating agent should cause the reaction to proceed selectively at the 7-position (see Figure 53). If alkylation is desired at the 4'-position, the dianionic species must first be generated by the addition of two or three molar equivalents of base. Because the less acidic phenolic group should result in the more nucleophilic anion, subsequent treatment 
of the dianion with the alkylating agent at low temperature should result in reaction at the $4^{\prime}-\mathrm{OH}$.<smiles>O=c1c(-c2ccc(O)cc2)coc2cc(O)cc(O)c12</smiles><smiles>CC#CCCCCCCCCCCCO</smiles>

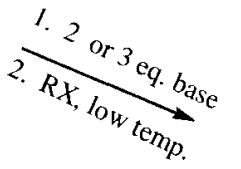<smiles>O=c1c(-c2ccc(O)cc2)coc2cc(O)cc(O)c12</smiles>

Figure 53: Options for the regioselective alkylation of genistein.

For the purposes of this project, the position at which the alkylation occurred was not of great consequence, so long as the reaction proceeded selectively. A synthetic scheme based on the work by Al-Maharik, Kaltia, and Wähälä (1999) was proposed (see Scheme 17). In the published reference, genistein was alkylated selectively either at the 7- or 4'-position with ethyl bromoacetate under the applicable conditions. The ethyl ester was then cleaved via acidolysis to yield the corresponding carboxylic acid. To make the precursor for the bone-targeted genistein, it was decided that tert-butyl bromoacetate would be used instead of ethyl acetate, simply because t-butyl esters cleave easily with trifluoroacetic acid under non-rigorous conditions. 

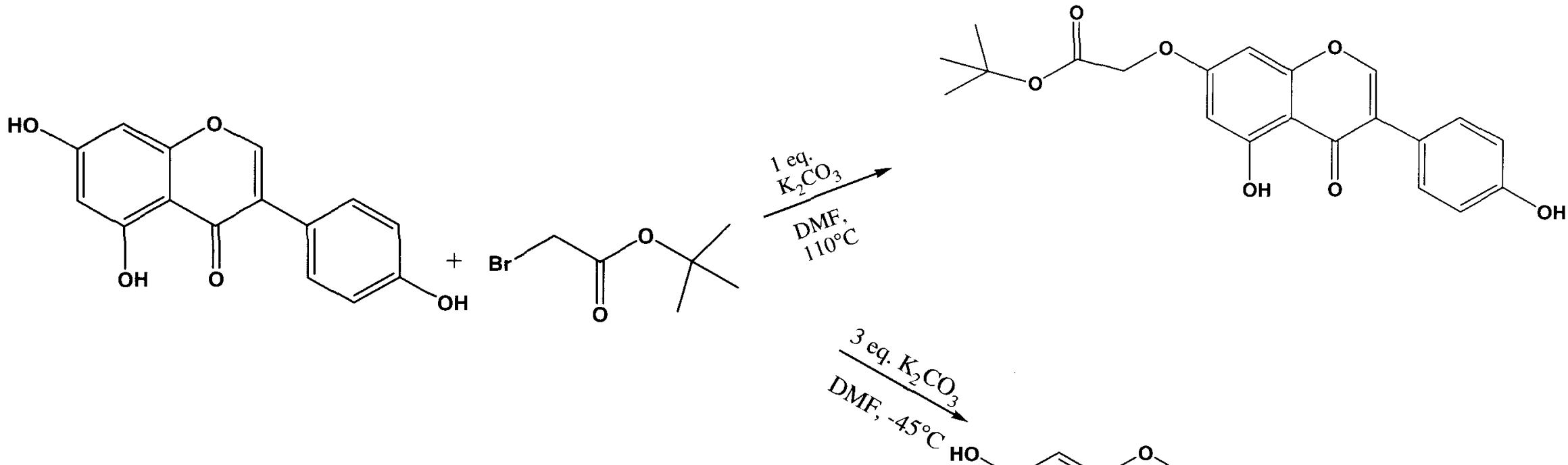
Optimizing the reaction conditions for the alkylation proved to be a nontrivial task. Potassium t-butoxide was determined to be a better base than potassium carbonate for this particular reaction. Equimolar amounts of base and genistein were used when the reaction was run at high temperature to alkylate position 7 , while a 3 to 1 stoichiometric ratio was employed for alkylation at the 4'-position at low temperature. For alkylation at the 7-OH, it was found that 2 to 1 stoichiometry of alkylating agent to genistein resulted in more product than 1 to 1 stoichiometry. Using excess alkylating agent in the presence of excess base lead to the formation of a dialkylated species. The addition of both 18crown- 6 ether as a potassium ion scavenger and potassium iodide as an iodide source seemed to improve both reaction speed and yield.

The formation and isolation of product 18 (Figure 54), the 7-O alkylated product, was the most facile of the possible synthetic choices. Although some impurities were observed in the thin-layer chromatography of the alkylated product, the ${ }^{1} \mathrm{H}$ NMR spectrum revealed that these were minimal (see Figure 55). Chromatographic separation at this point was ineffective. Superior purification was achieved after the acidolysis performed in the next step. As described in the Experimental section, the acidic genistein species generated after acidolysis could easily be purified by stirring in warm solvent and filtering, although it is still unclear if the purification at this step is necessary for successful coupling to the bone-targeted miniPEG. 


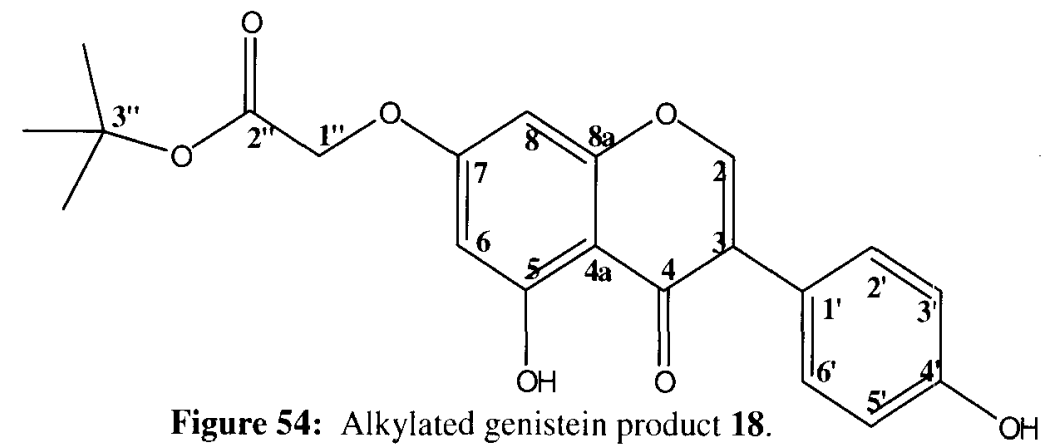

t-butyl

C5 OH

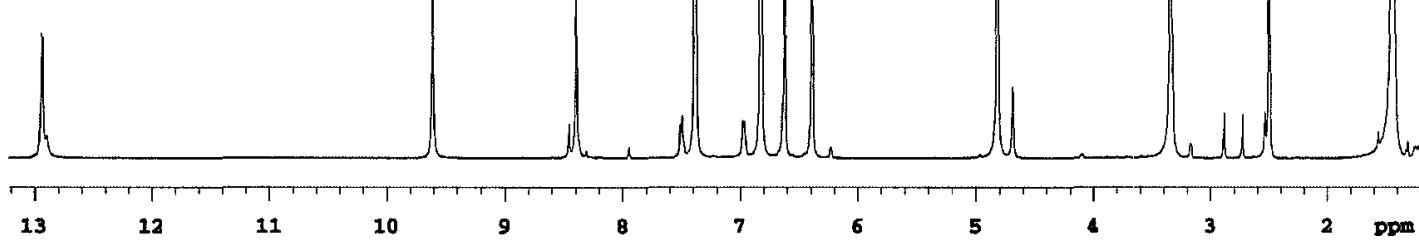

Figure 55: 'H NMR of alkylated genistein product 18. Since the impurities at this point appeared to be minimal, the crude material was used immediately in the next step. 
The regioselectivity of the reaction was confirmed via HMQC/HMBC experiments. The observable couplings of $\mathrm{C} 7$ and protons 6 and 8 validated the correlation between $\mathrm{C} 7$ and the 1" protons, therefore ensuring that alkylation took place at the 7 position. The HMBC spectrum is shown in Figure 56. It appeared that no alkylation took place at the 4' position under these conditions.

During the exploration of fluorescein chemistry, a side reaction was noted between the 5-aminofluorescein quinone system and BOP. Also, the use of HOBt and BOP as coupling agents requires a base wash during the work-up. Under basic conditions, deprotonation of the 5-OH group is possible and the product could end up in the aqueous layer. With these issues in mind, coupling of the genistein acid to compound $\mathbf{8}$ was performed with 1-ethyl-3-(3-dimethylaminopropyl) carbodiimide hydrochloride ("EDC") instead of the HOBt and BOP used for the other conjugates.

The final bone-targeted product precipitated out of methanol to give a clean solid. Undesirably, ${ }^{1} \mathrm{H}$ NMR spectroscopy revealed that the polar product was distributed between the aqueous and organic layers, resulting in a low yield. It may be possible to chromatographically separate the product from the aqueous layer. 


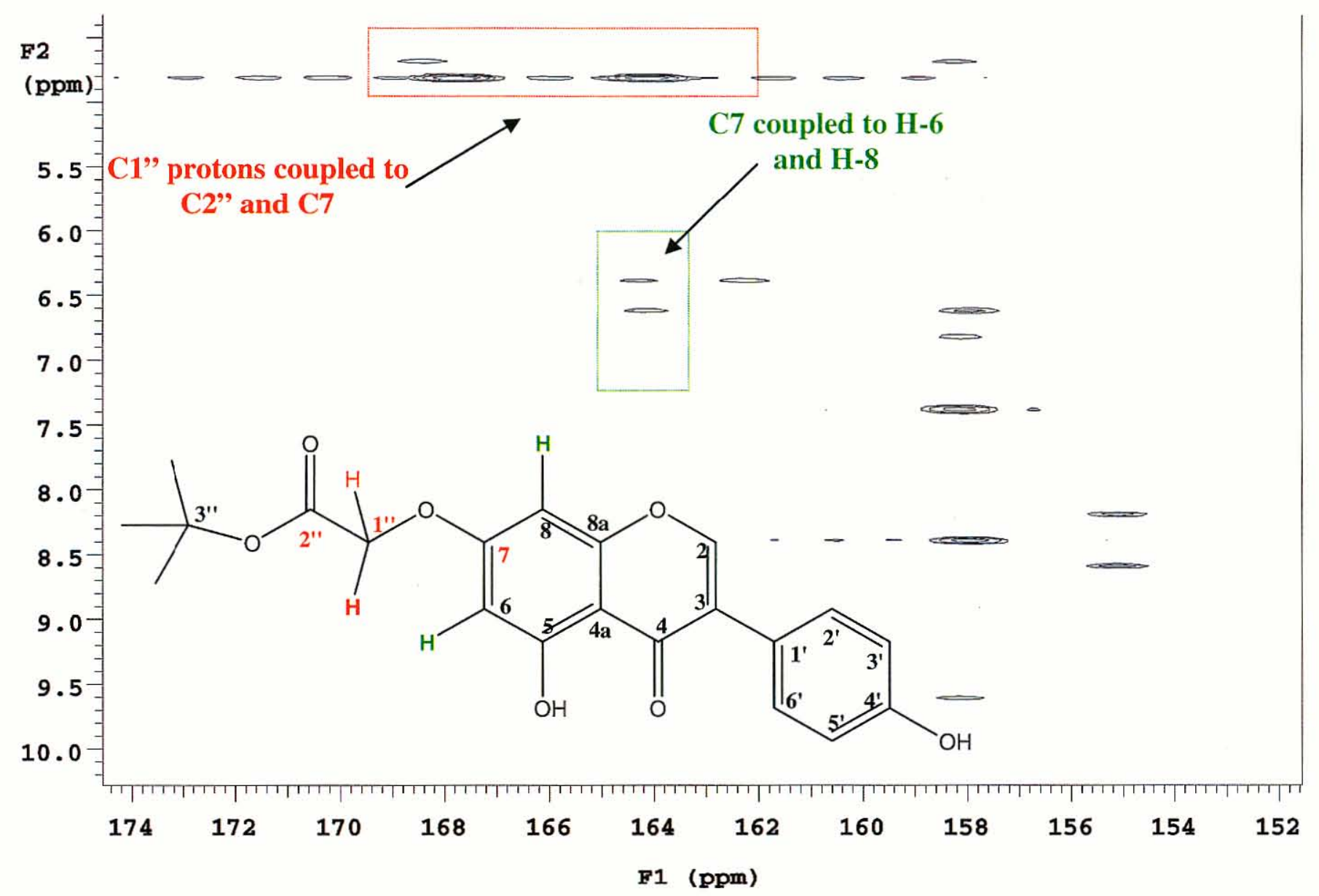

Figure 56: HMBC spectrum of alkylated genistein product. The spectrum confirms the regioselectivity of the reaction at the 7-position. Coupling interactions between the 1" protons and C2" and C7 are highlighted in red. The highlighted green protons are also coupled to C7, showing that indeed $\mathrm{Cl}$ " is connected to the diphenolic aromatic ring. 


\section{SUMMARY}

Ten novel bone-targeted molecules were designed, synthesized, purified, and characterized: four bone-targeted ("BT") miniPEG derivatives, three BT-estrogens, a BT-doxorubicin, a BT-fluorescein, and a BT-genistein. Fmoc-protected miniPEGs were preferred over Boc-protected miniPEGs. Three of the bone-targeted miniPEGs had basic termini, while the fourth had an acidic terminus. The basic BT-miniPEGs appeared to be stable as $\mathrm{HCl}$ salts.

Because of the successful synthetic results, compound $\mathbf{8}$, with a basic terminus, was chosen for use in future BT-drug conjugates. Its acidic counterpart, 15, was developed out of necessity during the design of a BT-doxorubicin. Hence, this project led to the development of two new "universal" bone-targeting agents.

Although no formal assessment of water-solubility was performed, it was apparent from experimental observation that the miniPEG-linked estrogens were more hydrophilic than those with no miniPEG linker (i.e. the bone-targeted estrogens from previous studies). During reaction work-ups, often times the conjugated products would appear in both the aqueous and organic layers. Also, a direct comparison showed that the older generation conjugates with no miniPEG linker dissolved more readily in organic solvent than the miniPEG-linked conjugates.

To demonstrate the potential of the "universal" bone-targeting agents, as well as produce additional prospective therapies, conjugates of doxorubicin, fluorescein, and genistein were synthesized. Genistein required a regioselective alkylation and subsequent acidolysis to be compatible for coupling to the bone-targeted miniPEG. The reaction conditions for each conjugate were optimized. Each of these conjugates 
displayed significantly different solubility properties and, consequently, demanded different methods of isolation and purification.

Biological evaluation ${ }^{*}$ of some of the BT-conjugates was performed. The procedures and results are discussed in the appendices (pp. 186-199). In vivo testing of all three BTestrogens revealed that although some extraosseous effects were observed, the conjugates appeared to preserve bone density in ovariectomized rats and possibly even had an anabolic effect. In vitro studies showed that the bone-targeted doxorubicin conjugate maintains the potency of the parent doxorubicin compound.

* Biological studies of the bone-targeted estradiol conjugates were performed by the following persons from the University of Louisville: Department of Pharmacology and Toxicology: Dr. Kevyn Merten, Dr. Jian Cai, and Ned Smith; Department of Physiology: Dr. Jeff Falcone and Kathleen Hamilton; Department of Orthopaedic Surgery: Dr. Michael Voor and Qian Xiao. Biological evaluation of the bone-targeted doxorubicin was performed at Tufts University in the laboratory of Michael Rosenblatt M.D. 


\section{FUTURE DIRECTIONS}

To reduce extraosseous effects from the bone-targeted estrogens, a third generation of conjugates will be synthesized. These conjugates will be phosphorylated at the phenolic 3-position of the estradiol molecule (see below). The rationale behind such a modification is that the phosphorylated conjugate would not be activated until hydrolyzed via a phosphoesterase in the bone. Unwanted estrogenic effects on the uterus could possibly be avoided by treatment with a prodrug of this kind, as accumulation of the conjugate in the bone tissue and in situ hydrolysis would minimize exposure to the reproductive organs.

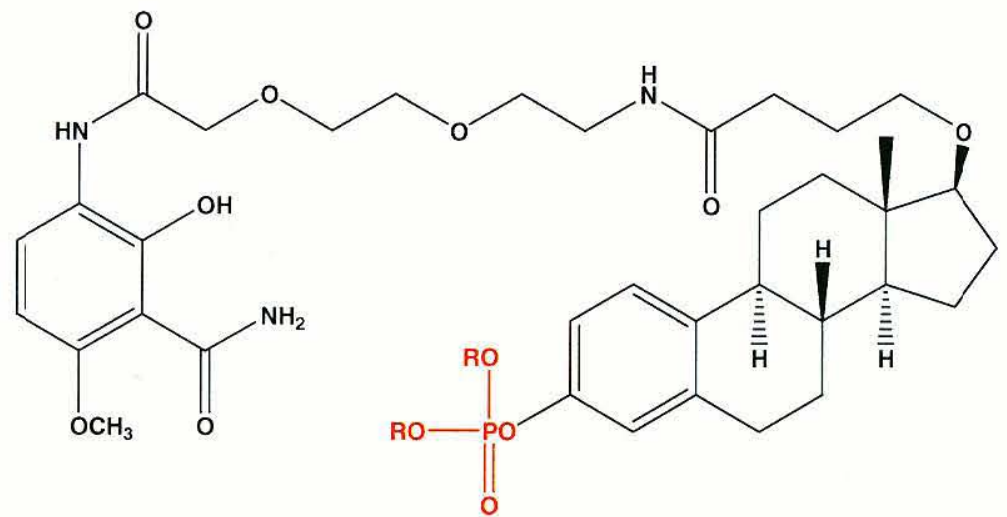

Biological testing will also be performed on the bone-targeted genistein compound. The bone-targeted doxorubicin will be subjected to in vivo analysis. The bone-targeted fluorescein will be used in imaging studies to further investigate where the bone-targeted compounds are distributed in vivo. Future synthetic work will be decided after the biological data from these compounds is collected. By employing infrared spectroscopy, it is anticipated that some insight may be gained into the structural characteristics of the compounds while bound to hydroxyapatite.

Other bone-targeted conjugates that are of interest include BT-vancomycin and BTtestosterone. 


\section{REFERENCES}

Acton, N., Komoyira, A., Org. Prep. Proc. Int., 1982, 14(16), 381.

Albert A. 1979. In: Selective Toxicity. The physicochemical basis of therapy. $6^{\text {th }} \mathrm{ed}$. pp. 431-433.

Al-Maharik NI, Kaltia SA, and Wähälä K. 1999. Mol. Online. 3: 20-24. Bach AC, Eyermann CJ, Gross JD, Bower MJ, Harlow RL, Weber PC, and Degrado WF. 1994, J. Am Chem. Soc. 116: 3207-3219.

American Cancer Society. 2008. Cancer Facts and Figures 2008. Atlanta, GA: American Cancer Society. Retrieved May 1, 2008, from http://www.cancer.org/downloads/STT/2008CAFFfinalsecured.pdf.

Boothe JH. 1953. J. Am. Chem. Soc. 75: 4621. Burchak ON, Mugherli L, Chatelain, F, and Balakirev, MY. 2006. Bioorg. Med. Chem. 14: 2559-2568.

Burchak ON, Mugherli L, Chatelain F, and Balakirev MY. 2005. Bioorg. Med. Chem. 14(8): $2559-2568$.

Bystrov VF, Portnova SL, Balashova TA, Koz'min SA, Gavrilov YD, and Afanas'ev VA. 1973. Pure Appl. Chem. 36: 19-34.

Callahan, J. F. et al, J. Med. Chem., 1989, 32(2), 391. 
Canne, L. E., Winston, R. L., Kent, B. H., Tet. Lett., 1997, 38(19), 3361.

Colditz GA, Hankinson SE, Hunter DJ, Willett WC, Manson JE, Stampfer MJ, Hennekens CH, Rosner B, and Speizer FE. 1995. New Eng. J. Med. 332: 1589-1593.

Daines, R. A., J. Med. Chem., 1994, 37, 3327.

Darlak K, Romanovskis P, and Spatola, A. 1994. In: Peptides: Chemistry, Structure, and Biology. pp 981-983.

Floyd JD, Nguyen DT, Lobins RL, Bashir Q, Doll DC, and Perry MC. 2005. J. Clin. Oncol. 23(30): 7685-7696.

Green J and Bradley K. 1993. Tetrahedron. 49(20): 4141-4146.

Haubner R, Finsinger D, and Kessler H. 1997. Angew. Chem., Int. Ed. Engl. 36(13-14): 1375-1389.

Hirabayashi H and Fujisaki J. 2003. Clin. Pharmacokinet. 42(15): 1319-1330.

Ishimi Y, Miyaura C, Ohmura M, Onoe Y, Sayo T, Uchiyama Y, Ito M, Wang X, Suda T, and Ikegami S. 1999. Endocrinology. 140: 1893-1900.

Jackson S, Degrado W, Dwivedi A, Parthasarathy A, Higley A, Krywko J, Rockwell A,

Markwalder J, Wells G, Wexler R, Mousa S, and Harlow R. 1994. J. Am. Chem Soc. 116: $3220-3230$.

Lindsay R, Aitken JM, Anderson JB, Hart DM, MacDonald ED, and Clarke AC. 1976. Lancet 1: 1038-1041.

Jordan VC. 1993. Br. J. Pharmacol. 110: 507-517. 
Kasugai S, Fujisawa R, Waki Y, Miyamoto K, and Ohya K. J. Bone Min. Res. 2000. 15(5): 936-943.

Kessler, H. Ang. Chem., Int. Ed. Engl. 1982. 21: 512.

Kostidis S, Stavrakoudis A, Biris N, Tsoukatos D, Sakarellos C, Tsikaris V. 2004. J. Peptide Sci. 10(8): 494-509.

Lewis PT, Wähälä K, Hoikkala A, Mutikainen I, Meng QH, Aldercreutz H, and Tikkanen MJ. 2000. Tetrahedron. 56: 7805-7810.

Merrifield RB. 1964. Biochemistry. 3: 1385.

Myers HM. 1968. Am. J. Phys. Anthrop. 29: 179-182.

Myers HM, Tochon-Danguy HJ, and Baud CA. 1983. Calcif. Tiss. Int. 35: 745-749.

Neale J. 2002. PhD Dissertation. University of Louisville, Louisville, KY.

Orme MW and Labroo VM. 1994. Bioorg. Med. Chem. Lett. 4(11): 1375-1380.

Persson I, Weiderpass E, Bergkvist L, Bergstrom R, and Schairer C. 1999. Cancer Causes and Control 10: 253-260.

Pierce WM and Waite LC. 1987. Proc. Soc. Exp. Biol. Med. 186: 96-102.

Rizo J and Gierasch LM. 1992. Ann. Rev. Biochem. 61: 387-418.

Rodriguez C, Patel AV, Calle EE, Jacob EJ, and Thun MJ. 2001. J. Am. Med. Assoc. 285(11): 1460-1465.

Rovero P, Quartara L, and Fabbri G. 1991. Tetrahedron Lett. 32: 2639-2642.

Ruoslahti E and Pierschbacher MD. 1987 Science. 238(4826): 491-497.

Sallan SE and Clavell LA. 1984. Semin. Oncol. 11: 19-21. 
Schairer C, Lubin J, Troisi R, Sturgeon S, Brinton L, and Hoover R. 2000. J. Am. Med. Assoc. 283: 485-491.

Sia KK, Iser D, Heng R, and Chen RY. J. Gastroenterology \& Hepatology. 2004. 19(8): 936.

Siconolfi SF, Gretebeck RJ, Wong WW, Moore SS, and Gilbert III JH. 1998. J. Appl. Physiol. 85(4): 1578-1582.

Skinner HCW. 1975. Yale J.Biol.Med.. 48: 377-397.

Smith DC, Prentice R, Thompson DJ, and Herrmann WL. 1975. New Eng. J. Med. 293: 11641167.

Spatola AF. 1983. In: Chemistry and Biochemistry of Amino Acids, Peptides, and Proteins, vol. Vii. pp. 267.

Spatola AF and Crozet Y. 1996. J. Med. Chem. 39: 3842-3846.

Spatola AF, Darlak K, and Romanovskis P. 1996. Tetrahedron Lett. 37: 591-594.

Spatola AF and Romanovskis P. 1998. J. Pep. Res. 52(5): 356-374.

Stepensky D, Kleinberg L, and Hoffman A. 2003. Clin. Pharmacokinet. 42(10): 863-881.

Wang D, Miller S, Sima M, Kopec`kova` P, and Kopec`ek J. Bioconjugate Chem. 2003. 14: 853-859.

Wang SF, Jiang Q, Ye YH, Li Y, and Tan RX. 2005. Bioorg. Med. Chem. 13: 4880-4890.

Willson TM, Charifson PS, Baxter AD, and Geddie NG. 1996. Bioorg. Med. Chem. Lett. 6(9): 1043-1046. 
Yamaguchi M. 2002. J. Health Sci. 48(3): 209-222.

Zhang S, Gangal G, and Uludag H. 2007. Chem. Soc. Rev. 36: 507-531.

Ziel HK and Finkle WD. 1975. New Eng. J. Med. 293: 1167-1170. 
APPENDICES 


\section{In Vivo Biological Studies of Estradiol Conjugates}

Biological studies of the bone-targeted estradiol conjugates were performed by the following persons from the University of Louisville: Department of Pharmacology and Toxicology: Dr. Kevyn Merten, Dr. Jian Cai, and Ned Smith; Department of Physiology: Dr. Jeff Falcone and Kathleen Hamilton; Department of Orthopaedic Surgery: Dr. Michael Voor and Qian Xiao.

\section{In Vivo Experimentation}

\section{Methods and Materials}

\section{Animals}

Six month old, bilaterally ovariectomized (OVX) or sham operated SpragueDawley female rats (Harlan Laboratories, Indianapolis, IN) were maintained at the University of Louisville Research Resources Center at $22^{\circ} \mathrm{C}$ with a 12 -h light/dark cycle and ad libitum access to tap water and rodent chow (Purina Laboratory Rodent Diet 5001). All animal procedures were approved by the Institutional Animal Care and Use Committee, which is certified by the American Association for Accreditation of Laboratory Animal Care.

\section{Experimental Design}

Three in vivo experiments were conducted in order to investigate the therapeutic effects of second and third generation bone-targeted estrogens (BTE). In all of the experiments, OVX and sham operated rats were randomly divided into groups of 5-7

animals. In all of the studies experimental groups included i) Sham-operated control 
(euthanized six weeks post surgery as a pretreatment control), ii) OVX control

(euthanized six weeks post surgery as a pretreatment control), iii) Sham control receiving vehicle, iv) OVX control receiving vehicle, v) OVX receiving 17-ethinyl estradiol (equimolar concentration with a selected BTE group), vi) OVX receiving alendronate (1.6 mg/kg), and vii) OVX receiving parathyroid hormone 1-34 (PTH) $(80 \mu \mathrm{g} / \mathrm{kg})$. All drugs and vehicle (1\% DMSO in corn oil) were administered three times per week orally by gavage except for PTH which was administered via a subcutaneous injection in a volume of $0.5 \mathrm{ml} / \mathrm{kg}$ body mass thrice per week. Drug administration was initiated 6 weeks following surgery and lasted for 6 weeks (18 doses total).

In the first study (Study 07 XP 2) a second generation BTE, BTE 2 -pg2-D2, was orally administered to OVX rats at doses of 10,100 , or $1000 \mu \mathrm{g} / \mathrm{kg}$ (vehicle $=1 \%$ DMSO in corn oil). In the second study (Study 07 XP 3) the second generation BTE, BTE 2 -pg3D2, was orally administered to OVX rats at doses of 10,100 , or $1000 \mu \mathrm{g} / \mathrm{kg}$. In the third study (Study 07 XP 4) the second generation BTE, BTE2-pg2-D3 was orally administered to OVX rats at doses of 10,100 , or $1000 \mu \mathrm{g} / \mathrm{kg}$ and two third generation BTE's, BTE $2^{-}$ D2-3-O-DBtP and $\mathrm{BTE}_{2}-\mathrm{D} 2-3-\mathrm{O}-\mathrm{DBnP}$ were orally administered to OVX rats at doses of 25 and $250 \mu \mathrm{g} / \mathrm{kg}$. As indicated above all BTE's were administered three times per week for 6 weeks.

Following 6 weeks of treatment, blood was obtained from each animal via cardiac puncture following an overnight fast and animals were subsequently euthanized via carbon dioxide asphyxiation. Blood was centrifuged immediately and the obtained serum samples were aliquoted and stored at $-70^{\circ} \mathrm{C}$ prior to analysis. Uteri were removed and fresh weights were obtained. Uterine masses were normalized to body mass at the end of 
the experiment. The left and right femora and left and right tibiae were subsequently collected from each animal, cleaned of soft tissue, and stored in saline at $4^{\circ} \mathrm{C}$ prior to analysis.

\section{Femoral Density via Archimedes' Principle}

Right femora were submerged in distilled water and fully hydrated under a vacuum for $1 \mathrm{hr}$. Subsequently, the mass of each hydrated femur was obtained in air and when submerged in water. Densities were determined using Archimedes' Principle according to the following formula: density $=$ [mass of hydrated femur $/$ (mass of hydrated femur - mass of hydrated femur submerged in water)] $\mathrm{x}$ density of distilled water at a given temperature (1).

\section{Regional Femoral Density via Archimedes' Principle}

The proximal and distal ends of the femur are comprised primarily of cancellous/trabecular bone, whereas the femoral diaphysis contains primarily cortical bone. Evaluation of the density of each of these femoral regions may thereby increase our understanding of the effect of a drug on each of these types of bone. The left femora were separated into three regions (proximal left femur, distal left femur, and left femoral diaphysis) using an Isomet Low Speed Precision Sectioning Saw from Buehler Limited (Lake Bluff, IL) with a diamond blade. Briefly, each femur was measured with a CenTech Digital Caliper and a cut was made from each end at $20 \%$ of the length of the femur plus half the width of the blade. Subsequently, the bone marrow was washed out of the 
femoral diaphysis and the Archimedes density for each of the three femoral regions was determined as described above.

\section{Ex vivo micro-computed tomography $(\mu \mathrm{CT})$}

Volume fraction is a representative value for the amount of bone that occupies a given volume or space. High resolution image data were collected using a customized micro-CT system (ACTIS 150/225 system, BIR Inc., Lincolnshire, IL). The metaphysis of each right tibia was scanned over a three millimeter range and three-dimensional images were reconstructed. Data were subsequently processed to reveal the volume fraction (BV/TV) occupied by trabecular (cancellous) bone tissue, cortical bone tissue, and whole bone tissue.

\section{Bone Mechanical Competence Indentation Test}

After sacrifice, the left tibiae were trimmed to expose the cancellous bone of the proximal tibial metaphysis and an indentation test was performed by advancing a flattipped cylindrical post ( $1.5 \mathrm{~mm}$ diameter) axially into the cut surface to measure the compressive strength of the cancellous bone structure.

\section{Rat Osteocalcin EIA}

Osteocalcin is a hydroxyapatite-binding protein that is synthesized by osteoblasts during bone formation. Thereby, serum osteocalcin levels are commonly used as a biochemical marker of bone formation. Rat serum osteocalcin levels were measured 
using the Rat Osteocalcin EIA Kit from Biomedical Technologies, Incorporated (Stoughton, MA) as recommended by the manufacturer.

\section{RatLaps $^{\text {TM }}$ ELISA for C-telopeptide Fragments of Collagen Type I (CTX-I)}

Osteoclast mediated breakdown of collagen type I in bone leads to the release of free and peptide bound fragments of the collagen type I molecule. The fragment released from the carboxy-terminal region of collagen type I is termed the C-telopeptide fragment of collagen type I (CTX-I) and is commonly used as a biochemical marker of bone resorption. Bone resorption (CTX-I) was quantitatively assessed in rat serum using the commercially available RatLaps ${ }^{\mathrm{TM}}$ ELISA KIT from Nordic Bioscience Diagnostics A/S (Herlev, Denmark) as recommended by the manufacturer.

\section{Quantitative Determination of Lipid Metabolism (Total Cholesterol, HDL, and}

\section{LDL) in Rat Serum}

Total cholesterol, high-density lipoprotein (HDL), and low-density lipoprotein (LDL) were quantitatively determined in the serum of rats in order to evaluate the extraosseous effects of estrogen treatment on lipid metabolism. Commercially available kits from Wako Diagnostics (Richmond, VA) were used for the evaluations as recommended by the manufacturer. 
[1] Keenan MJ, Hegsted M, Jones KL, Delany JP, Kime JC, Melancon LE, Tulley RT, Hong KD. Comparison of bone density measurement techniques: DXA and Archimedes' principle. J Bone Miner Res 1997;12:1903-7.

\section{Results and Discussion}

Ovariectomy (OVX) is a surgical removal of the ovaries. Six-month old female rats underwent either sham or OVX surgery at time equals zero. OVX animals gradually lose bone over time due to decreased estrogen levels as would be seen in women with postmenopausal osteoporosis. After six weeks a group of OVX animals and a group of sham animals were sacrificed. After 6 more weeks (12 weeks total) another OVX group and another sham group were sacrificed. At the six-week time point following OVX, drug administration was initiated. At that point, the drug was administered for six weeks, three times per week for a total of eighteen doses. Micro-computed tomography (microCT) scans (Figure 57) show the bone loss that occurs in the tibia following OVX surgery. Similar scans were taken for bones treated with osteoporosis drugs currently being prescribed (Figure 58) and those treated with our novel drug conjugate $\mathbf{1 3}$ (Figure 59).

Archimedes density measurements of the right femur were taken to assess bone density (Figure 60). When administered in vivo to OVX rats, conjugate 13 was shown to preserve femoral bone density in a dose-dependent fashion. The conjugate was found to maintain bone density as well or better than $17-\beta$-estradiol ("OVX $+17 \mathrm{EE")} \mathrm{or}$ parathyroid hormone ("OVX + PTH"). 


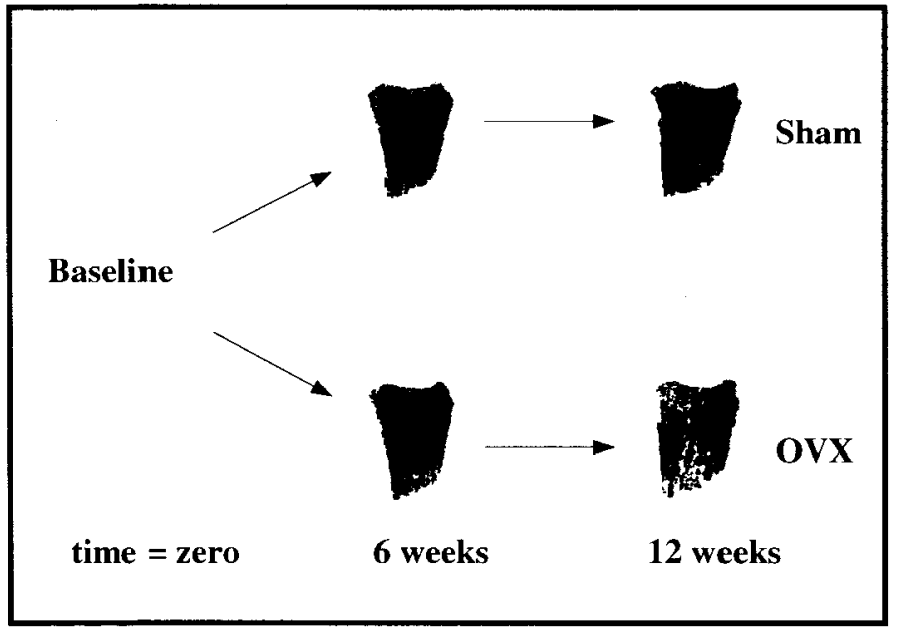

Figure 57: Micro-computed CT scans show the effect of OVX on bone density.

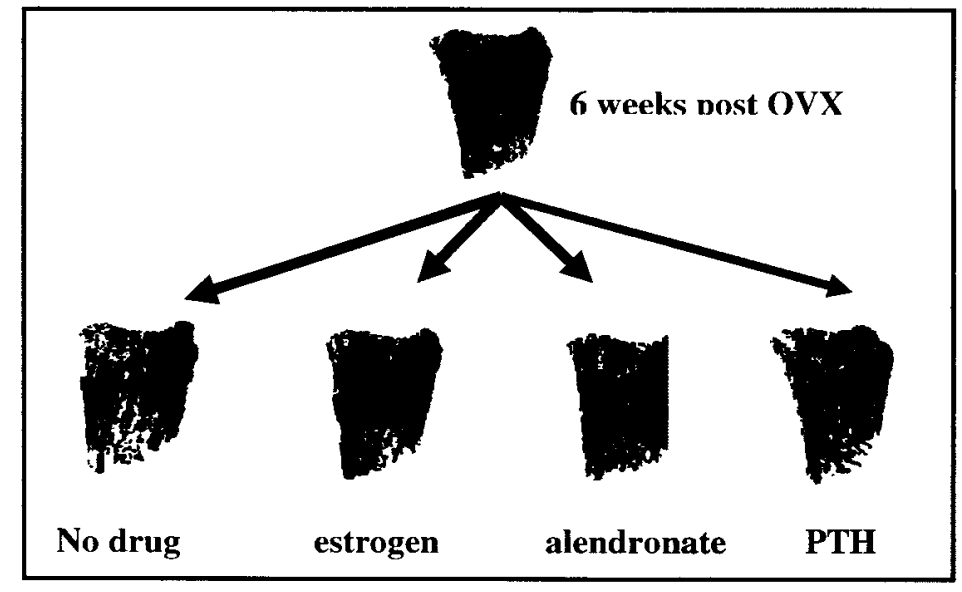

Figure 58: Effects of available treatments for osteoporosis after 6 weeks of administration.

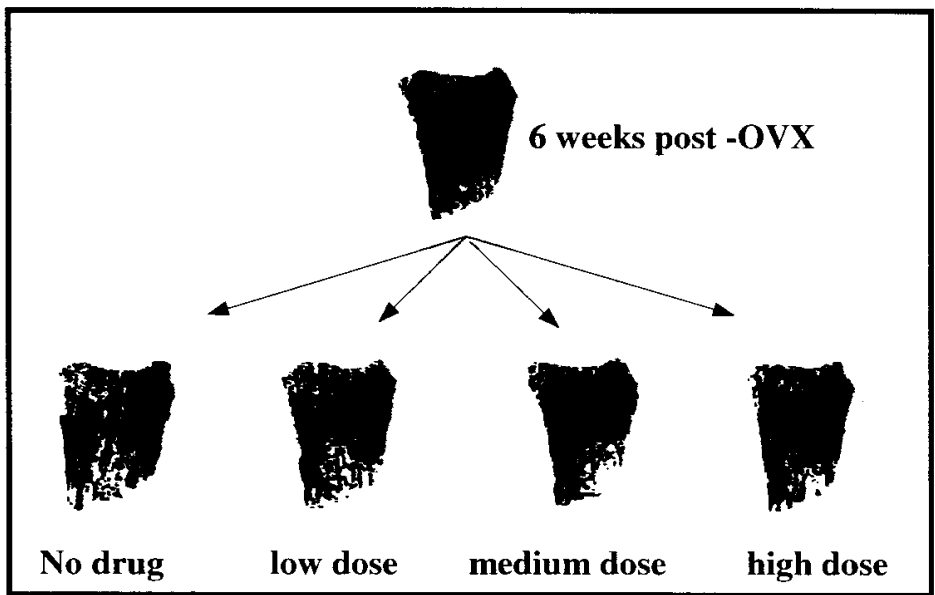

Figure 59: Effects of estradiol conjugate 13 (BTE2-pg3-D2) after 6 weeks of administration. 


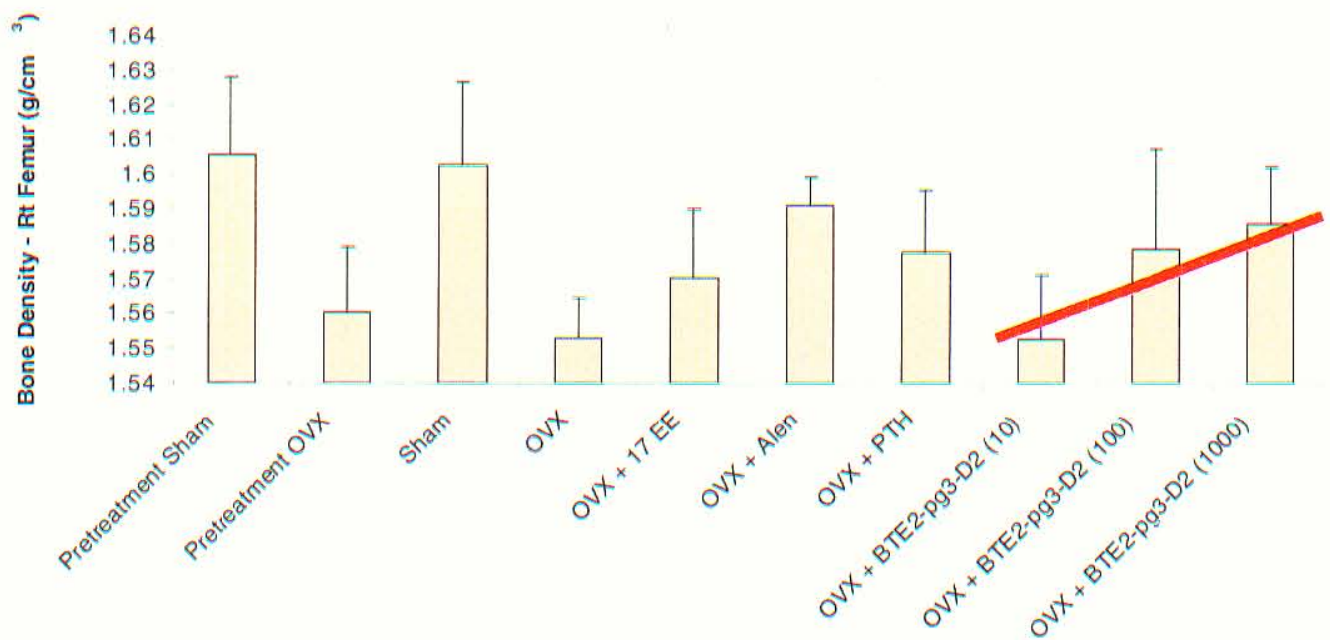

Figure 60: When administered in vivo to OVX rats, conjugate 13 (BTE2-pg3-D2) was shown to preserve femoral bone density in a dose-dependent fashion. Note that at the two higher doses, the estrogen conjugate maintains bone density as well or better than 17- $\beta$-estradiol ("OVX + 17 EE") or parathyroid hormone ("OVX + PTH").

The mechanical strength of the bone was measured via a blunt force indentation test in which a flat-tipped cylindrical post is advanced into the trabecular bone until the bone breaks (see Figure 61). A dose-dependence was also noted for the preservation of the mechanical competency of the bone when $\mathbf{1 3}$ was administered orally to OVX rats for a period of six weeks. The mechanical strength of the tibia was found to be comparable to that seen following treatment with the bisphosphonate alendronate and parathyroid hormone. 


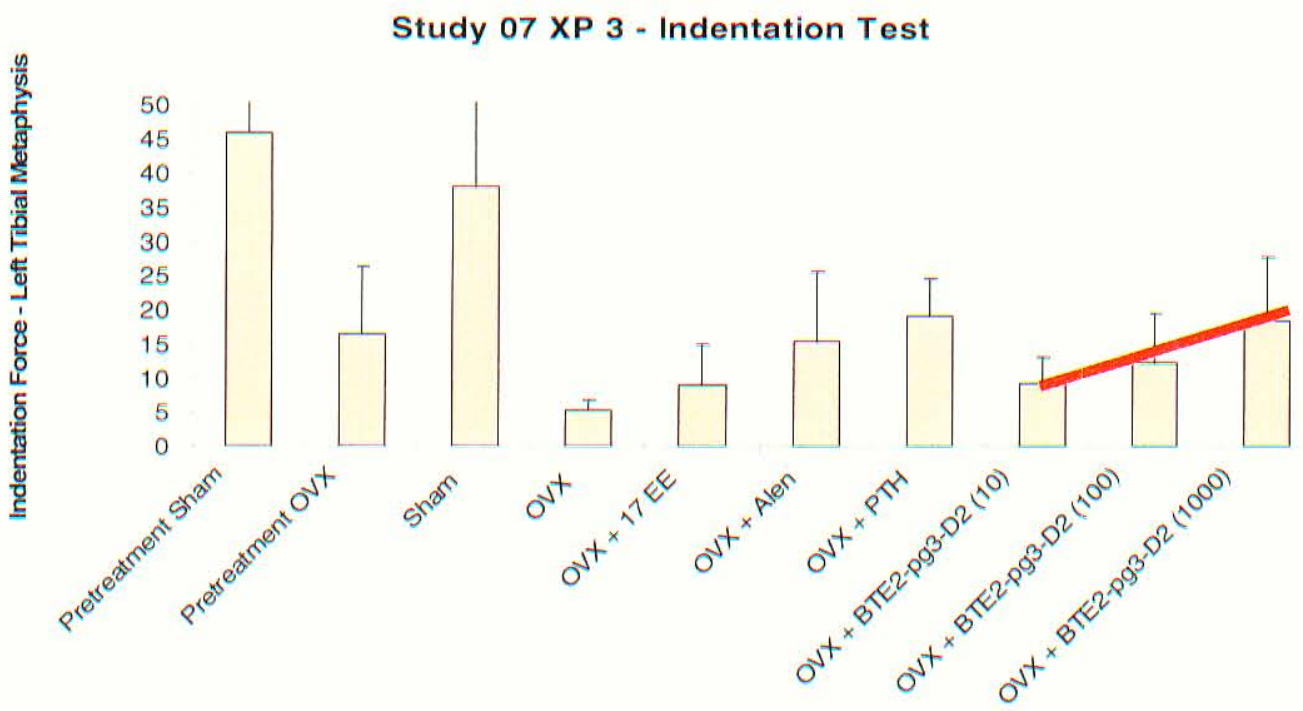

Figure 61: A dose-dependence was also noted for the preservation of the mechanical competency of the bone when 13 (BTE2-pg3-D2) was administered orally to OVX rats for a period of six weeks, as determined by blunt force indentation tests. The mechanical strength of the tibia was found to be comparable to that seen following treatment with alendronate (a bisphosphonate; "OVX + Alen") and parathyroid hormone ("OVX + PTH").

Another test performed on the estrogen conjugates was a measurement of osteocalcin in the blood (Figure 62). Anabolic drugs build bone and in the process a bone protein known as osteocalcin is excreted into the blood. This protein can be measured from the blood as a measure of anabolic potential. For example, parathyroid hormone is an anabolic agent and causes an increase in osteocalcin levels. At high doses, $\mathbf{1 3}$ administration resulted in a much higher blood serum concentration of osteocalcin than estradiol treatment. Although these studies did not conclusively prove that we developed an anabolic agent, the osteocalcin measurements are intriguing and will be investigated further. 

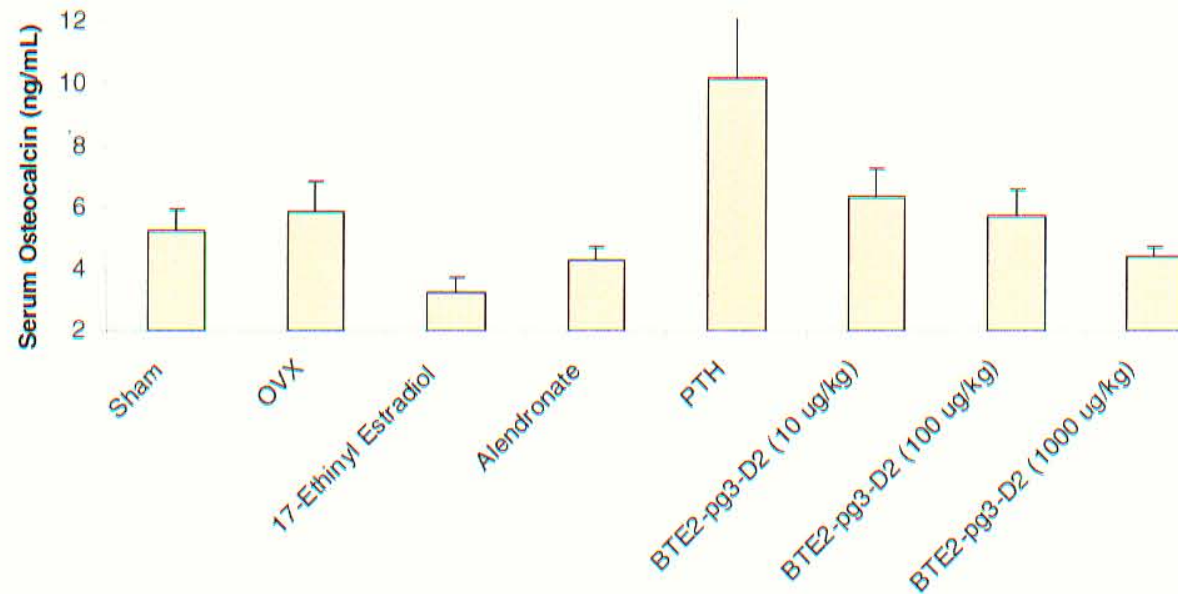

Figure 62: At high doses, 13 (BTE2-pg3-D2) administration resulted in a much higher blood serum concentration of osteocalcin than estradiol treatment, demonstrating potential for an anabolic agent.

Upon ovariectomy, animals gain a substantial amount of weight in comparison to sham-operated animals. When estradiol is administered, a decrease in the body weight of the OVX animals is observed. This observation can be used to help determine if the bone-targeted estrogens are causing estrogenic effects outside of the bone. The highest dose of $\mathbf{1 3}$ causes a decrease in body weight similar to that following estradiol (Figure 63). Unfortunately, this indicates that our conjugate is causing unwanted effects outside of bone tissue, or "extraosseous effects."

A second extraosseous effect of estradiol is the stimulation of the uterus, leading to an increase in uterine mass. By bone-targeting estradiol we would hope to prevent this increase in uterine mass. However, this is not the case as $\mathbf{1 3}$ causes a dose-dependent increase in uterine mass comparable to estradiol (Figure 64). 


\section{Study 07 XP 3 - Body Weight}

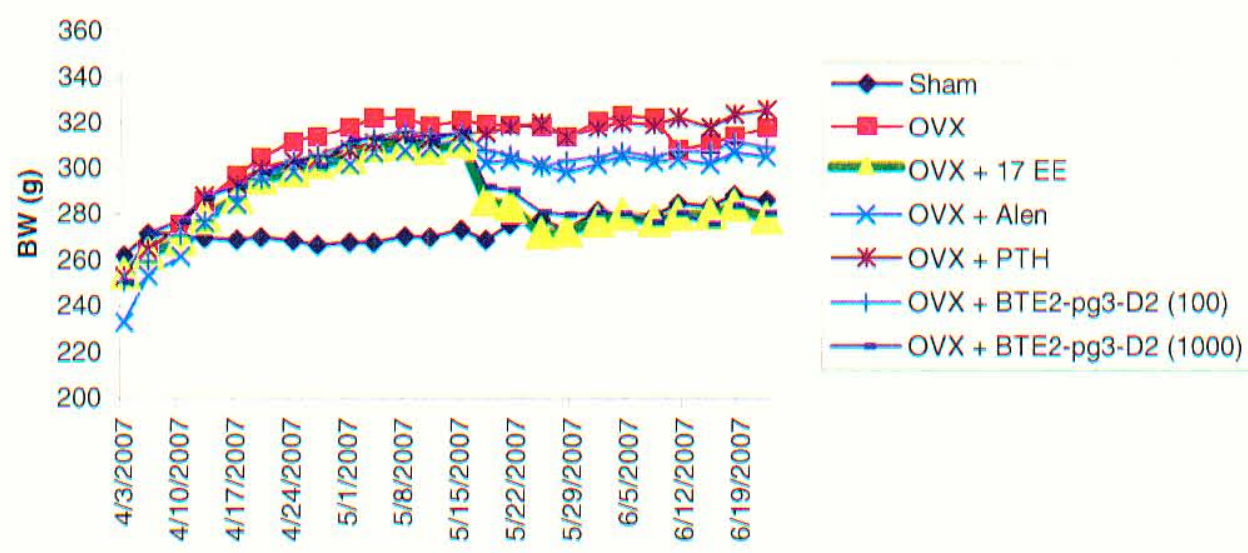

Figure 63: The highest dose of 13 (BTE2-pg3-D2) causes a decrease in body weight similar to that following estradiol (OVX $+17 \mathrm{EE})$.

Study 07 XP 3 - Uterine Mass
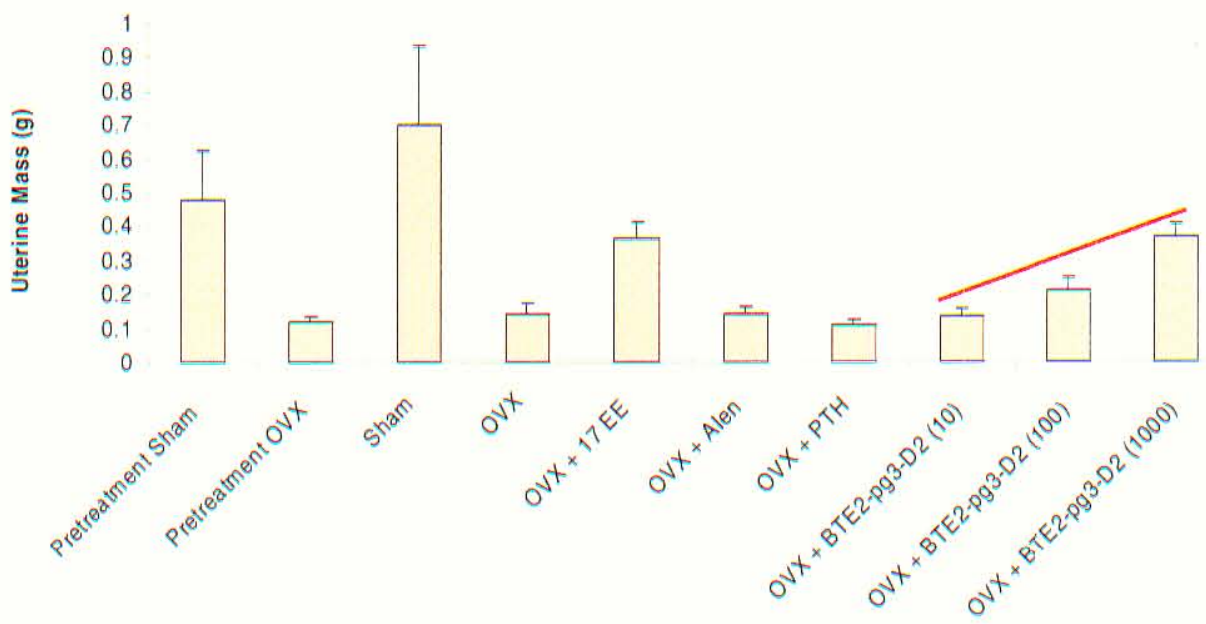

Figure 64: 13 (BTE ${ }_{2}$-peg3-D2) causes a dose-dependent increase in uterine mass comparable to estradiol. 


\section{In Vitro Evaluation of the Effect of BT2-pg2-Doxorubicin and Free Doxorubicin on SUM1315 Human Breast Cancer Cells}

Biological evaluation of the bone-targeted doxorubicin was performed at Tufts University in the laboratory of Michael Rosenblatt M.D.

\section{Materials and Methods}

\section{Colony formation assay:}

SUM1315 human breast cancer cells (derived from a clinical metastatic nodule) were seeded in 6 well plates at 5000 cells/well in $2 \mathrm{ml}$ of medium. Cells were allowed to adhere overnight prior to drug treatment. BT2-pg2-doxorubicin (Nbr-VI) or free doxorubicin were added to the cells at concentrations of $0.05,0.1,0.5,1,5$, and $10 \mu \mathrm{M}$ and cells were allowed to grow at $37^{\circ} \mathrm{C}$ for 10 days. In addition, untreated and vehicle (0.1\% DMSO) treated wells were included as controls. After 10 days of treatment, medium was removed from each well and cells were subsequently washed with water. Cells were then fixed in $10 \%$ formaldehyde for 10 minutes, washed with water and then stained with $0.5 \%$ crystal violet for 5 minutes. Colonies of cells were subsequently counted under the microscope in three separate frames. Three independent experiments were performed and the results are an average of the three experiments. Images are from one representative well for each concentration.

\section{Cell Proliferation Assay - MTT Assay:}

The MTT assay is a colorimetric assay that is based on the cleavage of a yellow MTT tetrazolium salt to purple formazan crystals by the mitochondria of metabolically active and viable cells. The formazan crystals are insoluble in aqueous solution but may be 
dissolved in acid and quantified using a spectrophotometer. The number of living and viable cells in a sample directly correlates to the amount of purple formazan crystals formed. SUM1315 human breast cancer cells were seeded in triplicate in 96 well plates at 1000 cells/well and were allowed to adhere overnight prior to drug treatment. BT2pg2-doxorubicin (Nbr-VI) or free doxorubicin were added to the cells at concentrations of $0.05,0.1,0.5,1,5$, and $10 \mu \mathrm{M}$ and cells were allowed to grow at $37^{\circ} \mathrm{C}$ for $1,2,3,4,5$, or 6 days. In addition, untreated and vehicle (0.1\% DMSO) treated wells were included at each time point as controls. Following treatment the MTT assay was subsequently performed and the absorbance at $490 \mathrm{~nm}$ was recorded. Three independent experiments were performed and the results are an average of the three experiments.

\section{Results and Discussion}

Bone-targeted doxorubicin conjugate $\mathbf{1 6}$ was evaluated in tandem with doxorubicin $\bullet \mathrm{HCl}$ for toxicity against SUM1315 human breast cancer cells. The cancer cells were allowed to colonize overnight before being treated with either drug. Two different assays were performed on these cells. In the colony formation assay, the colonies were treated with BT-doxorubicin or free doxorubicin then left to incubate at $37^{\circ} \mathrm{C}$ for ten days. Untreated colonies, as well as those treated with $0.1 \%$ DMSO, were used as controls. Subsequent cell counts gave the results shown in Figure $\mathbf{6 5}$. 


\section{Colony formation assay}

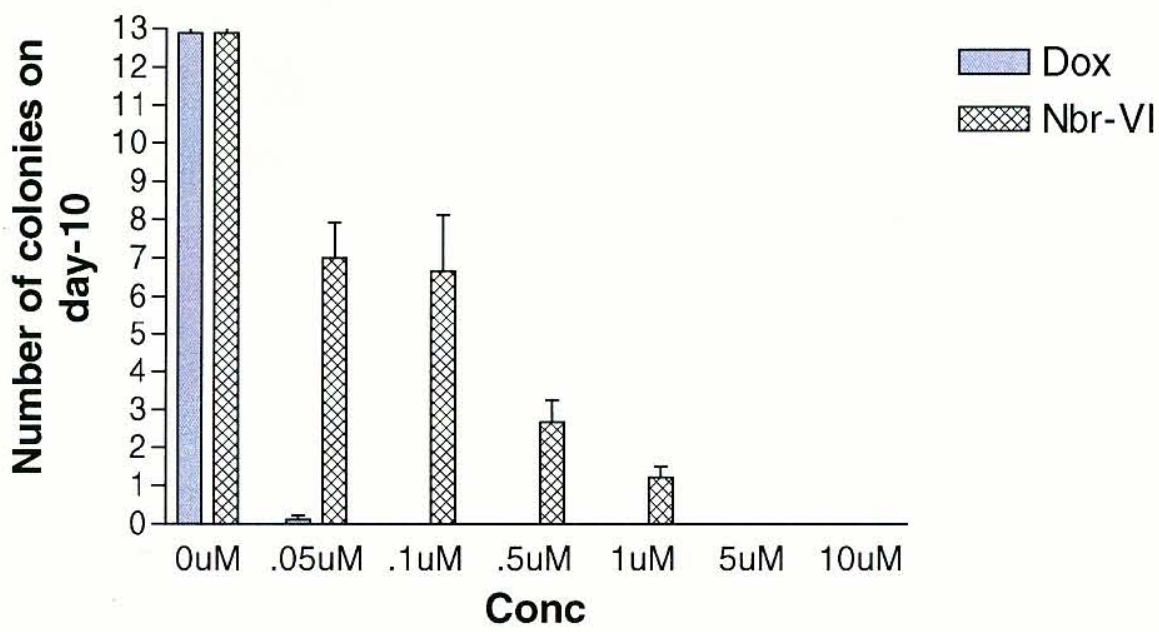

Figure 65: Colony counts after 10 days of colony growth at various concentrations of drug. Dox = free doxorubicin; Nbr-VI = BT-doxorubicin conjugate 16.

At the higher concentrations, the bone-targeted doxorubicin conjugate did seem to maintain the potency of the parent doxorubicin.

The second assay performed on breast cancer cell colonies was a cell proliferation assay, in which cells were allowed to grow in varying concentrations of drug for either 1 , $2,3,4,5$, or 6 days at $37^{\circ} \mathrm{C}$. Cell proliferation was monitored via the cleavage of 3-(4,5Dimethylthiazole-2-yl)-2,5-diphenyltetrazolium bromide ("MTT") by the mitochondria of active cells. Upon cleavage, a purple formazan product is formed and can be quantitated spectrophotometrically. The number of living and viable cells in a sample directly correlates to the amount of purple formazan crystals formed. The results of the assay using conjugate $\mathbf{1 6}$ and free doxorubicin after 5 and 6 days of treatment are shown in Figure 66. At high dosages, the bone-targeted drug conjugate appears to display a toxicity similar to that of free doxorubicin. 

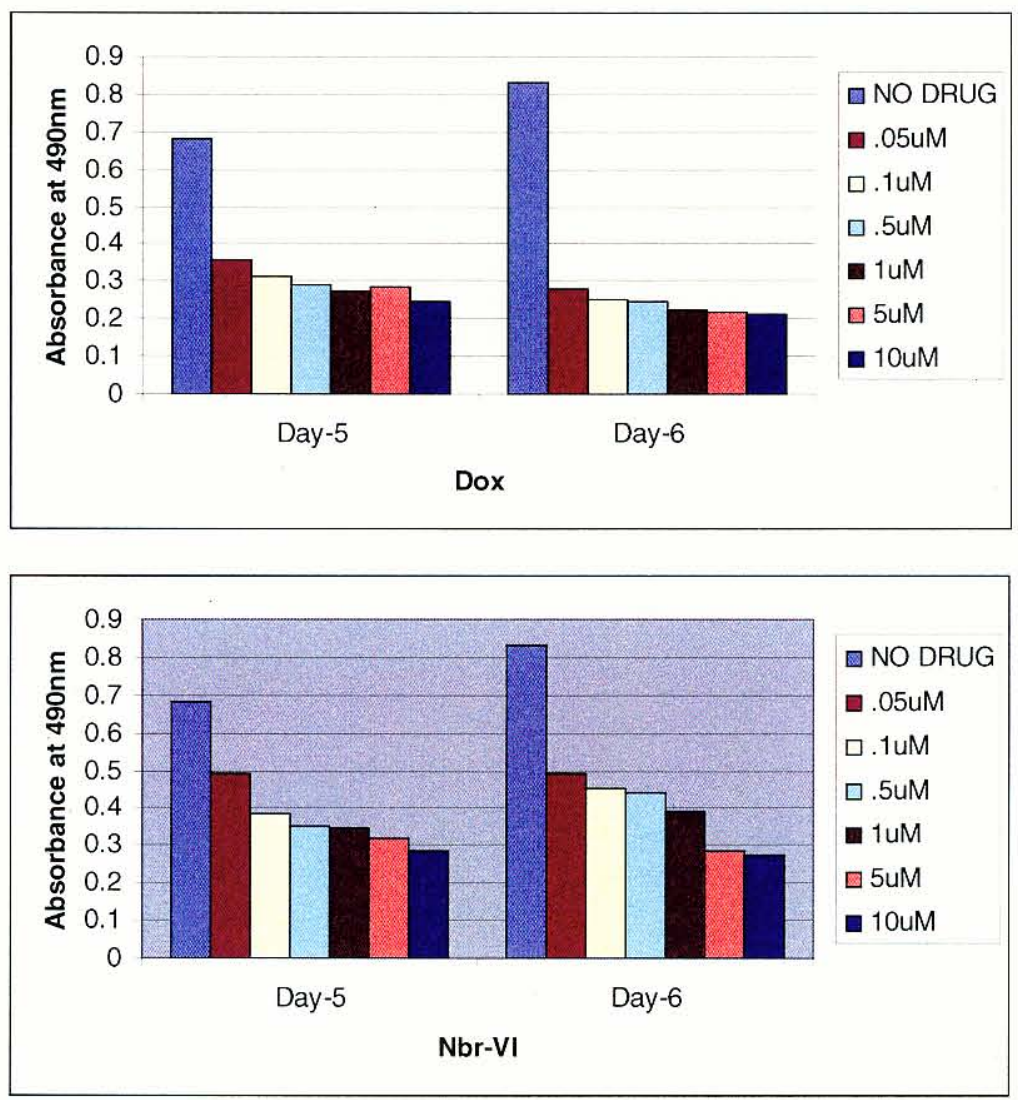

Figure 66: Cell proliferation data after 5 and 6 days of treatment with doxorubicin ("Dox"; top) and conjugate $\mathbf{1 6}$ ("Nbr-VI"; bottom) at various concentrations. 


\section{Glossary Of Abbreviations}

$\delta$

ACE

3-AMB

Arg

Asp

Boc

BOP

BT

BTA

$\mathrm{BTE}_{2}$

BT-MP

COSY

DCM

DHBA

DIEA

DMF

DMSO

DQCOSY

EDC

\section{7-EE}

EtOAc

$\mathrm{EtOH}$

FITC

Fmoc

Gly

HA

HIV

HOBt

HMBC

HMQC

HPLC

HRT

MALDI-TOF

$\mathrm{MeOH}$

miniPEG

miniPEG-3

$\mathrm{mL}$

mmol

NMR

OVX chemical shift

acetylcholine esterase

3-aminomethylbenzoic acid

arginine

aspartic acid

tert-butyloxycarbonyl

benzotriazole-1-yl-oxy-tris-(dimethylamino)

phosphonium hexafluorophosphate

bone-targeted

bone-targeting agent

bone-targeted estradiol

bone-targeted miniPEG

correlation spectroscopy

dichloromethane

dihydroxybenzoic acid

diisopropylethylamine

dimethylformamide

dimethylsulfoxide

double quantum correlation spectroscopy

1-ethyl-3-(3-dimethylaminopropyl)

carbodiimide hydrochloride

17 - $\beta$-estradiol

ethyl acetate

ethanol

fluorescein isothiocyanate

9-fluorenylmethoxycarbonyl

glycine

hydroxyapatite

human immunodeficiency virus-1

1-hydroxybenzotriazole

heteronuclear multiple bond correlation

heteronuclear multiple quantum coherence

high performance liquid chromatography

hormone-replacement therapy

matrix-assisted laser desorption-ionization time-of-flight

methanol

8-amino-3, 6-dioxaoctanoic acid

11-amino-3,6,9-trioxaundecanoic acid

milliliter

millimole

nuclear magnetic resonance

ovariectomized 
Phe

PTH

RGD

RP-HPLC

SAR

SPPS

TFA

THF

TLC

TOCSY

Tos

UV phenylalanine

parathyroid hormone

Arg-Gly-Asp

reverse-phase high performance liquid chromatography

structure-activity relationship solid-phase peptide synthesis

trifluoroacetic acid

tetrahydrofuran

thin-layer chromatography

total correlation spectroscopy

p-toluenesulfonate

ultraviolet 


\section{CIRRICULUM VITAE}

\section{EDUCATION}

Expected 2008 Ph. D. in Chemistry, University of Louisville, GPA: 4.00/4.00, Advisors: Drs. K. Grant Taylor and William M. Pierce, Jr.

\section{PROFESSIONAL EXPERIENCE}

2002-current Research Assistant, Drs. K. Grant Taylor and William M. Pierce, Jr.

Synthesis and characterization of bone-targeted drug conjugates:

- Developed, performed, and evaluated synthetic protocols for a number of novel bone-targeted drug conjugates

- Developed purification techniques for small organic molecules using flash chromatography and/or recrystallization

- Performed one- and two-dimensional ${ }^{1} \mathrm{H}$ and ${ }^{13} \mathrm{C}$ NMR spectroscopy on synthetic products and intermediates and interpreted/assigned spectral data

- Conducted literature searches and contributed to the design of synthetic strategies

- Assessed and maintained inventory of laboratory supplies including chemicals, glassware and equipment

- Extensive use of MS Office for data analysis and presentations

- Knowledge of SciFinder Scholar, ChemDraw, Corel Draw, MestReC

Teaching Assistant for organic recitation and laboratory sections:

- Conducted undergraduate laboratory sessions

- Wrote and graded quizzes, graded lab reports

- Coordinated laboratory material 
NSF Groundwork Education in Mathematics and Science (GEMS) Fellowship:

- Communicated scientific principles and concepts to elementary school students and teachers during a year-long NSF GK-12 fellowship

- Taught and helped develop core science curriculum for Jefferson County Public elementary schools

2000-2003

Research Assistant for Dr. Arno F. Spatola, Dr. K. Grant Taylor Synthesis and characterization of linear and cyclic peptides and pseudopeptides:

- Synthesized small linear and cyclic peptides using solidphase peptide synthesis, both automated and manual

- Developed purification techniques for peptides and other small organic molecules using high-performance liquid chromatography or flash chromatography and/or recrystallization

- Performed MALDI-TOF mass spectrometry on cyclic peptide products

- Performed one- and two-dimensional ${ }^{1} \mathrm{H}$ and ${ }^{13} \mathrm{C}$ NMR spectroscopy on synthetic products and intermediates and interpreted/assigned spectral data

\section{AWARDS, HONORS, AND PROFESSIONAL SOCIETIES}

University of Louisville Graduate Fellowship $2002-2004$

NSF Groundwork Education in Mathematics and Science (GEMS) Fellowship 2004-2005 University of Louisville Chemistry Graduate Student Association (Secretary: 2002 2004)

Institute for Molecular Diversity and Drug Design 2000 - present

American Chemical Society 2001 - present

Sigma Xi Scientific Research Society 2002 - present 